\title{
(a) Consensus practice guidelines on interventions for OPEN ACCESS cervical spine (facet) joint pain from a multispecialty
international working group
}

\author{
Robert W Hurley, ${ }_{1}^{1}$ Meredith C B Adams $\left(10,{ }^{2}\right.$ Meredith Barad, ${ }^{3}$ Arun Bhaskar, ${ }^{4}$ \\ Anuj Bhatia (1), ${ }^{5}$ Andrea Chadwick (1), ${ }^{6}$ Timothy R Deer (1) , ${ }^{7}$ Jennifer Hah, ${ }^{8}$ \\ W Michael Hooten (1) ${ }^{9}$ Narayan R Kissoon, ${ }^{10}$ David Wonhee Lee, ${ }^{11}$ \\ Zachary Mccormick, ${ }^{12}$ Jee Youn Moon 주, ${ }^{13,14}$ Samer Narouze 주, ${ }^{15}$ \\ David A Provenzano, ${ }^{16,17}$ Byron J Schneider, ${ }^{18}$ Maarten van Eerd, ${ }^{19}$ Jan Van Zundert, ${ }^{19}$ \\ Mark S Wallace, ${ }^{20}$ Sara M Wilson, ${ }^{21}$ Zirong Zhao, ${ }^{22}$ Steven P Cohen ${ }^{23}$
}

\begin{abstract}
- Additional supplemental material is published online only. To view, please visit the journal online (http://dx.doi.org/ 10.1136/rapm-2021-103031).
\end{abstract}

For numbered affiliations see end of article.

Correspondence to Dr Steven P Cohen, Anesthesiology, Pain Medicine Division, Johns Hopkins School of Medicine, Baltimore, Maryland, USA; scohen40@jhmi.edu

This article is being simultaneously published in the Regional Anesthesia and Pain Medicine and Pain Medicine.

Received 12 July 2021 Accepted 2 August 202 Published Online First 11 November 2021

\section{Linked}

- http://dx.doi.org/10.1136/ rapm-2021-103111

Check for updates

(C) American Society of Regional Anesthesia \& Pain Medicine 2022. Re-use permitted under CC BY. Published by BMJ.

To cite: Hurley RW,

Adams MCB, Barad M,

et al. Reg Anesth Pain Med

2022;47:3-59.

\section{ABSTRACT}

Background The past two decades have witnessed a surge in the use of cervical spine joint procedures including joint injections, nerve blocks and radiofrequency ablation to treat chronic neck pain, yet many aspects of the procedures remain controversial. Methods In August 2020, the American Society of Regional Anesthesia and Pain Medicine and the American Academy of Pain Medicine approved and charged the Cervical Joint Working Group to develop neck pain guidelines. Eighteen stakeholder societies were identified, and formal request-for-participation and member nomination letters were sent to those organizations. Participating entities selected panel members and an ad hoc steering committee selected preliminary questions, which were then revised by the full committee. Each question was assigned to a module composed of 4-5 members, who worked with the Subcommittee Lead and the Committee Chairs on preliminary versions, which were sent to the full committee after revisions. We used a modified Delphi method whereby the questions were sent to the committee en bloc and comments were returned in a non-blinded fashion to the Chairs, who incorporated the comments and sent out revised versions until consensus was reached. Before commencing, it was agreed that a recommendation would be noted with $>50 \%$ agreement among committee members, but a consensus recommendation would require $\geq 75 \%$ agreement.

Results Twenty questions were selected, with 100\% consensus achieved in committee on 17 topics. Among participating organizations, 14 of 15 that voted approved or supported the guidelines en bloc, with 14 questions being approved with no dissensions or abstentions. Specific questions addressed included the value of clinical presentation and imaging in selecting patients for procedures, whether conservative treatment should be used before injections, whether imaging is necessary for blocks, diagnostic and prognostic value of medial branch blocks and intra-articular joint injections, the effects of sedation and injectate volume on validity, whether facet blocks have therapeutic value, what the ideal cut-off value is for designating a block as positive, how many blocks should be performed before radiofrequency ablation, the orientation of electrodes, whether larger lesions translate into higher success rates, whether stimulation should be used before radiofrequency ablation, how best to mitigate complication risks, if different standards should be applied to clinical practice and trials, and the indications for repeating radiofrequency ablation.

Conclusions Cervical medial branch radiofrequency ablation may provide benefit to well-selected individuals, with medial branch blocks being more predictive than intra-articular injections. More stringent selection criteria are likely to improve denervation outcomes, but at the expense of false-negatives (ie, lower overall success rate). Clinical trials should be tailored based on objectives, and selection criteria for some may be more stringent than what is ideal in clinical practice.

\section{INTRODUCTION}

There are few subjects in interventional pain and spine medicine as controversial as the diagnosis, etiology, and treatment of neck pain. Neck and posterior head pain have a high prevalence rate in both developed and undeveloped regions, being particularly common in the USA, Western Europe, East Asia, Northern Africa, and the Middle East. ${ }^{1}$ A systematic review estimated the annual and lifetime prevalence rates to be $37.2 \%$ (range $16.7-75.1 \%$ ), and $48.5 \%$ (range 14.2-71\%), respectively. ${ }^{2}$ According to the Global Burden of Disease 2016 study, spine pain (including neck and low back) is the most common cause of disability in North America and globally for people 25-64 years of age. ${ }^{3}$ Age is positively related to the risk of neck pain, obesity is probably unrelated, and women are more likely to experience neck pain. ${ }^{14}$ When prevalence is broken down by spine joint or segment, the cited frequency of atlanto-axial (AA) joint pain ranges from as low as $16 \%$ to as high as $60 \%$ in patients with suspected cervicogenic headaches. ${ }^{5}$ Cervical facet (also known as zygapophysial or zygapophyseal) joints are considered to be the primary source of pain in $26-70 \%$ of patients with chronic neck pain ${ }^{6-9}$ and $54-60 \%$ of neck pain following whiplash injury. ${ }^{10-12}$ The C2-3 and C5-6 joints are the most common clinically implicated levels 
in neck pain, ${ }^{12-14}$ with $\mathrm{C} 2-3, \mathrm{C} 3-4$, and $\mathrm{C} 4-5$ being the most radiologically affected. ${ }^{1516}$ The wide disparity in reported prevalence raises questions regarding the use and accuracy of historical and physical exam signs as non-interventional diagnostic reference standards. The poor correlation between facet joint pathology on imaging and neck pain provokes further debate ${ }^{17}$ and disagreements with insurance payers. For diagnostic and/or prognostic criteria, the literature on the ideal patient response for designating a block as 'positive' and the optimal number of blocks that should be performed before cervical medial branch radiofrequency ablation (RFA) treatment is contentious and inconsistent, with no consensus emerging. ${ }^{18-23}$

Cervical spine joint interventions are commonly performed in interventional pain practices, with hundreds of thousands per year being performed in the USA alone. ${ }^{24}$ For cervical medial branch RFA, a recent review of the Medicare claims and encounters databases from 2000 to 2018 demonstrated a $112 \%$ overall increase in utilization ( $8.7 \%$ annually) over the past 9 years. ${ }^{24}$ Along with increased utilization, there was also a reciprocal increase in expenditures on cervical facet interventions of 53\% from 2009 to 2018; however, the cost per patient declined 7\% over this same time interval ( $0.8 \%$ annual reduction). ${ }^{25}$ The utilization of facet interventions is considerably higher than the most commonly cited prevalence rates. ${ }^{26}$ Although overall utilization of facet interventions is increasing at a rapid pace, there is a discrepancy in the growth of medial branch blocks (MBB) and intra-articular (IA) joint injections $(0.5 \%$ annual growth) and cervical medial branch RFA (8.7\% annual growth). ${ }^{24}$ This disconnect may reflect practice changes such as decreased use of cervical facet IA joint injections, a reduction in the number of diagnostic blocks used before medial branch RFA, or a higher rate of prognostic blocks designated as positive. Increasing utilization alters the risk to benefit ratio of treatments; this, along with inconsistencies in practice and the lack of widely accepted consensus guidelines, has led to increased scrutiny on the part of government regulatory agencies and insurance payers. The Spine Intervention Society (SIS) and the American Society of Interventional Pain Physicians (ASIPP) have published guidelines on the performance of cervical facet blocks and RFA, ${ }^{18} 27$ but these rigorous criteria have not been followed in recent randomized controlled and uncontrolled trials (RCTs). ${ }^{19} 28$ Whereas stringent selection criteria have been associated with high medial branch RFA success rates, ${ }^{21}$ the increased false-negative rate that inevitably accompanies strict diagnostic criteria and a host of other factors have resulted in an urgent need for guidelines to inform cervical joint interventions in clinical practice and trials. These factors include the absence of safer and more effective alternatives for neck pain (ie, spinal fusion and chronic opioid therapy were less scrutinized when many of the previous cervical facet studies were published), the publication of few high-quality clinical trials, rising utilization which alters the risk to benefit ratio, and questions surrounding the cost-effectiveness of diagnostic paradigms, which vary from country to country. We aimed to develop pragmatic guidelines that can be used to inform clinical care, improve the quality of research, and assist payers with clinical practice pathways and authorization decisions.

\section{METHODS}

The decision to convene a multispecialty and multinational Cervical Joint Working Group to develop atlanto-occipital (AO), atlanto-axial (AA), and cervical facet joint intervention guidelines was approved by the American Academy of Pain Medicine (AAPM) and American Society of Regional Anesthesia and Pain
Medicine (ASRA-PM) in August 2020. Fifteen stakeholder academies and societies as well as other organizations (eg, US Departments of Defense and Veteran Affairs) with a vested interest in cervical spine joint interventions were identified, and formal request-for-participation and member nomination letters were sent to those societies who approved involvement in September 2020. A single pain society (US Association for the Study of Pain, USASP) declined to participate. Organizations were asked to consider a candidate's expertise, clinical experience, academic interests, and diversity in their nomination process. Each sponsoring society (AAPM and ASRA-PM) nominated two members and participating organizations nominated one member (see online supplemental appendix A for a list of participating academies, societies, and respective representatives). The sole ad hoc member (MSW) had been preliminarily designated to represent USASP before their Board of Directors declined to participate. For the Departments of Defense and Veterans Affairs representatives, the Chairperson of the Department of Anesthesia at the Uniformed Services University of the Health Sciences and Director of the VA National Pain Management Program nominated individuals.

The Cervical Joint Working Group was charged with preparing guidelines on the use of $\mathrm{AO}, \mathrm{AA}$, medial branch and facet joint blocks, and medial branch RFA that spanned the entire spectrum of care to include patient selection, optimizing accuracy, interpreting results, and risk mitigation. Questions and formats were developed by the committee co-chairs (RWH, SPC) based on input from the working group and refined during the initial video-conference call. Guidelines for individual study questions were developed by subcommittees composed of 4-5 members, with one or two persons designated as the 'leads' responsible for task delegation. Once a subcommittee came to a consensus on an answer, the working group chairs assisted with editing and formatting, and the section was sent to the entire committee for open-forum comments and revisions. A modified Delphi method was used to tabulate comments, incorporate changes, and converge the answers towards consensus over rounds of teleconference or electronic correspondence. At the initial conference call, the working group decided that $>50 \%$ panel agreement was sufficient to report a recommendation, but $\geq 75 \%$ agreement was required for consensus, consistent with the Lumbar Facet Intervention Guidelines. ${ }^{29}$ After the working group completed the guidelines, the document was sent to participating organizations' boards of directors for approval, with only minor changes permitted at this stage. For organizational agreement, we determined that consensus required at least $\geq 75 \%$ agreement. At both the committee and organizational levels, dissensions and abstentions were tabulated for each question.

Search engines used during composition of the various sections included PubMed, Embase, Google Scholar, SCOPUS, and Cochrane Database of Systematic Reviews, in addition to examination of the reference sections of all manuscripts. Additional articles were identified by searching in topically related new journals that are not yet indexed by Science Citation Index or found within PubMed. There were no limitations on language or types of articles used to develop the guidelines, such that experimental studies were considered for the sections on physical examination, anatomy and technical parameters, and case reports were considered for sections pertaining to risk mitigation and complications. Keywords used to address guideline topics were tailored to individual questions and included 'atlantooccipital', 'atlantooccipital', 'atlanto-axial', 'atlantoaxial', 'cervicogenic', 'headache', 'facet', 'neck pain', 'zygapophysial', 'zygapophyseal', 'radiofrequency', 'denervation', 'ablation', 
Table 1 Levels of evidence for guidelines and recommendations

\begin{tabular}{lllll}
\hline & \multicolumn{4}{l}{ Magnitude of net benefit } \\
\cline { 2 - 5 } Certainty of net benefit & Substantial & Moderate & Small & Zero/negative \\
\hline High & A & B & C & D \\
\hline Moderate & B & B & C & D \\
\hline Low & Insufficient & & & \\
\hline
\end{tabular}

and 'arthritis', among others. In accordance with the Lumbar Facet Intervention Guidelines, ${ }^{29}$ conclusions for each topic were graded on a scale from A to D, or as insufficient, according to the US Preventative Services Task Force grading of evidence guidelines, with the level of certainty rated as high, moderate, or low (tables $1-3) .^{30}$

This system, which has been modified for use in interventional pain management guidelines drafted by the ASRA-PM, AAPM, American Society of Anesthesiologists (ASA), ASIPP, and the International Neuromodulation Society (INS), ${ }^{31-34}$ was chosen over others because of its flexibility ${ }^{35} 36$ which permits high-grade recommendations in the absence of high-quality level I studies, which are challenging to conduct for invasive procedures. ${ }^{37}$

\section{QUESTION 1: CAN HISTORY AND PHYSICAL EXAMINATION BE USED TO IDENTIFY PAINFUL AO OR AA JOINTS OR TO SELECT PEOPLE FOR PROGNOSTIC BLOCKS?}

$\mathrm{AO}$ and $\mathrm{AA}$ joint disease may be a source of both neck pain and headache. Accurate diagnosis and management of neck and head pain can be challenging. Pain may be referred from other cervical sources including cervical intervertebral discs, cervical facet joints, ligaments, fascia, and muscles. Detailed history and physical examination can be valuable to help distinguish the etiology of the pain and to target diagnostic and therapeutic injection targets. $^{3839}$

\section{Relevant anatomy of the $\mathrm{AO}$ and $\mathrm{AA}$ joints}

The AO and AA joints are unique in the cervical spine. The AO and AA joint complexes allow for a significant range of motion (ROM) between the head and mid-cervical spine. The AO and AA joints are innervated by the ventral rami of $\mathrm{C} 1$ and $\mathrm{C} 2$, respectively. ${ }^{40-42}$ The $\mathrm{AO}$ joint is a synovial articulation between the occipital bone and the first cervical vertebra (the atlas). The joint is formed superiorly by the convex occipital condyle and inferiorly by the concave superior articular surface of the C1 lateral mass. The AA joint complex consists of three joints, two lateral and one median. The lateral AA joint is formed by the superior articular surface of C2 (the axis) and the inferior articulating surface of $\mathrm{C} 1$. The median (or middle) AA joint is a pivot joint that represents the articulation between the odontoid process and the posterior surface of the anterior arch of the atlas anteriorly and the transverse ligament posteriorly. In this document, the AA joint refers to the lateral AA joint, unless otherwise specified.

C1 does not have a vertebral body and is not separated from adjacent levels by an intervertebral disc. ${ }^{43}$ In addition to the five main ligamentous structures of the spinal column (anterior longitudinal ligament, posterior longitudinal ligament, ligamentum flavum, interspinous ligament, and supraspinous ligament), the AO joint complex has additional overlying ligaments including the AO ligament, tectorial membrane, apical ligament, and the cruciate ligaments (comprised of the transverse ligament and a superior and inferior band) which provide stability and flexibility, but can also be a pain generator. ${ }^{43}$ The AA joint complex has additional ligaments as well, namely the anterior and posterior AA ligaments, transverse ligament of the atlas, apical ligament, alar ligaments, and tectorial membrane. These ligaments can become calcified in elderly people, leading to decreased ROM and increased neck pain. ${ }^{44}$

The AO and AA joints, as described above, provide mechanical strength to stabilize the head, while allowing for complex movements of the cervical spine. Approximately 50\% of total cervical spine flexion and extension occurs at the $\mathrm{AO}$ articulation. ${ }^{45} 46$ Over $50 \%$ of all cervical spine rotation is provided by the dens of C2 which articulates with C1 and transverse ligaments. ${ }^{45} 46$ The synovial joints at $\mathrm{C} 1$ and $\mathrm{C} 2$ rely more on ligamentous stabilizers because they do not have intervertebral discs to provide stabilization. ${ }^{4748}$ The weight from the occipital condyles transfers the load from the occiput to the $\mathrm{C} 1$ lateral masses and then onto the C2 lateral masses. ${ }^{46}$

\section{Referral patterns for pain arising from $\mathrm{AO}$ and $\mathrm{AA}$ joints}

The diagnosis of pain arising from the AO and AA joints has been less well studied than $\mathrm{C} 2-3$ through $\mathrm{C} 7-\mathrm{T} 1$ cervical facet joint pain. As seen in figure 1A,B, pain arising from C1-C2 most often occurs in the suboccipital region, commonly extending cephalad into the head or caudad into the upper neck. Referred pain patterns have been studied in healthy volunteers without neck pain as well as in those with proven cervical joint pain. ${ }^{49-51}$

Dreyfuss $e{ } a l^{50}$ studied pain referral patterns in asymptomatic patients from provocative testing of the $\mathrm{AO}$ and lateral AA joints via fluoroscopically-guided IA injections. The authors confirmed the nociceptive ability of the AO and AA synovial joints and found that AA injections resulted in consistent referral patterns whereas the AO referral patterns varied significantly.

Referral patterns from asymptomatic patients based on pain provocation are consistent with those from symptomatic patients, based on pain relief after injection. AO-mediated pain has consistently been reported as suboccipital, but may extend

Table 2 What the grades of evidence mean and suggestions for practice

\begin{tabular}{llll}
\hline Grade & Definition & Suggestions for practice \\
\hline A & $\begin{array}{l}\text { Our committee recommends this treatment, test or strategy to improve outcomes. There is high certainty that } \\
\text { the net benefit is substantial }\end{array}$ & Offer or provide this service \\
\hline B & $\begin{array}{l}\text { Our committee recommends this treatment, test or strategy to improve outcomes. There is high certainty that } \\
\text { the net benefit is moderate or there is moderate certainty that the net benefit is moderate to substantial }\end{array}$ & Offer or provide this service \\
\hline C & $\begin{array}{l}\text { Our committee recommends selectively offering or providing this treatment, test or strategy to improve } \\
\text { outcomes to individual patients based on professional judgment and patient preferences. There is at least } \\
\text { moderate certainty that the net benefit is small }\end{array}$ & $\begin{array}{l}\text { Offer or provide this service for selected patients depending on individual } \\
\text { circumstances }\end{array}$ \\
\hline D & $\begin{array}{l}\text { Our committee recommends against the treatment, test, strategy or intervention. There is moderate or high } \\
\text { certainty that the service has no net benefit or that the harms outweigh the benefits }\end{array}$ & Discourage the use of this service \\
\hline $\begin{array}{l}\text { I } \\
\text { Statement }\end{array}$ & $\begin{array}{l}\text { Our committee concludes that the current evidence is insufficient to assess the balance of benefits and harms } \\
\text { cannot be determined }\end{array}$ & $\begin{array}{l}\text { Read the clinical considerations section of the recommendation. If the treatment } \\
\text { or service is offered, patients should understand the uncertainty about the } \\
\text { balance of benefits and harms }\end{array}$
\end{tabular}


Table 3 Levels of certainty regarding net benefit

\begin{tabular}{|c|c|}
\hline $\begin{array}{l}\text { Level of } \\
\text { certainty }\end{array}$ & Description \\
\hline High & $\begin{array}{l}\text { The available evidence usually includes consistent results from well-designed, well-conducted studies in representative populations with suspected cervicogenic } \\
\text { headache and/or facetogenic pain and/or compelling evidence from non-randomized studies. The studies assess the effects of the treatment, test, or other } \\
\text { intervention on treatment or other relevant outcomes. The conclusion is therefore unlikely to be strongly affected by the results of future studies }\end{array}$ \\
\hline Moderate & $\begin{array}{l}\text { The available evidence is sufficient to determine the effects of the intervention on outcomes, but confidence in the estimate is constrained by such factors as: } \\
\text { The number, size, or quality of individual studies } \\
\text { Inconsistency of findings across individual studies } \\
\text { Limited generalizability of findings to individuals with suspected cervicogenic headache and/or cervical facetogenic pain } \\
\text { High likelihood of bias } \\
\text { Lack of coherence in the chain of evidence } \\
\text { As more information becomes available, the magnitude or direction of the observed effect could change, and that change may be large enough to alter the } \\
\text { conclusion }\end{array}$ \\
\hline Low & $\begin{array}{l}\text { The available evidence is insufficient to assess effects on treatment and other outcomes of interest. Evidence is insufficient because of: } \\
\text { The limited number or size of studies } \\
\text { Important flaws in study design or methods } \\
\text { Inconsistency of findings across individual studies } \\
\text { High likelihood of bias } \\
\text { Findings not generalizable to individuals with suspected cervicogenic headache and/or cervical facetogenic pain } \\
\text { Lack of information on important outcome measures } \\
\text { More information may allow estimation of effects on treatment outcomes }\end{array}$ \\
\hline
\end{tabular}

Note, the levels of certainty described in the definitions for the grading of evidence in table 2 refer solely to the magnitude of benefit attributed to the intervention, while the levels of certainty in table 3 consider the basis of evidence for the recommendation and the likelihood the recommendation will be affected by future studies. Whereas the two are related, the grading of evidence and rating of certainty were considered separately.

to the frontal area, slightly anterior to the vertex. ${ }^{50}$ The referral zone approaches-but does not include-the ear in most cases. Other patterns that have been described are isolated suboccipital pain, suboccipital and supraorbital pain, and rarely the entire hemicranium. ${ }^{50}$

The spinal nucleus of the trigeminal nerve extends caudally to the dorsal horn of the first 3-4 cervical spinal nerves. ${ }^{38} 5253$ The trigeminal nerve and the upper three cervical nerves provide afferent fibers to the trigeminocervical nucleus, which may account for the overlapping pain patterns described in $\mathrm{AO}$ and AA joint pain which include upper neck pain that spreads to the oculofrontotemporal area. 385455
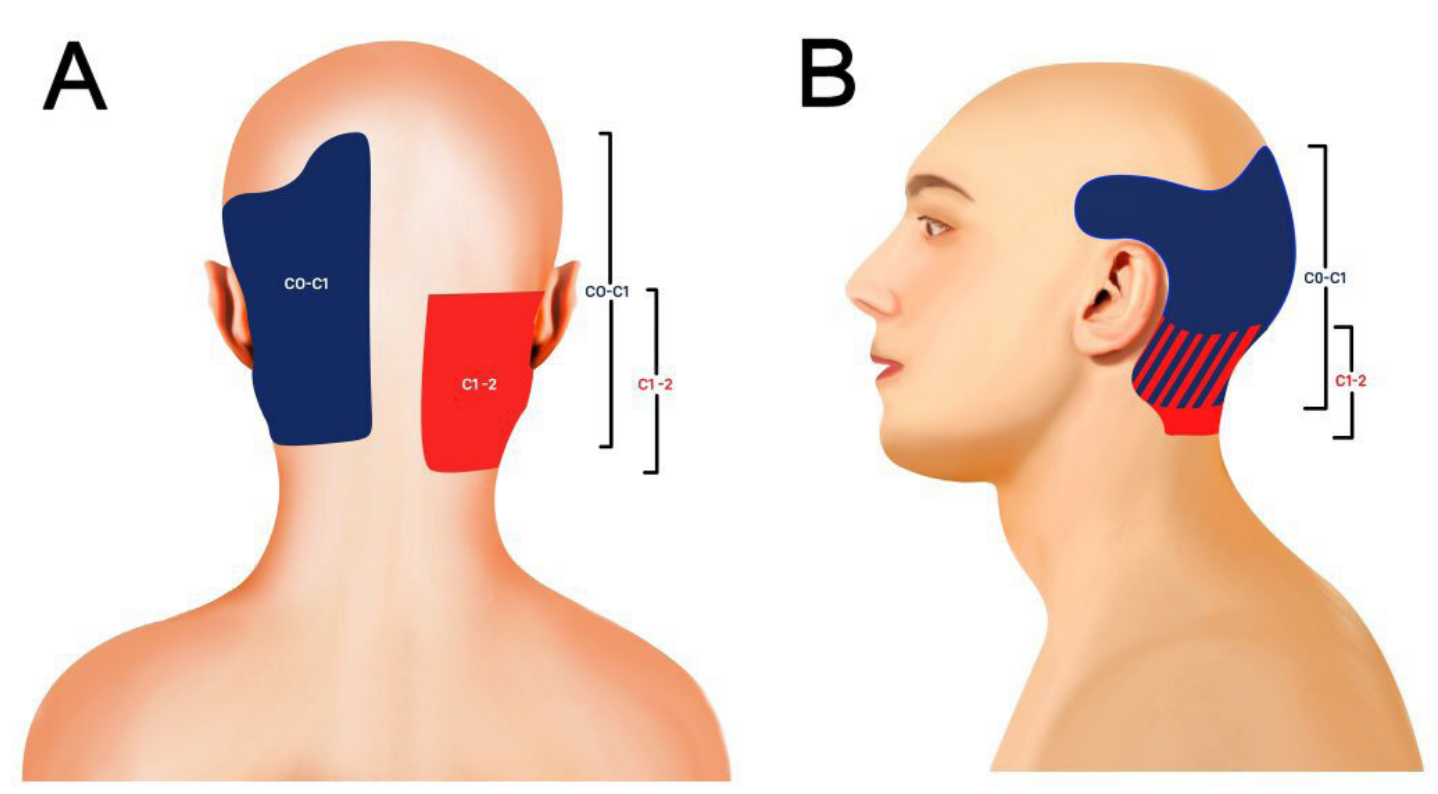

Figure 1 Posterior (A) and lateral (B) segmental maps showing the typical pain referral patterns of the atlanto-occipital (C0-C1, blue) and atlantoaxial (C1-2, red) joints . ${ }^{49-51}$ Striped areas (blue/red hash marks) represent overlapping atlanto-occipital and atlanto-axial pain maps.

The pain referral patterns of the AA joint reported by Dreyfuss $e t a l^{50}$ are consistent with prior studies. ${ }^{5657}$ Pain emanating from the AA joint was described as discrete unilateral pain at the occipito-cervical junction, retro-mastoid area, and in the upper cervical region. ${ }^{505657}$ This is in contrast to pain from the AO joint reported in the same study which tended to radiate more cephalad towards the vertex of the head, and occasionally into the temporal and posterior auricular areas. ${ }^{50}$ Cooper $e t a l^{49}$ reported that AA pain often encompassed the region of the posterior ear and orbit. It sometimes encompassed the ear itself and was rarely experienced in the temporoparietal area. The pain quality has been described as 'deep', 'boring', and 'aching'. ${ }^{56}$ Patients with 
AA joint pain often report occipital headaches, suboccipital neuralgia, and sometimes pain radiating to the shoulder. Radicular pain or a history suggestive of myelopathy is an uncommon finding; however, these have been reported in rare cases of C1C2 pseudoarticulation. ${ }^{58-61}$

Historical features suggestive of lateral AA joint pain include occipital or suboccipital pain, focal tenderness over the suboccipital area, focal tenderness over the transverse process of $\mathrm{C} 1$, and pain provoked by active or passive rotation of $\mathrm{C} 1$ on $\mathrm{C} 2{ }^{62}$ Using these features, Narouze et al ${ }^{62}$ treated 32 patients who were screened from a total of 115 patients referred with cervicogenic headache. Only 15 of those 32 patients experienced complete pain relief following an IA block, thereby confirming the diagnosis and yielding a positive predictive value (PPV) of $47 \%$ using historical and examination criteria. This low PPV may be explained by the fact that cervicogenic headache can be referred from any structure innervated by the upper three cervical spinal nerves including the $\mathrm{AO}$ joint, median $\mathrm{AA}$ joint, C2-3 disc, and $\mathrm{C} 2-3$ facet joints. ${ }^{63}$ The lateral AA joint may account for approximately $16 \%$ of patients with occipital headaches. ${ }^{5}$ Although clinical signs are consistently present, they are not specific enough to establish a definitive diagnosis and the authors recommend confirming the presumptive pain generator with a diagnostic IA block, especially before considering surgical options. Based on a cohort study involving 34 patients in which 21 responded to lateral AA joint injections, Aprill et al ${ }^{5}$ concluded that the only way to confirm whether a joint is painful is by anesthetizing the joint. They found that history in conjunction with physical examination has a PPV of only $60 \%$ for pain stemming from the AA joint, meaning that without diagnostic blocks a substantial proportion of patients will be misdiagnosed (table 4).

Physical examination of the neck to diagnose $A O$ and $A A$ pain The AA joint complex accounts for $60 \%$ of cervical rotational movement. ${ }^{64}$ The pivot articulation occurs between the odontoid process of the axis and the ring formed by the transverse ligament of the atlas and the anterior arch. Common historical and physical examination findings of AA dysfunction include limited ROM during rotation as well as flexion and extension depending on the extent of tectorial membrane impairment. In more advanced cases, examination signs can include severely restricted rotation and lateral flexion of the cervical spine to the affected side ${ }^{65}$ crepitus, prominent tenderness at the occipitocervical junction, craniocervical kyphosis, and torticollis. ${ }^{66}$ The presence of gait abnormalities, radicular symptoms, and audiovisual symptoms are unlikely to be related to isolated $\mathrm{AO}$ or $\mathrm{AA}$ dysfunction.

Although the AO and AA joints can be visualized on imaging, including plain radiographs, imaging cannot confirm the origin of pain. Normal imaging does not rule out arthropathy and radiographic joint abnormalities are incapable of identifying a painful joint. For example, in a study involving 400 patients with rheumatoid arthritis, $45.8 \%$ had radiographic evidence of AA involvement but only $45.4 \%$ of those individuals had neck pain. ${ }^{67}$ Paradoxically, greater AA joint ventral subluxation was associated with less pain. Alternative imaging including bone

Table 4 Studies evaluating pain referral patterns for atlanto-occipital and atlanto-axial injections

\begin{tabular}{|c|c|c|c|c|}
\hline $\begin{array}{l}\text { Author, } \\
\text { year }\end{array}$ & Patients & Design & Results & Comments \\
\hline $\begin{array}{l}\text { Busch } \\
\text { and } \\
\text { Wilson, } \\
1989^{168}\end{array}$ & $\begin{array}{l}25 \text { pts with head and neck pain of which } 2 \text { pts } \\
\text { received } L A \text { and steroid } A O \text { and } A A \text { joints injections }\end{array}$ & $\begin{array}{l}\text { Case series/ } \\
\text { retrospective }\end{array}$ & $\begin{array}{l}\text { Pain relief in both cases ranged from } 3 \text { weeks to } 4 \\
\text { months (one patient received serial injections). AA } \\
\text { and AO joints may be a source of occipital headache } \\
\text { refractory to conservative therapy }\end{array}$ & 25 pts treated but only 2 cases described \\
\hline $\begin{array}{l}\text { Aprill et } \\
\text { al } 2002^{5}\end{array}$ & $\begin{array}{l}34 \text { pts with history of occipital or SO pain, } \\
\text { tenderness over C1 and decreased ROM of AA joint } \\
\text { treated with AA IA injection of LA and steroid }\end{array}$ & $\begin{array}{l}\text { Prospective } \\
\text { observational }\end{array}$ & $\begin{array}{l}21 \text { of } 34(62 \%) \text { pts experienced complete relief } \\
\text { ( } \leq 1 / 10 \text { on VAS) for } 2 \text { hours following the injection }\end{array}$ & $\begin{array}{l}\text { No control group, no sham injection or } \\
\text { other joints examined }\end{array}$ \\
\hline $\begin{array}{l}\text { Narouze } \\
\text { et al } \\
2007^{62}\end{array}$ & $\begin{array}{l}32 \text { pts with clinical exam consistent with AA- } \\
\text { mediated pain treated with AA IA injection of LA } \\
\text { and steroid }\end{array}$ & $\begin{array}{l}\text { Retrospective } \\
\text { study }\end{array}$ & $\begin{array}{l}15 \text { of } 32(46.8 \%) \text { pts obtained complete pain } \\
\text { relief (NRS pain score }=0), 26 / 32(81.2 \%) \text { pts } \\
\text { with } \geq 50 \% \text { pain relief }\end{array}$ & $\begin{array}{l}\text { No control or comparison groups or other } \\
\text { joints examined }\end{array}$ \\
\hline $\begin{array}{l}\text { Lee et al } \\
2015^{165}\end{array}$ & $\begin{array}{l}24 \text { pts with headache and/or SO pain, SO tenderness, } \\
\text { and limited range of lateral bending with rotation } \\
\text { at the } \mathrm{AO} \text { joint, treated with AO IA injection of LA. } \\
\text { Responders received IA LA and steroid injection }\end{array}$ & $\begin{array}{l}\text { Prospective } \\
\text { observational }\end{array}$ & $\begin{array}{l}20 \text { of } 24(83 \%) \text { pts had } \geq 50 \% \text { pain relief for } 30 \mathrm{~min} \\
\text { following the injection. } 18 \text { of } 20(90 \%) \text { pts had a } \\
2 \text {-point or greater reduction in pain score }\end{array}$ & $\begin{array}{l}\text { No control or sham groups, } 2 \text { month follow- } \\
\text { up. } 14 \text { of } 14 \text { pts with headache had } \geq 50 \% \\
\text { relief. } 15 \text { of } 20 \text { pts with posterior neck } \\
\text { pain had } \geq 50 \% \text { relief. } 13 \text { of } 17 \text { pts with } \\
\text { shoulder/arm pain had } \geq 50 \% \text { relief }\end{array}$ \\
\hline $\begin{array}{l}\text { Dreyfuss } \\
\text { et al } \\
1994^{50}\end{array}$ & $\begin{array}{l}5 \text { asymptomatic volunteers (no history of headache } \\
\text { or neck pain) received one } A 0 \text { and one } A A \\
\text { provocative injection with contrast }\end{array}$ & $\begin{array}{l}\text { Prospective } \\
\text { observational }\end{array}$ & $\begin{array}{l}\text { AO injections provoked variable referred pain } \\
\text { from the level of the } C 5 \text { spinal segment through } \\
\text { the vertex of the head. AA injections were more } \\
\text { consistent, producing pain only in the SO region }\end{array}$ & $\begin{array}{l}\text { Provoked pain described as dull, deep ache, } \\
\text { or heavy pressure }\end{array}$ \\
\hline $\begin{array}{l}\text { Cooper } \\
\text { et al } \\
2007^{49}\end{array}$ & $\begin{array}{l}5 \text { pts with neck or SO headache treated with AA } \\
\text { injection of LA (one patient had bilateral injections) }\end{array}$ & $\begin{array}{l}\text { Prospective } \\
\text { observational }\end{array}$ & $\begin{array}{l}\text { Responders had } 100 \% \text { pain relief or relief in a } \\
\text { definable portion of the patient's area of pain. } 5 \\
\text { out of } 134(3.7 \%) \text { total pts with positive cervical } \\
\text { diagnostic blocks had C1-2 as a source }\end{array}$ & $\begin{array}{l}\text { AA injections relieved pain in the neck up } \\
\text { to the vertex of the head, occasionally in } \\
\text { the region of the ear and orbit }\end{array}$ \\
\hline $\begin{array}{l}\text { Fukui et } \\
\text { al } 1996^{51}\end{array}$ & $\begin{array}{l}10 \text { pts with neck pain were treated with } A O \text { and } \\
10 \text { pts with neck pain were treated with } A A \text { IA } \\
\text { injections with } L A \text { and steroid }\end{array}$ & $\begin{array}{l}\text { Prospective } \\
\text { observational }\end{array}$ & $\begin{array}{l}\mathrm{AO} \text { and } \mathrm{AA} \text { injections produced pain in the posterior } \\
\text { occiput and posterolateral cervical spine (areas over } \\
\text { the mastoid process) }\end{array}$ & $\begin{array}{l}\text { Pain relief was not reported, although LA } \\
\text { and steroid was used in the provocative } \\
\text { injection }\end{array}$ \\
\hline $\begin{array}{l}\text { Ehni and } \\
\text { Benner, } \\
1984^{56}\end{array}$ & $\begin{array}{l}7 \text { pts with SO pain, tenderness and pain during } \\
\text { rotation were treated with AA IA injection of LA and } \\
\text { steroid }\end{array}$ & Case series & AA injections produced immediate relief & $\begin{array}{l}\text { No details provided regarding injection } \\
\text { technique. No quantification of pain relief } \\
\text { was provided }\end{array}$ \\
\hline
\end{tabular}

AA, atlanto-axial (C1-C2) joint; AO, atlanto-occipital (CO-C1) joint; IA, intra-articular; LA, local anesthetic; MBB, medial branch blocks; NRS, numerical rating scale; pts, patients; $\mathrm{ROM}$, range of motion; $\mathrm{SO}$, suboccipital. 
window CT views of the AA joint, MRI, or cervical myelography may be needed to rule out concomitant alternative cervical spine pathology. ${ }^{57}$

\section{Recommendations}

In summary, there are no pathognomonic historical signs or physical examinations that can reliably predict response to AA or AO joint blocks in individuals with chronic neck pain. AA and $\mathrm{AO}$ joint pain typically manifest in the $\mathrm{C} 1, \mathrm{C} 2$, or trigeminal nerve distribution, with AA pain having more reproducible and consistent symptoms than $\mathrm{AO}$ joint pain. We conclude that history and physical examination cannot reliably identify painful AO or AA joints, but can guide injection decisions which could confirm the $\mathrm{AO}$ and $\mathrm{AA}$ joints as pain generators: grade $\mathrm{C}$ recommendation, low level of certainty.

\section{QUESTION 2: CAN HISTORY AND PHYSICAL EXAMINATION BE USED TO IDENTIFY A PAINFUL FACET JOINT, OR TO SELECT PEOPLE FOR PROGNOSTIC BLOCKS?}

Cervical facet joints are proposed as the primary source of pain in $25-67 \%$ of patients with chronic neck pain. The C2-3 and C5-6 joints are the most common clinically implicated in neck pain, ${ }^{12} 6869$ while $\mathrm{C} 2-3, \mathrm{C} 3-4$, and $\mathrm{C} 4-5$ joints are the most likely to display radiological features of degeneration ${ }^{15}{ }^{16}$; injury to the neck increases the probability of the facet joints being the source of chronic neck pain (see below for whiplash). Frequently used criteria for considering patients for prognostic blocks include neck pain of moderate-to-severe intensity (score $\geq 4$ out of 10 on a pain intensity scale) radiating to the head, shoulder, or upper arm for at least 6 weeks in the absence of focal neurological findings. The targeted facet joints are usually decided on based on patient report and tenderness on examination, sometimes performed under fluoroscopy. In patients who are postsurgical, adjacent segments are often affected after arthrodesis, and treated levels bear more force during extension following disc arthroplasty. ${ }^{70}$ Factors that decrease the probability of the cervical facet joints being pain generators include prominent pathology of other likely sources of neck pain such as markedly degenerated or herniated intervertebral discs and symptomatic spinal stenosis. ${ }^{20}$ In a study by Cohen et $a l^{20}$ that evaluated historical and physical examination features associated with successful cervical medial branch RFA outcomes, pain radiating to the occiput and a history of headaches increased the probability of treatment failure. In this study, paraspinal tenderness, but not neck pain worsened by facet loading (extension and rotation of the cervical spine), was highly predictive of a successful outcome, with two-thirds of patients with paraspinal tenderness reporting a successful outcome versus the same proportion of those without tenderness failing RFA.

Importance of whiplash as a cause of cervical facet joint pain Mechanical injury is often an initiating factor for cervical facet joint pain. ${ }^{71}$ The cervical facet joints were identified as a source of neck pain in 54\% (95\% CI 40\% to 68\%) of individuals (as confirmed by dual diagnostic $\mathrm{MBB}$ ) in a study performed in patients with chronic whiplash-associated disorders (WAD). However, the incidence of cervical facet joint pathology contributing to neck pain as calculated based on patients who completed this study was $71 \% .^{10} 12$ WAD represent a spectrum of symptoms arising from an initial whiplash injury that usually occurs as a result of a motor vehicle collision (MVC). ${ }^{72}$ Smith and colleagues ${ }^{73}$ enrolled patients with Quebec Task Force WAD grade II injury (ie, neck pain and associated symptoms in the presence of objective non-neurological physical signs such as decreased ROM and point tenderness) ${ }^{72}$ in a cross-sectional study comparing physical and psychological features of responders and non-responders to cervical IA facet injections or MBB. The authors found that both responders and non-responders with WAD experienced increased hypersensitivity, decreased ROM, and increased superficial muscle activity compared with controls, but there were no differences in outcomes-based response to facet blocks. Most individuals with WAD as a result of an MVC are reported to be either drivers or front-seat passengers, while other types of road accidents (bicycle or motorcycle crashes) usually involve an element of hyperextension injury. Neck pain is present in all patients with WAD, but headache is also a prevalent symptom $(88 \%)$, especially in patients in whom the C2-3 facet joint is implicated as a cause of pain. ${ }^{1068}$

\section{C2-3 facet joint}

The C2-3 joint pathology is considered a valid etiology of cervicogenic headaches. ${ }^{74}$ The $\mathrm{C} 2-3$ facet joint is innervated by the third occipital nerve (TON); hence, headaches arising from C2-3 pathology were called third occipital headache in the past. Lord and colleagues ${ }^{75}$ evaluated the prevalence of TON headache among 100 patients with neck pain for at least 3 months following whiplash using history, physical examination, and diagnostic cervical MBB with local anesthetics (LA). The prevalence of TON headache in this cohort was 27\% (95\% CI 18\% to $36 \%)$ and as high as $53 \%$ (95\% CI $37 \%$ to $68 \%$ ) among those with headache as the dominant symptom. No unique features on history or examination correlated with positive MBB results. Patients with a positive block were significantly more likely to be tender over the $\mathrm{C} 2-3$ facet joint, with a sensitivity of $85 \%$.

Reports in the literature suggest available evidence is not definitive on any symptoms or signs being specific for the cervical facet joints as the cause of pain. The generally accepted reference standard for diagnosing the cervical facet joints as the primary cause of pain is relief of the pain following cervical MBB with LA of nerves that supply the putative painful joint(s). ${ }^{1876}$ Diagnostic blocks are performed at segments suggested by matching the distribution of the patient's pain with known referral patterns ${ }^{13} 495177$ or by identifying tender areas under fluoroscopy. ${ }^{78}$

\section{Referral patterns of pain for pain arising from cervical facet joints}

The referral patterns of pain arising from the cervical facet joints have been evaluated in volunteers ${ }^{77}$ and in patients with pain proven to arise from the cervical facet joints. ${ }^{134951}$ Dwyer $e t a l^{77}$ performed IA facet joint injections in four volunteers and one patient with neck pain to map the area of pain produced by injection into each joint (figure 2A,B). Stimulation of the C2-3 joint by capsular distension was associated with upper neck pain that extended into the head (often towards the ear, vertex, forehead, or eye). Stimulating the C5-6 joint resulted in pain radiating into the lower neck, top of the scapula, and shoulder above the level of the scapular spine that was distinguishable from pain extending caudally to the scapular spine from irritation of the $\mathrm{C} 6-7$ joint. Injections into the $\mathrm{C} 3-4$ joint resulted in pain in the neck extending from the suboccipital region to the lower neck without involving the shoulder, whereas injection into the C4-5 joint caused pain that was more caudal, in the top of the shoulder and lower part of the neck.

Cooper et $\mathrm{l}^{49}$ conducted a study in 194 patients with neck pain who received dual LA diagnostic MBB. They reported the most common cervical facet joints associated with neck pain were $\mathrm{C} 2-3$ (36\%), followed by C5-6 (35\%), and C6-7 (17\%). Joints at C1-2, 

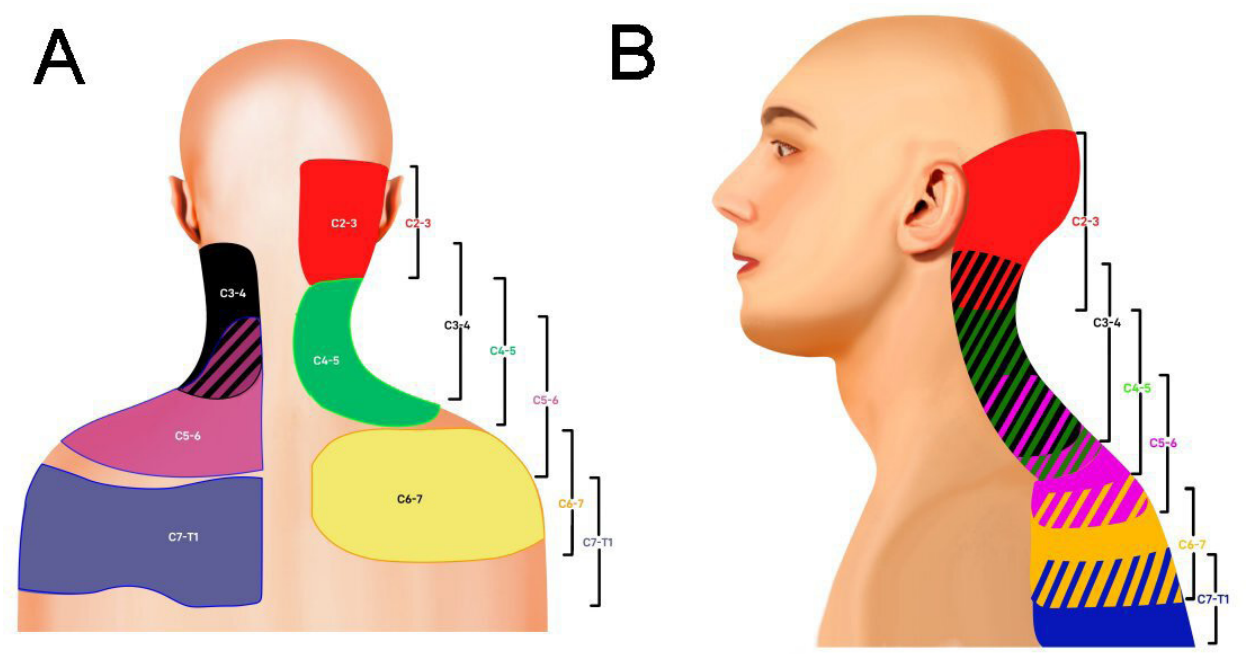

Figure 2 Posterior (A) and lateral (B) segmental maps showing pain referral patterns from the cervical facet joints (C2-3, red; C3-4, black; C4-5, green; C5-6, purple; C6-7, yellow; C7-T1, blue) . ${ }^{13495177413}$ Striped areas (hash marks) represent overlapping cervical facet joint pain maps.

C3-4, C4-5, and were each symptomatic in less than 5\% of cases. Among patients with cervical facet joint pain, 52\% had only 1 symptomatic joint. In the remainder, multiple symptomatic joints occurred in various combinations. These included bilateral joints at the same segment (eg, C2-3 or C5-6), adjacent joints on the same side (eg, C5-6, C6-7), and non-adjacent joints on the same side (C2-3 and C5-6). When C3-4 and C4-5 facet joints were symptomatic, it was usually in combination with an adjacent joint (table 5 ).

\section{Physical examination of the neck to diagnose facetogenic pain}

Physical examination of the neck was found to have a high sensitivity but low specificity in a study in which $77 \%$ of subjects were identified as having primarily facet joint pain. ${ }^{79}$ However, other studies have suggested that specific physical examination maneuvers can identify cervical facet joints as the primary cause of neck pain (Box 1). ${ }^{8081}$

In a study involving 125 patients who received dual LA diagnostic cervical MBB, a protocol consisting of manual spinal examination, palpation for segmental tenderness, and extension-rotation testing was found to have a specificity of $84 \%$ (95\% CI $77 \%$ to $90 \%)$ and a positive likelihood ratio of 4.94 (95\% CI 2.8 to 8.2 ) for identifying cervical facet joints as the principal source of neck pain. ${ }^{80}$ Table 5 summarizes the evidence for features on history and physical examination suggestive of cervical facetogenic pain.

\section{Recommendations}

In summary, there are no single pathognomonic historical symptoms or physical examination signs that can reliably predict the response to facet joint blocks in individuals with chronic neck pain, although a history of whiplash and the presence of paraspinal tenderness in the muscles overlying the facet joints appear to be associated with a positive response to facet joint interventions. Maneuvers associated with radicular signs may be predictive of negative diagnostic cervical MBB. There does not appear to be a difference between the psychological profiles of patients who respond and those who do not respond to interventions targeting the innervation to the cervical facet joints. When selecting targets for blocks, levels should be determined based on clinical presentation (tenderness on palpation (preferably performed under fluoroscopy), pain referral patterns); grade C recommendation, low level of certainty.

\section{QUESTION 3: IS THERE ANY CORRELATION BETWEEN RADIOLOGICAL FINDINGS AND PROGNOSTIC BLOCK OR RFA OUTCOMES?}

\section{Radiological findings and painful facet joints}

In order to correlate radiological findings with a painful facet joint, or outcomes of prognostic IA blocks, MBB or RFA, radiological findings must be compared with patient-reported pain outcomes. Degenerative changes noted in radiological studies may not always be symptomatic, and the presence of findings does not always correlate with clinical symptoms.

Plain film radiographic examinations of the cervical spine represent a simple imaging modality for the evaluation of spine pathology. However, research to date has not found a strong association between the presence of cervical spondylosis on $\mathrm{x}$-rays and clinical pain symptoms. Heller et $a l^{82}$ described a retrospective case-control study in 653 patients referred for $\mathrm{x}$-ray examination of the cervical spine for neck pain compared with 365 asymptomatic patients referred for barium studies. No significant differences were noted in the presence of cervical spondylosis between groups, and there were also no significant associations between pain in the arm, shoulder, scapula, neck, and back of the head, and neck stiffness with pathologic $x$-ray findings. Similar findings have been noted in other retrospective cohort studies, with a lack of association between longitudinal plain film changes and the presence or severity of pain 10 years after the onset of neck pain. ${ }^{83}$ The lack of association between facet joint osteoarthritis on cervical spine radiographs with reports of neck pain has been reported in larger population studies of women and men aged 20-65 years. ${ }^{17}$ More recently, a retrospective cohort study confirmed these earlier findings of the lack of association between facet or uncinate process hypertrophy and pain intensity, headaches, referred shoulder/hand pain, radiculopathy, or numbness. ${ }^{84}$ More high-quality prospective research is needed to understand the relationship between cervical spine $\mathrm{x}$-ray findings and facet-mediated pain.

CT represents a more sensitive imaging modality for the assessment of cervical facet pathology and may yield abnormalities in asymptomatic individuals, with one study finding a 33\% prevalence of cervical facet arthritis in patients who underwent CT scans for non-spinal pain. ${ }^{85}$ Morishita et $a l^{86}$ performed a retrospective study in 215 patients with cervical spine degenerative disease. Although the authors reported a significant 


\begin{tabular}{|c|c|c|c|c|}
\hline $\begin{array}{l}\text { Author, } \\
\text { year }\end{array}$ & Patients & Design & Results & Comments \\
\hline $\begin{array}{l}\text { Dwyer et } \\
\text { al } 1990^{77}\end{array}$ & $\begin{array}{l}4 \text { asymptomatic volunteers and } 1 \text { patient } \\
\text { with neck pain whose cervical facet joint } \\
\text { capsules were 'stimulated' using } 1 \mathrm{~mL} \\
\text { IA contrast }\end{array}$ & Prospective cohort study & $\begin{array}{l}\text { Pain referral maps produced for C2-3 (lower head, upper neck), } \\
\text { C3-4 (upper neck), C4-5 (well localized to mid-neck below } \\
\text { C3-4), C5-6 (top of scapula and shoulder above the scapular } \\
\text { spine) and C6-7 (lower neck to inferior angle of scapula) joints }\end{array}$ & $\begin{array}{l}\text { Pain produced by injection in } 9 \text { out of } \\
11 \text { joints }\end{array}$ \\
\hline $\begin{array}{l}\text { Aprill et al } \\
1990^{13}\end{array}$ & $\begin{array}{l}10 \text { pts with neck pain received MBB with } \\
\text { LA and steroid }\end{array}$ & Prospective cohort study & $\begin{array}{l}\text { Concordance between painful joint level(s) predicted based on } \\
\text { clinical evaluation and response to diagnostic blocks }\end{array}$ & $\begin{array}{l}4 \text { pts had undergone anterior cervical } \\
\text { fusions. } 3 \text { pts had negative discography } \\
\text { results for cervical discogenic pain }\end{array}$ \\
\hline $\begin{array}{l}\text { Barnsley } \\
\text { and } \\
\text { Bogduk, } \\
1993^{76}\end{array}$ & $\begin{array}{l}16 \text { pts with chronic neck pain, with or } \\
\text { without referred pain in the head or } \\
\text { shoulder after MVC, received controlled } \\
\text { MBB with LA }\end{array}$ & Prospective study & $\begin{array}{l}11 \text { of } 16 \text { pts had complete relief of neck pain with restoration } \\
\text { of neck movements after cervical MBB; } 4 \text { of the remaining } 5 \text { pts } \\
\text { had a positive cervical MBB at non-predicted levels }\end{array}$ & $\begin{array}{l}\text { No control group. } \\
\text { Levels for cervical MBB chosen } \\
\text { based on pain maps and sites of } \\
\text { maximal tenderness. No patient had } \\
\text { radiculopathy. Normal imaging studies. } \\
\text { The } 25 \text { MBB performed were highly } \\
\text { specific }\end{array}$ \\
\hline $\begin{array}{l}\text { Lord et al } \\
1994^{75}\end{array}$ & $\begin{array}{l}100 \text { pts with chronic neck pain after } \\
\text { whiplash received double diagnostic } \\
\text { MBB with LA }\end{array}$ & Prospective study & $\begin{array}{l}\text { C2-3 joint was responsible for headaches in } 27 \% \text { of pts } \\
\text { confirmed by diagnostic TON block. Tenderness over C2-3 joint } \\
\text { on examination predicted positive block }\end{array}$ & $\begin{array}{l}\text { No control group. C2-3 joint } \\
\text { responsible for headaches in } 53 \% \text { of pts } \\
\text { when headache was main symptom }\end{array}$ \\
\hline $\begin{array}{l}\text { Lord et al } \\
1996^{68}\end{array}$ & $\begin{array}{l}24 \text { pts with chronic neck pain after MVC } \\
\text { with Quebec Task Force WAD grade I-IV } \\
\text { selected by double diagnostic MBB with } \\
\text { LA and placebo injection who underwent }\end{array}$ & Prospective RCT & $\begin{array}{l}44 \% \text { of screened pts had headache and neck pain from cervical } \\
\text { facet joints }\end{array}$ & $\begin{array}{l}\text { Sham medial branch RFA group } \\
\text { included } \\
\text { C2-3 facet joint pain in 33\% of pts }\end{array}$ \\
\hline
\end{tabular}

Fukui et al 61 pts with neck pain from the cervical Prospective cohort study $1996^{51} \quad$ facet joints confirmed by IA capsular stimulation or electrical stimulation of dorsal rami C3-7
Pain region and source (joint and/or DR):

Occipital region: C2-3 and C3 DR

Upper posterolateral cervical region: $\mathrm{C} 0-1, \mathrm{C} 1-2$, and $\mathrm{C} 2-3$

Upper posterior cervical region: C2-3, C3-4, and C3 DR

Middle posterior cervical region: $\mathrm{C} 3-4, \mathrm{C} 4-5$, and C4 DR

Lower posterior cervical region: C4-5, C5-6, C4, and C5 DR

Suprascapular region: $\mathrm{C4}-5, \mathrm{C} 5-6$, and C4 DR

Superior angle of scapula: C6-7, C6, and C7 DR

Mid-scapular region: C7/TI and C7 DR

\section{Jull et al 20 pts with neck pain who had complete Observational study \\ $1998^{413}$ pain relief with dual MBB. Assessed}

the diagnostic accuracy of physical

examination

Cooper et 194 pts with neck pain who underwent a/ $2007^{49}$ dual comparative MBB in all pts

\section{Segmental patterns of pain arising from cervical facet joints} identified:
15 of $15(100 \%)$ pts with cervical MBB-proven facet joint pain (and no CMBB-negative pts) were correctly identified based on physical examination. The correct segmental level was identified

Suboccipital: C1-2, C2-3

Posterolateral neck: C3-4

Neck to shoulder girdle: $\mathrm{C} 4-5$

Lower neck to upper limb girdle: $\mathrm{C} 5-6, \mathrm{C} 6-7$

Cohen et 92 pts who underwent cervical medial Retrospective study al $2007^{20}$ branch RFA

King et al 173 pts with suspected cervical facet Observational study $2007^{79} \quad$ joint pain based on physical examination studied with MBB

Smith et al 90 subjects with WAD $>6$ months $2013^{73}$ duration post-MVC who received IA injections and MBB; 30 healthy controls

Schneider 125 pts with neck pain in whom a et al clinical examination protocol was $2014^{80} \quad$ validated against positive dual cervical MBB outcome ( $\geq 80 \%$ reduction of pain) to determine factors associated with successful RFA

Paraspinal tenderness associated with successful outcome

Physical examination lacked validity, refuting results of a previous study with overlapping authors. ${ }^{413}$

Examination had a high sensitivity (88\%) but low specificity (39\%)

Cross-sectional design comparing physical and psychological examination in responders and nonresponders with WAD to control pts

Prospective cohort study

58 of $90(64 \%)$ achieved at least $50 \%$ pain relief with IA or

or ROM between facet block responders and non-responders,

but all were abnormal compared with controls. Facet nonresponders had greater medication use and catastrophizing scores compared with responders
A protocol consisting of MSE, PST, and ER test had a specificity of $84 \%$ ( $95 \% \mathrm{Cl} 77 \%$ to $90 \%$ ) and a positive likelihood ratio of 4.94 ( $95 \% \mathrm{Cl} 2.8$ to 8.2 ) for cervical facet joints being the source of neck pain MBB. No difference in objective sensory testing, muscle activity lost to follow-up

Internal controls were asymptomatic joints. $100 \%$ sensitivity and specificity physical examination to predict block response. Incidence of cervical facet joints as the cause of neck pain was $75 \%$

Pain patterns of adjacent segments overlapped

DR, dorsal ramus; ER, extension rotation: ITT, intention to treat: LA, local anesthetic; LR, likelihood ratio: MBB, medial branch block: MSE, manual spinal examination; MVC, motor vehicle collision; PP, per protocol; PST, palpation for segmental tenderness; pts, patients; QTF, Quebec Task Force; RFA, radiofrequency ablation; ROM, range of motion; TON, third occipital nerve; WAD, whiplash associated disorders.

association between hypertrophic changes on CT studies and the presence of neck pain, the statistical analysis was flawed in that it failed to control for important covariates such as age and gender known to affect the prevalence of facet degenerative changes and neck pain. Similar cross-sectional studies with limited numbers of patients report a weak association, but the lack of statistical power in describing small cohorts of patients represents a serious limitation. ${ }^{87}$ CT can demonstrate osteophytes and hyperostosis, but not changes in articular cartilage, which presents limitations in identifying painful facet joints. ${ }^{88}$ The high prevalence of asymptomatic cervical facet osteoarthritis (33\%) decreases the prognostic value of this imaging modality. ${ }^{85}$ Given that CT 
Box 1 Proposed protocols for identifying painful cervical facet joints

\section{Cervical spine range of motion (ROM)}

Measurements of cervical ROM for flexion and extension in the sagittal plane, left- and right-sided lateral flexion, and rotation are taken with the patient seated. The patient is asked to report any pain response and these responses are categorized as increased, decreased, or resulting in no change in baseline cervical spine pain.

\section{Extension-rotation (ER) testing}

Patients are seated and asked to fully extend their head, followed by rotation to both sides. Subjects report any pain at the end of motion. A positive test for pain arising from the cervical facet joints is provocation of baseline cervical spine pain.

\section{Manual spinal examination (MSE)}

The patient is positioned prone with the cervical spine in a neutral position. The assessor applies a posteroanterior directed force over the articular pillars from C2-3 to $\mathrm{C} 6-7$ on each side. The subject reports any pain provocation, whereby a positive test is defined as worsening baseline or referred pain when the assessor perceives moderate or marked resistance to motion.

\section{Palpation for segmental tenderness (PST)}

PST is performed with the subject in the prone position. The assessor palpates the segmental muscles overlying the facet joints ( $C 2-3$ to $\mathrm{C} 6-7)$ bilaterally. These muscles have the same nerve supply as the painful joint(s) and elicit tenderness and spasm. The test is considered positive if the patient reports an increase in baseline pain, either localized or referred. Paraspinal tenderness was reported to be predictive of a positive response to cervical medial branch RFA in one study. ${ }^{20}$

evidence of cervical facet arthrosis is common among older patients with neck pain at the C2-6 levels, additional imaging techniques may need to be incorporated to differentiate the characteristics of painful cervical facet joints from those that are asymptomatic. ${ }^{88}$ At present, the limited research that has examined the association of CT findings with cervical facet-mediated pain is inconclusive.
MRI represents an imaging modality that can identify the presence of edema in a degenerated facet joint. In a retrospective study composed of 173 patients, Nevalainen et al ${ }^{15}$ found a significant correlation between the presence (vs absence) of neck pain and the presence of ipsilateral cervical facet bone marrow edema. However, the severity of neck pain did not significantly increase with the severity of bone marrow edema, raising questions regarding the utility of this finding for characterizing facetmediated pain severity. Future research to confirm the presence of facet-mediated pain through prognostic blocks would build on these study findings.

Radionuclide bone scintigraphy with single-photon emission computed tomography (SPECT) provides functional imaging to assess microcalcification resulting from increased osteoblastic activity. This increased activity may reflect areas of mechanical stress and degenerative changes. SPECT alone as a diagnostic tool is limited by imprecise localization of affected spinal segments and low spatial resolution. The SPECT/CT modality combines the high sensitivity of SPECT with the anatomic localization of $\mathrm{CT}^{89}$ The addition of CT corrects for soft tissue attenuation, thereby improving scan sensitivity. CT also increases specificity by demonstrating structural pathology that is causing increased tracer activity. Two small retrospective studies have examined the association between SPECT/CT findings and outcomes of cervical facet joint blocks. Neither study found a correlation, and each noted a large discrepancy between facet joint SPECT activity and the location of the cervical facet joint injection or MBB. ${ }^{89} 90$

There are more robust data investigating the use of SPECT to identify levels in the lumbar spine. Moderate evidence supports the use of SPECT for the identification of painful lumbar facet joints prior to $\mathrm{MBB}$, and weak evidence supports the use of SPECT to identify painful lumbar facet joints prior to IA joint injections. ${ }^{29}$ Future research extending into these combined imaging modalities may elucidate a connection between radiological findings and facet-mediated pain (tables 6-9).

Radionuclide bone scintigraphy with positron emission tomography (PET) provides real-time information on abnormal biological processes. It can demonstrate foci of hypermetabolism in several inflammatory and infectious disease processes. Intense F-fluorodeoxyglucose (F-FDG) activity has been noted in regions of facet joint arthropathy. ${ }^{91}$ Combining F-FDG PET with MRI allows for further accurate anatomic localization of metabolic information demonstrated through PET. Benefits of

Table 6 Studies evaluating the association between cervical plain film imaging pathology and facet pain

\begin{tabular}{|c|c|c|c|c|}
\hline $\begin{array}{l}\text { Author, } \\
\text { year }\end{array}$ & Patient population & Design & Results & Comments \\
\hline $\begin{array}{l}\text { Rudy et al } \\
2015^{84}\end{array}$ & $\begin{array}{l}322 \text { pts with neck stiffness, shoulder } \\
\text { pain, arm pain and/or headache } \\
\text { attending chiropractic teaching clinics } \\
\text { with cervical radiographs }\end{array}$ & $\begin{array}{l}\text { Retrospective } \\
\text { cross-sectional } \\
\text { study }\end{array}$ & $\begin{array}{l}\text { Symptoms of neck pain, headaches, referral of pain to } \\
\text { the shoulder, and upper extremity radiculopathy did not } \\
\text { correlate with cervical facet joint degeneration }\end{array}$ & $\begin{array}{l}\text { Convenience sample with no asymptomatic } \\
\text { comparison group. } \\
\text { Small association between neck stiffness } \\
\text { and facet hypertrophy }\end{array}$ \\
\hline $\begin{array}{l}\text { Van der } \\
\text { Donk et al } \\
1991^{17}\end{array}$ & $\begin{array}{l}5440 \text { volunteers } 20-65 \text { years of age } \\
\text { enrolled in a national survey study } \\
\text { stratified by presence of neck pain }\end{array}$ & $\begin{array}{l}\text { Cross-sectional } \\
\text { survey study }\end{array}$ & $\begin{array}{l}\text { Osteoarthritis of the facet joints noted on cervical } \\
\text { radiographs was not associated with neck pain }\end{array}$ & $\begin{array}{l}\text { Mean age of participants was } 46 \text { years. } \\
\text { Age was positively associated with neck } \\
\text { pain }\end{array}$ \\
\hline $\begin{array}{l}\text { Gore et al } \\
1987^{83}\end{array}$ & $\begin{array}{l}205 \text { pts with neck pain }>10 \text { years } \\
\text { duration }\end{array}$ & Retrospective & $\begin{array}{l}\text { Presence or severity of pain was not associated with } \\
\text { the presence of degenerative changes including facet } \\
\text { arthropathy, sagittal diameter of the spinal canal, or } \\
\text { degree of cervical lordosis on initial or final cervical x-ray }\end{array}$ & $\begin{array}{l}68 \text { of } 205(33 \%) \text { were involved in litigation. } \\
\text { Mean age at onset of neck pain was } 43 \\
\text { years; mean age at final evaluation was } \\
58 \text { years. }\end{array}$ \\
\hline $\begin{array}{l}\text { Heller et al } \\
1983^{82}\end{array}$ & $\begin{array}{l}653 \text { case pts were referred for cervical } \\
\text { spine } x \text {-ray. } 365 \text { control pts who were } \\
\text { referred for barium studies received } \\
\text { cervical spine x-rays }\end{array}$ & $\begin{array}{l}\text { Retrospective } \\
\text { case-control }\end{array}$ & $\begin{array}{l}\text { No significant difference in the presence of cervical } \\
\text { spondylosis between groups. There were no significant } \\
\text { associations between neck, arm, or occipital pain, and } \\
\text { neck stiffness with x-ray findings }\end{array}$ & $\begin{array}{l}\text { Cervical spondylosis was positively } \\
\text { correlated with age }\end{array}$ \\
\hline
\end{tabular}


Table 7 Studies evaluating the association between $\mathrm{CT}$ imaging pathology and facet pain

\begin{tabular}{|c|c|c|c|c|}
\hline Author, year & Patient population & Design & Results & Comments \\
\hline $\begin{array}{l}\text { Tiwari et al } \\
2020^{87}\end{array}$ & $\begin{array}{l}10 \text { pts were referred for cervical spine CT for } \\
\text { reasons unrelated to spinal pain }\end{array}$ & $\begin{array}{l}\text { Cross- } \\
\text { sectional }\end{array}$ & $\begin{array}{l}\text { Facet joint arthritis on } \mathrm{CT} \text { was negatively } \\
\text { associated with patient-reported neck pain }\end{array}$ & Subgroup analysis of only $10 \mathrm{pts}$ \\
\hline $\begin{array}{l}\text { Kim et al } \\
2019^{85}\end{array}$ & $\begin{array}{l}50 \text { pts who received CT scans for non-spinal } \\
\text { pathologies. Pts with neck pain were excluded }\end{array}$ & Retrospective & $\begin{array}{l}33.4 \% \text { prevalence of asymptomatic cervical } \\
\text { facet arthritis }\end{array}$ & $\begin{array}{l}\text { C6-7 joint was most likely to demonstrate } \\
\text { arthritic changes with findings more common } \\
\text { among older ( } \geq 40 \text { years) pts }\end{array}$ \\
\hline $\begin{array}{l}\text { Rydman et al } \\
2019^{93}\end{array}$ & $\begin{array}{l}121 \text { pts present to the emergency department } \\
\text { for neck pain after MVC with a cervical CT scan } \\
\text { performed at admission }\end{array}$ & $\begin{array}{l}\text { Prospective } \\
\text { longitudinal }\end{array}$ & $\begin{array}{l}\text { Moderate facet joint degeneration, but not } \\
\text { disc degeneration, was associated with } \\
\text { persistent pain after } 6 \text { months }\end{array}$ & $\begin{array}{l}\text { Regions of mild and severe facet degeneration } \\
\text { were not associated with recovery }\end{array}$ \\
\hline $\begin{array}{l}\text { Le Clec'h et al } \\
2016^{97}\end{array}$ & $\begin{array}{l}121 \text { pts who underwent cervical IA facet } \\
\text { injections based on MRI or CT imaging findings } \\
\text { (91 pts) vs palpation for pain ( } 30 \mathrm{pts} \text { ) }\end{array}$ & $\begin{array}{l}\text { Prospective } \\
\text { observational }\end{array}$ & $\begin{array}{l}\text { A greater proportion of pts referred for } \\
\text { injections based on pain palpation reported } \\
\text { relief for up to } 1 \text { month }\end{array}$ & $\begin{array}{l}\text { Cervical facet joint injections were completed } \\
\text { under } \mathrm{CT} \text { guidance }\end{array}$ \\
\hline $\begin{array}{l}\text { Morishita et al } \\
2008^{86}\end{array}$ & $\begin{array}{l}215 \text { pts with degenerative disease of the } \\
\text { cervical spine }\end{array}$ & Retrospective & $\begin{array}{l}\text { Neck pain was more common among pts } \\
\text { with hypertrophic changes in facet joints }\end{array}$ & Did not control for confounding variables \\
\hline $\begin{array}{l}\text { Hechelhammer } \\
\text { et al } 2007^{96}\end{array}$ & $\begin{array}{l}37 \text { pts who underwent } 50 \text { cervical IA facet joint } \\
\text { injections }\end{array}$ & Retrospective & $\begin{array}{l}\text { No statistically significant difference in pain } \\
\text { relief from cervical facet joint blocks based } \\
\text { on osteoarthritis grade }\end{array}$ & $\begin{array}{l}\text { IA injections performed under CT guidance. } \\
56 \% \text { of injections were peri-articular, } 40 \% \text { were } \\
\text { peri- and IA, and } 4 \% \text { were IA }\end{array}$ \\
\hline
\end{tabular}

this technique over F-FDG PET/CT include lower radiation exposure. In a small case-control study performed in 10 patients with clinically diagnosed cervical facet syndrome, F-FDG PET/ MRI localized CT-guided MBB resulted in significantly greater pain relief for up to 3 months compared with landmark-guided injections in patients with negative PET/MRI. ${ }^{92}$ However, the $\mathrm{MBB}$ technique was non-standard due to its high volume $(3 \mathrm{~mL})$ and inclusion of steroids (dose unmentioned).

To date, conventional MRI, plain CT, dynamic flexion films, and radionuclide bone scanning have not demonstrated reliable diagnostic utility for identifying suspected cervical facetmediated pain generators. ${ }^{89}$

\section{Radiological findings associated with whiplash injury}

Imaging findings immediately after whiplash illustrate the extent of injury to cervical facet joints. In a prospective study by Rydman et al ${ }^{93}$ conducted in 121 patients presenting to the ED after MVC who underwent cervical CT scans within 10 days of admission, the authors found that mean pain intensity 6 months after MVC was significantly associated with baseline CT findings of facet joint degeneration. Overall, the prevalence of cervical facet joint degeneration was $45.5 \%$, and those patients with a moderate degree of facet joint degeneration were significantly more likely (OR 6.7, 95\% CI 1.9 to 24.3 ) to self-report absence of recovery at 6 months. Facet joint degeneration on CT was graded by the presence of joint space narrowing, osteophytes, and irregularities of the articular surface. However, any specific correlation between the affected facet joints on CT and the suspected levels of pain was not analysed. In a longitudinal study by Daimon et al ${ }^{94}$ comparing MRIs of the cervical spine obtained 2 weeks and 20 years after a whiplash injury, changes in clinical symptoms (eg, neck pain, shoulder stiffness, dizziness, and tinnitus) were not associated with the progression of degenerative changes on MRI. In another study by Gore et $a l^{83}$ the presence or severity of neck pain was not related to the presence of degenerative changes on radiographs. However, postmortem studies performed in victims of fatal MVCs have identified lesions and small fractures undetectable on plain radiographs, which raises the possibility that more sensitive radiological studies may also fail to detect clinically significant injuries. ${ }^{71} 95$ More data are needed to understand the link between radiological findings and pain after a whiplash injury.

\section{Radiological findings and outcomes after prognostic blocks or RFA}

The association of radiological findings with outcomes of diagnostic cervical facet joint blocks has rarely been examined. Among 37 patients presenting for single, unilateral or bilateral, one-level CT-guided cervical facet joint blocks, no significant difference in pain relief was noted based on the grading of cervical facet osteoarthritis. ${ }^{96}$ In a prospective observational study conducted in 121 patients referred for CT-guided cervical IA facet injections with steroid, a greater proportion of patients referred based on pain palpation compared with imaging (CT or MRI) reported improvement for up to 1 month. ${ }^{97}$

Table 8 Studies evaluating the association between MRI imaging pathology and facet pain

\begin{tabular}{|c|c|c|c|c|}
\hline Author, year & Patient population & Design & Results & Comments \\
\hline $\begin{array}{l}\text { Daimon et al } \\
2019^{94}\end{array}$ & $\begin{array}{l}81 \text { pts presenting immediately } \\
\text { and } 20 \text { years after whiplash } \\
\text { injury for MRI }\end{array}$ & $\begin{array}{l}\text { Prospective } \\
\text { longitudinal }\end{array}$ & $\begin{array}{l}\text { Progression of degeneration on MRI was observed in } 95 \% \text { of } \\
\text { subjects. Changes in neck pain severity was not associated } \\
\text { with progression of degenerative changes on MRI }\end{array}$ & $\begin{array}{l}\text { C4-5 and C5-6 levels most frequently exhibited } \\
\text { degeneration }\end{array}$ \\
\hline $\begin{array}{l}\text { Nevalainen et } \\
\text { al } 2016^{15}\end{array}$ & $\begin{array}{l}173 \text { pts with MRI studies } \\
\text { demonstrating cervical facet } \\
\text { edema }\end{array}$ & Retrospective & $\begin{array}{l}\text { Significant correlation between neck pain and/or unilateral } \\
\text { radiculopathy and ipsilateral bone marrow edema. No } \\
\text { correlation between pain intensity and severity of edema }\end{array}$ & $\begin{array}{l}9 \% \text { prevalence of cervical facet edema, most } \\
\text { commonly at } C 3-4, C 4-5 \text {, and } C 2-3 \text {. The study did } \\
\text { not confirm the presence of facet-mediated pain } \\
\text { through diagnostic blocks }\end{array}$ \\
\hline $\begin{array}{l}\text { Cohen et al } \\
2007^{20}\end{array}$ & $\begin{array}{l}92 \text { pts who underwent cervical } \\
\text { facet RFA after positive MBB }\end{array}$ & Retrospective & $\begin{array}{l}\text { The only clinical variable associated with positive response to } \\
\text { cervical medial branch RFA was paraspinal tenderness }\end{array}$ & $\begin{array}{l}\text { Facet pathology was noted on cervical spine MRI } \\
\text { in } 48 \% \text { of pts but was not predictive of treatment } \\
\text { outcome }\end{array}$ \\
\hline
\end{tabular}

MBB, medial branch block; MRI, magnetic resonance imaging; pts, patients; RFA, radiofrequency ablation. 
Table 9 Studies evaluating the association between SPECT and PET imaging modalities and facet pain

\begin{tabular}{|c|c|c|c|c|}
\hline Author, year & Patient population & Design & Results & Comments \\
\hline $\begin{array}{l}\text { Sawicki et al } \\
2017^{92}\end{array}$ & $\begin{array}{l}10 \text { pts with suspected cervical } \\
\text { facet joint pain }\end{array}$ & $\begin{array}{l}\text { Retrospective } \\
\text { case-control }\end{array}$ & $\begin{array}{l}\text { F-FDG PET/MRI was used to determine the location of MBB in } 6 \text { pts. } \\
\text { Landmarks were used in } 4 \text { PET-negative pts. The PET-positive pts had } \\
\text { significantly less pain up to } 3 \text { months after MBB }\end{array}$ & $\begin{array}{l}\text { CT-guided MBB done with } 3 \mathrm{~m} \\
\text { of LA and steroid. } \\
\text { Pain did not decrease in PET- } \\
\text { negative pts }\end{array}$ \\
\hline $\begin{array}{l}\text { Lehman et al } \\
2014^{90}\end{array}$ & $\begin{array}{l}74 \text { pts with SPECT/CT scan of the } \\
\text { cervical spine who underwent } \\
\text { IA facet joint injection or dual } \\
\text { comparative MBB }\end{array}$ & Retrospective & $\begin{array}{l}18 \text { pts received cervical IA facet joint injections and } 1 \text { received cervical } \\
\text { MBB. } 52 \text { pts }(70 \%) \text { had at least one discrepancy between facet joint } \\
\text { activity on SPECT/CT and clinical treatment }\end{array}$ & $\begin{array}{l}103 \text { of } 195(53 \%) \text { active facet } \\
\text { joint(s) observed on SPECT/CT } \\
\text { did not correlate with clinical } \\
\text { findings }\end{array}$ \\
\hline $\begin{array}{l}\text { Matar et al } \\
2013^{89}\end{array}$ & $\begin{array}{l}72 \text { pts with clinically suspected } \\
\text { facet-mediated neck and back } \\
\text { pain and non-conclusive MRI/CT } \\
\text { findings }\end{array}$ & Retrospective & $\begin{array}{l}\text { Among the } 24 \text { cervical SPECT-CT scans, } 13(52 \%) \text { had evidence of } \\
\text { active cervical facet joint arthropathy and } 10(36 \%) \text { demonstrated other } \\
\text { pathology }\end{array}$ & $\begin{array}{l}\text { No correlation with outcomes } \\
\text { from IA facet joint blocks }\end{array}$ \\
\hline $\begin{array}{l}\text { Perez-Roman } \\
\text { et al } 2020^{414}\end{array}$ & $\begin{array}{l}190 \text { pts with axial neck }(\mathrm{n}=25) \\
\text { or back pain underwent high- } \\
\text { resolution SPECT/CT scan }\end{array}$ & Retrospective & $\begin{array}{l}\text { A total of } 202 \text { hypermetabolic facet joints in } 85 \text { pts }(48 \%) \text { were identified. } \\
\text { Lumbar facet joints were most commonly affected }(69 \%) \text {, followed by } \\
\text { cervical }(24 \%) \text { and thoracic regions }(6 \%) \text {. C1-2 and C2-3 (22\% each) were } \\
\text { the most commonly affected in the neck. In the } 37 \text { pts who reported axial } \\
\text { neck pain, } 16(43.2 \%) \text { were found to have cervical facet hypermetabolism }\end{array}$ & $\begin{array}{l}\text { Diagnostic facet blocks were } \\
\text { not performed. } \\
\text { Injection techniques were not } \\
\text { described }\end{array}$ \\
\hline
\end{tabular}

CT, computed tomography; F-FDG, F-fluorodeoxyglucose; MBB, medial branch block; MRI, magnetic resonance imaging; PET, positron emission tomography; pts, patients; SPECT, single photon emission CT.

Minimal research has examined the association between radiological findings and RFA outcomes. Cohen et $a l^{20}$ performed a retrospective study evaluating factors associated with outcomes in 92 patients who underwent cervical medial branch RFA after positive diagnostic blocks. Although facet pathology was found on cervical MRI in almost half the patients, these findings were not predictive of treatment outcomes.

\section{Recommendations}

We conclude that the current evidence is insufficient to assess the balance of harms and benefits of radiological imaging modalities for the diagnosis of cervical facetogenic pain and as a prognostic indicator for the success of cervical facet blocks or RFA; Grade I recommendation. However, for the purpose of procedural planning, radiological imaging should be strongly considered when indicated; Grade C recommendation, low level of certainty.

\section{QUESTION 4: SHOULD PHYSICAL THERAPY AND/OR CONSERVATIVE TREATMENT BE A PREREQUISITE BEFORE PROGNOSTIC FACET BLOCKS? IF SO, FOR HOW LONG SHOULD THEY BE CONTINUED?}

Conservative management of cervical facet joint pain typically involves a trial of analgesic and anti-inflammatory medications, physiotherapy (also known as physical therapy), and various other modalities (heat and/or ice, massage, transcutaneous electric nerve stimulation, traction, and spinal mobilization). Although supported by little evidence, these conservative treatments are frequently applied before consideration for interventional treatments. ${ }^{98}$ Many clinical studies ${ }^{6899} 100$ evaluating cervical facet injections or radiofrequency $(\mathrm{RF})$ neurotomy have required a course of conservative treatment, while others have not. ${ }^{101-103}$

Although not well supported in the literature, the rationale behind the de facto use of conservative management is that it may assist the recovery process. The use of conservative management prior to prognostic facet blocks is based on pragmatism and to some extent insurance requirements, not empiric data. As with the majority of musculoskeletal conditions, neck pain generally is self-limiting. However, the clinical course of neck pain in the absence of formal treatment is not well-documented. One prospective cohort study describes the natural course of acute neck and low back pain (LBP) in the general population of Norway. ${ }^{104}$ The authors found that the course of pain declined rapidly within 1-2 months of onset in most subjects, with small changes over the follow-up year. These findings provide a general timeframe for the use of conservative management for most patients with acute, but not chronic, neck pain.

The efficacy of physiotherapy for acute neck pain was examined in a prospective cohort study by Vos et al ${ }^{105}$ in which 187 patients with acute neck pain (mean duration at baseline was 16 days) were followed for 1 year. During that period, 118 patients were referred to a physiotherapist with 74\% (87/118) reporting recovery at 1 -year follow-up. Interestingly, the authors found that $79 \%(55 / 69)$ of control patients reported similar recovery at 1-year follow-up without any physiotherapy intervention. This again implies that most cases of acute neck pain resolve spontaneously without the need for further work-up and treatment. An RCT performed on 156 patients with neck pain found that the use of a multimodal approach containing self-management with coping skill training was more effective than individualized physical therapy over a 2 -year follow-up. ${ }^{106}$ However, in another study, manual physical therapy and exercise were shown to be a more effective treatment strategy than advice on motion exercises for chronic mechanical neck pain. ${ }^{107}$ It is important to note that neck pain does not necessarily equate to cervical facet joint pain, as there are other causes of neck pain including myofascial or discogenic neck pain. However, cervical facet joint pain is known to make up a substantial portion of the patient population with neck pain, with a reported prevalence in a pain clinic population approaching $60 \% .^{6}$

The use of conservative treatments (which are often advocated for non-specific symptoms) prior to prognostic blocks may also be related to the absence of pathognomonic physical examination or radiological findings for facet joint pain. In the absence of any reliable means of clinically diagnosing facet joint pain, the treatment of mechanical or neuropathic neck pain often starts with less invasive treatments. The response to conservative treatments may prevent the need for further work-up and interventions. Of note, there is no evidence that conservative treatment guarantees functional improvement or pain reduction, nor does lack of response to conservative measures predict success or failure of procedural interventions. Confounding things further, 
responders and non-responders to prognostic facet blocks were found in one study to demonstrate similar presentation of sensory disturbances, motor dysfunction, and psychological distress. $^{73}$

In a Cochrane Database systematic review of physical therapy for the treatment of non-specific chronic neck pain, there was moderate evidence supporting cervico-scapulothoracic and upper extremity strength training, endurance training, strengthening and stretching exercises, mindfulness exercise, and stabilization exercises to improve pain and function based on moderate-quality evidence. ${ }^{108} \mathrm{~A}$ meta-analysis evaluating physical therapy techniques found that therapeutic exercise had significant short-term and intermediate-term effects, but no long-term benefit on pain. ${ }^{109}$ Physical therapy did not provide significant short-term, intermediate-term, or long-term effects on disability. In a systematic review evaluating exercise programs for chronic non-specific neck pain, the authors found strong evidence for the effectiveness of muscle strengthening and endurance exercises. ${ }^{110}$ Moderate evidence supported the use of muscle endurance exercise in reducing disability attributed to neck pain. However, no physical therapy efficacy studies were found in the literature that included patients with MBB-proven cervical facet joint pain.

Medications have been recommended as part of a conservative treatment regimen for patients with cervical facet-related pain, despite there being a scarce number of high-quality studies evaluating pharmacotherapy for chronic neck pain. Accurate extrapolation is even more challenging since most studies included individuals with non-specific neck pain. As noted in a review by Cohen, ${ }^{111}$ systemic non-steroidal anti-inflammatory drugs have been found to be beneficial for spinal pain in general, but not specifically neck pain. The use of acetaminophen, topical and oral non-steroidal anti-inflammatory drugs, and intermediate doses of the muscle relaxant (cyclobenzaprine) were found to be useful in the treatment of acute and subacute neck pain symptoms. ${ }^{112-115}$

\section{Third occipital neuralgia/cervicogenic headaches}

As with cervical facet joint-mediated pain, third occipital neuralgia and cervicogenic headaches can only be reliably diagnosed with IA injection or MBB. As per revised criteria of the International Headache Society (IHS), ${ }^{116}$ evidence of a cervical source of pain is required for the diagnosis of cervicogenic headache. However, the IHS notes that clinical features historically thought to be related to cervicogenic headaches are not unique and "they do not necessarily define causal relationships". In a review by Bogduk and Govind, ${ }^{117}$ the authors concluded that diagnostic blocks are the only means of reliably establishing this diagnosis.

There have been several moderate quality studies exploring the use of conservative treatments including therapeutic exercises for third occipital neuralgia and cervicogenic headache. ${ }^{118-123}$ These studies have reported conflicting evidence regarding the effects of manipulative therapy on cervicogenic headaches. However, study results must be interpreted with caution since the diagnosis of cervicogenic headache was made clinically instead of by diagnostic blocks. In the only RCT that investigated the effects of exercise in the treatment of cervicogenic headache, Jull et $a l^{121}$ found that either exercise or spinal manipulation provided statistically significant improvements relative to a control group through 12 weeks, with the combination treatment group faring no better than stand-alone treatments. For chronic cervicogenic headache, moderate-quality evidence supports static-dynamic cervico-scapulothoracic strengthening/endurance exercises including pressure biofeedback at long-term follow-up. ${ }^{108}$ In a review by Bogduk and Govind, ${ }^{117}$ the authors concluded that manual therapy (including physiotherapy) was no more effective than exercise alone. The authors further proposed a 'pragmatic clinical approach' involving exercises with or without manual therapy for clinically suspected cervicogenic headache, with the efficacy of most other treatments (eg, medications, transcutaneous electrical stimulation) being speculative at best.

\section{Recommendations}

Due to a generally favorable natural history of acute neck pain symptoms, our recommendation is for a 6-week trial of conservative management prior to prognostic cervical facet blocks to prevent unnecessary invasive procedures and associated healthcare costs. The use of conservative measures may prevent the need for prognostic blocks (or further interventions) but does not preclude the use of blocks for those patients who have failed conservative treatments. Grade B recommendation, moderate level of certainty for a requirement of conservative management before prognostic blocks in patients with at least 3 months of neck pain; Grade C recommendation, low level of certainty for at least a 6-week trial of conservative therapy which may vary based on a personalized medicine paradigm; grade I recommendation for concomitant use of conservative measures to accompany prognostic blocks.

\section{QUESTION 5: IS IMAGE GUIDANCE NECESSARY FOR CERVICAL FACET BLOCKS AND RFA?}

\section{Guidance versus no guidance: accuracy and safety}

Whereas no specific imaging modality has been identified as the reference standard, image guidance for cervical spine interventions has become an essential component in minimizing patient harm and optimizing results. ${ }^{124}$ For cervical facet procedures including IA injections, MBB and medial branch RFA, fluoroscopy and, to a much lesser extent, CT and ultrasound (US) are commonly used. Cervical procedures may pose a higher risk than analogous procedures in the lumbar region ${ }^{125}$; therefore, the use of advanced imaging including US or CT may be more common and useful. Similar to the lumbar region, the use of imaging allows accurate needle placement to ensure the lowest volume of anesthetic is administered, thereby reducing spread to surrounding tissues which may lead to false-positive test results. Image guidance also improves safety through direct visualization of bony elements of the neuraxis, thus avoiding proximal structures including pleura, neural foramina, and vascular supply. In the USA, the current procedural terminology (CPT) code 77003 (fluoroscopic guidance and localization of needle or catheter tip for spine or paraspinous diagnostic or therapeutic injection procedures) should not be used for facet blocks or RF as imaging is considered an integral part of the procedures. When US guidance is used, the category III codes $0213 \mathrm{~T}-0218 \mathrm{~T}$ should be reported.

Manchikanti et al ${ }^{126}$ examined procedural risks of fluoroscopically-guided cervical facet procedures in a prospective observational study in which 3370 cervical MBBs were performed. They found no instances of nerve damage, spinal cord injury, infection, or epidural hematoma; however, cervical procedures had a higher risk of intravascular adverse events (eg, oozing, intravascular penetration) compared with thoracic and lumbar regions. The lack of moderate to severe adverse events or a difference in incidence between cervical and lumbar spine interventions when image guidance is used is unsurprising given the 
Table 10 Studies comparing imaging modalities for cervical facet injections

\begin{tabular}{|c|c|c|c|c|}
\hline Author, year & Patient population & Study design & Results & Comments \\
\hline $\begin{array}{l}\text { Park et al } \\
2017^{145}\end{array}$ & $\begin{array}{l}\text { Pts with injection-confirmed chronic } \\
\text { cervical facet joint pain who received US- } \\
\text { guided }(n=68) \text { or fluoroscopically-guided } \\
\text { cervical MBB }(n=58)\end{array}$ & Retrospective & $\begin{array}{l}\text { Both groups showed improvements, with no } \\
\text { significant differences between groups for pain } \\
\text { scores or responder rates }\end{array}$ & $\begin{array}{l}\text { Compared with fluoroscopically-guided cervica } \\
\text { MBB, US-guided cervical MBB was associated } \\
\text { with a shorter performance time and fewer } \\
\text { needle passes }\end{array}$ \\
\hline $\begin{array}{l}\text { Finlayson et al } \\
2013^{136}\end{array}$ & $\begin{array}{l}40 \text { pts undergoing TON block were } \\
\text { randomized to fluoroscopic or US guidance }\end{array}$ & Randomized & $\begin{array}{l}\text { Fluoroscopy and US guidance provided similar } \\
\text { technical success rates (95-100\%) and pain relief }\end{array}$ & $\begin{array}{l}\text { US guidance was associated with a } \\
\text { significantly shorter performance time ( } 212.8 \\
\text { vs } 396.5 \text { seconds) and fewer needle passes ( } 2 \\
\text { vs 6) }\end{array}$ \\
\hline $\begin{array}{l}\text { Finlayson et al } \\
2015^{147}\end{array}$ & $\begin{array}{l}50 \text { pts undergoing C7 MBB under US or } \\
\text { fluoroscopic guidance }\end{array}$ & Randomized & $\begin{array}{l}\text { Similar accuracy rates }(92-96 \%) \text { and post-block } \\
\text { pain relief between modalities }\end{array}$ & $\begin{array}{l}\text { US guidance was associated with shorter } \\
\text { performance time, fewer needle passes and } \\
\text { less intravascular spread }\end{array}$ \\
\hline $\begin{array}{l}\text { Manchikanti et } \\
a / 2012^{126}\end{array}$ & $\begin{array}{l}7500 \text { episodes of } 43000 \text { facet joint nerve } \\
\text { blocks with } 3370 \text { episodes in the cervical } \\
\text { region. All facet joint nerve blocks were } \\
\text { performed under fluoroscopic guidance }\end{array}$ & $\begin{array}{l}\text { Prospective } \\
\text { observational }\end{array}$ & There were no major complications & $\begin{array}{l}\text { For cervical MBB, } 20 \% \text { incidence of } \\
\text { intravascular penetration }\end{array}$ \\
\hline $\begin{array}{l}\text { Zhou et al } \\
2010^{167}\end{array}$ & $\begin{array}{l}31 \text { pts with refractory cervicogenic } \\
\text { headache who underwent fluoroscopically- } \\
\text { guided } A A \text { and } C 2-3 \text { facet joint injections } \\
\text { and } C 2 \text { and } 3 \text { dorsal rami blocks }\end{array}$ & $\begin{array}{l}\text { Prospective } \\
\text { observational }\end{array}$ & $\begin{array}{l}28(90.3 \%) \text { pts experienced }>50 \% \text { headache relief } \\
\text { after treatment, with an average duration of } 21.7 \\
\text { (range 1-90) days }\end{array}$ & No treatment-related complications \\
\hline $\begin{array}{l}\text { Obernauer et } \\
\text { al } 2013^{143}\end{array}$ & $\begin{array}{l}40 \text { pts ( } 54 \text { joints) with subacute axial neck } \\
\text { pain were randomly assigned to US- or } \\
\text { CT-guided IA facet injections }\end{array}$ & Randomized & $\begin{array}{l}\text { Accuracy of US-guided interventions was } 100 \% \text {. } \\
\text { Mean time (min:sec) to final needle placement in } \\
\text { the US group was } 04: 46 \text { vs } 11: 12 \text { ( } p<0.05 \text { ) in the } \\
\text { CT group for one injected level, and 05:49 in the US } \\
\text { group vs 14:32 ( } p<0.05 \text { ) in the CT group for two } \\
\text { injected levels }\end{array}$ & $\begin{array}{l}\text { US-guided single-level IA injections resulted } \\
\text { in slightly greater pain relief immediately } \\
\text { 1-month post-procedure compared with CT- } \\
\text { guided injections. For two-level injections, pain } \\
\text { reduction was comparable }\end{array}$ \\
\hline
\end{tabular}

$\mathrm{AA}$, atlanto-axial; $\mathrm{CT}$, computed tomography; IA, intra-articular; MBB, medial branch block; pts, patients; TON, third occipital nerve; US, ultrasound.

rarity of moderate to severe complications associated with either region. ${ }^{125}$ Neither this nor other studies examined the relative risk of performing cervical joint procedures with and without image guidance. This type of empiric study is unlikely to be designed or performed, as the scientific community has encouraged image guidance as a general harm reduction strategy. ${ }^{124}$ Heckman and colleagues ${ }^{127}$ reported a case of transient tetraplegia following cervical facet IA injection in which no image guidance was used, and closed claims analyses have revealed at least two other cases involving facet injections in which the use of imaging was not noted. ${ }^{128}{ }^{129}$ Cervical joint procedures performed without image guidance are likely to result in at least as many complications and poor outcomes as unguided lumbar paravertebral or facet injections. ${ }^{29} 130$

\section{Existing guidelines and insurance coverage}

The scientific question related to the accuracy and safety of image- versus non-image-guided procedures has not been adequately evaluated in clinical trials. ${ }^{125}$ The ASA's 2010 practice guidelines are referenced in some insurance company determinations, although their language more generally references 'appropriate image guidance' and does not limit recommendations to specific imaging modalities. ${ }^{131}$ The SIS guidelines recommend the use of fluoroscopic imaging with multiple views using the lowest amount of radiation but do not mention the use of CT, US, and imaging modality combinations. ${ }^{132}$ For MBBs, the nerve is not directly visible with fluoroscopy, but its location can be inferred based on accepted bony landmarks. Fluoroscopy is a familiar technology that most pain physicians are comfortable using. However, either real-time fluoroscopy or preferably digital subtraction angiography (DSA) is needed to reliably detect and visualize intravascular injection. ${ }^{133134}$ Nevertheless, fluoroscopy-and particularly CT-have considerable costs associated with them, including purchase price, maintenance, and the need for dedicated facilities. Further, both modalities—and particularly
CT-expose patients and providers to significant radiation, which may have cumulative health effects. The CPT codes for cervical joint procedures that are recognized by most insurance companies are bundled with image guidance, specifically fluoroscopic and CT guidance. Separate US-based codes for cervical procedures (eg, 0213 T-0215T) are considered experimental and investigational by the Centers for Medicare and Medicaid Services (CMS). The 2008 Health and Human Services (HHS) guidelines (next projected update 2021) support the routine use of radiographic guidance and indicate that performing facet procedures without image guidance could put patients at risk; consequently, many local coverage areas automate payment rejections based on lack of use of radiographic imaging. ${ }^{135}$ The original study supporting the HHS guidelines reported a lack of precision and potentially catastrophic outcomes for procedures performed without imaging. ${ }^{130}$ Despite growing evidence for the use of US as an imaging modality for cervical MBBs, ${ }^{136-138}$ which has no radiation risks and may lower the entry cost for physicians, a major carrier for CMS determined that US imaging for facet injections would not be reimbursed. However, their determination supported the use of fluoroscopic or CT guidance for facet joint procedures including cervical MBBs. ${ }^{139}$ Multiple insurance companies have aligned their coverage requirements with that ruling including BlueCross BlueShield, ${ }^{140}$ Cigna, ${ }^{141}$ and UnitedHealthcare, ${ }^{142}$ determining that facet blocks performed with US are experimental.

Imaging for prognostic interventions (medial block and third
occipital nerve (TON) blocks with local anesthetic)
Use of fluoroscopy
Fluoroscopy is the reference standard for prognostic interven-
tions of the cervical spine including TON block and MBB.
A randomized study of the cervical spine found the incidence
of 'missed nerves' to be $7 \%$ using fluoroscopic guidance with




\begin{tabular}{|c|c|c|c|c|}
\hline $\begin{array}{l}\text { Author, } \\
\text { year }\end{array}$ & Patient population & Design & Results & Comments \\
\hline $\begin{array}{l}\text { Busch and } \\
\text { Wilson, } \\
1989^{168}\end{array}$ & $\begin{array}{l}25 \text { pts with head and neck pain of which } 2 \text { pts received } \\
L A \text { and steroid } A O \text { and } A A \text { joint injections }\end{array}$ & Retrospective & $\begin{array}{l}\text { Pain relief in both cases ranged from } 3 \\
\text { weeks to } 4 \text { months (1 patient received } \\
\text { serial injections) }\end{array}$ & $\begin{array}{l}\text { No reported adverse events other than } \\
\text { transient ataxia and worsening pain for } \\
24-48 \text { hours. Fluoroscopically-guided } A O \text { and } \\
\text { AA injections performed concurrently }\end{array}$ \\
\hline $\begin{array}{l}\text { Dreyfuss } \\
\text { et al } \\
1994^{159}\end{array}$ & 3 pts who received fluoroscopically-guided AO injections & Case series & $\begin{array}{l}\text { Pain relief in all } 3 \text { pts ranging from } 6 \text { to } \\
12 \text { months }\end{array}$ & $\begin{array}{l}\text { No reported adverse events. Multiple } \\
\text { concurrent injections limits generalization }\end{array}$ \\
\hline $\begin{array}{l}\text { Lee et al } \\
2015^{165}\end{array}$ & $\begin{array}{l}29 \text { pts with refractory headache and neck pain and } \\
\text { findings suggestive of } A O \text { joint pain. Pts with } \geq 50 \% \text { pain } \\
\text { relief after diagnostic } A O \text { block underwent } \\
\text { fluoroscopically-guided AO joint injections with LA and } \\
\text { steroid }\end{array}$ & $\begin{array}{l}\text { Prospective } \\
\text { observational } \\
\text { study }\end{array}$ & $\begin{array}{l}20 \text { of } 24(83 \%) \text { pts had a positive } \\
\text { diagnostic block. Pain scores and } \\
\text { function improved from baseline at } \\
\text { 2-month follow-up }\end{array}$ & $\begin{array}{l}\text { Pts received two } \mathrm{AO} \text { joint injections } 1 \text { week } \\
\text { apart. No reported adverse events }\end{array}$ \\
\hline $\begin{array}{l}\text { Centeno et } \\
\text { al } 2018^{158}\end{array}$ & 10 pts received bilateral $\mathrm{A} 0$ joint injections & Case series & $\begin{array}{l}\text { All injections reported as 'successful' } \\
\text { with no adverse events }\end{array}$ & $\begin{array}{l}\text { Head flexed to open up joint and rotated } \\
\text { ipsilaterally to displace vertebral artery } \\
\text { medially. Injectate composition not reported. } \\
\text { Effectiveness outcome measures and follow- } \\
\text { up period not reported }\end{array}$ \\
\hline $\begin{array}{l}\text { Shin et al } \\
2018^{171}\end{array}$ & $\begin{array}{l}23 \text { pts with chronic upper cervical pain, pain score } \geq 3 / 10 \text {, } \\
\text { and } \geq 50 \% \text { pain relief after diagnostic } A O \text { joint block } \\
\text { received either } A O \text { joint injection with } L A \text { and steroid } \\
(n=11) \text { or pulsed RF of the } A O \text { joint }(n=12)\end{array}$ & $\begin{array}{l}\text { Randomized } \\
\text { comparative- } \\
\text { effectiveness } \\
\text { trial }\end{array}$ & $\begin{array}{l}\text { Pain score improved from baseline with } \\
\text { sustained relief at } 6 \text { months with no } \\
\text { differences between groups }\end{array}$ & $\begin{array}{l}\text { Between } 60 \% \text { and } 70 \% \text { of pts } \\
\text { achieved }>50 \% \text { pain relief through } 6 \text {-month } \\
\text { follow-up. Study not blinded. No adverse } \\
\text { events reported }\end{array}$ \\
\hline $\begin{array}{l}\text { El Abd et } \\
\text { al } 2008^{166}\end{array}$ & $\begin{array}{l}\text { Single patient with right-sided neck pain and headache } \\
\text { due to congenital fusion of AO joints bilaterally. Two } \\
\text { injections done with LA and steroid }\end{array}$ & Case report & $\begin{array}{l}2 \text { weeks after second therapeutic } \\
\text { injection, patient reported } 75 \% \\
\text { improvement. At } 6 \text { and } 12 \text { month follow- } \\
\text { ups, pain reduction persisted }\end{array}$ & $\begin{array}{l}\text { Authors reported no noticeable improvement } \\
\text { in ROM }\end{array}$ \\
\hline
\end{tabular}

$A A$, atlanto-axial; $A O$, atlanto-occipital; $L A$, local anesthetic; pts, patients; RF, radiofrequency; ROM, range of motion.

$0.25-0.5 \mathrm{~mL}$ of injectate, ${ }^{78}$ and an earlier study showed that a $0.5 \mathrm{~mL}$ injection reliably encompassed the target nerve. ${ }^{76}$

\section{Use of CT or US}

In a randomized trial comparing CT-guided to US-guided IA injections in 40 patients with neck pain, Obernauer et $a l^{143}$ found superior benefit immediately post-procedure and at 1 month for US-guided single-level injections, with shorter procedure duration. For two-level injections, the benefit favoring US-guided injections fell shy of statistical significance. Eichenberger et $^{1 l^{144}}$ achieved cutaneous analgesia in the distribution of the TON after a US-guided TON block in nine of 10 injections in normal volunteers. It should be noted that the authors used a large volume $(0.9 \mathrm{~mL})$ of injectate which will spread well beyond the margins of the TON. ${ }^{78}$ The $\mathrm{C} 2-3$ joint was correctly identified in 27 of 28 cases, and in 23 of 28 injections the needle fell within $0.5 \mathrm{~mm}$ of the target nerve. ${ }^{144}$ These findings were confirmed in a subsequent volunteer study by a group with overlapping authors. $^{137}$

Finlayson et $a l^{136}$ performed a randomized study in 40 patients undergoing TON block to determine the comparative effectiveness of fluoroscopic versus US guidance. Their study found comparable effectiveness (19 of 20 patients received successful TON hypoesthesia) with US guidance, which required fewer needle adjustments than fluoroscopically-guided interventions. The TON was directly identified in 16 of 20 US procedures and vascular penetration was observed in zero patients in the US group versus one in 20 in the fluoroscopy group.

These findings were replicated in a retrospective comparative study by Park et $a l^{145}$ conducted in 126 patients undergoing cervical MBB by either fluoroscopic or US guidance. Their results demonstrated similar accuracy rates, but reduced procedure time and needle adjustments using US. Paredes et al ${ }^{146}$ conducted a systematic review and meta-analysis showing that using US for cervical prognostic interventions including TON block and cervical MBB was non-inferior to fluoroscopic guidance, albeit with a lower incidence of vascular penetration and no radiation exposure. US may also offer the additional benefit of real-time imaging of the cervical spine.

Whereas US may provide comparable accuracy and confer some advantages over fluoroscopy, several studies have revealed diminished accuracy rates for $\mathrm{C} 7$, which may also be more challenging to block with fluoroscopy. ${ }^{137}{ }^{138}$ In one randomized study involving 50 patients, US and fluoroscopy were found to have similar accuracy rates $(92-96 \%)$ and to provide comparable post-block pain relief, although the former was associated with shorter performance time and less intravascular contrast spread. ${ }^{147}$ It is important to recognize that even an imaging modality that permits direct visualization of neurovascular structures is not devoid of risks, with Park et $a l^{148}$ reporting a case of permanent spinal cord injury after a $\mathrm{C} 7 \mathrm{MBB}$ was performed under US guidance, which reinforces the challenges at this cervical level (table 10). ${ }^{137}$

\section{Imaging for therapeutic interventions (IA steroid and RFA) Use of fluoroscopy, CT, and US}

In the lumbar anatomic region, recent multi-society guidelines recommended fluoroscopy as the preferred imaging modality for IA injections and lumbar medial branch RFA. ${ }^{29}$ The use of fluoroscopic guidance is well-established for TON through C8 medial branch RFA procedures. ${ }^{21} 68101149$ However, the use of CT and US guidance for cervical interventions including IA facet injections with steroid is still in its infancy and cadaveric evaluation has yet to definitively establish comparative effectiveness and safety relative to the fluoroscopic approach. ${ }^{143} 150$ A prospective clinical trial comparing CT versus US-guided IA facet injections in 40 adults demonstrated equivalent accuracy 
Table 12 Clinical studies evaluating AA joint injections

\begin{tabular}{|c|c|c|c|c|}
\hline $\begin{array}{l}\text { Author, } \\
\text { year }\end{array}$ & Patient population & Design & Results & Comments \\
\hline $\begin{array}{l}\text { Bogduk } \\
\text { and } \\
\text { Marsland, } \\
1988^{8}\end{array}$ & $\begin{array}{l}24 \text { consecutive pts who underwent } \\
\text { cervical injections for head and neck } \\
\text { pain, } 4 \text { of whom received AA injections } \\
\text { with LA and steroid }\end{array}$ & $\begin{array}{l}\text { Retrospective } \\
\text { study }\end{array}$ & $\begin{array}{l}1 \text { of } 4(25 \%) \text { pts obtained pain relief from AA joint } \\
\text { injection for } 2 \text { months }\end{array}$ & $\begin{array}{l}\text { Used a fluoroscopically-guided posterior approach. } \\
\text { Pts had also trialed other cervical injections. } \\
\text { No reported adverse events }\end{array}$ \\
\hline $\begin{array}{l}\text { Lamer, } \\
1991^{170}\end{array}$ & $\begin{array}{l}2 \text { pts with cervical spine } O A \text { and ear } \\
\text { pain provoked with head turning } \\
\text { received } A A \text { joint injection with } L A \text { and } \\
\text { steroid }\end{array}$ & Case series & Both pts had pain relief following injection & $\begin{array}{l}\text { Used a fluoroscopically-guided posterior approach. } \\
\text { Injectate volumes not noted. } \\
\text { Duration of pain relief not reported }\end{array}$ \\
\hline $\begin{array}{l}\text { Chevrot et } \\
\text { al } 1995^{160}\end{array}$ & $\begin{array}{l}100 \text { pts (osteoarthritis, rheumatoid } \\
\text { arthritis, ankylosing spondylarthritis, and } \\
\text { diverse conditions) who received AA } \\
\text { joint injections with LA and steroid }\end{array}$ & $\begin{array}{l}\text { Retrospective } \\
\text { study }\end{array}$ & $\begin{array}{l}18(60 \%) \text { of first } 30 \text { pts showed clinical } \\
\text { improvement (duration of follow-up } 6 \text { months to } \\
3 \text { years) }\end{array}$ & $\begin{array}{l}\text { Used a fluoroscopically-guided posterior oblique } \\
\text { approach. } \\
\text { One accidental vertebral artery puncture without } \\
\text { clinically significant sequelae }\end{array}$ \\
\hline $\begin{array}{l}\text { Glemarac } \\
\text { et al } \\
2000^{172}\end{array}$ & $\begin{array}{l}26 \text { pts with either mechanical }(n=16) \\
\text { or inflammatory disorders }(n=10) \text { who } \\
\text { received AA joint injections with steroid } \\
\text { (no LA) }\end{array}$ & $\begin{array}{l}\text { Retrospective } \\
\text { study }\end{array}$ & $\begin{array}{l}69.3 \% \text { responder rate with mean pain score } \\
\text { reduction of } 52.3 \% \text { and mean duration of pain relief } \\
8.1 \text { months }\end{array}$ & $\begin{array}{l}\text { Used a fluoroscopically-guided posterior approach. } \\
\text { Those with inflammatory conditions responded } \\
\text { better than those with mechanical disorders. One } \\
\text { case of moderately severe hypertension following } \\
\text { injection }\end{array}$ \\
\hline $\begin{array}{l}\text { Aprill et al } \\
2002^{5}\end{array}$ & $\begin{array}{l}34 \text { pts with occipital pain and clinical } \\
\text { features suggestive of AA joint origin } \\
\text { received AA injection with LA and } \\
\text { steroid }\end{array}$ & $\begin{array}{l}\text { Prospective } \\
\text { observational } \\
\text { study }\end{array}$ & $\begin{array}{l}21 \text { of } 34(62 \%) \text { pts obtained complete pain relief for } \\
\text { at least the duration of action of LA }\end{array}$ & $\begin{array}{l}\text { Used a fluoroscopically-guided posterior approach. } \\
\text { Duration of response not assessed. Clinical features } \\
\text { did not predict positive response }\end{array}$ \\
\hline $\begin{array}{l}\text { Narouze et } \\
\text { al } 2007^{62}\end{array}$ & $\begin{array}{l}32 \text { pts with clinical features suggestive } \\
\text { of AA joint pain who received AA } \\
\text { injection with LA and steroid }\end{array}$ & $\begin{array}{l}\text { Retrospective } \\
\text { study }\end{array}$ & $\begin{array}{l}15 \text { of } 32(47 \%) \text { pts had complete pain relief for the } \\
\text { duration of action of } L A, 26 \text { of } 32(81 \%) \text { had } \geq 50 \% \\
\text { improvement sustained at } 3 \text { months }\end{array}$ & $\begin{array}{l}\text { Used a fluoroscopically-guided posterior approach. } \\
5 \text { of } 32(16 \%) \text { pts stopped opioid use and } 3 \text { of } 32 \\
(9 \%) \text { pts had complete pain relief sustained at } 9 \\
\text { months }\end{array}$ \\
\hline $\begin{array}{l}\text { Zhou et al } \\
2010^{167}\end{array}$ & $\begin{array}{l}31 \text { pts with suspected cervicogenic } \\
\text { headache who received } A A \text { joint, } C 2 \\
\text { and } C 3 \text { dorsal rami, and } C 2-3 \text { facet joint } \\
\text { injection with } L A \text { and steroid }\end{array}$ & $\begin{array}{l}\text { Retrospective } \\
\text { study }\end{array}$ & $\begin{array}{l}28 \text { of } 31(90 \%) \text { pts had }>50 \% \text { pain relief with an } \\
\text { average duration of } 21.7 \text { days }\end{array}$ & $\begin{array}{l}\text { Used fluoroscopically-guided posterior approach. } \\
\text { Pts also experienced decreased headache frequency } \\
\text { and duration. } 3 \text { non-responders diagnosed with } \\
\text { temporomandibular disorder }(n=2) \text { and migraine } \\
(n=1) \text {. }\end{array}$ \\
\hline $\begin{array}{l}\text { Aiudi et al } \\
2017^{163}\end{array}$ & $\begin{array}{l}72 \text { pts who received AA joint injections } \\
\text { with LA and steroid }\end{array}$ & $\begin{array}{l}\text { Retrospective } \\
\text { study }\end{array}$ & $\begin{array}{l}\text { Adverse event rate was } 25 \text { of } 135 \text { (18.5\%) } \\
\text { injections with } 13 \text { procedural events (vascular } \\
\text { uptake/paresthesia) and } 12 \text { post-procedural events } \\
\text { (increased pain/neurologic symptoms) }\end{array}$ & $\begin{array}{l}\text { Used a fluoroscopically-guided posterior approach. } \\
\text { No serious adverse events noted and all post- } \\
\text { procedural adverse events resolved within } 3 \\
\text { months. } \\
\text { Pain outcomes not reported }\end{array}$ \\
\hline $\begin{array}{l}\text { Hetta et al } \\
2019^{173}\end{array}$ & $\begin{array}{l}60 \text { pts with rheumatoid arthritis and } \\
\text { AA joint pain received AA joint injection } \\
\text { with } L A \text { and steroid or LA and saline }\end{array}$ & $\begin{array}{l}\text { Randomized } \\
\text { controlled }\end{array}$ & $\begin{array}{l}\text { LA+steroid injection > LA-only injection through } \\
\text { 3-month follow-up for pain and function, with } \\
\text { improvement in imaging findings not observed in } \\
\text { LA-only group }\end{array}$ & $\begin{array}{l}\text { Fluoroscopically-guided } \\
\text { posterior approach. } \\
\text { Permitted continued use of disease-modifying } \\
\text { agents and oral NSAIDs for breakthrough pain }\end{array}$ \\
\hline $\begin{array}{l}\text { Kuklo et al } \\
2006^{169}\end{array}$ & $\begin{array}{l}14 \text { pts with AA joint pain received AA } \\
\text { joint injection 'via a standard technique' } \\
\text { with } L A+\text { steroids - no specifics provided }\end{array}$ & Retrospective & $\begin{array}{l}11 \text { of } 14(79 \%) \text { pts treated 'successfully' with 1-4 } \\
\text { injections over the study period with significant } \\
\text { pain relief. } 3 \text { refused injections, } 3 \text { had no relief from } \\
\text { multiple injections, } 3 \text { had temporary relief from } \\
\text { injections and went on to C1-2 fusion surgery }\end{array}$ & $\begin{array}{l}\text { No discussion on how 'significant' relief was } \\
\text { defined }\end{array}$ \\
\hline
\end{tabular}

AA, atlanto-axial; LA, local anesthetic; NSAIDs, non-steroidal anti-inflammatory drugs; OA, osteoarthritis.

and effectiveness. ${ }^{143}$ However, the US-guided procedures were faster to perform, with no radiation exposure. A single RCT has been performed evaluating cervical medial branch RFA using US. Siegenthaler et al ${ }^{151}$ examined the effect of US-positioned and fluoroscopically-confirmed placement to refine cannula positioning for cervical medial branch RFA in a cohort study involving 15 patients with an average body mass index of 26 . The authors demonstrated that the target nerve was visible under US guidance in all patients at all levels and that long-term effectiveness was comparable to the fluoroscopic interventional literature. However, the authors cautioned against performing US-guided cervical medial branch RFA without fluoroscopic guidance.

\section{Limitations of fluoroscopy, CT, and US}

The use of fluoroscopy is limited by radiation exposure and an inability to directly visualize the nerve and its trajectory.
Additionally, the upfront costs including the C-arm and monitor, radiology technician, and fluoroscopic table represent a barrier. For MBB, CT precludes the use of real-time contrast injection or DSA to detect intravascular uptake. Regarding cervical medial branch RFA, the imaging constraints imposed by trajectory recommendations are present but less substantial than in the lumbar spine, enabling parallel or near-parallel placement of electrodes. ${ }^{152}$ Yet, the widespread use of CT remains limited because of substantial equipment costs, radiation exposure, lack of real-time vascular imaging, and the need for different patient positions during procedures performed at the upper and lower facet joints. ${ }^{152}$

The use of US may provide an alternative imaging modality for performance of $\mathrm{MBB}$ but it is not ideal for cervical IA injections or medial branch RFA that require a set trajectory. Although US is portable, can be used in pregnancy, and does not require the use of protective garments, there are significant 
disadvantages of using US guidance for cervical spine interventions. US cannot visualize the entire field including adjacent levels, thereby increasing the risk of incorrect level identification. ${ }^{153}$ Widespread adoption may also be limited by anatomic difficulties associated with specific anatomic levels in the neck, especially involving C7. ${ }^{137}$ Of note, the US-guided approach to the cervical medial branch is less commonly taught in residency, fellowship, and postgraduate courses; therefore, widespread adoption would require additional physician training. Although US enables direct visualization of nearby vessels, it does not easily detect inadvertent vascular uptake, which can be reliably detected using real-time contrast injection or DSA. ${ }^{154}$ The limitations in the lumbar spine related to decreased needle visibility due to body habitus and depth to target are present, but may be less of a barrier in the cervical spine.

\section{Recommendations}

We recommend that fluoroscopy or (in providers with expertise) US be used for cervical MBB. US can be useful in patients in whom radiation exposure may be associated with potential harm; however, the lack of training may limit widespread adoption; Grade A recommendation, moderate level of certainty. For IA injections, we recommend the use of fluoroscopic imaging as the additional radiation exposure from CT compared with fluoroscopy precludes any theoretical benefit; Grade C recommendation, low level of certainty. For cervical medial branch RFA, we recommend that fluoroscopy be used as the additional radiation exposure from CT compared with fluoroscopy precludes any theoretical benefit. Whereas CT-fluoroscopy is associated with less radiation than CT alone, it is not widely available and adds significant upfront equipment costs and radiation exposure; Grade A recommendation, high level of certainty for the use of imaging, Grade B recommendation, moderate level of certainty for the use of fluoroscopy instead of other imaging modalities.

\section{QUESTION 6: WHAT IS THE OPTIMAL TECHNIQUE FOR INJECTION INTO THE AA AND AO JOINTS? SHOULD STEROIDS BE USED AND, IF SO, WHAT TYPE OF STEROIDS? WHAT ARE THE MOST COMMON COMPLICATIONS AND HOW CAN THEY BE MINIMIZED? Image guidance and patient positioning}

The use of image guidance is essential when performing AA and $\mathrm{AO}$ joint injections (tables 11 and 12). In clinical practice, fluoroscopy is typically used. Although CT guidance has been anecdotally reported, no studies describe this technique or outcomes in the literature. The feasibility of an US-guided approach for AO joint injection has been described in cadavers, ${ }^{155}$ but no clinical studies have been published to demonstrate safety or efficacy. However, a combined approach using fluoroscopy with US assistance to identify the vertebral artery has been advocated. ${ }^{156}$ For both AO and AA joint injections, patients are typically placed in the prone position with a pillow or cushion under the chest to allow for flexion of the neck. ${ }^{156} 157$

\section{Atlanto-occipital (C0-1) joint injection}

A fluoroscopically-guided posterior (also known as posterior parasagittal or posterior sagittal) approach is typically employed (table 11). Some advocate rotating the head 30 degrees ipsilateral to the side of injection to displace the vertebral artery to a more medial location. ${ }^{158}$ However, earlier descriptions of AO injections had patients placed in a lateral decubitus position with the head rotated contralaterally to the side of the injection. ${ }^{50} 159$ Unlike the AA joint in which the vertebral artery is generally situated lateral to the joint margin, the artery traverses the $\mathrm{AO}$ joint space (figure 3). To avoid inadvertent vertebral artery injury or injection, the most superior and lateral portion of the joint is targeted. The joint may be accessed either directly in a coaxial view or after contacting the periosteum and redirecting into the joint. After confirmation of IA needle placement using lowvolume contrast injected under real-time fluoroscopy or DSA, approximately $1 \mathrm{~mL}$ of injectate is administered (table 11).

\section{Atlanto-axial (C1-2) joint injection}

Although a posterior approach is most commonly used to access the AA joint (table 12), posterior oblique (also known as posterolateral) ${ }^{160}$ and lateral approaches ${ }^{5051}$ have also been described. In light of the potential for vascular injury (internal jugular vein/ vertebral artery) and vagal nerve injury, ${ }^{160}$ along with access to a larger joint space posteriorly, ${ }^{161}$ the posterior oblique and lateral approaches have for the most part been abandoned in clinical practice. ${ }^{156157}$ In one study evaluating 500 CT-angiograms performed for cerebrovascular accident or trauma, a loop of the vertebral artery was found on the lateral quarter of the dorsal aspect of the AA joint in $1 \%$ of individuals $(0.6 \%$ on the left, $0.4 \%$ on the right). ${ }^{162}$ In the anteroposterior view, AA joint visualization is optimized with cephalocaudal tilt. The optimal target point is the junction of the lateral one-third and medial two-thirds of the AA joint to minimize the risk of vertebral artery
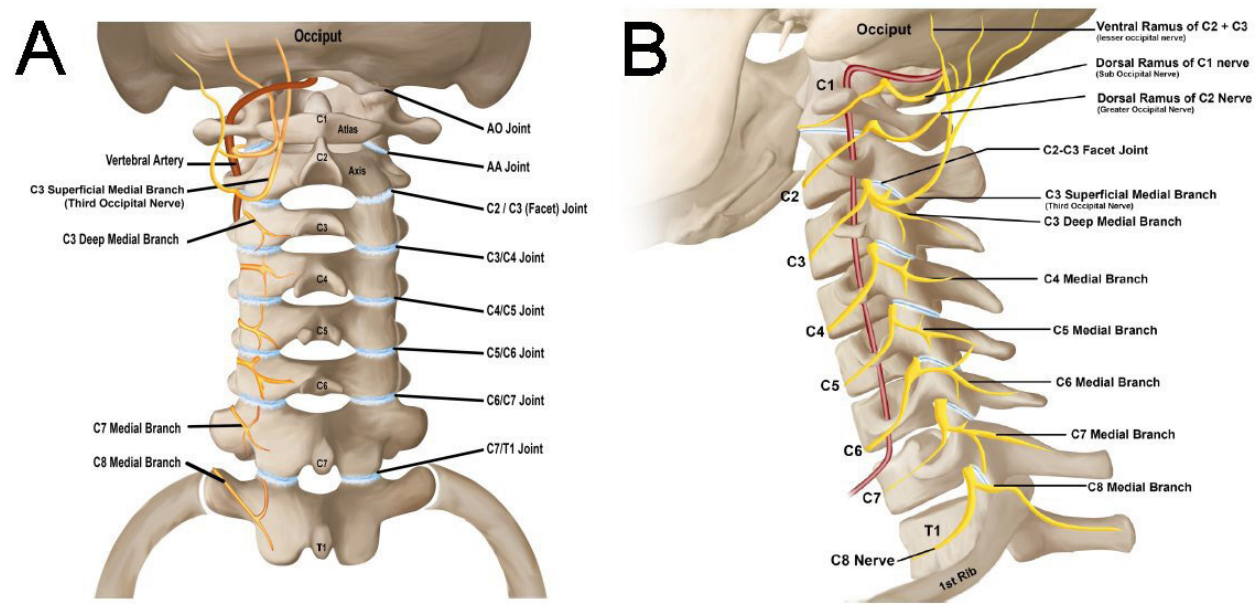

Figure 3 Posterior (A) and sagittal (B) images demonstrating the relationship between the upper cervical joints, vertebral artery and nerve supply. 
injury (which is generally lateral to the joint line), contacting the C2 nerve root, or dural puncture with intrathecal spread of injectate. ${ }^{156157163}$ The joint may be accessed either via a straight coaxial trajectory or after first making contact with the periosteum along the joint margin to establish depth. ${ }^{157}$ After confirmation of IA needle placement in posteroanterior and lateral views, and with a very small volume of contrast injected under DSA or real-time fluoroscopy, $<0.5 \mathrm{~mL}$ of injectate is typically used, as is illustrated in all but one of the clinical studies where the volume of injectate was described (table 12). The use of higher contrast volumes is discouraged given the relatively small capacity $(\leq 1 \mathrm{~mL})$ of the joint. ${ }^{164}$

\section{Intra-articular steroids for $\mathrm{AO}$ and $\mathrm{AA}$ joint injections}

$\mathrm{AO}$ and AA IA steroid injections have been reported to be therapeutic interventions for pain emanating from these joints since the late 1980s. Subsequently, evidence supporting this modality has come primarily from case reports and series and retrospective studies. Very few of these studies reported administration of a separate diagnostic IA injection with LA prior to the administration of a therapeutic injection with steroid. ${ }^{165} 166$ More recently, prospective observational studies and RCTs have been performed to identify whether IA steroid injections have superior efficacy to non-steroid (LA or saline) IA injections. The current body of available literature has provided modest evidence that is generally supportive of the use and effectiveness of IA steroid $\mathrm{AA}$ and $\mathrm{AO}$ injections in the treatment of a variety of different patient populations including: cervicogenic and occipital headache, ${ }^{5} 165-167$ chronic neck and head pain, ${ }^{8} 62158159163168-171$ and pain due to inflammatory disease of the $\mathrm{AO}$ and/or AA joints. ${ }^{160172}{ }^{173}$ No studies or review articles have been published regarding which type of steroid (short-acting, long-acting, particulate vs non-particulate) should be used for $\mathrm{AO}$ and $\mathrm{AA}$ joint injections. (tables 11 and 12)

Only two studies have used a prospective randomized design with a comparative/control arm to determine potential efficacy differences between $\mathrm{AO}$ or $\mathrm{AA}$ injections with and without steroids. In the study by Hetta et $a l,{ }^{173}$ patients with rheumatoid arthritis and AA inflammation and pain were randomized to either AA injections with LA and steroid or LA and normal saline. All patients were maintained on a standardized regimen of oral steroids and immunosuppressive therapy during the study. The authors reported that patients who received LA and steroid AA injections experienced statistically significantly greater reductions in numerical pain scores and improvements in physical functioning as measured by the Neck Disability Index at 3-month follow-up. They determined that the LA and steroid group had MRI-confirmed resolution of the inflammation observed pre-procedure compared with the LA and saline group. Shin $e t a l^{171}$ performed a randomized prospective study investigating the comparative effectiveness of $\mathrm{AO}$ joint LA and steroid injection versus AO joint pulsed RF. The findings in this study showed no superiority of one modality compared with the other; however, both groups experienced significant withingroup reductions in numerical pain score ratings over 6 months.

A systematic review and meta-analysis has recently been published highlighting that, in the broad scope of non-cancer interventional injections, there is little statistical increase in the effect sizes seen with the addition of steroid to LA and/or saline for IA injections and other procedures. ${ }^{174}$ The authors concluded that the use of steroids in interventional pain procedures may not be justified in all, or even most cases. They recommended that an in-depth evaluation of the risks, benefits, and safety of using steroids should be prioritized when performing interventional pain procedures for patients with non-cancer pain.

\section{Complications of $\mathrm{AO}$ and $\mathrm{AA}$ joint injections and risk mitigation}

The risk of adverse events associated with AA joint injections was found to be $18.5 \%$ ( 25 of 72 patients) in a retrospective observational study. ${ }^{163}$ In this cohort, no serious adverse events were reported and the most common side effects were dizziness, paresthesia, and/or increased pain. Vascular uptake on contrast injection (not differentiated between arterial or venous) was noted on real-time imaging or DSA during five of the injections that either resolved with needle repositioning or resulted in aborting the procedure due to safety concerns. One patient was noted to have blood return on aspiration with needle insertion which resulted in cessation of the procedure. Whereas no serious adverse events were reported in this study, the potential for serious adverse events such as inadvertent intrathecal injection, vertebral artery injury or injection, and C2 dorsal root ganglion injury (with AA injection) exist. ${ }^{175}$ The risk of adverse events is reduced with optimal needle placement. However, the presence of anatomic variations could result in adverse events. For example, anatomic studies have shown that in $0.72-1 \%$ of patients the vertebral artery is present along the needle trajectory for AA joint injections, and in $1.64 \%$ of patients the dural sac is vulnerable. ${ }^{162} 176$ These anatomic variations are the basis for obtaining advanced imaging (CT/MRI of the cervical spine) prior to performing $\mathrm{AO}$ and $\mathrm{AA}$ injections. ${ }^{176}$

The type of steroid used is also important to minimize the risk of complications. In a preclinical study performed in 11 pigs, the injection of particulate steroid in the vertebral artery resulted in all four pigs failing to regain consciousness and requiring ventilatory support, while the seven pigs injected with non-particulate steroid all recovered. ${ }^{177} \mathrm{~A}$ case of posterior circulation stroke resulting in a coma with the withdrawal of care following AA joint injection with a particulate steroid has been reported. ${ }^{178}$ It is unknown whether pre-procedural advanced imaging was obtained (as is generally recommended) or what type of approach was used, since the only image saved from the injection was in a lateral view. ${ }^{179} 180$ The use of real-time fluoroscopy and/or DSA has been advocated to prevent intravascular injection and has been mandated in guidelines for transforaminal lumbar epidural steroid injections, given its greater sensitivity for detecting intravascular uptake and hence preventing catastrophic neurological complications. ${ }^{156} 157181182$ Another case report described the development of AA joint pyogenic osteomyelitis requiring debridement and joint arthrodesis that remained unrecognized for 4 months after an AA joint injection. ${ }^{183}$ In this report, little information was provided to draw any conclusions regarding risk mitigation and a history of diabetes mellitus placed the patient at higher risk for infection. Although no reported serious complications have been identified with $\mathrm{AO}$ joint injections, the theoretical risks are higher than for AA joint injections given the exposed location of the vertebral artery and the closer proximity to the brainstem. ${ }^{177}$

\section{Recommendations}

Pre-procedural advanced imaging of the cervical spine with either CT or MRI should be obtained prior to performing AO and AA joint injections to ascertain pathology and help guide needle trajectory; Grade C recommendation, low level of certainty. When performing $\mathrm{AO}$ and $\mathrm{AA}$ joint injections, we recommend a posterior approach with confirmation of IA spread using 
real-time fluoroscopy or DSA in both anteroposterior and lateral views; Grade B recommendation, moderate level of certainty. There is insufficient evidence regarding the use of CT guidance or US guidance without fluoroscopy when performing $\mathrm{AO}$ and AA injections; Grade I recommendation. There is a small body of evidence that the use of steroids in $\mathrm{AO}$ and $\mathrm{AA}$ joint injections may be beneficial in selected populations; however, the magnitude of benefit is small; Grade C recommendation, low level of certainty. Based on indirect evidence, we recommend that, if steroids are administered, $<1 \mathrm{~mL}$ of non-particulate steroids be administered; Grade C recommendation, low-to-moderate level of certainty.

\section{QUESTION 7: WHAT IS THE MOST APPROPRIATE APPROACH TO CERVICAL MBB? WHAT ARE THE RISKS/BENEFITS OF THE DIFFERENT APPROACHES?}

There is no published consensus regarding the 'correct' approach to performing cervical MBBs. The SIS MBB safety practices publication states, "The ultimate choice of approach or technique to use should be made by the treating physician by balancing potential risks and benefits with each technique for each patient". ${ }^{184}$ It is generally thought that a lateral approach to the TON and the C3 through C7 medial branch nerves is most optimal, while a posterior approach to the C8 medial branch nerve (target is the superior lateral aspect of T1 transverse process) is most ideal. This is, in part, related to the fact that in most patients these respective approaches allow for the target injection site to be accessed by traversing the least amount of tissue from the skin entry point, which may decrease procedure time as well as improve patient comfort and satisfaction. However, critics of this viewpoint argue that a posterior approach best simulates the RF electrode trajectory and that, when physicians use the injection approach with which they are most comfortable, the best results are obtained.

A lateral needle approach can be performed with the patient in the prone, lateral decubitus, and supine position, ${ }^{78} 185$ and there are no studies comparing these approaches. Of note, the benefits purported by a lateral approach remain largely theoretical with minimal literature comparing approaches. ${ }^{78}$ Furthermore, exceptions exist and are often dependent on unique anatomic considerations (eg, body habitus, neck length and thickness, neurovascular anatomy). Regardless, lateral and posterior approaches during the performance of these nerve blocks are recommended in established clinical practice guidelines based on foundational literature establishing safety and accuracy when these approaches are employed. ${ }^{18}$ Recent studies have introduced the feasibility of US-guided cervical MBBs. ${ }^{136} 137145153186$ However, the safety and diagnostic characteristics of the US technique, in which contrast spread cannot be observed, are not yet well-defined, and fluoroscopic guidance remains the clinical standard (as discussed in Question 5). In order to appropriately assess the optimal approach to fluoroscopic TON and cervical MBBs, both the accuracy and safety of each approach must be considered.

\section{Accuracy}

There is currently no direct comparative evidence indicating that a specific approach is associated with greater target specificity during TON block or cervical MBB. One RCT demonstrated no difference in target specificity of $\mathrm{C} 3-\mathrm{C} 7 \mathrm{MBB}$ when comparing a lateral approach in the decubitus position to a posterior approach. ${ }^{78}$ Another study assessed target specificity of C4-C6 MBB comparing different injectate volumes, but not stratified by different (lateral vs posterior) approaches. ${ }^{187}$ No study has reported on the accuracy of the lateral versus posterior approach for TON or C8 MBB. Notably, the foundational studies that established the accuracy and diagnostic value of TON and C3C7 MBB have generally used a lateral approach (table 13). ${ }^{9} 188189$

\section{Safety}

A lateral approach to TON and $\mathrm{C} 3-\mathrm{C} 7 \mathrm{MBB}$ and a posterior approach to $\mathrm{C} 8 \mathrm{MBB}$ may confer practical (a lateral approach may be faster to perform and allows for easier use of the singleneedle technique), ${ }^{190}$ clinical (less procedure-related pain from less tissue penetration leading to more accurate post-block pain

Table 13 Studies evaluating the accuracy of different approaches for cervical MBBs

\begin{tabular}{|c|c|c|c|c|}
\hline Author, year & Patient population & Design & Results & Comments \\
\hline $\begin{array}{l}\text { Cohen et al } \\
2010^{78}\end{array}$ & $\begin{array}{l}24 \text { pts with axial neck pain. Evaluated the accuracy } \\
\text { and safety of posterior vs lateral approach for cervical } \\
\text { MBBs }\end{array}$ & $\begin{array}{l}\mathrm{RCT} \text {, radiologist } \\
\text { blinded }\end{array}$ & $\begin{array}{l}\text { No difference in target specificity of TON and } \\
\text { C3-C7 MBBs when comparing lateral to posterior } \\
\text { approach }\end{array}$ & $\begin{array}{l}\text { Only RCT to directly compare } \\
\text { posterior vs lateral approach for } \\
\text { TON and cervical MBBs }\end{array}$ \\
\hline $\begin{array}{l}\text { SIS } \\
\text { guidelines }^{18}\end{array}$ & $\mathrm{~N} / \mathrm{A}$ & Guidelines & $\begin{array}{l}\text { Lateral approach recommended for TON and C3- } \\
\text { C7 MBBs }\end{array}$ & $\begin{array}{l}\text { Expert consensus regarding cervical } \\
\text { MBB approach based on literature } \\
\text { review }\end{array}$ \\
\hline $\begin{array}{l}\text { Finlayson et al } \\
2013^{136}\end{array}$ & $\begin{array}{l}40 \text { pts undergoing TON block with US vs fluoroscopy } \\
\text { using a posterior approach }\end{array}$ & $\mathrm{RCT}$ & $\begin{array}{l}\text { IA spread of contrast and vascular breach occurred } \\
\text { in } 15 \% \text { and } 10 \% \text { of participants, respectively, with } \\
\text { the posterior fluoroscopic approach vs } 0 \% \text { with US }\end{array}$ & $\begin{array}{l}\text { No comparison of posterior vs } \\
\text { lateral approach }\end{array}$ \\
\hline $\begin{array}{l}\text { Wahezi et al } \\
2019^{187}\end{array}$ & $\begin{array}{l}\text { C4-6 cervical MBBs using a posterior approach } \\
\text { with } 0.25 \text { or } 0.50 \mathrm{~mL} \text { of injectate. Post-injection (CT) } \\
\text { imaging and gross dissection performed to assess } \\
\text { injectate spread }\end{array}$ & $\begin{array}{l}\text { Cadaveric study } \\
(\mathrm{n}=6,18 \mathrm{MBBs})\end{array}$ & $0.25 \mathrm{~mL}$ volume was target-specific & $\begin{array}{l}\text { No comparison of posterior vs } \\
\text { lateral approach }\end{array}$ \\
\hline $\begin{array}{l}\text { Verrills et al } \\
2008^{194}\end{array}$ & 4134 cervical MBBs (number of pts not noted) & $\begin{array}{l}\text { Retrospective } \\
\text { cohort study }\end{array}$ & $\begin{array}{l}3.9 \% \text { rate of vascular uptake associated with the } \\
\text { lateral approach }\end{array}$ & $\begin{array}{l}\text { No comparison of posterior } \\
\text { vs lateral approach. Posterior } \\
\text { approach noted to be used 'at } \\
\text { times on lower cervical joints' }\end{array}$ \\
\hline $\begin{array}{l}\text { Jeon et al } \\
2015^{134}\end{array}$ & 178 cervical MBBs in 72 pts & $\begin{array}{l}\text { Prospective } \\
\text { cohort study }\end{array}$ & $\begin{array}{l}10.7 \% \text { rate of vascular uptake associated with the } \\
\text { lateral approach (as detected by DSA) }\end{array}$ & $\begin{array}{l}\text { No comparison of posterior vs } \\
\text { lateral approach }\end{array}$ \\
\hline $\begin{array}{l}\text { Elgueta et al } \\
2018^{162}\end{array}$ & 500 pts with $\mathrm{CT}$ angiograms of the head and neck & $\begin{array}{l}\text { Retrospective } \\
\text { cohort study }\end{array}$ & $\begin{array}{l}\text { Vertebral artery loop located in the typical location } \\
\text { of a TON block in } 5-8 \% \text { of individuals }\end{array}$ & $\begin{array}{l}\text { Safety implications with anterior } \\
\text { needle trespass during TON blocks }\end{array}$ \\
\hline
\end{tabular}


assessment and in some cases a decreased need for sedation), and/ or safety benefits, although clear images with a lateral approach may be challenging in heavy-set people and those with broad shoulders. These respective approaches allow the advancement of the needle to the target location using a coaxial trajectory with the bony articular pillar functioning as a safety backstop. The lateral approach to TON block is the singular exception to this principle, as the needle tip may need to be directed slightly superficial to the lateral aspect of the C2-3 facet joint in order to provide a block that accounts for the cephalo-caudal variability of the TON. ${ }^{191}$ The possibility of inadvertent IA penetration or through-and-through trespass into the central canal with a lateral approach must be acknowledged and mitigated. Regardless of the level, this is possible if a true lateral view is not obtained and a long needle is used. The lateral approach also presents the possibility of trespass into the neuroforamen with possible encounter of the exiting spinal nerve root and/or puncture of the dura or spinal cord, or anterior to the neuroforamen and into the vascular prevertebral space. This may occur if the needle is advanced anterior to the lateral pillar. The safety and feasibility of a lateral approach to TON block is supported by a prospective clinical study, ${ }^{136}$ and while a posterior MBB approach best simulates the recommended needle trajectory for RFA, similar investigations using a posterior approach have not been reported. Further, large cohort studies of cervical MBB procedures performed according to clinical practice guidelines (lateral approach to TON and C3-C7 MBB and posterior approach to $\mathrm{C} 8 \mathrm{MBB}$ ) have been associated with an excellent safety profile. ${ }^{192}$ Alternative methods have been associated with various severe and minor complications, although it is unclear what role the use of a lateral versus posterior approach played as authors did not describe this element of the procedures. ${ }^{126} 193$ Since a posterior approach is associated with a longer insertion distance and more tissue trauma, an effect which may be magnified in individuals with thick necks, the need for sedation may be higher in some patients. Finally, there is no evidence that the lateral versus posterior approach is associated with a lower likelihood of intravascular injection including inadvertent arterial injection (ie, cervical radiculomedullary and vertebral arteries). ${ }^{78194}$ Depending on the cervical level, the rate of inadvertent vascular injection appears to vary from $2 \%$ to $>10 \%$ when DSA is used ${ }^{78134194}$; however, the level of confidence in this incidence rate is low due to small sample sizes in the representative primary literature. In one large study evaluating 4134 cervical MBBs, the authors reported a rate of cervical intravascular injection of $3.9 \%$, with a lateral approach used for most blocks and a posterior approach occasionally used for lower cervical levels. ${ }^{194}$

\section{Considering anatomic variations unique to each patient}

When determining the ideal approach to TON and cervical $\mathrm{MBB}$, anatomic factors unique to each patient must be considered. Unique anatomic variations might impact the possibility of: (1) penetration of the C2-3 joint, through and through, with subsequent trespass into the dura or spinal cord (unique to TON targeting from a lateral approach); (2) breach of the vertebral artery; (3) trespass into the neuroforamen with possible encounter of the exiting spinal nerve root and/or puncture of the dura or spinal cord; or (4) needle trespass posterior to the articular pillar and into the dura or spinal cord. In most patients, a needle shorter than 3.5 inches $(6.35-8.9 \mathrm{~cm})$ is adequate to reach the target using a lateral approach, thereby reducing the risk of inadvertently reaching the dura or spinal cord as described above. A small diameter (eg, 25-gauge) short needle may reduce the risk of trauma to the vertebral artery if punctured, although there are no studies to support this supposition. Specific to TON block, a CT-angiography study demonstrates that a loop of the vertebral artery may be located in the typical location of a TON block (midpoint of the lateral C2-3 facet joint margin) in 5-8\% of individuals. $^{162}$

\section{Recommendations}

For logistical reasons that vary by level and patient, and to optimize safety, we recommend consideration of a fluoroscopicallyguided lateral approach for TON and C3-C7 MBB, but a fluoroscopically-guided posterior or posterior oblique approach for C8 MBB. However, physician comfort with these approaches and unique anatomy should be a primary consideration. Primary data comparing the safety and accuracy of the two approaches are limited to one prospective study. Notably, given the unique anatomic considerations in each patient, the approach at a given level should ultimately be at the discretion of the treating physician. For needle size, we recommend consideration of a short 25 -gauge needle to reduce the risk of arterial trauma or trespass into the dura or spinal canal when a lateral approach is used, although again physician judgment should be prioritized (ie, longer needles might be needed in obese patients); grade I recommendation.

\section{QUESTION 8: WHAT IS THE IDEAL VOLUME FOR PROGNOSTIC MBB AND IA INJECTIONS? \\ Factors affecting injectate spread and rationale for considering injectate volume}

TON and MBB are considered both diagnostic for facet joint pain and prognostic for nerve ablation. Both functions are contingent on precisely targeting the nerve with minimal or no spread to the surrounding areas. ${ }^{29} 7678195$ The distribution of fluid after injection into anatomic spaces can be affected by several factors including fluid viscosity, injection velocity, direction of the bevel tip, and fluid volume, all of which may interact with one another. Injection velocity has not been found to be a significant factor in neuraxial injection and the effect of bevel orientation has demonstrated inconsistent results. ${ }^{196-198}$ Regarding composition, most LA agents have similar viscosities, which is lower than that of contrast media and liposomal formulations. This could result in a wider spread to the surrounding structures when using LA alone compared with solutions mixed with contrast or contrast media alone, resulting in false-positive results. ${ }^{187} 199$

In addition to injectate properties, ${ }^{187}$ the anatomy of the cervical spine ${ }^{200}$ and needle trajectory (ie, fluoroscopic lateral or posterior) can theoretically influence injectate spread. ${ }^{78} \mathrm{LA}$ can spread to adjacent pain-generating or transmitting structures besides the targeted nerve(s) to include the lateral branches innervating paraspinal musculature, neural foramen and spinal nerve root, the facet joint capsule, adjacent levels, muscles and ligaments, and into the cervical epidural space. Spread to any of these structures could compromise the specificity, reliability, and positive predictive value of the MBB due to false-positive results. ${ }^{29}$ Although studies have found no significant difference in the accuracy of cervical MBB and other injections based on needle trajectory and size, there is a theoretical underpinning for technical factors to affect injectate spread. ${ }^{78} 201$

The anatomy of the cervical spine is such that the vertebrae and medial branches are smaller and closer together than at adjacent lumbar levels. ${ }^{200}$ The largest of the cervical medial branches, the TON has a mean diameter of $1.5 \mathrm{~mm},{ }^{202}$ with the other medial 
branches ranging from 0.6 to $1.2 \mathrm{~mm}$ in diameter, being slightly smaller at more caudal levels. ${ }^{202} 203$ The C4-C 8 medial branches vary in their courses in relation to the rostral-caudal location of the waist of the articular pillar between the periosteum and the tendon of the semispinalis capitis muscle. ${ }^{200} 203$ Barring the C5 medial branch which traverses the center of the trapezoid, the medial branches at $\mathrm{C} 3, \mathrm{C} 4, \mathrm{C} 6$, and $\mathrm{C} 7$ course higher on their articular pillars (figure 3 ). ${ }^{203}$ It has been shown that about onequarter of individuals have a dual medial branch at $\mathrm{C} 4$, with a smaller percentage having two nerves in close proximity at more caudad levels. ${ }^{203}$ The target points for the medial branches are closer to the spinal nerve roots than in the lumbar spine, which suggests the need for lower volumes. ${ }^{203}$ The horizontally aligned cervical facet joints are also smaller in size than lumbar facet joints and the injectate may therefore be more likely to extravasate out of the joint during IA injections. ${ }^{77} 204205$

\section{Medial branch block (MBB)}

\section{Indirect evidence from lumbar MBB and other injections}

The most influential factor that affects the validity and specificity of blocks is the area of the spread of the injectate. It has been shown from studies involving selective nerve root blocks, lumbar MBB, and sacroiliac joint injections that lower volumes increase the accuracy and specificity of blocks. ${ }^{29} 206207$ Studies have shown that volumes as low as $0.3 \mathrm{~mL}$ for cervical MBB could result in false positives. ${ }^{78}$ However, even $0.3 \mathrm{~mL}$ spreads to an area greater than the volume of a thermal RF lesion created by an 18-gauge cannula with a $10 \mathrm{~mm}$ active tip. ${ }^{208} 209$

Several studies carried out in the lumbar spine indicate that the use of smaller MBB volumes may enhance specificity. ${ }^{195} 210$ Volumes used for prognostic lumbar MBB have varied from 0.3 $\mathrm{mL}$ to $1.0 \mathrm{~mL}$, with no obvious effect on medial branch RFA clinical outcomes based on indirect comparisons. ${ }^{211-214}$ In the study by Tekin $e$ t $a l^{212}$ which used a single block with $0.3 \mathrm{~mL}$ of LA as a diagnostic test, conventional lumbar medial branch RFA was found to be superior to pulsed RF for up to 1 year. For therapeutic lumbar and cervical MBB, the volumes have ranged from 0.5 to $2 \mathrm{~mL}$ in clinical trials. ${ }^{214-218}$ A CT study performed in the lumbar spine clearly demonstrated that fluoroscopically-guided MBB with $0.5 \mathrm{~mL}$ was sufficient to anesthetize the lumbar medial branch in all 120 blocks, which suggests that lower volumes may enhance specificity. ${ }^{195}$ In a case report published in abstract form, a total of $4 \mathrm{~mL}$ of LA given before right-sided C3-5 medial branch RFA resulted in temporary hoarseness, dysphagia, and difficulty coughing. ${ }^{219}$ For the smaller cervical medial branch contained within a more confined area, it is difficult to justify the use of higher volumes.

\section{Direct evidence from cervical MBB injections}

Cohen et $a l^{78}$ conducted an RCT evaluating the accuracy and specificity of different cervical MBB injectate volumes. The authors randomized 24 subjects to receive either $0.5 \mathrm{~mL}$ or $0.25 \mathrm{~mL}$ of LA injectate mixed with contrast. Subjects were suballocated to receive blocks using either a posterior or lateral approach. The accuracy of the block and the incidence of aberrant spread of the injectate were then evaluated by CT scan. The study found that both $0.25 \mathrm{~mL}$ and $0.5 \mathrm{~mL}$ volumes of injectate enveloped the medial branch in $93 \%$ of the 86 injections, with no statistically significant difference in analgesic benefit, although aberrant spread to adjacent levels was over twice as likely $(38 \%$ vs $16 \%$ ) with the higher volume. At C3, adjacent spread to the TON occurred in $57 \%$ of blocks irrespective of volume. Foraminal spread was noted in five instances with $0.5 \mathrm{~mL}$ and two instances with $0.25 \mathrm{~mL}$. There were no differences in accuracy rate or specificity between the posterior or lateral approach.

In a small $(n=6)$ cadaveric study that sought to determine the optimal cervical MBB injectate volume, Wahezi and colleagues ${ }^{187}$ found that 0.25 and $0.5 \mathrm{~mL}$ of contrast and methylene blue fully incorporated the targeted C4-6 medial branch using a fluoroscopically-guided posterior oblique approach. However, the lower injectate volume spread to fewer adjacent structures including intermediate and superficial spinal muscles, surrounding fascia, and terminal branches of the medial branch nerve. They concluded that smaller volumes are more specific and should be used for prognostic MBB before RFA. An earlier study by the same group of authors performed in the lumbar spine found $0.25 \mathrm{~mL}$ lumbar $\mathrm{MBB}$ to be more specific than 0.5 mL blocks. $^{210}$

Wahezi and colleagues ${ }^{220}$ performed a similar study in five cadavers to determine optimal TON block volumes. Using landmarks for injections after partial dissection, the authors found that six of 10 TON blocks using $0.25 \mathrm{~mL}$ captured the greater occipital nerve, while increasing the volume to $0.5 \mathrm{~mL}$ resulted in $100 \%$ of blocks inadvertently anesthetizing the greater occipital nerve. The use of US guidance when performing cervical MBB may enable the operator to visualize the spread of injectate in real time and allow the physician to limit the volume only to that necessary to incorporate the medial branch. Although some earlier US studies used volumes as high as $0.9 \mathrm{~mL},{ }^{144}$ subsequent studies have used much smaller volumes (eg, $0.2-0.3 \mathrm{~mL}$ ) to accurately target the medial branches from C3-C6. ${ }^{136} 137147221222$

\section{Cervical IA facet joint injections}

The cervical facet joint is a true synovial joint with a reported capacity of $1.0 \mathrm{~mL}$ of fluid. ${ }^{204}$ There is very limited evidence for short- and long-term analgesic benefits using IA facet joint injections in the cervical spine. ${ }^{8102223}$ In RCTs examining the efficacy of cervical IA injections, a wide range of volumes have been used from as little as $0.5 \mathrm{~mL}^{224}$ to as high as $2 \mathrm{~mL}^{8}$ Volumes greater than $1.0 \mathrm{~mL}$ may result in rupture of the joint capsule leading to inadvertent spread to other potential pain generators, thereby undermining specificity.

Several studies have sought to determine the specificity of IA cervical facet injections. In an observational study examining the accuracy of 760 fluoroscopically-guided IA injections performed in 208 patients using $0.2 \mathrm{~mL}$ of contrast administered through a 25 -gauge needle, Won et al ${ }^{225}$ found that joint overflow occurred in $23.6 \%$ of injections, being highest at C5-6 (36.2\%) and lowest at C3-4 (3.3\%). In a retrospective study evaluating the spread patterns of 29 patients who underwent a single CT-fluoroscopyguided cervical IA facet injection performed with $0.5-1 \mathrm{~mL}$ of contrast and $1 \mathrm{~mL}$ of steroid, Bureau et $a l^{224}$ reported IA and retrodural spread in $62 \%$ of injections, IA and epidural spread in $7 \%$, and extra-articular spread without IA contrast was observed in $21 \%$ of injections. In only $7 \%$ of injections was IA spread without contrast extravasation reported. Collectively, these studies suggest that even very low volumes injected into cervical facet joints lack specificity. Yet, using volumes that are too low may result in failure to achieve IA spread leading to a false-negative result, which may be more common in people with facet joint osteoarthritis.

\section{Recommendations}

We recommend that cervical MBB volumes be $\leq 0.3 \mathrm{~mL}$, though slightly higher volumes may be considered if contrast spread fails to capture the most frequent patterns of medial branch 
innervation; grade $\mathrm{C}$ recommendation, low level of certainty. For cervical IA facet joint injection, a total volume not to exceed $1 \mathrm{~mL}$ including contrast injection should be used to prevent capsular rupture and/or aberrant injectate spread and enhance the specificity of the block; grade $\mathrm{C}$ recommendation, low level of certainty.

\section{QUESTION 9: DO INTRA-ARTICULAR FACET BLOCKS OR MEDIAL BRANCH BLOCKS CONFER THERAPEUTIC VALUE?}

The cervical facet joints are innervated either by the TON or the medial branch of the dorsal rami that innervate the joints above and below. Medial branch RFA is considered to be a definitive durable analgesic treatment for patients with neck pain arising from the cervical facet joints. ${ }^{68}$ However, there is conflicting evidence in the literature about the therapeutic (durable) benefits of MBB or IA with LA and/or steroids.

\section{Efficacy of TON and cervical MBB}

\section{Prolonged relief from diagnostic blocks}

Diagnostic blocks of cervical medial branches and the TON involve an injection of a short-acting LA such as lidocaine with its effect lasting around 2 hours, or a long-acting LA such as bupivacaine that reliably provides pain relief for 3-8 hours in some studies, ${ }^{226}$ but not all. ${ }^{189}{ }^{227}$ However, prolonged analgesic benefit with LA following these procedures in some patients has been reported, which may obviate the need for medial branch RFA. Bogduk and colleagues ${ }^{8}$ injected LA (bupivacaine $0.5 \%$ ) to block the TON or other cervical medial branches in 24 patients with idiopathic neck pain. Seventeen patients reported pain relief for at least 2 hours with 15 undergoing a repeat block with LA to confirm their response. The two major groups of patients identified in this study were patients with neck pain and headache stemming from the $\mathrm{C} 2-3$ joint and those with neck pain and shoulder pain stemming from the C5-6 joint. One patient who had a TON block reported relief of headaches for over a month. In a study performed in 47 patients with neck pain who received dual diagnostic cervical MBB with lidocaine and bupivacaine, 13 patients reported pain relief for a period longer than the duration of action of the LA with one or both LA. Five patients had prolonged pain relief with lidocaine, three patients had prolonged relief with bupivacaine, and five patients reported prolonged benefit with both LA agents. ${ }^{227}$

In one study, 50 patients received double comparative diagnostic blocks with LA and a third placebo injection for neck pain following an MVC. Investigators in the study classified patients based on the duration of pain relief. ${ }^{189}$ Among the 14 patients with a concordant response to LA (duration of pain relief consistent with the drug's pharmacokinetics), three also experienced pain relief with placebo. Two patients had a concordant prolonged response (duration of pain relief prolonged for one or both LA with a longer response to the long-acting LA) and neither had a placebo response. Eleven patients had a discordant prolonged response (duration of pain relief prolonged for one or both of injected LA with a longer response to the short-acting LA), but four of these patients were also placebo responders. There were 23 patients with a discordant (duration of pain relief prolonged for the short-acting LA) or discrepant (pain relief with only one of the two LA injections) response, and 13 of these were placebo responders. It was concluded that a placebo response is more likely if patients who receive dual comparative diagnostic LA blocks have a more prolonged response with the shorter-acting LA or if they report pain relief with only one of the LA. ${ }^{189}$ The phenomenon of prolonged analgesic benefit in some patients has also been reported with other (non-cervical medial branch) nerve blocks ${ }^{228}$ and in one randomized trial evaluating lumbar medial branch RFA, ${ }^{211}$ and may be due to prolonged neural conduction blockade, ${ }^{229}$ a reduction in neural inflammation, or reversing central or peripheral sensitization. ${ }^{230}$

\section{Randomized trials evaluating long-term benefit}

The impact of adding steroids to LA for TON and cervical MBB was addressed in an RCT that compared the analgesic benefit and duration of action of LA and sarapin to a combination of LA, sarapin and steroids in 120 patients with chronic neck pain who responded to comparative LA blocks. ${ }^{231}$ Blocks were repeated over a 2-year period when pain relief returned to more than $50 \%$ of baseline. Over $85 \%$ of patients obtained $\geq 50 \%$ pain relief over the study duration, with no significant differences between groups. The average duration of relief for each procedure (mean 5.7 blocks over 2 years) was over 4 months in both groups. However, the trial had serious methodological flaws including an enriched enrollment design, failure to control for concurrent interventions, repetitive blocks providing longterm relief without the need for RFA, a high percentage of patients on opioids, and an unclear methodology for evaluating outcomes. More recently, Hussain et $a l^{215}$ performed a randomized, double-blind study in 60 patients with non-radiating neck pain comparing two-level cervical MBB performed with LA and steroid to trigger point injections with the same solution. Through 12 weeks of follow-up, the MBB group had greater reductions in pain intensity and disability scores than those who received trigger point injections (table 14).

\section{Double-blind placebo-controlled studies evaluating cervical RFA against MBB}

There have been three double-blind trials that evaluated outcomes of cervical MBB in the context of a 'sham-controlled' study. Van Eerd and colleagues ${ }^{28}$ randomized 76 patients with presumptive facetogenic pain based on historical and physical examination findings to receive cervical MBB at three contiguous levels with $0.5 \mathrm{~mL}$ bupivacaine and sham RFA, or the same volume of bupivacaine and true RFA. In theRFA group, the mean average neck pain score decreased from 6.8 to 3.6 and 3.8 at 3and 6-month follow-ups, respectively. In the bupivacaine/sham RFA group, these 3- and 6-month average neck pain scores were 4.3 and 4.5, respectively. The responder rates for 'significant improvement' in the RFA group were $57 \%$ and 50\%, respectively, at the 3-and 6-month time points (vs $51 \%$ and $41 \%$ at these time points for the bupivacaine $\mathrm{MBB} / \mathrm{sham} \mathrm{RFA}$ group, with no significant difference between groups). The differences in pain reduction and functional improvement favoring the RFA group did not reach statistical significance through 6 months after the procedures, although the benefits statistically and clinically lasted longer (42 months vs 12 months for median benefit).

In a small randomized study by Stovner et al, ${ }^{103} 12$ patients with cervicogenic headache and neck pain were allocated to TON and C3-6 MBB with $1 \mathrm{~mL}$ LA (specific LA not noted) plus sham RFA on the symptomatic side or TON and MBB followed by real RFA. Although dual comparative LA blocks were performed, the results were not used for patient selection. For the primary outcome measure, days per week with moderate or severe pain, $4 / 6$ in the treatment group experienced a positive outcome versus $2 / 6$ in the control group at 3 months posttreatment, with no differences noted at later follow-ups.

In an earlier RCT, Lord and colleagues ${ }^{68}$ randomized 24 patients with chronic neck pain attributable to an MVC to 
Table 14 Summary of studies on therapeutic benefits from cervical facet medial branch and intra-articular injections

\begin{tabular}{|c|c|c|c|c|}
\hline Author, year & Patient population & Design & Results & Comments \\
\hline $\begin{array}{l}\text { Dory et al } \\
1983^{204}\end{array}$ & $\begin{array}{l}14 \text { pts ( } 22 \text { joints) received IA injections with } \\
\text { steroids for neck pain }\end{array}$ & $\begin{array}{l}\text { Prospective cohort } \\
\text { study }\end{array}$ & 9 pts had pain relief for 3 days to 13 months & $\begin{array}{l}\text { Distension of the joint capsule } \\
\text { provoked pain in } 50 \% \text { of pts }\end{array}$ \\
\hline $\begin{array}{l}\text { Bogduk et al } \\
1988^{8}\end{array}$ & $\begin{array}{l}\text { Pts with neck pain received cervical medial } \\
\text { branch or TON block with } L A(n=24) \text { and IA } \\
\text { injections with LA and steroids }(n=8)\end{array}$ & $\begin{array}{l}\text { Prospective cohort } \\
\text { study }\end{array}$ & $\begin{array}{l}17 \text { of } 24(71 \%) \text { pts had pain relief for at least } 2 \text { hours } \\
\text { with TON or MBB. } \\
7 \text { of } 7 \text { pts had pain relief with IA injections varying } \\
\text { from } 4 \text { days to } 12 \text { months (median } 1 \text { month) }\end{array}$ & $\begin{array}{l}1 \mathrm{pt} \mathrm{had} \mathrm{relief} \mathrm{of} \mathrm{headaches} \mathrm{for} \mathrm{over} \\
1 \text { month }\end{array}$ \\
\hline $\begin{array}{l}\text { Barnsley et al } \\
1993^{227}\end{array}$ & $\begin{array}{l}47 \mathrm{pts} \text { with chronic neck pain received dual } \\
\text { comparative TON or cervical MBB with } \\
\text { lidocaine and bupivacaine. }\end{array}$ & $\begin{array}{l}\text { Prospective cohort } \\
\text { study }\end{array}$ & $\begin{array}{l}13 \text { of } 47(29 \%) \text { pts had pain relief lasting longer } \\
\text { than expected for either LA: } 5 \text { with lidocaine, } 3 \text { with } \\
\text { bupivacaine, and } 5 \text { for both LA agents. }\end{array}$ & \\
\hline $\begin{array}{l}\text { Barnsley et al } \\
1994^{102}\end{array}$ & $\begin{array}{l}41 \text { pts with chronic neck pain following } \\
\text { whiplash injury and a positive response to } \\
\text { dual LA diagnostic cervical MBB received } \\
\text { IA injections of either bupivacaine or } \\
\text { betamethasone }\end{array}$ & RCT & $\begin{array}{l}\text { No long-term analgesic benefit in either group; } \\
\text { median duration of } 50 \% \text { pain relief was } 3 \text { days in } \\
\text { both groups }\end{array}$ & $\begin{array}{l}15 \text { of } 21 \text { pts in the steroid group and } \\
13 \text { of } 20 \text { pts in the LA group had } \\
\geq 50 \% \text { pain relief for } \leq 10 \text { days }\end{array}$ \\
\hline $\begin{array}{l}\text { Lord et al } \\
1995^{189}\end{array}$ & $\begin{array}{l}50 \text { pts with chronic neck pain after MVC who } \\
\text { received triple comparative TON or cervical } \\
\text { MBB with lidocaine, bupivacaine and saline }\end{array}$ & $\begin{array}{l}\text { Prospective cohort } \\
\text { study }\end{array}$ & $\begin{array}{l}2(4 \%) \text { pts had 'concordant prolonged' response } \\
\text { (pain relief }>7 \text { hours with lidocaine and/or }>24 \text { hours } \\
\text { with bupivacaine, but longer with bupivacaine) }\end{array}$ & $\begin{array}{l}\text { None of the 'concordant prolonged' } \\
\text { response pts were placebo } \\
\text { responders }\end{array}$ \\
\hline $\begin{array}{l}\text { Manchikanti } \\
\text { et al } 2010^{231}\end{array}$ & $\begin{array}{l}120 \text { pts with neck pain who responded to } \\
\text { comparative } L A \text { blocks were randomized to } \\
\text { cervical MBB with } L A \text { and sarapin or with } L A \text {, } \\
\text { sarapin and steroid }\end{array}$ & RCT & $\begin{array}{l}\text { Similar responder rate ( } \geq 50 \% \text { reduction in pain NRS } \\
\text { scores) in both groups ( } 85 \% \text { for LA and sarapin, } 93 \% \\
\text { for LA, sarapin and steroid) }\end{array}$ & $\begin{array}{l}\text { Average number of treatments was } \\
5.7 \text { in } 2 \text { years. Co-interventions not } \\
\text { controlled for }\end{array}$ \\
\hline $\begin{array}{l}\text { Park et al } \\
2012^{223}\end{array}$ & $\begin{array}{l}400 \text { pts with chronic neck pain secondary to } \\
\text { myofascial and facet joint pathology were } \\
\text { randomized to receive bilateral C5-6 and } \\
\text { C6-7 IA facet injections with LA+steroid } \\
\text { and conservative treatment (155 with 1-year } \\
\text { follow-up) or conservative treatment alone } \\
\text { (151 pts with 1-year follow-up) }\end{array}$ & RCT & $\begin{array}{l}\text { IA injection cohort had increased cervical ROM, } \\
\text { greater pain relief, and fewer headaches during the } \\
\text { 1-year follow-up }\end{array}$ & $\begin{array}{l}\text { Analgesic medications, trigger point } \\
\text { injections with } L A \text { and botulinum, } \\
\text { and home exercises used variably in } \\
\text { both cohorts }\end{array}$ \\
\hline $\begin{array}{l}\text { Smith et al } \\
2013^{73}\end{array}$ & $\begin{array}{l}90 \text { pts with WAD grade II }>6 \text { months post- } \\
\text { MVC who received dual IA facet injections } \\
\text { and MBB (medications not noted); } 30 \text { healthy } \\
\text { controls }\end{array}$ & $\begin{array}{l}\text { Cross-sectional study } \\
\text { comparing physical } \\
\text { and psychological } \\
\text { profiles of } 58 \\
\text { injection responders } \\
\text { vs } 32 \text { non-responders }\end{array}$ & $\begin{array}{l}\text { Similar level of sensory disturbance, motor } \\
\text { dysfunction, psychological distress in both groups }\end{array}$ & $\begin{array}{l}\text { No patient experienced pain relief } \\
\text { for } \geq 3 \text { months following IA facet } \\
\text { injections }\end{array}$ \\
\hline $\begin{array}{l}\text { Lee et al } \\
2018^{234}\end{array}$ & $\begin{array}{l}51 \text { pts (44 with 1-year follow-up) with neck } \\
\text { pain and positive dual diagnostic cervical MBB } \\
\text { who received IA cervical facet injections with } \\
\text { LA and steroid }\end{array}$ & $\begin{array}{l}\text { Prospective cohort } \\
\text { study }\end{array}$ & $\begin{array}{l}24(54.5 \%) \text { pts reported } \geq 2 \text {-point reduction in pain } \\
\text { NRS or } \geq 50 \% \text { overall improvement in pain; } 9 / 44 \\
(18 \%) \text { underwent RFA }\end{array}$ & $\begin{array}{l}11 \text { pts required repeat IA injections } \\
\text { in the } 1 \text {-year study period with a } \\
\text { mean interval of } 6 \text { weeks between } \\
\text { injections }\end{array}$ \\
\hline $\begin{array}{l}\text { Hussain et al } \\
2020^{215}\end{array}$ & $\begin{array}{l}60 \text { pts with non-radiating neck pain received } \\
\text { cervical MBB at two levels with LA and steroid } \\
\text { or trigger point injections with LA and steroid }\end{array}$ & RCT & $\begin{array}{l}\text { Cervical MBB pts had mean pain score of } 2.0 \text { at } \\
12 \text { weeks vs } 6.96 \text { in trigger point injection group. } \\
\text { Functional improvement also greater in MBB group }\end{array}$ & $\begin{array}{l}\text { Technique for MBB and number of } \\
\text { trigger point injections not noted }\end{array}$ \\
\hline
\end{tabular}

IA, intra-articular injections; LA, local anesthetics; MBB, medial branch block; MVC, motor vehicle collision; NRS, numerical rating scale; pts, patients; RCT, randomized controlled trial; RFA, radiofrequency ablation; ROM, range of motion; TON, third occipital nerve; WAD, whiplash-associated disorder(s).

receive cervical MBBs and RFA at one or two levels based on complete pain relief following dual comparative LA blocks and a negative response to placebo injection (ie, 3 blocks), or cervical $\mathrm{MBB}$ and sham RFA. The MBBs were performed with $2 \mathrm{~mL}$ bupivacaine. The median time for $>50 \%$ of the pain to return was 8 days in the bupivacaine-only group versus 263 days in the MBB plus RFA group. Among those who received only bupivacaine, three of $12(25 \%)$ experienced at least $50 \%$ pain relief at 100 days after treatment and one continued to have pain relief after 200 days.

\section{Efficacy of cervical IA facet joint injections}

Bogduk and Marsland ${ }^{8}$ injected LA and steroid into cervical facet joints in eight patients with idiopathic neck pain, finding a median duration of pain relief of 1 month (range 4 days to 12 months). However, repeat IA injection in three patients provided pain relief for only 4-7 days. Similar variability in the duration of relief, with mostly short-term benefit, has been reported with cervical IA facet injections in other studies. ${ }^{68204232} 233$ In a study that compared the physical and psychological characteristics of responders versus non-responders to cervical IA facet injections, LA and a steroid were injected into the joints of 90 patients. Fifty-eight patients who experienced pain relief following the IA injections and confirmatory $\mathrm{MBB}$ were classified as responders. The duration of pain relief in this population varied from 2 hours to just under 3 months. ${ }^{73}$ In a prospective cohort study performed in 51 patients ( 44 with 1 -year follow-up) who had cervical facetogenic pain confirmed by dual diagnostic MBB, 24 $(54.5 \%)$ patients reported analgesic benefit from IA facet injections at 1 year, with 11 patients requiring a repeat procedure within 2-52 weeks. None of the 24 patients required cervical medial branch RFA during the study. ${ }^{234}$ In an RCT conducted in 400 patients with myofascial neck and shoulder pain and a positive response to dual cervical IA or MBB, 155 patients with 1-year follow-up received bilateral C5-6 and C6-7 IA injections, while no injections were performed in the other 151 patients with 1-year follow-up. Both groups also received exercise therapy, medications, and trigger point injections. The 
treatment group reported a greater range of cervical motion, lower pain scores, and a reduction in the incidence of tensiontype headaches at 1-year follow-up, although the variable use of co-interventions limits generalization. ${ }^{223}$ Finally, in an RCT performed in 41 patients with chronic neck pain following whiplash injury who responded to dual comparative cervical $\mathrm{MBB}$, Barnsley and colleagues ${ }^{102}$ compared IA injections of LA to steroids as stand-alone treatments. In both cohorts, a majority of patients (over $65 \%$ ) experienced $50 \%$ or greater pain reduction lasting less than 10 days, with only $10 \%$ in each cohort reporting substantial pain relief lasting more than 3 months. In summary, it appears that some patients may have prolonged therapeutic benefit with cervical facet IA injections with LA and/or steroids, with stronger evidence for chronic neck pain in the absence of whiplash injury.

\section{Recommendations}

We recommend against the routine use of IA injections, although we acknowledge that in patients who may be at risk of adverse consequences from RFA (eg, young athletes, older individuals on anticoagulation therapy, or with implantable cardiac devices) in whom there is a strong likelihood of success (eg, individuals who obtained prolonged relief from previous diagnostic injections with or without steroids), and/or patients who do not have readily available access to cervical medial branch RFA, it may be reasonable to consider IA facet joint injections with steroid (non-particulate at C2-3) in the hope of deriving intermediate-term relief; grade $\mathrm{C}$, low-to-moderate level of certainty. Given the lack of a pathophysiological basis for prolonged relief and the known risks of steroids, the routine use of steroids with cervical MBB should be avoided; grade D recommendation, moderate level of certainty.

\section{QUESTION 10: SHOULD BILATERAL CERVICAL MBB OR RFA BE PERFORMED DURING THE SAME VISIT? SHOULD THE NUMBER OF LEVELS BLOCKED OR DENERVATED BE LIMITED TO A CERTAIN NUMBER? \\ Clinical anatomy and function of the cervical medial branch nerves}

The cervical facet joints, C2-3 to C7-T1, are innervated by the medial branches derived from the dorsal rami of the cervical spinal nerve roots. ${ }^{200} 235$ These include the TON (to the C2-3 joint), the deep C3 medial branch (to the C3-4 joint), and the C4 to C8 medial branches (C3-4 to C7-T1 facet joints), all of which are targets for cervical MBB or RFA. In addition to giving off articular branches to the facet joints, medial branch nerves also innervate the semispinalis capitis (C2 and 3), multifidi and semispinalis cervicis muscles, and cutaneous areas. The semispinalis capitis is innervated by both medial and lateral branches of the C2 and C3 dorsal rami. Semispinalis capitis, semispinalis cervicis and multifidus muscles are considered important posterior neck stabilizers. ${ }^{236}$ Muscle spindles are present in cervical muscles and the density is higher in the upper region of the neck. 237238 Mechanoreceptor endings have been identified in the human cervical facet joint capsules as well. ${ }^{239}$ The vestibular system incorporates input from the eyes and cervical proprioceptors when stabilizing head and body positions. ${ }^{240}$ Injury of afferent nerves that carry proprioceptive information from these receptors may impair one's position sense. Compared with lumbar facet joint pain, cervical facet joint pain is more likely to be unilateral, perhaps because of the increased mobility in the neck and since cervical facet joint pain is more likely to result from trauma. ${ }^{241}$

\section{Direct evidence}

No study was identified that addresses this question.

\section{Indirect evidence}

Data extracted from studies designed for other objectives

Table 15 shows studies denoting the number of facet joints and laterality of treated patients. More procedures were performed on one to two joints than on multiple joints, and a large majority of procedures were unilateral. No sustained complication or side effects were reported that can be attributed to bilateral and/or multi-level facet nerve blocks or RFA, even in cases in which the TON was ablated bilaterally alone or in combination with other medial branches.

Studies by the same group of investigators have sought to determine, through controlled blocks performed one level at a time, the number and distribution of affected joints in patients with chronic neck pain after whiplash. ${ }^{1268}$ In the most comprehensive of these studies, 31 of 52 patients were diagnosed with cervical facet joint pain, with four patients having two-joint involvement and only one having three-joint involvement. ${ }^{12}$ Although elderly patients with advanced osteoarthritis often have multiple levels concomitantly affected, ${ }^{242}$ the clinical significance of this in the context of other degenerative changes (eg, uncovertebral joints, cervical discs) is unclear. Performing MBB at multiple segments may lead to the unnecessary treatment of unaffected levels, not only for the initial RFA but for subsequent procedures as well.

\section{Case reports}

There are two published case reports of dropped head syndrome after cervical medial branch RFA. In one instance, severe progressive cervical kyphosis with inability of active head raising developed after bilateral C2-C3, C3-C4, and C5-C6 facet joint medial branch RFA. ${ }^{243}$ The ablations were performed on each side separated by 1 week. Subsequent electromyography (EMG) showed active denervation of the cervical paraspinous muscles and MRI revealed paraspinal muscle atrophy. In the second case, dropped head syndrome developed 3 months after left-sided TON and C3-C4 facet joint medial branch RF denervation with MRI evidence of left semispinalis cervicis and splenius capitis atrophy/degeneration. ${ }^{244}$ In neither case was sensory or motor stimulation used. In both cases, passive head extension was not impaired. The authors postulated the etiologies as loss of collateral muscle innervation from bilateral and/or multi-level RFA. It is worth noting that bilateral multi-level facet nerve blocks were performed without reported adverse effects in both cases. Although unpublished, the authors (SPC, RWH) are aware of several cases of temporary ataxia and loss of balance when bilateral upper cervical MBBs were performed.

\section{Guidelines}

The SIS Practice Guidelines state that cervical MBB, including the TON, can be done bilaterally at the same visit for patients with bilateral neck pain and headache. ${ }^{18}$ However, the guidelines advocate staged facet nerve blocks such as blocking one side or only upper or lower segments in different visits in order to isolate the painful joint(s). The guidelines explicitly caution against performing medial branch RFA bilaterally and at numerous levels without careful judgment because of the possibility that treating more than one segment could compromise the function of the cervical musculature. They recommend that bilateral TON ablation be performed on separate occasions after test blocks to establish tolerance for bilateral denervation without causing debilitating ataxia and other untoward side effects. These conservative recommendations are generally consistent 
Special article

Table 15 Studies reporting bilateral and/or multi-level cervical medial branch blocks or radiofrequency ablation

\begin{tabular}{|c|c|c|c|c|c|c|}
\hline Author, year & Patient population & Design & $\begin{array}{l}\text { Number } \\
\text { treated }\end{array}$ & $\begin{array}{l}\text { Bilateral treatments } \\
\text { (cases) }\end{array}$ & $\begin{array}{l}\text { Number of joints } \\
\text { treated (cases) }\end{array}$ & Adverse events \\
\hline Lord et al $1996^{68}$ & $\begin{array}{l}\text { Pts with chronic } \\
\text { whiplash disorder } \\
\text { treated with MBB and } \\
\text { medial branch RFA } \\
\text { (C2-3 joint was } \\
\text { excluded from ablation) }\end{array}$ & $\begin{array}{l}\mathrm{RCT} \text { (C2-3 joint } \\
\text { was excluded } \\
\text { from ablation) }\end{array}$ & $\begin{array}{l}\text { Blocks: } 24 \text { pts } \\
\text { Ablations: } 12 \text { pts }\end{array}$ & $\begin{array}{l}\text { All blocks: } \\
\text { Bilateral C2-3 plus C5-6 and } \\
\text { ipsilateral C6-7 (1) } \\
\text { Unilateral C2-3 and contralateral } \\
\text { C5-6 (2) }\end{array}$ & $\begin{array}{l}\text { Unilateral } \\
\text { blocks: } \\
1 \text { (18) } \\
2 \text { (2) } \\
3 \text { (1) } \\
\text { Ablation: } \\
1 \text { (12) } \\
\text { Bilateral } \\
\text { blocks: } \\
1 \text { \& } 1(2) \\
2 \text { \& } 3(1) \\
\text { Ablation: } \\
0\end{array}$ & $\begin{array}{l}\text { Cutaneous dysesthesia or numbness was } \\
\text { reported in } 4 \text { cases }\end{array}$ \\
\hline $\begin{array}{l}\text { Lord et al } \\
1998^{202}\end{array}$ & Cervical facet joint pain & Retrospective & $\begin{array}{l}\text { Ablations: } \\
\text { C2-3 joint: } \\
12 \text { pts ( } 25 \\
\text { procedures) } \\
\text { Lower cervical } \\
\text { facet joints: } \\
28 \text { pts ( } 48 \\
\text { procedures) }\end{array}$ & Not reported & $\begin{array}{l}C 2-3(25) \\
1(40) \\
2(8)\end{array}$ & $\begin{array}{l}\text { Vasovagal } 2 \% \\
\text { Postoperative pain } 97 \% \\
\text { Ataxia, special disorientation, unsteadiness } \\
23 \% \\
\text { Cutaneous numbness } \\
\text { C2-3 } 88 \% \\
\text { C3-4 } 80 \% \\
\text { Lower joints } 19 \% \\
\text { Dysesthesia } \\
\text { C2-3 } 56 \% \\
\text { C3-4 } 30 \% \\
\text { Lower joints } 17 \% \\
\text { Transient neuritis } 2 \% \\
\text { Dermoid cyst } 1 \% \\
\text { Köbner's phenomenon } 1 \%\end{array}$ \\
\hline $\begin{array}{l}\text { Govind et al } \\
2003^{307}\end{array}$ & Cervicogenic headache & $\begin{array}{l}\text { Prospective } \\
\text { cohort }\end{array}$ & $\begin{array}{l}\text { Ablations: } \\
49 \text { pts ( } 51 \\
\text { procedures) }\end{array}$ & $\begin{array}{l}\text { Bilateral C2-3 ablations (2), each } \\
\text { side was treated on separate days }\end{array}$ & $\begin{array}{l}\text { Unilateral } \\
\text { C2-3 ablation (47) }\end{array}$ & $\begin{array}{l}\text { Numbness } 97 \% \\
\text { Ataxia } 95 \% \\
\text { Dysesthesia } 55 \% \\
\text { (all self-limiting/no intervention needed) }\end{array}$ \\
\hline $\begin{array}{l}\text { Barnsley, } \\
2005^{101}\end{array}$ & Chronic neck pain & Retrospective & $\begin{array}{l}\text { Ablations: } \\
35 \text { pts ( } 47 \\
\text { procedures) }\end{array}$ & $\begin{array}{l}2 \text { joints were treated in } 3 \text { cases. It } \\
\text { is unclear if they were ipsilateral or } \\
\text { contralateral }\end{array}$ & $\begin{array}{l}C 2-3(23) \\
1(21) \\
2(3)\end{array}$ & $\begin{array}{l}\text { Nearly all had postoperative pain, lasting } \\
1 \text { week in most patients. } 1 \text { case of local } \\
\text { wound infection }\end{array}$ \\
\hline $\begin{array}{l}\text { Manchikanti, } \\
2006^{415}\end{array}$ & Chronic neck pain & $\mathrm{RCT}$ & $\begin{array}{l}\text { Blocks: } \\
60 \mathrm{pts}\end{array}$ & $75 \%$ cases & $\begin{array}{l}2(48 \%) \\
3(50 \%) \\
4(2 \%)\end{array}$ & Not reported \\
\hline $\begin{array}{l}\text { Shin et al } \\
2006^{285}\end{array}$ & Chronic neck pain & Retrospective & $\begin{array}{l}\text { Ablations: } \\
28 \text { pts ( } 6 \\
\text { excluded as } \\
\text { only one medial } \\
\text { branch nerve } \\
\text { of a facet joint } \\
\text { was recorded as } \\
\text { treated) }\end{array}$ & 8 & $\begin{array}{l}\text { Unilateral } \\
1(3) \\
2(9) \\
3(4) \\
\text { Bilateral } \\
1 \& 1(1) \\
1 \& 3(1) \\
2 \& 1(1) \\
2 \& 2(1) \\
2 \& 3(1) \\
3 \& 3(1)\end{array}$ & $\begin{array}{l}\text { Muscle cramping pain and numbness } \\
\text { lasting }<4 \text { weeks, in a majority of cases, } \\
<2 \text { weeks }\end{array}$ \\
\hline $\begin{array}{l}\text { Manchukonda et } \\
\text { a/ } 2007^{416}\end{array}$ & Chronic neck pain & Retrospective & $\begin{array}{l}\text { Blocks: } \\
251 \text { pts }\end{array}$ & 180 & $\begin{array}{l}2(127) \\
3(122) \\
4(2)\end{array}$ & None reported \\
\hline $\begin{array}{l}\text { Klessinger, } \\
2010^{313}\end{array}$ & $\begin{array}{l}\text { Pts had previous } \\
\text { anterior cervical } \\
\text { operations }\end{array}$ & Retrospective & $\begin{array}{l}\text { Ablations: } \\
32 \text { pts }\end{array}$ & 10 & $\begin{array}{l}\text { Unilateral: } \\
1 \text { (4) } \\
2 \text { (15) } \\
3 \text { (3) } \\
\text { Bilateral: } \\
1 \text { \& } 1(2) \\
2 \text { \& } 2 \text { (8) }\end{array}$ & Not reported \\
\hline $\begin{array}{l}\text { MacVicar et al } \\
2012^{69}\end{array}$ & Chronic neck pain & $\begin{array}{l}\text { Prospective } \\
\text { cohort }\end{array}$ & $\begin{array}{l}\text { Ablations: } \\
104 \text { pts }\end{array}$ & 6 & $\begin{array}{l}\text { Unilateral: } \\
\text { C2-3 (29) } \\
1 \text { (54) } \\
2 \text { (16) } \\
3 \text { (5) } \\
\text { Bilateral: } \\
\text { C2-3 (1) } \\
1 \text { \& } 1(3) \\
1 \text { \& } 2(2)\end{array}$ & Not reported \\
\hline $\begin{array}{l}\text { Hamer and } \\
\text { Purath, 2014 }\end{array}$ & Cervicogenic headache & Retrospective & $\begin{array}{l}\text { Ablations: } \\
17 \text { pts } \\
\text { C2/3 joint } \pm \text { C2 } \\
\text { DRG }\end{array}$ & 8 & $\begin{array}{l}\text { Unilateral } \\
\text { C2-3 (4) } \\
\text { C2-3 \& C2 DRG (5) } \\
\text { Bilateral } \\
\text { C2-3 (4) } \\
\text { C2-3 \& C2 DRG (4) }\end{array}$ & $\begin{array}{l}\text { Dizziness (1) and suboccipital hyperesthesia } \\
\text { ( } 2 \text { ) (in one unilateral and one bilateral C } 2 / 3 \\
\text { ablation case) }\end{array}$ \\
\hline
\end{tabular}


Table 15 Continued

\begin{tabular}{|c|c|c|c|c|c|c|}
\hline Author, year & Patient population & Design & $\begin{array}{l}\text { Number } \\
\text { treated }\end{array}$ & $\begin{array}{l}\text { Bilateral treatments } \\
\text { (cases) }\end{array}$ & $\begin{array}{l}\text { Number of joints } \\
\text { treated (cases) }\end{array}$ & Adverse events \\
\hline $\begin{array}{l}\text { Van Eerd et al } \\
2014^{298}\end{array}$ & $\begin{array}{l}\text { Chronic neck pain } \\
\text { (excluding whiplash and } \\
\text { C2-3 joint involvement) }\end{array}$ & Retrospective & $\begin{array}{l}\text { Ablations: } \\
65 \text { pts }\end{array}$ & 0 & $2(65)$ & Not reported \\
\hline $\begin{array}{l}\text { Hahn et al } \\
2018^{417}\end{array}$ & $\begin{array}{l}\text { Chronic neck pain and } \\
\text { vertigo }\end{array}$ & Retrospective & $\begin{array}{l}\text { Blocks: } \\
178 \text { pts }\end{array}$ & 142 & $\begin{array}{l}\text { Specific information } \\
\text { lacking }\end{array}$ & Not reported \\
\hline $\begin{array}{l}\text { Van Eerd et al } \\
2020^{28}\end{array}$ & Chronic neck pain & $\mathrm{RCT}$ & $\begin{array}{l}76 \text { pts } \\
\text { Blocks (39) } \\
\text { Ablations (37) }\end{array}$ & 0 & $\begin{array}{l}\text { Unilateral } 2 \text { joints per } \\
\text { patient (same session) } \\
\text { Blocks: } \\
\text { C3-4 \& C4-5: } 9 \\
\text { C4-5 \& C5-6: } 25 \\
\text { C5-6 \& C6-7: } 5 \\
\text { Ablations: } \\
\text { C3-4 \& C4-5: } 5 \\
\text { C4-5 \& C5-6: } 26 \\
\text { C5-6 \& C6-7: } 6\end{array}$ & $\begin{array}{l}3 \text { serious adverse events } \\
\text { (lung cancer, brain tumor, atrial fibrillation) } \\
\text { unrelated to treatment }\end{array}$ \\
\hline
\end{tabular}

with US Medicare coverage determinations which recommend that no more than two levels-unilateral or bilateral-be treated per session, with "3-level procedures considered under unique circumstances and with sufficient documentation of medical necessity on appeal". ${ }^{139}$

\section{Recommendations}

In summary, indirect evidence suggests bilateral cervical MBB, including the TON, can be performed during the same visit. Although bilateral and multi-segment ( $>2$ levels) RFA have been described, we recommend performing them at separate visits to maximize safety. Given the scant clinical evidence for treating multiple levels and lack of precision, performing $\mathrm{MBB}$ at more than two levels simultaneously should be routinely avoided in the absence of compelling clinical evidence to the contrary; grade $\mathrm{C}$ recommendation, low level of certainty.

\section{QUESTION 11: ARE FACET, AO, AA BLOCKS 'DIAGNOSTIC', 'PROGNOSTIC', OR BOTH?}

\section{Premise of cervical facet, $A O$, and $A A$ interventions}

The terms 'diagnostic', 'prognostic', and 'predictive' are commonly used interchangeably in the literature on chronic $\mathrm{LBP}^{29}$ athough they are not the same. ${ }^{245}$ A similar misconception holds true for LA interventions into the cervical spine joints. Portions of the discussion below are substantially derived from our previous lumbar facet intervention working group consensus guidelines. ${ }^{29}$ The term 'diagnosis' refers to the 'process of identifying a disease, condition, or injury from its signs and symptoms'. ${ }^{246}$ 'Prognosis' most commonly refers to the forecasting of the likely course of a disease (which may include the effects of treatment), while 'predictive' provides specific information about the likely effect of a therapeutic intervention. Whereas these terms may overlap in some scenarios, they refer to different concepts.

The patterns and location of the innervation of the cervical spine joints are more complicated than the thoracic and lumbar levels. The cervical spine can be divided into at least five distinct regions (AO, AA, C2-3, C3-4 through C6-7, and C7-T1 joints) based on their unique anatomy. These differences will be referenced where they impact the question of diagnosis and/or prognosis.

\section{Diagnosis}

Diagnostic injections can be used to isolate the anatomic structures that are the source of pain. ${ }^{76}$ They are a critical but potentially imperfect element in the practice of interventional pain and spine medicine. An indirect approach to diagnosis is relied on due to the lack of any pathognomonic historical or physical examination finding, diagnostic test, and/or spine imaging finding indicative of pain of facetogenic or joint origin (ie, a reference standard). Although the administration of LA into the joint itself or onto the nerves supplying the joint with diagnostic intent has face validity, it is based on the assumption that there are no other factors that will alter the pain, and relies on the patient's report of pain relief, which is subject to bias and cannot be independently verified. ${ }^{247}$ Therefore, the possibility of falsepositive or -negative reporting is an inherent risk with cervical IA or MBB injections. ${ }^{245}$ However, this potentially can be mitigated through placebo injections ${ }^{189}$ and a thorough understanding of cervical spine anatomy. ${ }^{2178} 187$

\section{Prognosis}

Prognostic injections can be used in risk stratification and treatment planning. Prognosis is closely aligned in medicine to predictability. A patient may appropriately ask his or her clinician, "What are the chances that I will get 50\% pain relief from this intervention?" Similarly, a patient may ask, "What is my prognosis or expectation if I get 70\% relief from the diagnostic block and then undergo RF denervation?" These are not easily answered questions. Evidence-based medicine may provide outcome estimates from interventions, but this is not the same as providing a prognosis or prediction.

\section{Limitations of diagnostic injections}

The limitation of cervical joint interventions in providing diagnostic information is confounded by the placebo response, which is robust for pain and spine procedures. ${ }^{248} 249$ Although a placebo response may be observed, this should not be interpreted as a lack of pathophysiological pain and is a factor in an unknown proportion of patients reporting concordant pain relief after diagnostic blocks. ${ }^{189}$ Placebo response is discussed at greater length in the lumbar facet guidelines ${ }^{29}$ and is similarly applicable to those of the cervical spine. Lord et $a l^{189}$ found that comparative diagnostic blockade was highly specific (88\%), but only marginally sensitive $(54 \%)$ in identifying painful cervical 
facet joints, resulting in potentially labeling $46 \%$ of the patients as 'placebo' responders and denying them access to RFA. This potentially very high false-negative rate might not be considered acceptable in light of the modest risks of the procedure and the certitude of continued pain and disability for the patient.

The accuracy of a diagnostic block is contingent on several technical and anatomic factors. First, it assumes the procedure is performed in a manner that results in anesthesia of the intended, but not unintended, structure(s). ${ }^{245}$ Similar to lumbar $\mathrm{MBB}$, anesthetic injections over the TON and the C3 through C8 medial branches are unlikely to be specific due to the proximity of lateral branches of the dorsal rami and the high likelihood for spread into the surrounding muscles, resulting in non-selective analgesia. In one prospective study, over half of C3 medial branch diagnostic injections performed at the midpoint of the $\mathrm{C} 3$ articular pillar resulted in spread onto the course of the TON, which innervates the supra-adjacent joint. ${ }^{78}$ Blocks can be made more selective through technical modifications including a reduction in anesthetic volume (including not mixing it with contrast) and adjusting one's approach to lateral (from posterior parasagittal) to the articular pillar. ${ }^{7678} 187$ The ventral $\mathrm{C} 1$ and $\mathrm{C} 2$ ramus innervate the $\mathrm{AO}$ and $\mathrm{AA}$ joints, respectively, and therefore the joint innervation is not amenable to percutaneous interventions. ${ }^{41}{ }^{42}$ An IA injection into the AO, AA, and C2-3 through C7-T1 facet joints, in which the LA is contained within the joint, does meet the requirements for classification as a diagnostic intervention. ${ }^{5165}$ However, there is a high rate of failed IA injections, ranging from 21\% (extra-articular) to $93 \%$ (intra-articular and extra-articular) with fluoroscopy ${ }^{224}$ and $22 \%$ with US. ${ }^{250}$ Second, a successful diagnostic block assumes that the anesthetized nerve supplies a single anatomic target and that the ensuing pain relief results from the anesthetization of only that structure. This is not the case for the TON which innervates the C2-3 facet joint, the semispinalis capitis muscle, and cutaneous tissue of the posterior occiput. ${ }^{200}$ The TON also has numerous distal collaterals with the greater and lesser occipital nerve. ${ }^{200}$ Third, for an injection to have diagnostic or construct validity assumes that the diagnostic target receives single-source innervation. A similar argument has been made for the lack of diagnostic validity of lateral branch blocks in the context of diagnosing sacroiliac joint pain. ${ }^{251}$ The $\mathrm{AO}$ and $\mathrm{AA}$ joints receive innervation from the $\mathrm{C} 1$ and $\mathrm{C} 2$ ventral ramus, respectively. ${ }^{41} 42$ The C3-4 through C7-T1 joints are innervated by the medial branches of the dorsal ramus above and below the joint. The C2-3 joint, however, receives its primary innervation from the C3 superficial (or principal) medial branch (also known as the TON) and occasionally a small inferior communicating branch from the C2 dorsal ramus. ${ }^{200}$ Unlike what occurs in the lumbar spine, ${ }^{252}$ in one study Bogduk and Marsland ${ }^{8}$ found that 7 subjects who underwent multiple image-guided MBB and experienced complete pain relief also experienced concordant relief when the innervated facet joints were injected with LA.

\section{Limitations of prognostic injections}

IA injections and MBB have been used to assess the probable response of medial branch RFA. The rationale is that, if an MBB relieves pain, then a treatment capable of interrupting conduction along the same nerve(s) should provide comparable relief, but last longer depending on the expected duration of disrupted signaling (ie, until nerve regeneration or reinnervation occurs). The use of these interventions as a surrogate measure for outcome prediction carries the same limitations as their use as a diagnostic tool. The accuracy of a prognostic test also depends on how success or failure is defined. For instance, the success of RFA might be expressed simply as pain relief at the point in time at which the LA is no longer active and the patient has recovered from procedural pain (days or weeks), or it could be defined as alleviation of pain at some pre-designated distant time point (months) following the procedure. Depending on the time chosen, the prognostic power of the initial intervention will be different.

\section{Evidence for diagnostic and prognostic utility}

The prevalence of cervical spine joint pain has a range of 26-60\% when using history, physical examination, and radiological imaging for diagnosis. ${ }^{67}$ In light of the lack of objective measures of cervical spine joint-mediated pain, IA and MBB injections with LA remain the most widely accepted approach to diagnosis and a surrogate measure for prognosis. An IA injection with LA can serve as a diagnostic tool for a subsequent therapeutic joint injection performed with a steroid into the AO and AA joints. In a small prospective observational study, 18 of 20 patients with a positive response to an IA AO injection with LA experienced a $>2$-point reduction in their pain score on a $0-10$ visual analog scale 2 months following a therapeutic IA injection with LA and steroid. ${ }^{165}$ In one arm of an RCT, seven of 11 patients who had a positive IA AO with LA experienced at least 50\% reduction in their pain 6 months after an $\mathrm{AO}$ injection with steroid. ${ }^{171}$ There are a lack of high-quality studies to address this question for the AA joint; a single study provides an incomplete answer. In a retrospective study, 26 of 32 patients who underwent lateral AA joint injections experienced $\geq 50 \%$ pain reduction post-procedure, with 15 reporting no pain. ${ }^{62}$ Unfortunately, the results did not differentiate characteristics of the subgroup who received relief immediately after the injection from those who did not achieve relief in the longitudinal results. Other studies used unreliable screening criteria for AA therapeutic injections leading to inconclusive results. ${ }^{173}$

Several studies have examined the prognostic utility of C3 through C7 medial branch interventions; however, high-quality evidence for the utility of C2-3 through C7-T1 IA injections is lacking. In the rigorous RCT by Lord et al ${ }^{68}$ using placebo-controlled MBB for patient selection, 58\% (7/12) of the patients experienced complete pain relief and restoration of function at 27 weeks following cervical medial branch RFA. A follow-up to this study with additional patients reported a similar success rate. ${ }^{149}$ A larger RCT using a similarly rigorous protocol as Lord et $a l^{68}$ included the $\mathrm{C} 2-3$ joint along with the lower cervical facet joints. ${ }^{101}$ Twenty-one of 35 patients in this study received complete relief from RFA at 12 weeks.

\section{Recommendations}

C3 through C8 MBB meet most criteria as a diagnostic intervention for cervical joint-mediated pain, although the nerves that innervate the facet joints innervate other potential pain-generating structures. Technically sound IA joint injections theoretically meet criteria as a diagnostic intervention for cervical joint-mediated pain, although they are characterized by high technical failure rates; grade $\mathrm{C}$ recommendation, low-to-moderate level of certainty. IA injections are less predictive than MBB for response to medial branch RFA for the C2-3 through C7-T1 joints; grade C recommendation, low level of certainty. Although accuracy may be improved with CT guidance or arthrography, these tools are not well supported in peer-reviewed investigations. IA injections of the AO and AA joints with LA may be diagnostic and provide predictive information for IA steroid injections; grade $\mathrm{C}$ recommendation, low level of certainty. 
QUESTION 12: WHAT IS THE EFFECT OF SEDATION ON THE ACCURACY OF DIAGNOSTIC OR PROGNOSTIC INTRAARTICULAR FACET JOINT BLOCKS AND MBB?

Arguments for and against sedation during diagnostic blocks The general arguments regarding the use of sedation during diagnostic blocks were eloquently outlined in the lumbar facet guidelines. ${ }^{29}$ Proponents assert that sedation allays anxiety and reduces procedure-related pain (thereby minimizing the likelihood of a false-negative block), enhances patient satisfaction (thereby reducing the chance of subsequent no-shows), and may prevent movement, thereby facilitating performance. Anxiety has also been shown to lower pain perception thresholds and tolerance in experimental studies. ${ }^{253}$ Critics argue that sedation increases the rate of false-positive blocks, increases risks and costs, and may interfere with physician-patient communication and engagement in post-procedure activities, which can interfere with the interpretation of post-block pain relief. Along with analgesics such as opioids and ketamine, benzodiazepines may also promote pain relief by virtue of their muscle relaxant properties, as a myofascial component is present in over $90 \%$ of patients with chronic axial neck pain. ${ }^{254} 255$ Estimates on the economic costs of sedation for interventional pain procedures exceed $\$ 300$ million per year in the USA. ${ }^{25}$

\section{Differences between the cervical spine and lumbar spine}

Unlike lumbar MBBs, cervical MBB procedures can be performed in the lateral or prone position. For cervical MBB, the lateral approach involves a shorter distance between skin insertion and the target medial branches and has been shown in a randomized trial to provide comparable accuracy and pain relief. ${ }^{78}$ Depending on the approach, cervical MBB may involve less tissue damage and consequent pain than lumbar MBB. However, a randomized trial comparing cervical and lumbar epidural steroid injections found a higher proportion of cervical patients requested additional LA, suggesting possible pathoanatomical differences. ${ }^{256}$ Compared with cervical epidural steroid injections (ESIs) whereby patient movement can result in neurological complications, $\mathrm{MBBs}$ are less subject to movement-related procedural complications.

Most, ${ }^{256} 257$ though not all, ${ }^{126}$ studies have found a significantly higher incidence of vasovagal reactions with cervical injections compared with lumbar injections, and sedation has been shown to reduce the incidence in those who are predisposed. ${ }^{258}$ In a large retrospective study by Kennedy et $a l^{258}$ that evaluated the incidence of vasovagal reactions during a host of spinal injections including cervical MBB and cervical medial branch RFA, the authors found that light sedation decreased the rate both in individuals without a prior vasovagal event compared with no sedation $(0 \%$ vs $3 \%)$ and in those with a prior history of a vasovagal reaction ( $0 \%$ vs $23 \%$ ). A history of an anxiety disorder is widely considered an indication for sedation, and there is a high co-prevalence rate in individuals with both neck and back pain, with one systematic review and metaanalysis reporting an anxiety risk ratio of 3.29 (95\% CI 2.16 to 5.00$)$ for neck pain. ${ }^{259}$ In a large cross-sectional study evaluating the incidence of anxiety in neck and back pain in 1580 adolescents, anxiety and depression scores on the Youth Self Report scale of the Child Behavior Check List were associated with a slightly higher association for neck pain than back pain with an OR of 1.43 (95\% CI 1.20 to 1.70 ) versus 1.38 (95\% CI 1.15 to 1.66$)$ (table 16$){ }^{260}$

\section{Clinical trials \\ Cervical facet blocks}

A randomized study by Manchikanti et al ${ }^{261}$ allocated 180 patients who had previously responded to comparative LA cervical MBB and were undergoing repeat procedures to receive midazolam $1-5 \mathrm{mg}$, fentanyl $50-250 \mu \mathrm{g}$, or up to $5 \mathrm{~mL}$ of saline titrated to effect. Pain scores were measured before medication administration and shortly thereafter, before performing the actual MBB. Using $80 \%$ pain relief as the threshold, the authors found that $5 \%$ of saline patients and $8 \%$ of both midazolam and fentanyl patients experienced significant pain relief before the MBB. Using 50\% pain relief as the cut-off threshold for a positive response, the authors reported that $8 \%, 13 \%$, and $27 \%$ of patients who received saline, midazolam, and fentanyl were responders, respectively $(\mathrm{p}<0.05$ between $50 \%$ and $80 \%$ relief only for fentanyl). In a follow-up randomized study performed by the same group of investigators evaluating the effect of sedation on pain relief prior to cervical and lumbar MBB in 60 patients, 30 of whom had neck pain, the authors reported $\geq 50 \%$ pain relief in $5 \%$ of saline patients, and in $15 \%$ of midazolam and fentanyl patients after medication administration. ${ }^{262}$ Using an $80 \%$ cut-off threshold resulted in $5 \%$ saline responders and 10\% midazolam and fentanyl responders. These studies did not address the question of the effect of sedation on the outcome of MBBs because, in each study, the authors evaluated the effect of medication administration before the MBB was performed. Flaws in these studies also include the high percentage of patients on opioids, the relatively high percentage with prior surgery, and that these blocks were being done for therapeutic and not diagnostic purposes.

Table 16 Differences between lumbar and cervical injections affecting the need for sedation

\begin{tabular}{|c|c|c|c|c|}
\hline Author, year & Patient population & Design & Results & Comments \\
\hline $\begin{array}{l}\text { Trentman et al } \\
2009^{257}\end{array}$ & $\begin{array}{l}498 \text { pts who received } \\
\text { cervical and lumbar } \\
\text { transforaminal ESI }\end{array}$ & $\begin{array}{l}\text { Case-control study. Control lumbar } \\
\text { injections }(n=249) \text { done on same } \\
\text { day or the closest day to cervical } \\
\text { transforaminal ESI }(n=249)\end{array}$ & $\begin{array}{l}8 \% \text { incidence of vasovagal reaction in cervical group vs } \\
1 \% \text { for lumbar injections }\end{array}$ & $\begin{array}{l}3 \% \text { of cervical pts required } \\
\text { sedation vs none in lumbar pts }\end{array}$ \\
\hline $\begin{array}{l}\text { Walega et al } \\
2015^{256}\end{array}$ & $\begin{array}{l}280 \text { pts equally divided } \\
\text { between those undergoing } \\
\text { cervical and lumbar } \\
\text { interlaminar ESI }\end{array}$ & Prospective observational study & $\begin{array}{l}10 \% \text { incidence of vasovagal reaction in cervical group vs } \\
3 \% \text { for lumbar injections. No difference in movement or } \\
\text { vocalizations. More cervical pts requested additional LA } \\
\text { ( } 6 \% \text { vs } 1 \%)\end{array}$ & $\begin{array}{l}\text { Excluded pts with anxiety disorder, } \\
\text { who had previous epidural } \\
\text { injection or who requested } \\
\text { sedation }\end{array}$ \\
\hline $\begin{array}{l}\text { Rees et al } \\
2011^{260}\end{array}$ & $\begin{array}{l}1580 \text { adolescent pts with } \\
\text { neck and/or back pain }\end{array}$ & Cross-sectional study & $\begin{array}{l}\text { Multinomial ORs for anxiety and/or depression for neck } \\
\text { pain, back pain, or neck and back pain } 1.43(95 \% \mathrm{Cl} \\
1.20 \text { to } 1.70), 1.38 \text { ( } 95 \% \mathrm{Cl} 1.15 \text { to } 1.66) \text {, and } 1.98(95 \% \\
\mathrm{Cl} 1.64 \text { to } 2.30) \text {, respectively. }\end{array}$ & $\begin{array}{l}\text { Reference group: adolescents } \\
\text { without back or neck pain. Source } \\
\text { of pain not identified. Did not } \\
\text { address causality }\end{array}$ \\
\hline
\end{tabular}




\section{Extrapolated evidence on the positive rate from other} prognostic blocks

The most methodologically sound study to examine the effect of sedation was a randomized crossover study by Cohen et $a l^{263}$ performed in 73 people who received two sympathetic or sacroiliac joint blocks, with sedation and no-sedation given in random order. Midazolam, with or without fentanyl, was titrated to effect by a board-certified anesthesiologist. In the main crossover analysis, procedures performed with light sedation were associated with a greater than two-fold increase in a positive block based on pain diary assessment using $\geq 50 \%$ pain relief as the cut-off, and a three-fold increase using $80 \%$ as the cut-off threshold. Similar increases in the rate of positive diagnostic blocks were noted for the parallel group and omnibus (all sedation vs all non-sedation) analyses. Whereas sedation reduced pain from procedures, it did not affect satisfaction scores or 1 month outcomes. Paradoxically, statistically significant differences were noted between the no-sedation group and those who received low-dose midazolam only $(\leq 4 \mathrm{mg})$ or light sedation with both midazolam and fentanyl $(\leq 4 \mathrm{~mL}$ of midazolam $1 \mathrm{mg} / \mathrm{mL}$ and/or fentanyl $50 \mu \mathrm{g} / \mathrm{mL}$ ), but not those who received heavy sedation ( $>4 \mathrm{~mL}$ of midazolam and/or fentanyl). Although not used diagnostically, a multicenter prospective study by Dreyfuss et $a l^{264}$ found no difference in immediate post-procedure pain scores after lumbar, thoracic, and cervical ESIs performed in 102 patients.

\section{Effect of sedation during prognostic blocks on treatment outcomes}

Several retrospective studies have evaluated the effectiveness of sedation during prognostic blocks on the results of therapeutic interventions. A retrospective study that sought to identify predictive factors associated with celiac plexus neurolysis in 50 patients with cancer pain reported a $73 \%$ success rate in people who underwent prognostic blocks without sedation versus 39\% in those who received sedation during celiac plexus blocks. ${ }^{265}$ However, in a large retrospective study evaluating outcome predictors in 265 patients who underwent genicular nerve RFA, the authors found no outcome differences stratified by whether or not sedation was used during the prognostic injections. $^{266}$

\section{Patient preference for sedation}

Two studies performed in the same private practice setting reported disparate results on the necessity of sedation before lumbar, thoracic, and cervical ESIs and facet blocks. ${ }^{267} 268$ In the survey study by Cucuzzella et $a l^{267}$ the authors found that $17 \%$ of 500 patients requested oral sedation before their procedure, with $28 \%$ reporting they would request it before a second injection. Surprisingly, those who were sedated reported nonsignificantly higher procedure-related pain scores than those who were not sedated on the first injection $(p=0.12)$ and significantly higher pain scores on the second injection. This may be attributable to those patients with anxiety and anticipating higher procedure-related pain being more likely to request sedation. This is supported by the observation that a history of anxiety, depression, and higher procedure-related pain were associated with requesting sedation. In a prospective follow-up study in which 301 patients were offered oral or IV sedation, $58 \%$ requested sedation, with $90 \%$ of these individuals being satisfied with the anxiolytic effect. ${ }^{268}$ For patients not requesting sedation, 93\% were satisfied.

\section{Guidelines}

Several guidelines have been published on the use of sedation for interventional procedures and have generally recommended against routine sedation for simple blocks such as facet blocks and ESIs based on the rationale that the risks outweigh the benefits. These include the ASA, SIS, ASRA, and the lumbar facet guidelines committee, ${ }^{29}$ 269-271 with ASIPP recommending the avoidance of opioids for diagnostic facet blocks but allowing for the use of sedation with midazolam and opioids to alleviate pain and anxiety for therapeutic procedures. ${ }^{27}$

\section{Recommendations}

We recommend performing cervical MBB without sedation, including using anxiolytics (benzodiazepines, propofol) or analgesics (opioids, ketamine) as there is evidence it may increase the false-positive rate. Patients in whom light sedation may be considered include those with pre-existing psychiatric conditions that may include anxiety and post-traumatic stress, and for procedures in which the blocks are expected to be particularly painful (eg, obesity, those with anatomic derangements); grade B recommendation, moderate degree of certainty.

\section{QUESTION 13: WHAT SHOULD THE CUT-OFF BE (PERCENT RELIEF) FOR DESIGNATING A BLOCK AS 'POSITIVE' AND IS THERE ANY BENEFIT IN USING NON-PAIN SCORE OUTCOME MEASURES?}

\section{Guidelines and basis for recommendation}

The multi-organizational lumbar facet guidelines advocate using 50\% pain relief as the cut-off for selecting patients for RFA, citing the rarity of isolated lumbar facet joint pain, maximizing access to treatment, and the absence of reliable treatment alternatives as the main reasons. ${ }^{29}$ In their 2013 guidelines, SIS advocates using 'complete relief of pain in the topographical region targeted' as a selection criterion. ${ }^{18}$ In a 2012 systematic review, ASIPP noted there was stronger evidence for the use of $\geq 75 \%$ pain relief with double blocks than there was for single blocks, or double blocks using lower thresholds. ${ }^{22}$ The recommendations by the lumbar facet guidelines group were based on numerous retrospective studies showing no difference in outcomes when cut-offs were stratified by $50 \%$ and $80 \%$ thresholds $^{29}$ and a prospective study demonstrating no differences in 3 -month outcomes between pain relief from single diagnostic blocks stratified by $10 \%$ increments. ${ }^{272}$ Two studies included in those guidelines did report non-statistically significant higher success rates for higher cut-off thresholds for lumbar medial branch RFA. Manchikanti et $a l^{273}$ reported 1-year success rates of $75 \%$ in individuals who obtained between $50 \%$ and $79 \%$ pain relief from prognostic blocks, and 93\% in those who obtained at least $80 \%$ relief, with some patients receiving serial $\mathrm{MBB}$ and others undergoing RFA. A retrospective study by Derby and colleagues ${ }^{274}$ reported a 54\% success rate at 6 months in patients who experienced between $50 \%$ and $79 \%$ relief on single or double lumbar MBB versus $84 \%$ in those who obtained at least $80 \%$ relief. However, the high RFA success rates in those who experienced less than $80 \%$ pain relief strongly support the consideration of using less rigorous cut-offs.

\section{Differences between the lumbar and cervical spine}

It is generally acknowledged that the prevalence of facet joint pain is higher in the neck than in the low back in individuals with axial complaints, which is a consequence of greater stress on the cervical than lumbar joints during spine movements, and the relatively greater size compared with the intervertebral 
discs. ${ }^{27} 275$ This should theoretically lead to greater pain relief during diagnostic facet blocks. But whereas radiological facet joint degeneration in the absence of disc degeneration is rarer in the lumbar spine than the cervical spine, the overall prevalence of degeneration is similar in the two regions. ${ }^{276}$ The proportion of individuals with cervical zygapophyseal joint disease is slightly higher than those with cervical disc degeneration, with one study finding $55 \%$ of individuals with cervical facet degeneration versus $45 \%$ with disc degeneration. ${ }^{93}$ There is some evidence that the density of nociceptors in the facet joint capsule and bone and mechanoreceptor firing in response to stimuli may be higher in the cervical spine than the lumbar spine. ${ }^{239}{ }^{277}$ In one observational study involving 56 patients with chronic neck pain, Bogduk and Aprill found that 23 patients (41.1\%) exhibited both a positive MBB, defined as complete pain relief lasting for the duration of action of the local anesthetic, and a positive discogram at the same level, indicating that neither the cervical facet joints nor intervertebral discs were likely to be the only source of pain, or that one or both tests are characterized by a high false-positive rate. ${ }^{278}$ Studies have also found electromyographic differences between neck pain and control patients and a very high prevalence rate of trigger points in individuals with neck pain. ${ }^{279} 280$

\section{Identifying meaningful cut-off thresholds}

Studies vary regarding RFA outcomes based on MBB cutoff thresholds in the cervical spine. Commonly cited cut-off values are discordant in cervical facet literature and are sometimes inferred from lumbar and thoracic facet studies. Cut-off thresholds commonly cited include $50 \%, 75 \%, 80 \%$, or $100 \%$ relief following cervical diagnostic MBB, with no consensus in the literature or pain community regarding which cut-off leads to the best outcomes. Initiative on Methods, Measurement, and Pain Assessment in Clinical Trials (IMMPACT) guidelines note that a $30 \%$ or a 2-point reduction in pain signifies clinically meaningful benefit, ${ }^{281}$ and the lumbar facet guidelines committee agreed with this threshold. ${ }^{29}$ Importantly, they also noted that quality of life changes should be considered as part of an individualized approach to identifying outcomes that individual patients consider important. ${ }^{29} 281$ Two points or $30 \%$ pain relief is also commonly used to designate responders in federally sponsored studies and late phase clinical trials, including those evaluating interventions for cervical pain and RFA. ${ }^{37282-284}$

\section{Studies stratifying cervical RFA outcomes by prognostic block cut-off thresholds}

One might argue that there should theoretically be some correlation between pain relief after cervical MBB and pain relief after RFA, but that numerous other factors might function to confound this correlation (eg, technique, number, and types of diagnostic blocks) and make it difficult to detect a signal. This is suggested by a recent systematic review. ${ }^{21}$ Despite the general recommendations for less than $50 \%$ pain relief to be considered clinically meaningful, many RFA studies maintain higher cut-off thresholds from MBB. Determination of a successful MBB can help the clinician decide which patients would most benefit from RFA; however, few studies have evaluated cervical medial branch RFA outcomes stratified by cut-off threshold. In the earliest study examining this question, Cohen et $a l^{20}$ evaluated factors associated with cervical medial branch RFA outcomes in 92 patients from three treatment centers. They reported a $56 \%$ success rate in those who obtained $50-79 \%$ pain relief versus $58 \%$ in those who experienced $\geq 80 \%$ relief. In this study, $\geq 50 \%$ pain relief lasting at least 6 months post-treatment was defined as a positive outcome. Other studies that examined cervical medial branch RFA outcomes have also failed to find a difference in results broken down by cut-off threshold.

In a cross-sectional study evaluating the effect of pain relief cut-off thresholds following dual MBB, Burnham et a $1^{19}$ found no difference in symptom relief (defined both as $\geq 50 \%$ pain reduction and 2-point or greater decrease on a $0-10$ scale after RFA) between patients who had reported 80-99\% symptom relief and those who experienced $100 \%$ symptom relief with dual MBBs. Holz and Sehgal ${ }^{23}$ evaluated lumbar and cervical medial branch RFA outcomes in 112 patients stratified by the results of diagnostic blocks, with a positive block designated as at least $70 \%$ pain relief. The authors found no correlation between the amount of pain relief after MBB and RFA outcomes. They did not perform a subgroup analysis based on the area of treatment. In both of these studies, the cut-off thresholds were determined based on payer requirements.

In an observational study that followed 28 patients with chronic neck pain who received dual comparative blocks using $>50 \%$ pain relief as the cut-off threshold, Shin et $a l^{285}$ found no correlation between pain relief after prognostic blocks and cervical medial branch RFA outcomes at 6-, 9-, and 12-month follow-up. For the cervical MBB, patients were stratified based on $50 \%, 75 \%, 80 \%$, and $100 \%$ relief cut-off thresholds. For RFA, percent pain relief was measured as a continuum. Nineteen (68\%) patients experienced a positive RFA outcome ( $\geq 50 \%$ pain relief) at 6-month follow-up, with eight $(29 \%)$ achieving complete pain relief (table 17).

\section{Reasons for discordance}

Due to the distinct nature of MBB and RFA from a procedural standpoint, it should be acknowledged that pain relief is likely going to be greater for MBB than for RFA. In the cervical and lumbar spinal regions, respectively, Cohen $e t \mathrm{al}^{78}$ and Dreyfuss $e t$ $a l^{195}$ found that the injectate in MBB frequently spreads to other pain-generating structures such as muscles, spinal nerve roots, and adjacent facet joints, which is not the case for the smaller controlled lesions affected by RFA. MBBs will also invariably block the dorsal ramus and its other branches, thereby alleviating pain arising from paraspinal musculature. Pain relief after MBB is measured in hours so, unlike RFA outcomes which should endure for months, the placebo effect may extinguish in some people who undergo denervation. This would result in better short-term outcomes for facet blocks than long-term outcomes for neurotomy. However, it should be noted that the placebo effect is generally stronger for more invasive procedures (ie, it may be greater for RFA than facet blocks), may last for months, and be repeated with similar results. ${ }^{248} 249286$

\section{Non-pain measures}

Pain should always be evaluated in context, as a change in activity levels, anxiety, or analgesic usage can significantly affect pain intensity. In patients with chronic pain, improving function may be a more meaningful and realistic benchmark than pain relief, with several high-impact spinal intervention studies using disability as their primary endpoint. ${ }^{287} 288$ For relief of acute pain, many experts advocate using the utilization of rescue analgesic medications as an appropriate benchmark for success. ${ }^{289}$ There is also an increased interest in pain biomarkers that may help guide diagnosis and response to treatment; however, the research and application of this information is still in its infancy. ${ }^{290}$ In one study performed in the lumbar spine, Cohen et al ${ }^{291}$ found that 
Table 17 Cervical medial branch blocks or IA cut-off correlation with RFA outcomes

\begin{tabular}{|c|c|c|c|c|}
\hline Study & Patient population & Design & Results & Comments \\
\hline $\begin{array}{l}\text { Cohen et } \\
a / 2007^{20}\end{array}$ & $\begin{array}{l}92 \text { pts with chronic neck pain from three treatment } \\
\text { centers who underwent RFA after a positive } \\
\text { response to diagnostic cervical LA blocks. Positive } \\
\text { response was defined as } \geq 50 \% \text { pain relief lasting at } \\
\text { least } 6 \text { months }\end{array}$ & $\begin{array}{l}\text { Retrospective } \\
\text { study }\end{array}$ & $\begin{array}{l}56 \% \text { of pts who had at least } 50 \% \text { but less } \\
\text { than } 80 \% \text { relief from diagnostic blocks had a } \\
\text { successful RFA procedure compared with } 58 \% \\
\text { who experienced at least } 80 \% \text { relief from MBB }\end{array}$ & $\begin{array}{l}\text { Multicenter study using single blocks, } \\
\text { evaluating cervical facet RFA }\end{array}$ \\
\hline $\begin{array}{l}\text { Burnham } \\
\text { et al } \\
2020^{19}\end{array}$ & $\begin{array}{l}50 \text { pts who received } 80-99 \% \text { vs } 100 \% \text { pain relief } \\
\text { after dual cervical MBB }\end{array}$ & $\begin{array}{l}\text { Cross-sectional } \\
\text { cohort study }\end{array}$ & $\begin{array}{l}54 \% \text { of pts in both groups reported } \geq 50 \% \text { pain } \\
\text { reduction }\end{array}$ & $\begin{array}{l}87 \text { records were screened and } 50 \text { pts } \\
\text { were included in the study. Follow-up was } \\
\text { conducted by phone call at various time } \\
\text { intervals after } 6 \text { months }\end{array}$ \\
\hline $\begin{array}{l}\text { Holz and } \\
\text { Sehgal, } \\
2016^{23}\end{array}$ & $\begin{array}{l}112 \text { pts with positive analgesic response to dual } \\
\text { comparative MBB }\end{array}$ & $\begin{array}{l}\text { Retrospective } \\
\text { chart review }\end{array}$ & $\begin{array}{l}\text { Percent pain relief after RFA was } 48 \% \text {. Overall } \\
\text { analysis showed no correlation between } \\
\text { percent or duration of pain relief after MBB } \\
\text { and pain relief after RFA }\end{array}$ & $\begin{array}{l}28 \% \text { underwent cervical facet interventions. } \\
\text { Highest pain relief was in individuals who } \\
\text { achieved } 100 \% \text { pain relief lasting }>8 \text { hours } \\
\text { with lidocaine, suggesting a strong placebo } \\
\text { response }\end{array}$ \\
\hline $\begin{array}{l}\text { Shin et al } \\
2006^{285}\end{array}$ & $\begin{array}{l}28 \text { pts with positive analgesic response to dual } \\
\text { comparative MBB }\end{array}$ & Observational & $\begin{array}{l}\text { No correlation between categorical pain relief } \\
\text { on prognostic blocks }(25 \%, 50 \%, 75 \%, 80 \% \\
\text { and } 100 \%) \text { and pain relief after RFA }\end{array}$ & $\begin{array}{l}5 \text { pts had whiplash injury and } 1 \text { had } \\
\text { penetrating neck trauma. Did not target TON }\end{array}$ \\
\hline
\end{tabular}

IA, intra-articular; RFA, radiofrequency ablation; MBB, medial branch block; TON, third occipital nerve.

while a decrease in diastolic blood pressure after MBB was significantly associated with a higher RFA success rate, the low sensitivity and negative predictive value precluded its use as a solitary screening tool. In clinical practice, the parameters assessed in validated disability instruments (eg, sleep, driving, activities of daily living, travel) preclude their use during the brief 2-6 hour diagnostic window after cervical facet blocks. The same is true for analgesic consumption, as long-acting medications cannot be tapered over a short period and withholding opioids may precipitate hyperalgesia. Future studies should explore whether ultralong-acting formulations of LA (eg, liposomal delivery systems) provide better predictive value than plain LA.

\section{Clinical trials evaluating cervical medial branch RFA after whiplash}

This committee considered differences in patient populations with facet pain due to degenerative and arthritic changes as opposed to younger patients who may have facet pain secondary to an isolated mechanism of injury (ie, whiplash). Studies have found that the cervical facet joints are responsible for $25-65 \%$ of non-traumatic and 50-60\% of trauma-induced cases of chronic neck pain. ${ }^{622} 292$ Given the higher prevalence, there should theoretically be a lower false-positive block rate in individuals with whiplash and older patients with osteoarthritis.

There are no direct comparisons of facet block pain relief cutoff thresholds in whiplash patients, but an indirect comparison of RFA outcomes does not reveal any significant differences between using $50 \%,{ }^{20} 80 \%,{ }^{19}$ and $100 \%{ }^{68}$ pain relief cut-offs. Whereas the literature varies on recommendations for cut-offs in patients with whiplash-induced facet joint pain, a conjectural argument might be made for a higher cut-off given the lower likelihood of confounding pain generators, the higher risk for neuritis at upper cervical levels, ${ }^{293}$ and the younger age (ie, greater impairment from muscle denervation) compared with those with facet joint osteoarthritis.

\section{Recommendations}

Given the strong evidence that $<50 \%$ pain relief may be clinically meaningful and the absence of direct evidence that using higher MBB cut-off thresholds results in higher RFA success rates, this committee recommends that $\geq 50 \%$ reduction in pain be considered a positive prognostic block. There are theoretical underpinnings that in younger individuals ( $\leq 45$ years of age) with whiplash injuries who are having C2 -3 and or C3 -4 treated, higher cut-offs should be used. Although deductive reasoning indicates that greater pain relief with MBB should lead to greater pain relief after RFA, the literature on the cervical spine does not support this; grade $\mathrm{C}$ recommendation, low-to-moderate level of certainty. At present, non-pain measures such as activity level should not be used as the sole criterion to determine the success or failure of a prognostic block, but may be used in conjunction with pain assessment; grade $\mathrm{B}$ recommendation, moderate level of certainty.

\section{QUESTION 14: HOW MANY PROGNOSTIC BLOCKS SHOULD ONE PERFORM BEFORE RFA?}

The utility of screening blocks depends on numerous factors such as the positive and negative predictive value, the diagnostic validity, and the relative risks and costs compared with the definitive treatment. These factors are in turn contingent on myriad other variables such as patient selection (the predominant predictor of outcome), definitions (ie, threshold for a positive block, benchmark for measuring success), prevalence rate (ie, pre-test probability and false-positive rate), and technique (eg, large electrodes may increase the chance of nerve capture, lower block volumes increase specificity, and higher precision may reduce false-positive blocks). Screening tests have greater benefit when there is:

- High positive predictive value.

- A low prevalence rate for the index condition.

- High false-positive and low false-negative rates.

- The definitive procedure carries significant risks and costs compared with the screening test.

\section{Cervical versus lumbar spine}

The rationale for performing more than one diagnostic block is to reduce the false-positive rate and improve the success rate for medial branch RFA. In the cervical spine, the reported falsepositive rates for uncontrolled MBB range from 36\% to 55\% based on dual block paradigms, although rates approaching 50\% are unlikely to be accurate given the relative prevalence rate of $25-66 \%$ in individuals with axial neck pain (ie, the sum of true and false-positives, and true and false-negatives must equal $100 \%)^{12} 2226275$ In double-block studies, it is assumed that a 
negative second block means the first block was falsely positive, though an equally plausible interpretation in the cervical spine is that the second block was falsely negative. Among patients with pain following whiplash, one placebo-controlled trial that used three blocks reported a prevalence rate of $60 \%$, with $50 \%$ of patients with headache having a symptomatic C2-3 joint. ${ }^{12}$ The prevalence (true positive rate) of cervical facet joint pain among individuals with axial neck pain is higher than the prevalence of facet joint pain in patients with chronic LBP owing to greater mobility in the neck, a possibly higher density of nociceptors, and the increased relative size of the cervical facet joints to discs; this should theoretically translate to a lower false-positive rate. 2698239275277

The effectiveness of cervical medial branch RFA has been less studied than in the lumbar spine, but there is no evidence to suggest it is less effective. Retrospective and observational studies by the same authors evaluating cervical and lumbar facet outcomes have consistently reported slightly to moderately higher success rates in the neck than low back. ${ }^{20} 294-297$

Studies have also reported high success rates for cervical medial branch RFA without the use of prognostic blocks. In describing their results using a new posterior oblique approach for cervical facet RFA, van Eerd et $a l^{298}$ reported that $51 \%$ of 65 patients were much or very much improved at 2 months. A later doubleblind randomized trial performed in 76 patients with axial neck pain reported $\geq 50 \%$ success rates based on meaningful reduction in pain scores in both the RFA group (56\%) and the LA block-sham RFA group (51\%) at 6-month follow-up. ${ }^{28}$ Earlier, in a randomized trial by Stovner et $a l^{103}$ that failed to enroll their intended sample size, 12 patients were allocated to true and sham denervation of the medial branches innervating the C2-6 facet joints. Although patients underwent medial branch and occipital nerve blocks before treatment, the results were not used to select participants. At 3 months post-treatment, four of six in the treatment groups experienced clinically meaningful benefit versus two of six in the sham group, with the differences disappearing at later time points. The reasons why cervical facet joint RFA may be more effective than lumbar facet joint RFA include a higher population prevalence/lower rate of falsepositive blocks, increased ability to place electrodes parallel to the target nerve, less variability in nerve location, and possibly a lower co-prevalence rate of concomitant pathology.

\section{False-negative blocks}

The rationale for the lumbar facet guidelines to recommend single blocks was based in large part on the incidence of falsenegative blocks of the lumbar medial branch nerves, which were estimated to be $47 \%$ in a retrospective study by Derby et al ${ }^{299}$ using either $50 \%(46.7 \%)$ or $70 \%(47.1 \%)$ cut-off thresholds. In this study, among the eight patients with initial false-negative blocks who underwent lumbar medial branch RFA after a positive subsequent block, six (75\%) experienced a positive outcome. However, for reasons outlined above, the extrapolation of studies performed in the lumbar spine to the cervical spine has drawbacks. In an elegant controlled study by Lord et $a l^{189}$ in 50 patients with whiplash injury, the authors performed LA blocks with lidocaine, bupivacaine, and saline in random order. Based solely on the response to comparative LA blocks which required longer 'complete' or 'profound' relief with bupivacaine than lidocaine, 34 individuals would have been classified as negative. However, when the authors reclassified a positive response as reproducible relief with both active agents but no relief with placebo, 11 (32.4\%) were considered to be false-negative.
Finally, Cohen $e t a l^{78}$ performed low-volume $(\leq 0.5 \mathrm{~mL})$ cervical MBB under fluoroscopy, after which patients were sent for CT scans to assess accuracy. In six of 86 blocks the contrast was noted to miss the medial branches despite appropriate needle placement, for a potential false-negative rate of 7.0\% (table 18).

In clinical practice and to reduce the number of procedures patients must endure, multiple joints are typically blocked at the same time which can lead to the treatment of an inappropriate level(s) (eg, a positive response to C4-5 and C5-6 MBBs in a patient with only C5-6 pain) but is less likely to result in a false-negative response. Conversely, anesthetizing only a single joint at a time may place an unreasonable burden on patients and healthcare resources, and lead to patients withdrawing from treatment before painful joints are identified. The use of pain referral patterns and the elicitation of tenderness under fluoroscopic guidance have been used in clinical trials to select levels in patients with cervical facetogenic pain, ${ }^{78}$ but secondary hyperalgesia and overlap in referral patterns limit their utility as a reference standard.

\section{Studies comparing different numbers of blocks before RFA}

The lumbar facet guidelines recommended single blocks based on high false-negative rates for lumbar facet blocks, which was based predominantly on indirect comparisons of outcomes in studies using single or multiple blocks, and retrospective studies comparing outcomes stratified by the number of blocks. ${ }^{29}$ Whereas the former suggests that using multiple blocks increases the lumbar medial branch RFA success rate, retrospective studies comparing single versus double blocks before RFA have mostly shown no 300301 or small, non-statistically significant differences (63.2\% success rate with mean relief of $76.7 \%$ in 38 patients who underwent a single block vs $84.6 \%$ success rate with mean relief of $71.1 \%$ in 13 patients who underwent double blocks) ${ }^{274}$ in outcomes. In the only RCT evaluating the effect of the number of prognostic blocks on lumbar medial branch RFA outcomes in 151 patients with suspected lumbar facetogenic pain, Cohen et $a l^{302}$ found the highest overall success rate when proceeding straight to RFA without blocks, but the highest RFA success rate (ie, considering only those who proceeded to RFA) when double blocks were employed. This predictable outcome was attributed to the inclusion of all placebo responders in the 0-block group, and the exclusion of all potential false-negatives. In the costeffectiveness analysis, the 0 -block paradigm was associated with the lowest cost per successful treatment and also lowest overall costs. The RFA to MBB reimbursement ratio for most payers is comparable in the cervical and lumbar spine, enhancing generalizability. Similar to the comments on false-negative blocks, the extent to which studies performed in the lumbar spine can be generalized to the cervical spine is unclear.

\section{Dual blocks}

The lumbar facet guidelines acknowledge that enhancing selection rigor, including by requiring more positive blocks, would likely increase the success rate, although at the expense of withholding treatment from individuals who might potentially benefit from RFA. ${ }^{29}$ Although strong data are lacking and a higher prevalence rate (pre-block probability) of facet joint pain in the neck may attenuate this effect, this may also be the case for cervical medial branch RFA. MacVicar et $a l^{69}$ reported a $66 \%$ success rate, defined as $100 \%$ pain relief, in 104 patients using dual blocks to select patients for RFA, but also employed multiple lesions with 16-gauge electrodes and required complete pain relief during diagnostic blocks as a selection criterion. The 
Table 18 Studies evaluating the false-positive and false-negative rates of cervical MBBs

\begin{tabular}{|c|c|c|c|c|c|}
\hline Study & No of subjects & Methodology & Prevalence & $\begin{array}{l}\text { False-positive/ } \\
\text { negative rate }\end{array}$ & Comments \\
\hline Barnsley et al $1993^{188}$ & 55 pts (60 joints) & $\begin{array}{l}\text { Near-complete relief with lidocaine and } \\
\text { bupivacaine MBB, with the duration of relief } \\
\text { lasting longer with bupivacaine }\end{array}$ & $73 \%$ & $\begin{array}{l}\text { FP rate } 27 \% \text { ( } 2 \text { pts had relief } \\
\text { with only } 1 \text { block while } 14 \text { had } \\
\text { longer relief with lidocaine) }\end{array}$ & $\begin{array}{l}\text { All pts had at least one positive block } \\
\text { (no negatives). All pts had whiplash after } \\
\text { an MVC }\end{array}$ \\
\hline Barnsley et al $1993^{227}$ & $47 \mathrm{pts}$ & $\begin{array}{l}\text { Near-complete relief with lidocaine and } \\
\text { bupivacaine MBB, with the duration of relief } \\
\text { lasting longer with bupivacaine but not } \\
\text { longer than the expected duration ( } 7 \text { hours for } \\
\text { lidocaine, } 24 \text { for bupivacaine) }\end{array}$ & $57 \%$ & $\begin{array}{l}\text { FP rate } 40 \% \text { ( } 1 \text { of } 45 \text { pts had no } \\
\text { relief after second block while } \\
17 \text { had discordant or prolonged } \\
\text { relief) }\end{array}$ & $\begin{array}{l}\text { All pts had whiplash after an MVC. Only } 2 \\
\text { of } 47 \text { pts obtained insufficient relief from } \\
\text { initial block }\end{array}$ \\
\hline Barnsley et al $1995^{10}$ & 50 pts & $\begin{array}{l}\text { Near-complete relief with lidocaine and } \\
\text { bupivacaine MBB, with the duration of relief } \\
\text { lasting longer with bupivacaine }\end{array}$ & $54 \%$ & $\begin{array}{l}\text { FP rate } 26 \% \text { ( } 2 \text { of } 38 \text { had pain } \\
\text { relief with only } 1 \text { block while } 8 \\
\text { had longer relief with lidocaine) }\end{array}$ & $\begin{array}{l}\text { All pts had whiplash after an MVC. } 7 \text { pts } \\
\text { withdrew and } 5 \text { only completed one block }\end{array}$ \\
\hline Lord et al $1995^{189}$ & 50 pts & $\begin{array}{l}\text { Near-complete relief with lidocaine and } \\
\text { bupivacaine MBB, with the duration of relief } \\
\text { lasting longer with bupivacaine but not } \\
\text { longer than the expected duration ( } 7 \text { hours for } \\
\text { lidocaine, } 24 \text { for bupivacaine) and a negative } \\
\text { response to saline }\end{array}$ & $\begin{array}{l}26 \% \text { based on concordant } \\
\text { response to LA blocks and } \\
\text { negative response to saline }\end{array}$ & $\begin{array}{l}\text { FP rate } 19 \% \text { based on } \\
\text { concordant response to LA but } \\
\text { (+) response to saline. In placebo } \\
\text { negative responders, FP rate } \\
63 \% \text { based on discordant or } \\
\text { prolonged concordant response } \\
\text { to lidocaine and bupivacaine. } \\
\text { FN rate } 32 \% \text { based on positive } \\
\text { but discordant response to } \\
\text { lidocaine and bupivacaine but } \\
\text { negative response to saline }\end{array}$ & $\begin{array}{l}20 \text { pts responded to saline injections, } \\
\text { including } 3 \text { of } 14 \text { who had concordant } \\
\text { response to lidocaine and bupivacaine }\end{array}$ \\
\hline $\begin{array}{l}\text { Manchikanti et al } \\
2002^{418}\end{array}$ & $\begin{array}{l}120 \text { pts with axial } \\
\text { neck pain }\end{array}$ & $\begin{array}{l}\geq 80 \% \text { pain relief after MBB with lidocaine } \\
\text { followed by bupivacaine }\end{array}$ & $67 \%$ & $\begin{array}{l}\text { FP rate } 24 \% \text { based on initial } \\
\text { positive blocks }\end{array}$ & $\begin{array}{l}\text { Required at least } 2 \text { hours relief with } \\
\text { lidocaine and } 3 \text { hours with bupivacaine. } \\
\text { Mixed sarapin and steroids with LA. All } \\
\text { pts sedated }\end{array}$ \\
\hline $\begin{array}{l}\text { Manchikanti et al } \\
2002^{6}\end{array}$ & $\begin{array}{l}106 \text { pts with } \\
\text { neck pain with or } \\
\text { without arm pain }\end{array}$ & $\begin{array}{l}\geq 75 \% \text { pain relief after MBB with lidocaine } \\
\text { followed by bupivacaine }\end{array}$ & $60 \%$ & $\begin{array}{l}\text { FP rate } 21 \% \text { based on initial } \\
\text { positive blocks }\end{array}$ & $\begin{array}{l}\text { Required at least } 90 \text { min relief with } \\
\text { lidocaine and } 3 \text { hours with bupivacaine. } \\
\text { Some patients had radicular pain. All pts } \\
\text { sedated }\end{array}$ \\
\hline $\begin{array}{l}\text { Manchikanti et al } \\
2004^{419}\end{array}$ & $\begin{array}{l}255 \text { pts with neck } \\
\text { pain }\end{array}$ & $\begin{array}{l}\geq 80 \% \text { relief during painful movements after } \\
\text { MBB with lidocaine followed by bupivacaine }\end{array}$ & $55 \%$ & $\begin{array}{l}\text { FP rate } 34 \% \text { based on initial } \\
\text { positive blocks }\end{array}$ & $\begin{array}{l}\text { Required at least } 2 \text { hours relief with } \\
\text { lidocaine and } 3 \text { hours with bupivacaine. } \\
\text { All pts sedated }\end{array}$ \\
\hline $\begin{array}{l}\text { Manchikanti et al } \\
2008^{14}\end{array}$ & $\begin{array}{l}251 \text { pts with non- } \\
\text { radicular neck pain } \\
\text { with }(n=45) \text { and } \\
\text { without ( } n=206) \\
\text { prior surgery }\end{array}$ & $\begin{array}{l}\geq 80 \% \text { relief and ability to perform previously } \\
\text { painful movements after MBB with lidocaine } \\
\text { followed by bupivacaine }\end{array}$ & $\begin{array}{l}39 \% \text { in non-surgical and } 36 \% \text { in } \\
\text { post-surgical pts }\end{array}$ & $\begin{array}{l}\text { FP rate } 43 \% \text { in non-surgical } \\
\text { group, } 50 \% \text { in post-surgical } \\
\text { group }\end{array}$ & $\begin{array}{l}\text { Required at least } 2 \text { hours relief with } \\
\text { lidocaine and } 3 \text { hours with bupivacaine. } \\
\text { All pts sedated }\end{array}$ \\
\hline $\begin{array}{l}\text { Manchukonda et al } \\
2007^{416}\end{array}$ & $\begin{array}{l}251 \text { pts with non- } \\
\text { radicular neck pain }\end{array}$ & $\begin{array}{l}\geq 80 \% \text { relief and ability to perform previously } \\
\text { painful movements after MBB with lidocaine } \\
\text { followed by bupivacaine }\end{array}$ & $39 \%$ & FP rate $45 \%$ & $\begin{array}{l}\text { Retrospective study. Required at least } \\
2 \text { hours relief with lidocaine and } 3 \text { hours } \\
\text { with bupivacaine. Many had involvement } \\
\text { of other spinal regions. All pts sedated. } \\
\text { Results nearly identical to reference } 14\end{array}$ \\
\hline $\begin{array}{l}\text { Yin and Bogduk, } \\
2008^{420}\end{array}$ & $\begin{array}{l}84 \text { pts with non- } \\
\text { radicular neck pain }\end{array}$ & $\begin{array}{l}\text { Complete pain relief after MBB lasting longer } \\
\text { with bupivacaine than lidocaine. Those with } \\
\text { discordant relief had to have negative block } \\
\text { to placebo }\end{array}$ & $55 \%$ & FP rate $15 \%$ & Retrospective study \\
\hline $\begin{array}{l}\text { Speldewinde et al } \\
2001^{9}\end{array}$ & $\begin{array}{l}97 \text { pts with } \\
\text { disabling axial } \\
\text { neck pain }\end{array}$ & $\begin{array}{l}\text { Near-complete pain relief (post-block pain } \\
\text { score } \leq 1 / 10 \text { ) after MBB done with lidocaine } \\
\text { and bupivacaine }\end{array}$ & $\begin{array}{l}36 \% \text { based only on confirmatory } \\
\text { double blocks, } 55 \% \text { if } 18 \text { pts who } \\
\text { did not receive a confirmatory } \\
\text { block are included }\end{array}$ & $\begin{array}{l}\text { FP rate } 0 \% \text {, though } 18 \text { of the } 53 \\
\text { pts with a (+) initial block did } \\
\text { not return for a confirmatory } \\
\text { block }\end{array}$ & $\begin{array}{l}\text { Retrospective study. Most pts had post- } \\
\text { traumatic pain }\end{array}$ \\
\hline Cohen et a/ $2010^{78}$ & $\begin{array}{l}24 \text { pts with axial } \\
\text { neck pain }\end{array}$ & $\begin{array}{l}\geq 50 \% \text { pain relief lasting } \geq 3 \text { hours after a } \\
\text { single bupivacaine block. Pts underwent } C T \\
\text { after MBB }\end{array}$ & $38 \%$ & $\begin{array}{l}\text { FN rate } 7 \% \text { ( } 6 \text { of } 84 \text { blocks failed } \\
\text { to capture target nerve) }\end{array}$ & $\begin{array}{l}\text { Randomized trial evaluating effect of } \\
\text { block volume on outcomes ( } 0.25 \text { vs } \\
0.5 \mathrm{~mL} \text { ), with lower volumes found to be } \\
\text { more specific }\end{array}$ \\
\hline
\end{tabular}

CT, computed tomography; FN, false-negative; FP, false-positive; LA, local anesthetic; MBB, medial branch blocks; MVC, motor vehicle collision; pts, patients.

authors did not note how many patients were screened, but in a similar study using nearly identical selection criteria performed in the lumbar spine in which 106 patients were treated, the same authors estimated that 575 were evaluated for treatment. ${ }^{303}$ In a randomized placebo-controlled trial evaluating cervical medial branch RFA in 24 whiplash patients, Lord et $a l^{68}$ reported $\geq 3$ months pain relief in seven of 12 RFA patients, with the median duration of pain relief being 263 days. They defined success as complete relief of their index neck pain, although some patients continued to have headache. In addition to performing three diagnostic blocks including one with saline, the authors required $100 \%$ pain relief during the diagnostic blocks and created multiple lesions per level. They screened 54 patients to obtain their enrollment numbers. Although these results suggest that multiple blocks may result in higher RFA success rates, these studies also employed more stringent diagnostic criteria and rigorous treatment parameters, making it difficult to separate out the effect of the dual blocks.

\section{Other randomized studies evaluating the utility of prognostic blocks}

In a randomized trial performed in 54 patients with knee osteoarthritis comparing genicular nerve RFA outcomes based on 0-blocks (ie, moving straight to RFA) to proceeding to RFA only after a positive prognostic block, McCormick et $a l^{304}$ found no significant difference between the groups (64\% success rate in the 0-block group vs $59 \%$ in the single-block group). Extrapolation of this finding to the cervical spine is limited by the differences in anatomy (including the multiple nerves providing 
nociceptive innervation to the knee joint) and that the diagnosis of knee osteoarthritis does not require diagnostic blocks, or even $\mathrm{x}$-rays.

\section{Third occipital nerve (TON) blocks}

Most, ${ }^{19} 20149305$ but not all studies ${ }^{68}$ evaluating cervical medial branch RFA have included the TON, so it is challenging to evaluate the evidence behind targeting the TON by itself. The pain referral pattern for TON also overlaps with that for upper cervical facet joints, making it difficult to distinguish the effect of TON RFA from that of the C3-4 and C4-5 joints in studies that evaluated multi-level RFA. ${ }^{51}$ In a retrospective study evaluating the effects of $\mathrm{C} 2$ dorsal root ganglion and/or TON RFA in 40 patients with refractory cervicogenic headache based on a single diagnostic block requiring at least $50 \%$ pain relief, $70 \%$ of patients reported at least $80 \%$ pain relief lasting a mean duration of 22.4 weeks. ${ }^{306}$ The results were not stratified by type of RFA, but bilateral TON-only and left-sided TON-only accounted for $17 \%$ of cases. In an observational study by Govind et $a l^{307}$ using comparative LA blocks to treat third occipital headache, 49 out of 120 patients responded positively and underwent RFA. Among these, $88 \%$ obtained a positive outcome, lasting a mean duration of 297 days.

\section{Predictive modeling}

The NIH Federal Pain Research Strategy designated identifying individuals likely to respond (or fare poorly) to treatment as a major priority, which may facilitate a precision or personalized medicine approach. ${ }^{308}$ In theory, this might include considering the results of genetic testing in the future, clinical findings, and environmental and cultural considerations. In practice, this might entail tailoring the approach based on radiological imaging if available, physical examination findings, pre-test probability (eg, a younger person with non-traumatic pain in whom the false-positive rate of a single block might be higher than in an elderly patient with osteoarthritis and paraspinal tenderness), the results of an initial block (ie, considering dual blocks in an individual with a borderline positive block) and unique patient circumstances (eg, needle aversion or the need for sedation, travel difficulties, concomitant anticoagulant therapy in high-risk individuals).

\section{Recommendations}

To maximize access to care, we recommend a single block before cervical medial branch RFA. We acknowledge that using dual blocks may increase the RFA success rate, but the evidence is clear that using double blocks will result in a significant proportion of false-negative procedures and a decreased overall success rate; grade $\mathrm{B}$ recommendation, low-to-moderate level of certainty.

\section{QUESTION 15: SHOULD ELECTRODES BE POSITIONED IN A CERTAIN ORIENTATION OR LOCATION AND, IF SO, WHAT IS THAT ORIENTATION? DOES THE ORIENTATION DIFFER WITH PRIOR SURGERY?}

There is no primary peer-reviewed evidence directly comparing electrode location or orientation for the technical performance of cervical medial branch RFA, with the only direct comparative information coming from a non-peer-reviewed abstract. ${ }^{309}$ In this retrospective study that examined the medical records of 82 patients, individuals who received a lateral (ie, perpendicular) approach experienced greater pain reduction at 6 months and 1 year than those who underwent RFA via a posterior (ie, parallel) approach.
Conceptually, it stands to reason that treatment is unlikely to be successful beyond a placebo effect if the target nerve is not captured by the lesion. There is an increased likelihood of ablating targeted nerves with larger lesions created along the known course of the nerves. Evidence can be gleaned regarding optimal electrode location and orientation by considering the anatomy of the cervical medial branches and TON (figure 3), and the physics of lesions created using traditional monopolar RF electrodes. As a corollary, the existing body of evidence on the effectiveness and efficacy of cervical medial branch RFA may also be used to address this question.

\section{Anatomy}

The anatomy of the cervical medial branches of the dorsal rami was first described in detail by Bogduk in $1982 .{ }^{200}$ This seminal work remains one of the best descriptions of the relevant anatomy to cervical medial branch RFA. In general, the cervical medial branches course around the ipsilateral articular pillars along the anterolateral, lateral, and posterolateral portions of the pillar. ${ }^{200}$ Using C5 as the reference, the general archetypal relationship between the nerve and bone consists of the nerve running transversely across the centroid of the articular pillar from a lateral view, and running in a cephalad to caudad direction at roughly the same angle as the facet joint itself. From a posterior anterior view, the medial branch courses just lateral to the concavity of the articular pillar. Slight variations exist at each segment, with the nerve location being slightly higher on their respective articular pillars at levels distal to $\mathrm{C} 5$. This results in the $\mathrm{C} 7$ medial branch nerve being located along the superior portion of the articular process itself, and the deep C3 medial branch being located so high along the $\mathrm{C} 3$ articular pillar that at times it may cross the lower portion of the $\mathrm{C} 2-3$ joint line itself. $^{200}$

The innervation of the $\mathrm{C} 2-3$ joint differs in that it is innervated exclusively in most people by the TON. The location of this nerve is more variable than the locations of other cervical medial branches. The TON crosses the C2-3 joint anywhere from the apex of the $\mathrm{C} 3$ superior articular process to opposite the bottom of the $\mathrm{C} 2-3$ intervertebral foramen. This difference in anatomy must be accounted for when lesioning the TON.

\section{Physics}

Using a traditional monopolar electrode, coagulation occurs primarily in a radial direction perpendicular to the long axis of the electrode so that the lesion generated is prolate spheroid in shape. ${ }^{310}$ The lesion extends minimally beyond the tip of the electrode. With a $10 \mathrm{~mm}$ active tip, the lesion is just longer than $10 \mathrm{~mm}$ in a longitudinal section, and slightly wider than the width (gauge) of the cannula in a transverse plane. ${ }^{310}$

Based on the known anatomy of the cervical medial branches and lesion shape created by a conventional unipolar RF electrode, using a posterior-to-anterior approach or a posterior oblique approach seems most likely to result in the active tip of the electrode being situated somewhere along the course of the nerve and generating a lesion that captures the medial branch (figure 4). This may be optimized by placing the electrodes in a plane parallel to the posteroanterior orientation of the articular pillar (ie, a posterior approach) in a trajectory that transects the nerves, or by creating multiple lesions in an orientation nearparallel to the target nerve(s). When choosing a posterior oblique approach, placing the cannula at the anterior aspect of the facet column has been recommended. ${ }^{203} 311$ No anatomic, physical, 


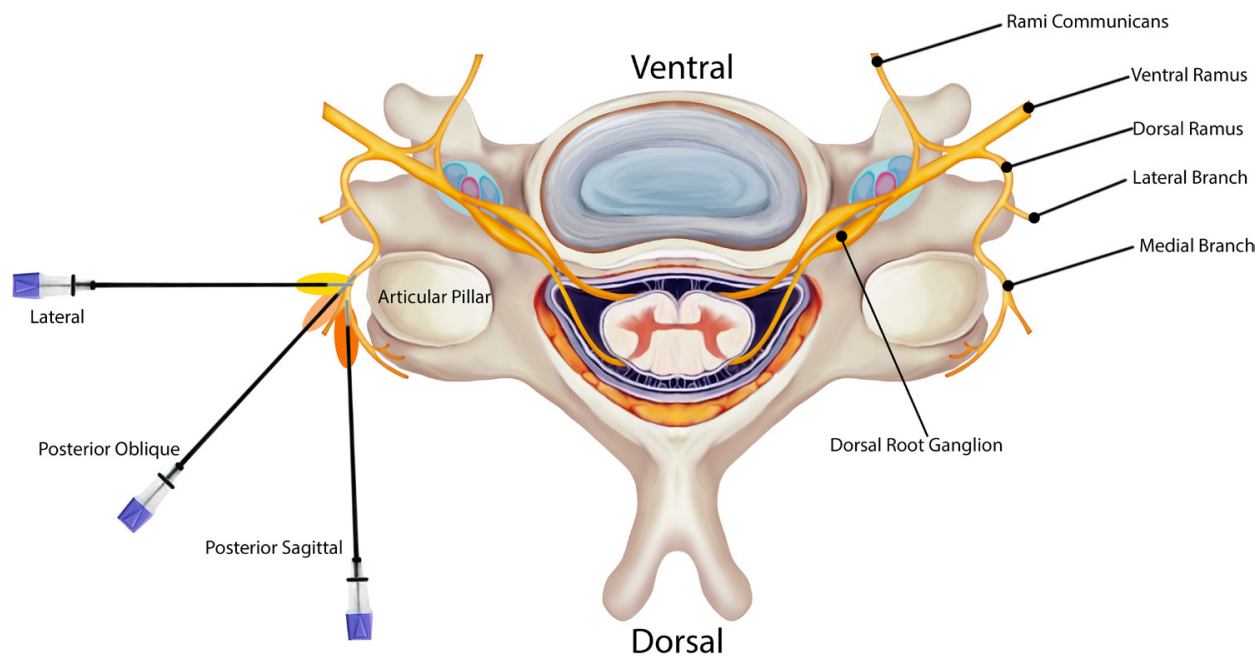

Figure 4 Axial view of the cervical spine demonstrating different cannula orientations.

or conceptual evidence supports the idea that placing an electrode in a plane perpendicular to the articular pillar (ie, using a lateral approach) will result in an equal or greater likelihood of a technically successful nerve ablation. For the TON, which innervates the C2-3 joint, the variable location of the nerve relative to other cervical medial branches suggests that multiple lesions that extend from the bottom of the $\mathrm{C} 2-3$ foramen to the apex of the C3 superior articular process may be required to reliably capture the nerve.

\section{Efficacy and effectiveness literature}

One of the most recent comprehensive systematic reviews of cervical medial branch RFA included both comparative and cohort studies. ${ }^{21}$ There were no exclusion criteria pertinent to electrode orientation, although four studies were excluded since the technique was deemed outdated and inconsistent with current practice. Twenty-one manuscripts were considered, all of which used some variation of parallel electrode placement. ${ }^{21}$ One randomized sham-controlled study demonstrating the efficacy of cervical medial branch RFA for the treatment of neck pain described a rigorous technique including both a posterior pass and an posterior oblique pass of the electrode. ${ }^{68}$ Two other sham-controlled trials that yielded equivocal results (ie, some benefit favoring RFA but failure to meet the primary endpoint) described posterior oblique approaches. ${ }^{28103}$ No published peer-reviewed studies supporting the use of cervical medial branch RFA for the treatment of neck pain have described using a perpendicular approach. As noted above, a single non-peer-reviewed abstract retrospectively comparing the perpendicular versus parallel approach in 82 patients concluded that "a statistically significant interaction between RFA treatment and post-procedural time indicated that the lateral RFA group experienced higher pain reduction at 6 months and 12 months $(p=0.004)$, while the differences in mean percent pain reduction were not statistically significant at 1 and 3 months $(p=0.05$ and 0.06 , respectively)". ${ }^{309}$ No actual data were reported, including the type of electrode used, the magnitude of relief, or the responder rate.

Literature specific to RFA of the TON is much less robust. This may be in part due to early findings that outcomes when targeting the C2-3 joint were inferior compared with RFA targeting other cervical facet joints, suggesting that technical advances were necessary to reliably lesion the TON. ${ }^{312}$ A 2003 study recommended a new technique using a parallel approach that created three successive lesions with the electrodes positioned no further than two electrode diameters apart. ${ }^{307}$ This accounted for the greater variability in the location of the TON, with outcomes mirroring the success rates of RFA applied to other cervical levels. This has since been replicated in other studies. ${ }^{306}$ There are no studies reporting RFA outcomes targeting the TON using a perpendicular approach.

\section{Performing RFA at operated levels}

There are no clear-cut indications for cervical medial branch RFA at the level of a fused cervical segment, which is a common treatment for a painful diarthrodial synovial joint. Outside of the presence of non-union, pseudoarthrosis, or hardware failure, it is less likely that a cervical facet joint is the predominant pain generator at a fused segment than a non-fused segment. Therefore, other causes of axial pain (eg, myofascial) must be ruled out. When performing plating or fusion of the articular pillars, some surgeons purposefully or inadvertently sever the medial branches. However, spondylotic disease and facet arthropathy may occur at increased rates at levels adjacent to fused cervical segments, which is a phenomenon known as adjacent segment disease. ${ }^{313}$ A cadaveric study performed in the lumbar spine found that fixation resulted in reduced facet joint capsular strain at the level of fixation, but increased strain at adjacent levels. ${ }^{314}$ In the cervical spine, another cadaveric study found increased facet joint forces at the treated level after arthroplasty during extension, and decreased forces at fused levels but increased forces at adjacent segments following arthrodesis. ${ }^{70}$

Several studies have examined facet block and RFA outcomes in patients who have previously undergone cervical spine fusion. Manchikanti et al ${ }^{14}$ performed double blocks in 251 patients with chronic neck pain, 45 of whom underwent prior surgery. They found no significant differences in prevalence rates between the surgical and non-surgical cohorts. However, the authors did not note whether the cervical MBB was performed at the operated or non-operated levels. Lang and Buchfelder ${ }^{315}$ reported a mean 176 days of pain relief (return to $50 \%$ of baseline) in 21 patients with cervicogenic headache who underwent C2-3 or C3-4 cervical facet RFA after pseudoarthrosis. A study by Cohen $e t a l^{20}$ reported a 59\% success rate in 29 patients who underwent cervical medial branch RFA after fusion, which was not significantly different from RFA outcomes in surgically-naïve patients. The authors in this study also failed to note whether 
the procedures were performed at the operated levels. Finally, a study by Klessinger $e t ~ a l^{313}$ evaluating cervical medial branch RFA outcomes in post-surgical patients reported a 59\% success rate, with no differences stratified by the type of operation (disc replacement, cage placement, surgical plate). Although statistical analysis was not performed, the outcomes did not appear to be different when RFA was performed on operated levels versus adjacent or non-operated levels.

When performing RFA at operated levels, it is important to avoid placing the electrode in contact with hardware because of theoretical concerns for heat injuries. Yet, no study to date has reported such an injury. ${ }^{20} 313315316$ Because hardware for anterior discectomy and cervical fusion is placed in areas distant to the site of cervical medial branch RFA, the presence of hardware should not influence the approach used. For hardware that involves the articular pillars, cervical medial branch RFA should either be avoided or, in cases of non-union, a modified (eg, posterior oblique or lateral) approach performed under CT may be necessary.

\section{Safety}

Different safety considerations exist for a posterior (parallel) and lateral (perpendicular) approach, both of which can be mitigated by meticulous use of fluoroscopy in multiple views. With a posterior approach, care must be made to avoid placing the electrode too anteriorly and risk violating the vertebral artery or cervical nerve root. With a lateral approach, care must be made to avoid advancing the electrode too medially into the spinal canal itself.

\section{Recommendations}

Current available basic science and outcome literature suggests a near-parallel (posterior or slight posterior oblique) approach should be used when performing cervical medial branch RFA for all cervical segments. This recommendation includes both anterior operations and non-operated spines but does not apply to the adaptation of other electrode technology, such as cooled RF; grade B recommendation, low-to-moderate level of certainty. For surgeries involving the articular pillars, a modified approach (posterior oblique with greater angulation or lateral) using advanced imaging may be necessary, with multiple lesions created if necessary; grade C recommendation, low level of certainty.

\section{QUESTION 16: SHOULD SENSORY AND/OR MOTOR STIMULATION BE PERFORMED BEFORE RFA?}

In addition to properly identifying patients whose pain is likely mediated via the medial branches, the RF cannula needs to be in close enough proximity to the intended target to adequately coagulate the medial branches. Care should also be made to avoid complications from lesioning the ventral ramus, spinal nerves, or other unintended structures. Although appropriate needle placement for the intended anatomic target can be achieved based on fluoroscopic landmarks, physiologic feedback via sensory and motor stimulation can provide additional input guiding optimal needle placement in the presence of advanced degenerative changes that limit visualization of fluoroscopic landmarks, and anatomic variations in the locations of non-medial branch and medial branch nerves, and/or multiple articular branches emanating from each nerve. ${ }^{200} 203317318$

\section{Rationale for sensory stimulation and evidence}

Sensory stimulation is typically achieved at a frequency of $50 \mathrm{~Hz}$ with an accepted threshold of $\leq 0.5 \mathrm{~V}^{2099311}$ When performing the stimulation, the patient is asked to inform the treating physician if they feel paresthesia (eg, tingling, buzzing, vibration, pain) and to identify the location of the sensory change to ensure concordance with established axial referral patterns. ${ }^{1377}$ In one study, Marks found that pain evoked from medial branch stimulation often extended distal to generally recognized facet referral patterns as outlined by other means. ${ }^{319}$

Ideally, the sensory threshold can be used to determine optimal RF cannula placement whereby the placement of the cannula can be adjusted in all three dimensions (anterior-posterior, cephalad-caudal, and medial-lateral) to achieve the relative lowest stimulation threshold. Local muscle stimulation and a perpendicular approach can ostensibly lead to adequate sensory stimulation (threshold $\leq 0.5 \mathrm{~V}$ ) but result in a situation where the subsequent lesion is insufficient for complete coagulation of the nerve and relief of pain.

There are scant data on the relationship between sensory stimulation threshold and the distance to a nerve, although there is clearly a direct, but imperfect, correlation. In rodent and computer simulation studies, nerve activation with anodic stimulation at 0.5 milliamperes occurs at a distance of around $4 \mathrm{~mm}$, while cathodic stimulation at 0.5 milliamperes can activate nerves at a distance of $7 \mathrm{~mm} .{ }^{320} 321$ For regional anesthesia nerve blocks, the elicitation of a motor response at or below 0.5 milliamperes is considered to be a common aim for successful neural blockade. ${ }^{322}$

Only one study has examined the correlation between medial branch RFA outcomes in humans. In a prospective study performed in 61 individuals who underwent lumbar medial branch RFA with light sedation after a positive diagnostic block, Cohen $e t a l^{323}$ found no significant correlation between the average absolute sensory threshold and treatment results. However, for each patient sensory testing was used to optimize cannula placement so the lack of correlation between the average sensory thresholds and treatment outcomes could be related to other factors (eg, sedation, baseline analgesics, comorbidities, age, and genetics) that affect sensory perception. Compared with light sedation (ie, the patient is relaxed but responsive to verbal stimuli), deep sedation could preclude the utility or even use of sensory stimulation to guide RF cannula placement. Sensory stimulation may be particularly important in the upper cervical levels (eg, TON, C3 medial branch, and C4 medial branch) wherein motor stimulation does not always result in discernable distal muscle contraction as seen in lower cervical levels where the spinal nerves innervate the arm. ${ }^{324}$

\section{Rationale for motor stimulation and evidence}

Motor stimulation is typically performed at $2 \mathrm{~Hz}^{20} 99311$ The presence of multifidus or other paraspinal muscle stimulation can be a marker of proper cannula placement. ${ }^{325}$ In a small study performed in the lumbar spine, when multifidus stimulation was used without sensory stimulation, a success rate of $87 \%$ was observed at 12 months post lumbar medial branch RFA. ${ }^{325}$ In a retrospective review of 68 patients by Koh et $a l^{326}$ patients who underwent lumbar medial branch RFA were stratified into three groups: complete twitching (paravertebral muscle contraction at all stimulated levels), partial twitching (paravertebral muscle contraction at one or two levels), and no twitching (no paravertebral contraction observed at any level). At 6 months, the proportion of successful procedures was statistically greater in the group with paravertebral muscle contraction at all stimulated levels compared with the group where no paravertebral muscle contraction was observed at any level. The mean duration of benefit was 4.6, 5.8, and 7.0 months for the 'no-twitch', 
'partial twitch', and 'complete twitch' groups, respectively. ${ }^{326}$ In a small observational study by Dreyfuss et $a l^{327}$ all patients treated with unilateral lumbar medial branch RFA had multifidus denervation observed on EMG 6 weeks following denervation and were noted to have sustained pain relief at 12 months, with no discernable segmental multifidus atrophy noted on MRI in long-term follow-up.

\section{Enhanced safety}

Eliciting multifidus and other paraspinal muscle contraction may provide false confidence in cannula placement when the motor nerve that is being stimulated does not innervate the facet joint (eg, cases of aberrant non-medial branch innervation, stimulation of other branches of the dorsal ramus). To enhance safety, practitioners typically increase the voltage to three times the sensory stimulation threshold $(1.5-2.0 \mathrm{~V})$ during motor testing. ${ }^{328}$ However, this threshold is based on typical sensory thresholds and anatomic relationships in the lumbar spine, ${ }^{329}$ which differ in the cervical spine. ${ }^{203}$ One case report described a patient who suffered L5 sensory radiculopathy following L3-5 dorsal ramus denervation when motor testing was not conducted above $1 \mathrm{~V}^{330}$ Following motor stimulation, if no muscle contraction in the appropriate myotomal distribution is identified, most practitioners believe it is safe to proceed. Some RF systems also require the electrode to be removed during LA administration which can lead to inadvertent needle movement. With these older systems, best practices would entail obtaining comparative images before and after anesthetic injection to ensure that no movement of the RF cannula has occurred. Many newer RF systems contain a separate port to allow for LA injection without significant manipulation of the cannula.

\section{C2-3 facet radiofrequency denervation}

Many of the initial studies investigating the efficacy of medial branch RFA did not use motor or sensory stimulation to help guide RF cannula placement, but rather created multiple (eg, 3-6) empirical lesions per level based on anatomic landmarks using fluoroscopic imaging. ${ }^{62} 211312$ Due to the high failure rate and ataxia observed in the pilot study, the C2-3 level was omitted from the incipient randomized double-blind placebo-controlled trial that demonstrated the efficacy of cervical RFA for the treatment of whiplash-induced neck pain. ${ }^{68}$ Subsequent studies with a revised technique and/or use of sensorimotor stimulation for TON RF neurotomy have demonstrated more sustained and reproducible responses along with fewer and more tolerable side effects after C2-3 facet denervation. ${ }^{2069} 101307$ One case of dropped head syndrome has been reported after denervation of the left $\mathrm{C} 2-4$ facet joints when motor stimulation was not performed. ${ }^{244}$ When sensorimotor testing was used with TON RFA in a retrospective review by Gazelka et $a l^{293}$ the reported rate of RFA-induced third occipital neuralgia was 19\%, which favorably compared with a prior report of Govind et $a l^{307}$ that found a 55\%

\begin{tabular}{lll}
\hline Table 19 & \multicolumn{2}{l}{ Cervical medial branch diameters } \\
& $\begin{array}{l}\text { Mean } \pm \text { SD diameter } \\
(\mathrm{mm})\end{array}$ & $\begin{array}{l}\text { Mean } \pm \text { SD } \\
\text { diameter }(\mathrm{mm}) \dagger\end{array}$ \\
\hline Medial branch & $1.5 \pm 0.4$ & \\
\hline C3 superficial medial branch (TON) & $0.5 \pm 0.2$ & $1.2 \pm 0.3$ \\
\hline C3 deep medial branch & $0.9 \pm 0.3$ & $1.2 \pm 0.3$ \\
\hline C4 medial branch & $0.9 \pm 0.3$ & $1.0 \pm 0.2$ \\
\hline C5 medial branch & $0.7 \pm 0.1$ & $1.0 \pm 0.3$ \\
\hline C6 medial branch & $0.6 \pm 0.2$ & \\
\hline C7 medial branch & & \\
\hline *Adopted from Lord et al. ${ }^{202}$ & & \\
†Adopted from Kweon et al. ${ }^{203}$ & & \\
\hline
\end{tabular}

rate of dysesthesia and 15\% rate of hypersensitivity when needles were placed solely by anatomic landmarks. When motor testing is used for levels above C5, one should look for contractions in muscles other than the arm to confirm the electrode is a safe distance from the spinal nerve or ventral ramus (eg, trapezius, sternocleidomastoid, scalenes, shoulder, diaphragm).

\section{Recommendations}

We recommend strong consideration of the use of sensory stimulation when single lesions are anticipated and/or with $\mathrm{C} 2-3$ facet denervation; grade $\mathrm{C}$ recommendation, low level of certainty. When multiple lesions are planned, the evidence for sensory stimulation is inconclusive; grade I recommendation. For motor stimulation, we find that it may be beneficial for both safety and effectiveness purposes; grade B recommendation, low-to-moderate level of certainty.

\section{QUESTION 17: IS THERE EVIDENCE FOR LARGER LESIONS TO IMPROVE OUTCOME MEASURES FOR RFA? IF SO, HOW CAN LESION SIZE BE INCREASED?}

\section{Anatomic considerations and challenges}

Multiple anatomic constraints and challenges provide a logical basis for modulating lesion size when targeting the cervical medial branches including the TON. The cervical medial branches are small and associated with variable anatomy. ${ }^{150} 200202203$ First, all the cervical medial branches except for the TON (ie, C3 superficial medial branch) have mean diameters $\leq 1 \mathrm{~mm}$ (table 19) and are often displaced from the bone approximately $1-2 \mathrm{~mm}$ by areolar tissue. ${ }^{18} 200202$ Second, the cervical medial branches have variable courses relative to bony anatomic targets. ${ }^{200} 202$ Specifically, the C3, C6, and C7 medial branches exhibit significant anatomic variation. The C5 medial branch position has a more consistent relationship and typically courses transversely across the center of the articular pillar. The C3, C4, and C6 medial branches are typically located higher on the respective articular pillar. Third, the cervical dorsal rami at C4, C5, and C6 often give off two medial branches. In one anatomic analysis performed in 20 cervical cadaver specimens, two cervical medial branches were found $27 \%, 15 \%$, and $2 \%$ of the time at the $\mathrm{C} 4$, C5, and C6 dorsal rami, respectively. ${ }^{203}$ Fourth, the articular pillar size and the proximity of the cervical nerve root at each level impose careful safety considerations when contemplating lesion size modification. ${ }^{200} 331-333$

Specifically for the TON, a high technical failure rate was noted when using small-gauge electrodes, with an early return of pain. ${ }^{312}$ When larger gauge electrodes were employed, an $88 \%$ initial success rate was documented with a median duration of complete pain relief in patients with a successful outcome of 297 days. $^{307}$ The TON has the largest mean diameter (table 19). A single application of thermal RFA with a small-gauge cannula creating a commensurately small lesion may therefore inadequately coagulate the nerve.

\section{Technical limitations and challenges}

In addition to the anatomic challenges associated with cervical medial branch RFA, technical challenges exist. The clinical cervical medial branch RFA data to date have examined the use of traditional thermal ablation; therefore, this question will limit discussion of RFA with internally-cooled electrodes. Thermal RFA involves a high-frequency alternating current that flows from the uninsulated active tip of the cannula/electrode apparatus into the tissue, causing ionic agitation. ${ }^{334}$ The ionic agitation then results in tissue frictional heating adjacent to the 
cannula and the tissue becomes the primary heat source. Three main factors determine tissue heat generation: the distance from the active tip, RFA current intensity, and duration of RFA application. ${ }^{335}$ Furthermore, the tissue including the bone-muscle interface and the fluid environment surrounding the RFA zone modulate lesion size. ${ }^{335-341}$

The lesion sizes associated with traditional thermal temperature-controlled RFA set-ups are small and therefore necessitate cannula placement extremely close or directly on top of the medial branch to ensure the created coagulation zone encompasses the full thickness of the targeted nerve. ${ }^{310}$ Although ex vivo studies examining RFA lesion dimensions can underestimate size, they do provide insight into lesion development. ${ }^{340} 342$ Traditional thermal RFA lesions develop horizontally with minimal ablation occurring distal to the tip. 310335343 When examining small-gauge cannulae (eg, 22-gauge) with small active tips $(\leq 5 \mathrm{~mm})$, lesion size is limited and the minimum diameter may be $\leq 1 \mathrm{~mm} .{ }^{18}$ Previous ex vivo work with 22-gauge $4 \mathrm{~mm}$ active tip cannulae with a set temperature of $90-95^{\circ} \mathrm{C}$ without pre-injected fluid demonstrated a maximal radius of $1.6 \pm 0.25 \mathrm{~mm} .{ }^{310}$ Ex vivo work using 18 -gauge $10 \mathrm{~mm}$ active tip cannulae with settings of $80^{\circ} \mathrm{C}$ for $90 \mathrm{~s}$ without pre-injected fluid resulted in the following measurements: a maximal radius, not including the shaft of the cannula, of $1.6 \pm 0.6 \mathrm{~mm}$, a horizontal diameter of $4.0 \pm 0.8 \mathrm{~mm}$, and a distal radius from the tip of $0.1 \pm 0.3 \mathrm{~mm} .{ }^{344}$ An in vivo study using histological measurements with 18-gauge $10 \mathrm{~mm}$ active tips with lesion times of $120 \mathrm{~s}$ demonstrated the following measurements: an effective radius of $5.4 \mathrm{~mm}(95 \%$ CI 5.0 to $5.7 \mathrm{~mm})$ and width of $10.7 \mathrm{~mm}(95 \% \mathrm{CI}$ 9.9 to $11.6 \mathrm{~mm}$ ). Furthermore, when performed for only $90 \mathrm{~s}$, thermal RFA lesions display significant size variability. ${ }^{339}$ The lesion size limitations and variability associated with smallgauge cannulae and active tips require the need for precise placement to ensure capturing the target nerve. Unfortunately, medial branches cannot be visualized under fluoroscopy; therefore, exact placement is not possible. Previous RCTs examining cervical medial branch RFA using a cannula with small active tips have often required multiple ablations (eg, 2-6 ablations) at each target level with two approaches (ie, posterior and posterior oblique) to overcome these limitations. ${ }^{68} 103$

\section{Neuropathological correlation: RFA physiological and functional responses}

In addition to limiting technical failures, increasing the energy delivered and hence lesion size may result in physiological and functional responses advantageous to prolonging pain relief with RFA. $^{345}$ Thermal RFA affects both myelinated and unmyelinated fibers and results in a third-degree peripheral nerve injury with extensive Wallerian degeneration. ${ }^{346-348}$ In a third-degree peripheral nerve injury, the myelin, axon, and endoneurium are disrupted while the fascicular arrangement, epineurium, and perineurium are maintained. ${ }^{348}$ Following thermal RFA, nerve regeneration may be initiated as early as $30 \mathrm{~min}$ post-lesion creation through three mechanisms: remyelination, collateral sprouting from preserved axons, and regeneration.

Recently, preclinical work suggests that RFA technology, lesion size, and energy deposited may result in different structural and functional changes in peripheral nerves. A preclinical study comparing internally-cooled electrodes versus traditional RFA demonstrated that the bigger lesions associated with greater energy delivery generated from internally-cooled electrodes resulted in larger areas of thermal damage, with edematous/ inflammatory zones persisting longer. ${ }^{345}$ In addition, there was greater attenuation with an extended loss of nerve function when assessed by EMG with internally-cooled electrodes. Future research is needed to determine if the greater interruption in axons and electrical conduction with internally-cooled electrodes is specific to the technology or solely dependent on the amount of energy delivered during RFA application. The addition of hypertonic saline to traditional thermal RFA also significantly increases peak power and total energy delivered during RFA. ${ }^{337}$

\section{Methods to enhance lesion size}

Multiple methods exist to increase lesion size (ie, length and width) with traditional thermal RFA. The primary methods include adjustments in active tip length, cannula size, temperature, and time settings. ${ }^{208} 339$ For example, increasing the cannula diameter from a 22-gauge to a 16-gauge increases average lesion width by $58-65 \%(3-4 \mathrm{~mm})$ with an RFA setting of $80^{\circ} \mathrm{C}$ for $2 \mathrm{~min}$. When temperature is increased from $60^{\circ} \mathrm{C}$ to $90^{\circ} \mathrm{C}$ for $2 \mathrm{~min}$, lesion width increases by $108-152 \% .{ }^{208}$ Lesion growth occurs most prominently during the initial portion of the lesion cycle, with approximately $40 \%$ of the mean maximum surface area occurring once the set temperature is achieved and $87 \%$ of the maximal lesion surface area occurring by $90 \mathrm{~s}$ after the set temperature is reached. ${ }^{339}$ However, extending lesion time beyond $90 \mathrm{~s}$ is still advantageous because of a further increase in lesion size in many patients and a reduction in lesion variability. ${ }^{208} 339$ Extending lesion time should particularly be considered when only one lesion cycle is being performed. Other methods to increase lesion size include modification of the local tissue environment through fluid pre-injection (ie, saline pre-injection) and the use of bipolar or internally-cooled electrodes. ${ }^{336-339} 344349$ However, caution is advised and future research focused on safety is warranted before routine deployment of these modalities in the cervical spine.

\section{Risk mitigation}

The creation of larger lesions with greater energy deposition must be performed with care in the cervical spine. Caution is heightened in the cervical spine because of cervical anatomy. ${ }^{331-333}$ The articular pillars are narrow in the cervical spine with critical structures in close proximity including the cervical nerve roots, deep cervical artery, radicular arteries, and vertebral artery. ${ }^{350}$ The CT-measured anterior-posterior (horizontal) diameters of the C3 through $\mathrm{C} 6$ vertebral body articular pillars range from $6.4 \mathrm{~mm}$ to $11.5 \mathrm{~mm}$, with a mean of $9.1 \pm 1.2 \mathrm{~mm}$. The CT-measured oblique anterior-posterior diameters of the articular pillars range from $11.4 \mathrm{~mm}$ to $19.3 \mathrm{~mm}$, with a mean of $14.5 \pm 1.7 \mathrm{~mm}$. The CT-measured average height of the articular pillars varies from $16.9 \mathrm{~mm}$ to $25.6 \mathrm{~mm}$, with a mean of $21.0 \pm 1.9 \mathrm{~mm}$. Therefore, depending on the RFA approach to the cervical medial branches, using a large active tip (ie, $10 \mathrm{~mm}$ ) may create an extended lesion that is longer than the articular pillar anterior-posterior diameter.

Practitioners must appreciate the proximity of the cervical nerve roots to the cervical articular pillars. For the C3 through C7 vertebrae, the average distance from the nerve roots to the superficial posterior center of the inferior lateral mass is $5.5 \pm 0.8 \mathrm{~mm}$, and $5.7 \pm 1.5 \mathrm{~mm}$ from the nerve roots to the superior lateral mass. ${ }^{333}$ Based on in vivo work, the lesion width (ie, horizontal diameter $10.7 \mathrm{~mm}$ ) created by an 18 -gauge $10 \mathrm{~mm}$ active tip electrode heated for $120 \mathrm{~s}$ may reach and exceed these boundaries, placing the cervical nerve root at risk of coagulation. 
Other technical factors must be considered when optimizing safety in the cervical spine. Traditional thermal RFA needles are associated with limited projection distal to the active tip $(<1 \mathrm{~mm})$. Internally-cooled electrodes project $40 \%$ of the lesion distal to the active tip. ${ }^{351}$ Therefore, if these needles are placed via the posterior parasagittal and oblique approaches, the lesion may project towards the cervical nerve root. Fluid pre-injection with hypertonic saline also alters lesion dimensions, with the maximum width of the lesion shifted more towards the distal end of the active tip. ${ }^{37}$ Currently, to optimize cervical medial branch RFA, it is recommended that the cannula lies on the anterior side of the facet column. ${ }^{203} 311$ Therefore, any additional forward projection of the lesion from the distal end of the cannulae may be in close proximity to the cervical nerve root. The presence of bone and posterior hardware also alters lesion geometry and energy and heat transmission. ${ }^{341}$ When placing a cannula against bone, the maximal effective radius away from bone approximately doubles. ${ }^{341}$ Posterior hardware not only obstructs needle placement but also allows for the transmission of heat distally towards vulnerable structures such as cervical nerve roots and the vertebral artery. ${ }^{352}$

\section{Recommendations}

Based on the current limitations of traditional thermal RFA and the small size of the targeted structures (ie, cervical medial branches), creating larger lesions with reduced lesion variability may increase the likelihood of lesioning the targeted structures. However, anatomic constraints limit the extent to which larger lesions can be employed in the cervical spine.

If larger lesions are used, care should be taken to limit damage to untargeted structures including vascular (eg, vertebral artery and deep cervical artery) and neurological structures (cervical nerve roots). Although improved outcomes have been demonstrated with larger gauge electrodes when targeting the TON, caution must be emphasized. When there is a concern for lesioning non-targeted tissue, but the need persists to optimize lesion size, a multi-lesion protocol with a smaller gauge and/or shorter active tip cannula may be considered. Sequential cannula placement for each targeted medial branch should be no more than 1 or 1.5 electrode widths apart. Multiple lesions are required when targeting the TON secondary to its relatively large and variable course. Before routine deployment of new cannula designs, bipolar or internally-cooled electrodes, and fluid modulation (besides pre-injection of LA for patient comfort), safety studies are required. Grade $\mathrm{C}$ recommendation with low-to-moderate level certainty for using larger lesions to improve the ability to capture the targeted nerves. Grade $\mathrm{C}$ with a low level of certainty for the ability of larger lesions to increase the duration of pain relief.

\section{QUESTION 18: WHAT ARE THE MOST COMMON COMPLICATIONS OF CERVICAL FACET INTERVENTIONS AND HOW CAN THEY BE MINIMIZED?}

Common complications of procedures on cervical facet joints

Cervical facet joint interventions (IA facet joint injections, MBB, and RFA of the innervation to the cervical facet joints) performed with appropriate use of image guidance rarely result in serious complications. However, both minor and major complications have been reported. Post-procedural pain and soreness at the procedure site, bruising, light-headedness, flushing, sweating, and nausea are some of the common but transient adverse effects following procedures on the cervical facet joints. ${ }^{76353}$ A recent comparative study reported an incidence of $4 \%$ for exacerbation of pain lasting 2 weeks, syncope, and headaches following US or fluoroscopy-guided cervical MBB, with no difference between the two imaging modalities. ${ }^{145}$ Transient disequilibrium on rising from the supine, lateral, or prone position after the procedure and presyncope during the procedure is common with cervical $\mathrm{MBB}$, especially in procedures on upper cervical facet joints. ${ }^{76}$ Headaches have been reported in 4\% of patients after CT-guided IA cervical facet steroid injections and there is one report of a postdural headache after an $\mathrm{MBB}$ performed in the supine position. ${ }^{185354}$ Incorrect position of the needle or use of large volumes of LA for procedures on cervical facet joints can result in temporary sensorimotor neurological deficits in the back of the head, neck and the upper limb due to blockade of branches of the cervical plexuses or the roots of the brachial plexus that are close to the injection site. Intravascular needle placement and/ or injection with bleeding, and hematoma formation $(2.3 \%$ of patients), infection of the superficial tissues (2.9\% of patients) $)^{101}$ and complications of LA such as temporary weakness and numbness $(0.15 \%$ of patients) have been reported in patients who received cervical facet joint procedures. ${ }^{126}$

\section{Major complications of procedures on cervical facet joints}

The most common cervical procedure-related serious adverse outcomes resulting in permanent neurologic injury or death are due to direct trauma from the needle to a nerve or spinal cord and infarction of the spinal cord or brainstem from arterial disruption or injection, usually of a particulate steroid into a feeder artery supplying the spinal cord or brain. ${ }^{129}$ Other causes of serious adverse outcomes from procedures performed on the cervical spine include hematomas causing cord compression, dural puncture, and high or total spinal block. ${ }^{355}$ Rathmell and colleagues $^{129}$ acknowledged in their closed claims review that most adverse outcomes reported in the literature have been associated with epidural (interlaminar or transforaminal) injections on the cervical spine. The authors found that the use of general anesthesia or deep sedation was higher in cervical procedure claims associated with spinal cord injuries than for claims that were not associated with spinal cord injuries (67\% vs 19\%). The rate of non-responsiveness during cervical procedures associated with spinal cord injuries was 5 -fold higher than in cervical procedures not associated with these injuries. A previous closed claims analysis by Fitzgibbon et $a l^{128}$ reported one case of spinal cord injury after a 'cervical facet injection'. An evaluation of trends in malpractice claims for pain medicine from 2010 to 2014 found that claims related to cervical procedures were disproportionate to the frequency with which they were performed. ${ }^{356} \mathrm{~A}$ more recent published analysis of 126 closed claims related to interventional pain procedures reported that eight $(6.3 \%)$ were related to cervical facet joint procedures (four with cervical $\mathrm{MBB}$, another four with RFA) while cervical interlaminar and transforaminal injections accounted for 32 (25\%) (table 20). ${ }^{125}$

\section{Vascular}

In addition to the anteriorly located carotid artery, the proximity of the cervical facet joints to other important vascular structures such as the vertebral artery, the deep cervical artery, the ascending cervical artery, and the transverse cervical artery exposes patients to the risk of vascular complications. Catastrophic consequences related to the penetration of these vascular structures include ischemic injury to the spinal cord and the brain, but these are rare and have mostly been reported with cervical transforaminal ESIs. ${ }^{355}$ Another aspect to consider regarding the potential for vascular penetration during cervical facet procedures is 
Table 20 Complications of cervical facet joint procedures

\begin{tabular}{|c|c|c|c|c|}
\hline Author, year & Patient population & Design & Results & Comments \\
\hline $\begin{array}{l}\text { Barnsley et al } \\
1993^{76}\end{array}$ & $\begin{array}{l}16 \text { pts with chronic neck pain after } \\
\text { MVC }\end{array}$ & Prospective observational & $\begin{array}{l}\text { Transient disequilibrium on rising after the } \\
\text { procedure lasting for a few minutes was common }\end{array}$ & $\begin{array}{l}4 / 16 \text { pts had presyncope that resolved } \\
\text { spontaneously }\end{array}$ \\
\hline $\begin{array}{l}\text { Lord et al } \\
1995^{312}\end{array}$ & $\begin{array}{l}\text { RFA of cervical facet joint } \\
\text { innervation in } 19 \mathrm{pts} \text { ( } 28 \text { procedures) }\end{array}$ & Prospective observational & $\begin{array}{l}\text { Ataxia was a common adverse effect of third } \\
\text { occipital neurotomy; numbness, dysesthesia, and } \\
\text { pruritus also reported }\end{array}$ & $\begin{array}{l}\text { High failure rate }(70 \%) \text { of TON } \\
\text { neurotomy }\end{array}$ \\
\hline $\begin{array}{l}\text { Lord et al } \\
1996^{68}\end{array}$ & $\begin{array}{l}\text { RFA of cervical facet joint } \\
\text { innervation in } 24 \text { pts (12: active; } 12 \text { : } \\
\text { control) }\end{array}$ & $\begin{array}{l}\text { Randomized, placebo- } \\
\text { controlled, double-blind }\end{array}$ & $\begin{array}{l}5 \text { of } 12(42 \%) \text { pts in active group had numbness in } \\
\text { the cutaneous distribution of ablated nerves }\end{array}$ & $\begin{array}{l}1 \text { patient developed a psoriatic rash at } \\
\text { the skin incision (Köebner's phenomenon) } \\
1 \text { week after RFA }\end{array}$ \\
\hline $\begin{array}{l}\text { Govind et al } \\
2003^{307}\end{array}$ & $\begin{array}{l}\text { RFA of TON (C2-3 facet joint } \\
\text { innervation) in } 49 \text { pts }\end{array}$ & Prospective observational & $\begin{array}{l}\text { Slight ataxia }(95 \%) \text {, numbness }(97 \%) \text {, and } \\
\text { temporary dysesthesia ( } 55 \%) \text { were common }\end{array}$ & $\begin{array}{l}\text { No intervention required for adverse } \\
\text { effects }\end{array}$ \\
\hline $\begin{array}{l}\text { Gazelka et al } \\
2014^{293}\end{array}$ & $\begin{array}{l}\text { RFA of TON (C2-3 facet joint } \\
\text { innervation) in } 64 \text { pts }\end{array}$ & Prospective observational & $\begin{array}{l}12(19 \%) \text { pts reported neuropathic pain in the } \\
\text { cutaneous distribution of the TON }\end{array}$ & $\begin{array}{l}\text { Effects of administering steroids at the } \\
\text { end of RFA unclear }\end{array}$ \\
\hline
\end{tabular}

MVC, motor vehicle collision; pts, patients; RFA, radiofrequency ablation; TON, third occipital nerve.;

the practice of injecting particulate steroids following cervical medial branch RFA. This has been suggested as a strategy to reduce post-RFA neuritis following lumbar facet RFA, ${ }^{357}$ but the evidence for this is conflicting, ${ }^{358}$ and it is unclear if the results of studies on lumbar facet RFA can be extrapolated to cervical facet RFA procedures. Given the higher probability of encountering important feeder vessels to the spinal cord during cervical medial branch RFA, it may be appropriate to consider the use of non-particulate steroids if there is a concern about post-lesion neuritis.

A recent study in 275 patients (36 of whom received cervical facet interventions) found that continuing the use of antiplatelet and anticoagulant medications in patients undergoing procedures on the cervical facet joints does not increase the risk of bleeding and hematoma. ${ }^{359}$ An online survey of 325 members of ASIPP also found that thromboembolic events were more severe and common when anticoagulants were stopped prior to performing fluoroscopically-guided interventional pain procedures on the spine, while there was no difference in the reported occurrence of bleeding complications based on whether or not anticoagulants were continued. ${ }^{360}$ However, cervical MBB and RFA are currently classified as 'intermediate-risk' procedures in the multi-organizational interventional guidelines for patients on anticoagulant and antiplatelet medications, and the recommendations regarding stopping these medications in the guidelines should be followed unless extenuating circumstances dictate otherwise. ${ }^{361}$

Recent studies that used one or more of the following imaging modalities-fluoroscopy with injection of contrast and DSA, US, and CT-have provided information about the risk of vascular injury with cervical facet joint interventions. In a study on the anatomic variations of the vertebral artery evaluated on CT-angiography imaging, a loop of the vertebral artery originating between $\mathrm{C} 1$ and $\mathrm{C} 2$ coursed over the anterolateral aspect of the caudad quarter of the articular pillar of $\mathrm{C} 2$ in $0.2 \%$ of subjects, over the cephalad quarter of $\mathrm{C} 3$ in $7.9 \%$, and over the $\mathrm{C} 2-3$ joint line in up to $5.5 \%$ of persons. ${ }^{162}$ This suggests that vascular injury and catastrophic complications can occur during procedures performed on the TON where it is amenable to treatment on the surface of the C2-3 facet joint. A recent study reported that intravascular spread was detected in $10.7 \%$ of DSA images versus $1.7 \%$ from static images during cervical MBB. The authors reported a higher incidence of intravascular injections during MBB at the C4, C5, C6 levels but did not perform blocks on the TON. ${ }^{134}$ Another study reported that $12 \%$ of fluoroscopicallyguided-but no US-guided-cervical MBBs were associated with intravascular placement of the needle tip. In the US-guided group, vascular structures were found to overlie the $\mathrm{C} 2-3$ joint $9 \%$ of the time, and the articular pillars of C3, C4, C5, C6, and C7 in $16 \%, 16 \%, 12 \%, 32 \%$, and $46 \%$ of cases, respectively. ${ }^{145}$ However, DSA is the reference standard for detecting intravascular uptake during facet procedures, with real-time fluoroscopy having a sensitivity of approximately 58\%, spot radiography having a sensitivity of $35 \%$, and needle aspiration being about $20 \%$ sensitive in comparison. ${ }^{133} 362$

The use of US has been advocated to reduce the risk of vascular injury during procedures on the cervical facet joints. ${ }^{154}$ An observational study on 102 patients found periforaminal blood vessels on the articular pillars of C6 and C7 articular pillars in 19\% and $16 \%$ of US scans, respectively. ${ }^{363}$ Three more publications by the same group of investigators reported an incidence of $10 \%, 30 \%$, and $40 \%$ for arteries identified with US overlying the target block area of the TON, ${ }^{136} \mathrm{C} 5-6^{221}$ and $\mathrm{C} 7^{147}$ medial branches, respectively (figure 5). A recent systematic review and metaanalysis confirmed that, compared with fluoroscopy, the use of US is associated with a shorter procedure time (among experienced personnel) and a lower incidence of vascular penetration during cervical MBB, with no difference in efficacy between the two imaging modalities. ${ }^{146}$

The potential risk for vascular injury and bleeding must be weighed against the risk of serious and catastrophic events when anticoagulation is held for interventional pain procedures. Two large cohort studies indicate there is a risk of between $0.2 \%$ and $0.4 \%$ for major thromboembolic events when anticoagulants are held before pain procedures. ${ }^{364} 365$ In a systematic review designed to determine the benefits of heparin bridging before

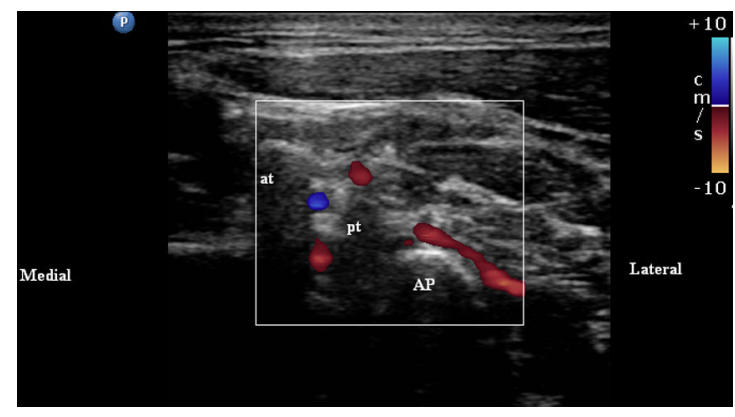

Figure 5 Ultrasound image demonstrating an artery running across a cervical facet articular pillar. AP, articular pillar; at, anterior tubercle of the transverse process; pt, posterior tubercle of the transverse process. 
invasive procedures or surgery, the risk of a thromboembolic event was $0.9 \%$ in bridged patients and $0.5 \%$ in non-bridged patients, which fell shy of statistical significance (RR 1.26, $95 \%$ CI 0.61 to $2.58 ; \mathrm{p}=0.53){ }^{366}$ A recent review by the Spine Intervention Society Patient Safety Committee found no cases of serious complications related to bleeding from cervical facet procedures, suggesting that the risk of discontinuing anticoagulants before cervical medial branch RFA might outweigh the benefits, and concluded that the decision to withhold anticoagulants should be made on a case-by-case basis. ${ }^{367}$ The risk of a thromboembolic event depends on several factors including indication, demographic and clinical factors (age, sex, genetics, past history, lifestyle, obesity, hormonal levels), and the type of anticoagulation and length of discontinuation. ${ }^{368}$

\section{Recommendations}

The committee recommends checking for intravascular placement of the needle tip by aspirating and visualizing the spread of contrast using real-time fluoroscopy, preferably with DSA, prior to performing $\mathrm{MBB}$; grade $\mathrm{B}$ recommendation, moderate level of certainty. Reviewing advanced imaging (MRI or CT scan) of the cervical spine for any aberrations in vascular anatomy around the facet articular pillars and/or a 'scout' US scan prior to performing the procedure may reduce the risk of vascular complications with cervical facet procedures; grade $\mathrm{C}$ recommendation, low level of certainty. Positioning the tip of the RF cannula in the posterior two-thirds of the $\mathrm{C} 2 / 3$ facet joint and avoiding the anterior part of the inferior $\mathrm{C} 2$ facet pillar may avoid penetration of an aberrant loop of the vertebral artery; grade $\mathrm{C}$ recommendation, low level of certainty.

The issue of continuing or stopping anticoagulation is complex, and readers are referred to existing guidelines. ${ }^{361}$ The risk: benefit ratio between stopping or continuing anticoagulation depends on a multitude of factors including the procedure, approach, the use of imaging, needle size and levels, indication for anticoagulation, clinical risk assessment, alternatives to facet interventions, and physician judgment. Healthcare providers considering discontinuation of anticoagulants prior to cervical joint blocks or RFA procedures should consult with the physician prescribing these medications, weigh the risks and benefits for the individual patient (personalized medicine), and discuss these recommendations with the patient (ie, a shared decision model) prior to making any changes. If anticoagulation is continued, the risks of vascular trauma in these circumstances may be attenuated by adjustments in needle and electrode size, insertion trajectory, and the strategic use of pre- and peri-procedural imaging. Ultimately, the decision as to whether or not to continue anticoagulation for cervical MBB and medial branch RFA should be made on a case-by-case basis after carefully reviewing all relevant clinical factors; grade I recommendation.

\section{Complications of RFA of the cervical medial branches}

RFA of the nerve supply to cervical facet joints may be associated with more significant complications than MBB or IA injections because the needle diameter is often larger and tissue damage can occur from the thermal lesion. A systematic review of publications on fluoroscopically-guided RFA of cervical medial branches reported only minor and temporary adverse effects, with no serious complications. ${ }^{369}$ Common (incidence above $40 \%$ in some reports) adverse effects of this procedure include post-procedural pain, cutaneous numbness, dysesthesias, dizziness, and ataxia lasting a few days to weeks. ${ }^{68} 307312$ Pruritus, vasovagal syncope, and transient neuritis occur in less than $10 \%$ of cases and are usually self-limited. Koebner's phenomenon (rash at the site of insertion of RF cannula in a patient with a history of skin rashes) is a rare adverse effect of RFA. ${ }^{68}$

\section{Third occipital nerve RFA}

A variable period of numbness in $60-97 \%$ of patients who undergo RFA of the TON in the cutaneous distribution of this nerve has been reported. The numbness usually lasts for 1-3 weeks and is often replaced by dysesthesia and pruritus followed by a return of normal cutaneous sensation. ${ }^{307312}$ This is likely due to denervation of its cutaneous branches. Ataxia is also a common adverse effect of TON neurotomy with a variable time period required by patients to adjust. ${ }^{307} 312$ A prospective observational study on neuropathic pain 1 month to 1 year after TON RFA in 64 patients reported symptoms in 12 patients, for an incidence of $19 \%$. Seven of the 12 patients had persistent symptoms for an average of 2.6 months after the ablation procedure (range 1-6 months). In four of the 12 patients the duration of symptoms could not be established because of a lack of follow-up. One patient had persistent pain at 1 year after TON RFA. ${ }^{293}$

Some studies on lumbar facet RFA procedures have sought to identify ways to prevent post-procedural pain and numbness. In a randomized trial performed in 45 patients, a significant decrease in local tenderness and post-lumbar medial branch RFA soreness was reported in patients who received either pentoxifylline $10 \mathrm{mg}$ or methylprednisolone $10 \mathrm{mg}$ after lesioning, but not in those receiving saline. ${ }^{357}$ However, a more recent retrospective study performed in 164 patients who underwent lumbar medial branch RFA found no difference in the incidence of post-procedure neuritis between individuals who received postneurotomy particulate steroids (6.4\%) compared with those who did not $(6.9 \%) .{ }^{358}$ If steroids are injected, given the proximity to radiculomedullary arteries feeding the spinal cord and the vertebral artery and the increased risks associated with the inadvertent injection of particulate steroids into these vessels, the use of non-particulate steroids, which have a faster onset, should be considered. ${ }^{177} 370$

Several studies have sought to determine whether adjuvants or non-steroidal anti-inflammatory drugs can prevent post-RFA neuritis, with mixed results. A retrospective study evaluating the incidence of neuritis in 215 patients after lumbar and cervical medial branch RFA found a lower incidence of neuritis in individuals taking gabapentin for at least 2 weeks before the procedure $(7.1 \%$ vs $13.2 \%)$ but the difference was not statistically significant (OR $0.51,95 \%$ CI 0.15 to 1.54 ). ${ }^{371}$ Another retrospective study by Singh et al ${ }^{358}$ performed in 164 patients found no difference in post-lumbar MBB RFA neuritis stratified by whether or not patients were receiving anti-neuropathic pain medications (membrane stabilizers and antidepressants). In an earlier randomized placebo-controlled trial by Ma et $a l^{372}$ performed in 66 patients who underwent lumbar medial branch RFA, the authors found that 3- and 7-day treatment regimens with diclofenac significantly reduced post-procedure pain for up to 7 days compared with placebo. A flaw in all of these preemptive analgesic studies is the failure to adequately discriminate between neuritis and procedure-related pain from electrode insertion.

\section{Recommendations}

The committee recommends that physicians inform patients about the common adverse effects of RFA including pain, dysesthesias, numbness, dizziness, and ataxia lasting from a few days to a few weeks following cervical facet joint denervation. The use 
of a short 3-day course of non-steroidal anti-inflammatory drugs commenced immediately after RFA and injection of steroids through the cannula after ablation but prior to its removal may reduce pain and discomfort following RFA. Given the relatively high incidence of critical arteries in the vicinity of an appropriately placed RF cannula, non-particulate steroids should be injected if there is heightened concern about the occurrence of post-RFA lesion neuritis (eg, younger individuals undergoing upper cervical medial branch RFA); grade $\mathrm{C}$ recommendation, low level of certainty. There is inconsistent evidence based on low-grade trials for the use of a 2-week course of gabapentin to prevent post-RFA neuritis; grade I recommendation. As noted above, there is evidence that a short course of non-steroidal anti-inflammatory drugs may decrease the severity of post-RFA pain, including neuritis; grade $\mathrm{C}$ recommendation, low level of certainty.

\section{Direct trauma to neural structures}

Cervical interlaminar and transforaminal epidural injections have been associated with rare catastrophic neurologic injury. In a closed claims analysis of the type of cervical interventional pain procedure associated with neurologic injury, only $3 \%(2$ out of 64) of procedures were done on the facet joints (both were IA injections). ${ }^{129}$ However, damage to the spinal cord from a cannula that deviated medially and was advanced too far anteriorly during a TON RFA procedure has been reported by authors performing a medicolegal review of complications of procedures on the cervical spine. ${ }^{350}$ Anteroposterior views on fluoroscopy showed the RF cannula in the C3-4 intervertebral foramen where it was postulated to have injured a reinforcing radicular artery resulting in spinal cord infarction. In a second case reported by the same authors, a patient developed BrownSequard syndrome following an attempted neurotomy of the nerve supply to the C3-4 facet joint. The fluoroscopic images showed the tip of the RF cannula had been placed medial to the facet joint resulting in penetration of the spinal cord. ${ }^{350}$ Anterior misplacement of the RF electrode into the neuroforamen can result in the active tip being situated near the cervical nerve root or ventral ramus. Although no such complications associated with cervical facet procedures have been reported in the liaterature, a case report described new sensory symptoms in the dermatomal distribution of the fifth lumbar nerve following RFA of the third to fifth lumbar medial branches and dorsal rami. ${ }^{330}$ Sensory and motor stimulation to reduce the probability of proximity of the RF cannula tip to the spinal nerve root traversing the foramen has been advocated to prevent injury to spinal nerves, but the evidence is inconclusive. Subarachnoid injection of LA has also been described following a fluoroscopically-guided IA injection of the $\mathrm{C} 6-7$ facet joint in a patient with a prior anterior fusion. ${ }^{373} \mathrm{~A}$ non-image-guided injection of $4 \mathrm{~mL} \mathrm{LA}$ into the C5-6 facet joint resulted in transient tetraplegia that lasted $30 \mathrm{~min}$. The authors postulated that the LA was injected into a radicular artery feeding into the anterior spinal artery at that level. ${ }^{127}$ Although the use of US may reduce the incidence of vascular penetration, injury to neural structures may occur with misplaced needles (irrespective of the imaging modality) as evidenced by a case of spinal cord injury during a cervical $\mathrm{MBB}$ at $\mathrm{C} 7 .^{148}$

\section{Recommendations}

The committee recommends the use of true anteroposterior and lateral views on fluoroscopy during placement of RFA cannulas or needles to ensure that the tips are positioned outside the neural foramina. A failure to obtain a true lateral view (ie, a complete overlap of the facet articular pillars) can result in inadvertent needle placement in the intervertebral foramen or the spinal canal. In addition to this view, a contralateral oblique view can be obtained to confirm the position of the tip of the RF cannula. The absence of sensorimotor responses in a radicular distribution in response to test stimulation prior to RFA may also reduce the probability of injury to the spinal cord and spinal nerve roots; grade B recommendation, low-to-moderate level of certainty.

RFA-related degeneration of spinal anatomy and musculature The main cervical paraspinal muscles include the semispinalis cervicis and capitis, multifidus, splenius cervicis and capitis, trapezius, and levator scapulae muscles. The semispinalis and multifidus muscles are responsible for rotation of the head and extension of the cervical spine. The cervical dorsal rami provide motor innervation to the semispinalis muscles. Edema in the cervical paraspinal muscles was found on imaging following RFA of the upper three cervical facet joints in a patient who developed severe neck pain 1 week after the procedure, possibly reflecting denervation of these muscles. ${ }^{374}$ This denervation may expose susceptible patients to the risk of cervical instability and ataxia. RFA of the innervation to two adjacent unilateral cervical facet joints (C2-3, C3-4) has been associated with the development of kyphosis ('dropped head' syndrome) due to loss of cervical extensor muscle action that required instrumented posterior fusion for correction. ${ }^{244}$ MRI of the cervical spine showed degeneration and atrophy of the semispinalis cervicis and splenius capitis muscles in this patient. Closed claims analysis revealed that this patient may have had unrecognized anterocollis. There is also a similar case reported of RFA of the TON and innervation to the $\mathrm{C} 3-\mathrm{C} 4$ and $\mathrm{C} 5-\mathrm{C} 6$ facet joints on one side followed by RFA at the same levels on the other side 1 week later in a patient who then developed an inability to actively extend his head. ${ }^{243}$ The electromyogram in this patient demonstrated active denervation of the cervical paraspinous musculature and the patient eventually required anterior and posterior fusion of the cervical spine from the C3 to C6 levels. The potential causes for this complication include incorrectly positioned RF cannulas resulting in ablation of the dorsal rami, and aberrant anatomy. However, it is also possible that some damage occurs to the innervation of paraspinous muscles despite optimal RF cannula positioning. Cervical medial branch RFA at two adjacent levels denervates only one complete joint and a little more than $20 \%$ of the muscles acting on that segment. ${ }^{149}$ However, bilateral procedures and/or those done at multiple levels can result in the denervation of a significant mass of cervical musculature. This does not usually result in motor deficits because of collateral innervation to the posterior cervical muscles from adjacent levels. This 'safety mechanism' may be lost if RFA is performed at several levels.

\section{Recommendations}

The committee recommends a comprehensive discussion with patients about the potential short- and long-term impact of cervical facet joint RFA on spinal anatomy. It should be explained that morphological changes to spinal muscles should not result in adverse clinical outcomes in most patients. Multilevel ( $>2$ joints) and/or bilateral RFA of cervical facet joints at a single treatment visit should be avoided if possible because of the possibility of a loss of function of cervical extensor muscles. Recommending physical therapy regimens aimed at restoring 
the function of paraspinal muscles prior to and after RFA may improve outcomes; grade C recommendation, low level of certainty.

\section{Impact of RFA on existing implanted devices}

Monopolar RFA of innervation to cervical facet joints involves the use of electrical current that emerges from the tip of the RF cannula and flows through the body before exiting through the dispersive electrode (also known as the grounding pad). Electromagnetic fields created from the use of short-wave diathermy can result in interference with the functioning of implanted electric devices such as deep brain or spinal cord stimulators. ${ }^{375}$ There is some evidence that bipolar RFA may be safer than monopolar RFA in patients with implanted devices, with a report of its safe use for cervical facet RFA. ${ }^{376}$ However, the aggressive lesions and additional tissue trauma entailed with the use of bipolar lesioning may outweigh any theoretical benefits for cervical medial branch RFA. Moreover, the safe use of monopolar RFA has also been reported in a patient with deep brain stimulators, with one of the implanted pulse generators located in the anterior abdominal wall. ${ }^{377}$ Unlike lumbar facet RFA procedures for which the grounding pad is usually placed on the lower extremity, cervical RFA theoretically carries a greater risk of damage to implanted devices because the current will likely pass through the torso before exiting at the grounding pad. It is recommended that the grounding electrode be placed at least $15 \mathrm{~cm}$ away from pacing leads for both permanent pacemakers and implantable cardiac defibrillators. ${ }^{378}$ If using monopolar $\mathrm{RF}$, placing the grounding pad close to the neurotomy site will reduce the size of the induced electromagnetic field. This will minimize the risk of heating the neurostimulator battery and electrodes. However, placing the grounding pad too close to the neurotomy site can increase the risk of tissue burns, particularly when using high current, long activation times, and the use of conductive fluid, since the energy has less tissue through which to dissipate. ${ }^{29}$

A study from 1995 reported on the pacemaker activity in 25 patients with 13 different devices, most of whom underwent RFA with monopolar electrodes. The authors observed sensing failures in eight $(32.0 \%)$ and pacing failures in four $(16.0 \%)$ patients. ${ }^{379}$ Prolonged pauses and induction of tachyarrhythmias were also detected. Although no pacemaker damage was reported, permanent damage has been described by other investigators in non-peer-reviewed literature. ${ }^{380}$ In a recent position paper by SIS, ${ }^{381}$ the authors recommended consultation with the device manufacturer and cardiologist or electrophysiologist, with consideration of the following: (1) having on-site support for interrogation of the cardiac device during the procedure in the event that reprogramming of the device is required; (2) placing a magnet over the device to inhibit triggering the device by RFA; and (3) removing the magnet or use external defibrillator/pacing electrodes should cardiac arrhythmias occur during the RFA procedure.

\section{Recommendations}

Guidelines should be reviewed, ${ }^{382}$ and healthcare teams responsible for managing the implanted devices (eg, neurology, cardiology/electrophysiology, pain medicine) should be consulted regarding the planned cervical RFA procedure. If RFA is performed, in the absence of evidence to the contrary, implanted electrical devices such as neurostimulators should be programmed to an output of zero volts and turned off before the procedure, and the risks of device damage discussed with the patient. For pacemakers and defibrillators, we recommend a shared-decision model, with the cardiology team and device manufacturer being consulted prior to medial branch RFA and their recommendations followed (eg, program pacemaker to asynchronous mode). Given the inherent risks of using bipolar electrodes (eg, additional trauma, aggressive, less predictable lesions) in the cervical spine, we cannot routinely recommend it at this time. Using no or judicious sedation will allow the physician to communicate effectively with the patient and detect any potential injury to the nervous system or cardiovascular decompensation at an early stage. A deactivated neurostimulator should be turned back on following the RFA procedure and reprogrammed to pre-procedural settings; grade $\mathrm{C}$ recommendation, low level of certainty.

\section{Tissue burns}

The musculature and skin overlying the cervical facet joints is usually thinner than around the lumbar spine. Skin burns from equipment malfunction (eg, incorrect application of the grounding pad) or extension of the RFA lesion into the dermis in areas such as the knee where there is less tissue between the target nerve and the skin have been reported ${ }^{383-385}$; given the reduced soft tissue in the cervical region, there is a possibility this could occur during cervical medial branch RFA. Extension of the RFA lesion into cervical paraspinal muscles may manifest as increased procedure-related pain. ${ }^{374}$ Use of larger grounding pads and thinner RF cannulas (22 or 20 gauge) with shorter active tips $(5 \mathrm{~mm})$ for high-risk procedures may mitigate the risk of cutaneous burns. ${ }^{386}$

\section{Recommendations}

A pre-procedure check of all RFA equipment to ensure that it is properly functioning, and positioning grounding pads in an optimal location and orientation is recommended. Applying a large, properly positioned grounding pad on a dry, clean-shaven skin that is devoid of scars or tattoos may minimize the risk of tissue burns; grade $\mathrm{C}$ recommendation, low-to-moderate level of certainty.

\section{Impact of RFA on spinal instrumentation in proximity of the procedure}

Anterior approaches for fusing the cervical spine are more frequently used than in the lumbar spine. However, it is not uncommon for patients who have had cervical spine surgery with instrumentation to undergo facet joint RF denervation at levels adjacent to the operated segments. In a retrospective study evaluating cervical medial branch RFA outcomes, Cohen et al found that $59 \%$ of 29 patients with prior cervical spine surgery experienced a positive outcome, which was no different than the success rate in surgically-naïve patients. ${ }^{20}$ No serious complications were noted in these patients. In another retrospective study on patients with hardware in the posterior cervical elements, Ellwood and colleagues ${ }^{316}$ reported no complications following 56 ablations performed in 36 patients, including 11 who underwent cervical RFA. However, concerns have been raised that the use of RFA in patients with existing posterior spinal instrumentation can cause thermal injury to surrounding structures through heating of the hardware. ${ }^{387}$ Yet, as noted and recommended in the multi-society consensus guidelines for lumbar facet joint procedures, ${ }^{29}$ there is no reported evidence of superficial or deep burns, denervation of the lateral branches or ventral rami, or coagulation of blood vessels with lumbar facet joint RFA procedures in patients with posterior spinal instrumentation. 


\section{Recommendations}

Multiplanar fluoroscopic image-guided techniques should be used to ensure that the RF cannula is not in contact with the pedicle screw in patients with posterior cervical instrumentation to avoid thermal injury to surrounding tissues. Depending on the type of surgery performed, consideration should also be given to the probability of accurately targeting cervical medial branches in the presence of spinal hardware placed using a posterior approach; grade $\mathrm{C}$ recommendation, low level of certainty.

\section{QUESTION 19: IN WHICH PATIENTS SHOULD REPEAT RFA BE CONSIDERED AND WHAT IS THE LIKELIHOOD FOR SUCCESS?}

\section{DO REPEAT DIAGNOSTIC BLOCKS NEED TO BE REPEATED AND, IF SO, AT WHAT INTERVAL?}

Rationale for repeating RFA and defining a positive outcome Pain relief after cervical medial branch RFA has shown durability but not permanence, with the median time to pain recurrence ranging from 6 to 14 months (table 21). In clinical practice, RFA is commonly repeated when pain returns. Pain physicians should educate patients about the duration of expected relief and the potential need for repeated treatment(s). To discuss the efficacy of repeat cervical RFA, 'success' needs to be defined. A successful RFA must result in a meaningful reduction of pain for a clinically relevant period of time. The definitions vary per

Table 21 Studies examining the effectiveness of repeat cervical medial branch RFA

\begin{tabular}{|c|c|c|c|c|c|c|}
\hline Author, year & Patients & $\begin{array}{l}\text { Joints } \\
\text { included }\end{array}$ & Design & Successful outcome & Results: Success & Duration of benefit \\
\hline $\begin{array}{l}\text { Lord et al } \\
1996^{68}\end{array}$ & $\begin{array}{l}24 \text { pts diagnosed with } \\
\text { cervical facet pain based } \\
\text { on three blocks including } \\
\text { one with saline }\end{array}$ & $\mathrm{C} 3-\mathrm{C} 7$ & $\begin{array}{l}\text { Randomized, } \\
\text { placebo- } \\
\text { controlled }\end{array}$ & $\begin{array}{l}\text { Complete pain relief for } \\
\geq 90 \text { days. Duration of } \\
\text { benefit was time for pain } \\
\text { to return to } \geq 50 \% \text { of } \\
\text { baseline }\end{array}$ & $\begin{array}{l}\text { Active group initial RFA failure: } 2 \text { of } 5(40 \%) \text { had } \\
\text { successful procedure } \\
\text { Control group: } 4 \text { of } 5(80 \%) \text { had success }\end{array}$ & $\begin{array}{l}\text { Median duration for initial RFA } \\
263 \text { days vs } 253 \text { days for repeat } \\
\text { RFA }\end{array}$ \\
\hline $\begin{array}{l}\text { Lord et al } \\
1995^{312}\end{array}$ & $\begin{array}{l}19 \text { pts with chronic } \\
\text { cervical facet pain after } \\
\text { MVC diagnosed by dual } \\
\text { blocks }\end{array}$ & $\mathrm{C} 2-\mathrm{C} 7$ & Retrospective & $\begin{array}{l}\text { Complete relief for a } \\
\text { clinically significant } \\
\text { duration }\end{array}$ & $\begin{array}{l}\text { C2-3: } \\
\text { Initial RFA success rate: } 4 \text { of } 10(40 \%) \\
\text { Repeat RFA success rate: } 2 \text { of } 2(100 \%) \\
\text { C5-C7: } \\
\text { Initial RFA success rate: } 7 \text { of } 10(70 \%) \\
\text { Repeat RFA success rate: } 3 \text { of } 3(100 \%)\end{array}$ & \\
\hline $\begin{array}{l}\text { Lord et al } \\
1998^{202}\end{array}$ & $\begin{array}{l}12 \text { pts with cervical facet } \\
\text { pain from C2-3 after } \\
\text { MVC diagnosed by dual } \\
\text { comparative or placebo- } \\
\text { controlled blocks }\end{array}$ & $C 2-3$ & Retrospective & $\begin{array}{l}\text { Complete relief in the } \\
\text { region treated for } \geq 90 \\
\text { days. Duration of benefit } \\
\text { was time for pain to return } \\
\text { to } \geq 50 \% \text { of baseline }\end{array}$ & $\begin{array}{l}\text { Initial RFA success (pts): } 5 \text { of } 12(42 \%) \\
\text { Repeat RFA success rate (procedures): } 10 \text { of } 13 \\
(77 \%)\end{array}$ & $\begin{array}{l}\text { Median duration of initial } \\
\text { successful RFA } 161 \text { days vs } 237 \\
\text { days for repeat RFA }\end{array}$ \\
\hline $\begin{array}{l}\text { McDonald et al } \\
1999^{149}\end{array}$ & $\begin{array}{l}28 \text { pts with cervical facet } \\
\text { pain from C2-3 after } \\
\text { MVC diagnosed by dual } \\
\text { comparative or placebo- } \\
\text { controlled blocks }\end{array}$ & $\mathrm{C} 3-\mathrm{C} 7$ & Retrospective & $\begin{array}{l}\text { Complete relief for a } \\
\text { clinically significant } \\
\text { duration }\end{array}$ & $\begin{array}{l}\text { Initial RFA success rate: } 18 \text { of } 28(64 \%) \\
\text { Repeat RFA success rate: } 7 \text { of } 8(87.5 \%) \\
\text { Initial RFA failure: } 10 \text { of } 28(36 \%) \\
\text { Repeat RFA success rate after initial RFA failure: } \\
2 \text { of } 6(33 \%)\end{array}$ & $\begin{array}{l}\text { Median duration of initial } \\
\text { successful RFA } 421 \text { days vs } \\
181.5 \text { days for first repeat RFA. } \\
\text { Median duration of all successful } \\
\text { repeat RFAs: } 218.5 \text { days }\end{array}$ \\
\hline $\begin{array}{l}\text { Govind et al } \\
2003^{307}\end{array}$ & $\begin{array}{l}49 \text { pts with complete } \\
\text { pain relief with dual } \\
\text { comparative blocks ( } 2 \text { pts } \\
\text { with bilateral pain) }\end{array}$ & TON/C2-3 & Retrospective & $\begin{array}{l}\text { Complete relief of } \\
\text { headache and restoration } \\
\text { of function for } 90 \text { days }\end{array}$ & $\begin{array}{l}\text { Initial RFA success rate: } 43 \text { of } 49(88 \%) \text {. } \\
\text { Repeat RFA success rate: } 12 \text { of } 14(86 \%)\end{array}$ & $\begin{array}{l}\text { Mean duration of relief after initial } \\
\text { successful RFA: } 297 \text { days. Mean } \\
\text { duration of relief after repeat RFA: } \\
217 \text { days }\end{array}$ \\
\hline $\begin{array}{l}\text { Barnsley, } \\
2005^{101}\end{array}$ & $\begin{array}{l}35 \text { pts with complete } \\
\text { relief of pain with dual } \\
\text { comparative blocks and } \\
\text { no relief with placebo } \\
\text { injection. } \\
12 \text { pts received repeat } \\
\text { RFA }\end{array}$ & $\mathrm{C} 2-\mathrm{C} 7$ & Retrospective & $\begin{array}{l}\text { Complete relief of neck } \\
\text { pain }\end{array}$ & $\begin{array}{l}\text { Initial RFA success rate: } 26 \text { of } 35(74 \%) \\
\text { Repeat RFA success rate: } 8 \text { of } 9(89 \%) \\
\text { Initial RFA failure rate: } 7 \text { of } 33(21 \%) \\
\text { Repeat RFA success rate after failure: } 2 \text { of } 3(67 \%)\end{array}$ & $\begin{array}{l}\text { Median duration of relief after } \\
\text { initial successful RFA: } 36 \text { weeks } \\
\text { Duration of relief after repeat } \\
\text { successful RFA: not reported }\end{array}$ \\
\hline $\begin{array}{l}\text { Husted et al } \\
2008^{389}\end{array}$ & $\begin{array}{l}22 \text { pts with 'good' relief } \\
\text { from } 2 \text { MBBs and } \geq 50 \% \\
\text { relief after RFA }\end{array}$ & $\mathrm{C} 2-\mathrm{C} 7$ & Retrospective & $\geq 50 \%$ pain relief & $\begin{array}{l}\text { Initial RFA success rate: } 22 \text { of } 22(100 \%) \\
\text { Repeat RFA success } \\
\text { (procedures): } 39 \text { of } 41 \text { ( } 95 \%) \\
21 \text { pts had a second RFA } \\
11,4,2,2,1 \text { patients had a third, fourth, fifth, } \\
\text { sixth, and seventh repeat procedure }\end{array}$ & $\begin{array}{l}\text { Mean duration of initial successful } \\
\text { RFA: } 12.5 \text { months. } \\
\text { Mean duration for subsequent } \\
\text { successful RFAs: } 11.5 \text { months }\end{array}$ \\
\hline $\begin{array}{l}\text { Rambaransingh } \\
\text { et al } 2010^{393}\end{array}$ & $\begin{array}{l}73 \text { pts with cervical } \\
\text { and lumbar pain who } \\
\text { received }>3 \text {-point pain } \\
\text { reduction (on } 0-11 \text { scale) } \\
\text { with RFA. } \\
15 / 73 \text { pts underwent } \\
\text { repeat cervical RFA }\end{array}$ & $\begin{array}{l}\text { Levels } \\
\text { unreported }\end{array}$ & Observational & $\begin{array}{l}\text { Improvement in pain and } \\
\text { disability }\end{array}$ & $\begin{array}{l}\text { Pain reduction and functional improvement } \\
\text { remained significantly improved from baseline } \\
\text { with each repeat procedure. } \\
43 \% \text { success rate ( } \geq 50 \% \text { improvement) vs } 64 \% \\
\text { with second RFA and } 86 \% \text { with third RFA }\end{array}$ & $\begin{array}{l}\text { Mean duration of relief after initial } \\
\text { successful RFA: } 9.9 \text { months. } \\
\text { Mean duration of relief after } \\
\text { second successful RFA: } 10.5 \\
\text { months (not reported for third } \\
\text { RFA) }\end{array}$ \\
\hline $\begin{array}{l}\text { Speldewinde, } \\
2011^{392}\end{array}$ & $\begin{array}{l}151 \text { pts with } \geq 80 \% \text { relief } \\
\text { from dual comparative } \\
\text { MBB blocks. } \\
26 \text { pts underwent repeat } \\
\text { RFA, } 47 \text { procedures }\end{array}$ & $\begin{array}{l}\text { Levels } \\
\text { unreported }\end{array}$ & Observational & $\begin{array}{l}\geq 50 \% \text { pain reduction } \\
\text { for } \geq 2 \text { months }\end{array}$ & $\begin{array}{l}\text { Initial RFA success: } 112 \text { of } 151(76 \%) \\
\text { Repeat RFA success rate after initial successful } \\
\text { RFA (procedures) } 34 \text { of } 40(85 \%) \\
\text { Repeat RFA success rate after initial failure: } 4 \text { of } \\
7(57 \%)\end{array}$ & $\begin{array}{l}\text { Mean duration of success after } \\
\text { initial RFA } 12 \text { months vs } 9.7 \text { after } \\
\text { repeat RFA }\end{array}$ \\
\hline $\begin{array}{l}\text { MacVicar et al } \\
2012^{69}\end{array}$ & $\begin{array}{l}104 \text { pts with complete } \\
\text { relief of pain from dual } \\
\text { comparative blocks }\end{array}$ & $C 2-7$ & Observational & $\begin{array}{l}\text { Successful outcome: } \\
\geq 80 \% \text { pain relief for } \\
\text { at least } 6 \text { months with } \\
\text { complete restoration of } \\
\text { ADLs }\end{array}$ & $\begin{array}{l}\text { Initial RFA success rate: } 69 \text { of } 104(66 \%) \\
\text { Repeat RFA success rate after initial success: } 23 \\
\text { of } 24(96 \%) \\
\text { Repeat RFA success rate after initial failure: } 2 \text { of } \\
2(100 \%)\end{array}$ & $\begin{array}{l}\text { Median duration of pain relief } \\
\text { after initial RFA } 17 \text { months and } 20 \\
\text { months in two practices. } \\
\text { Median duration of pain relief } \\
\text { after repeat RFA } 15 \text { months }\end{array}$ \\
\hline
\end{tabular}


study (see table 21 ) but, overall, most studies require $\geq 50 \%$ pain relief for $\geq 3$ months. However, more recent randomized studies evaluating lumbar medial branch RFA have used the IMMPACT guidelines recommendation of $\geq 2$-point (or $\geq 30 \%$ ) decrease in average pain, with 3 months designated as the primary endpoint. $^{214281283}$ The 3-month time point stems from patient and physician surveys performed in preparation for a randomized controlled lumbar facet RFA trial, ACTTION guidelines on unique aspects of interventional clinical trials, the MINT and FACTS trials evaluating lumbar medial branch RFA, and FDA guidance on randomized trials evaluating pharmacological treatments. $^{214283302388}$

\section{Likelihood of success with repeat cervical medial branch RFA}

The results from multiple studies are remarkably consistent, with an average of $84 \%$ of patients obtaining a successful repeat RFA after an initial successful RFA. ${ }^{69} 101149389$ In these individuals, the duration of benefit ranges between 7 and 20 months. This average differs slightly from the systematic review and meta-analysis by Smuck et $a l^{296}$ which reported a non-weighted $88 \%$ average success rate (range 67-95\%) in previous studies when the first RFA was successful, but a success rate of only $38 \%$ (range 0-67\%) when the initial RFA was unsuccessful. This discrepancy results from inappropriate meta-analysis application which included studies by Lord et $a l^{312}$ Lord et al $l^{68}$ and McDonald et $a l^{149}$ in which some duplicate patients were included. ${ }^{296}$ The results of denervation of the C2-3 joint appear to be comparable to outcomes with lower cervical levels in that $77-84 \%$ of patients respond with $\geq 50 \%$ pain relief after repeat RFA for 7.2-7.9 months (table 21). ${ }^{202} 307$

\section{Number of times RFA can be repeated at the same level(s)}

Considering that many patients experience neck pain and undergo cervical medial branch RFA after MVCs, questions about the likelihood of success for repeat procedures and how many times procedures should be repeated have major relevance for litigation attorneys and insurance companies. ${ }^{390} 391$ No studies have directly examined the number of times that RFA can be repeated at the same level. Speldewinde et $a l^{392}$ followed 26 patients who underwent repeat treatment up to five times. Although the authors did not break down the success rate for each procedure, they reported an average duration of 9.7 months among subsequent RFA successes. McDonald et al ${ }^{149}$ described four patients who underwent multiple repeat procedures, with the benefit from each procedure lasting for at least 90 days. Husted et $a l^{389}$ followed a group of 22 patients who had up to seven repeat RFAs, with each repeat RFA having a $90-100 \%$ success rate and an average duration of benefit of 11.5 months. Rambaransingh et $a l^{393}$ reported the results of repeat cervical medial branch RFA in 14 patients (nine of whom underwent a third RFA), noting a significant decrease in pain intensity, pain frequency, and disability in pre- and post-treatment measurements. These improvements were similar in magnitude for each RFA, suggesting no or minimal loss of effectiveness with repeat procedures.

\section{Decision to repeat RFA determined by initial RFA response}

In general, the decision to repeat a procedure should depend on the magnitude of pain, results of the previous procedure(s), and the concordance of location and quality. In patients who undergo repeat cervical medial branch RFA after an initially successful procedure, McDonald et al ${ }^{149}$ noted the initial median duration of pain relief to be 14 months, which compared favorably with a 7.3-month median duration of relief for repeated successful procedures. Although this represents a meaningful attenuation in the duration of benefit for subsequent RFAs, several studies have reported more modest declines. Speldewinde et $a l^{392}$ reported the mean duration of benefit for subsequent RFAs to be 9.7 months, which was less than the 12-month duration of the initial procedure. MacVicar et $a l^{69}$ reported that the median duration of benefit after initial successful RFAs was 17 and 20 months in two private practice groups. Successful repeat cervical medial branch RFA procedures resulted in a median duration of benefit of 15 months in both groups. Govind et $a l^{307}$ also noted a small decrement in effect, with the initial TON RFA lasting a mean of 9.9 months and the repeat RFA lasting an average of 7.2 months. In a study by Husted et $a l^{389}$ the authors reported a mean duration of initial benefit of 12.5 months, which was only slightly longer than the 11.5-month mean duration of benefit after subsequent procedures.

Other authors have reported longer benefits after repeat procedures compared with initial ones. Rambaransingh et al ${ }^{393}$ reported a mean duration of 9.9 months pain relief after initially successful lumbar and cervical medial branch RFA versus 10.5 months of relief after a repeat procedure. In the Lord et $a l^{202}$ study evaluating TON RFA, 12 patients had a median duration of benefit of 5.4 months after the initial procedure versus 7.9 months after repeat denervation. The variability in the duration of response to repeat cervical facet RFA in comparison to the initial denervation is likely due to several factors including technical details (needle placement, lesion size, duration of recurrence of pain prior to repeat RFA), progression of degenerative changes since the last treatment (eg, worsening facet arthropathy), and potential differences in the calculations of duration of benefit (ie, inclusion or exclusion of treatment failures). However, collectively these studies suggest that the duration of pain relief after an initially successful RFA appears comparable to the duration of pain relief for subsequent RFAs.

As one might expect, successful procedures are less likely after initial treatment failures. Among six patients who underwent a repeat cervical medial branch RFA procedure after an initial unsuccessful RFA, McDonald et $a l^{149}$ found that only two experienced relief, with none who obtained less than 30 days of relief after the first procedure experiencing benefit. In a small study by Lord $e t a l^{202}$ the success rate of TON RFA after a previous unsuccessful procedure was also $0 \%$. In an observational study by MacDonald et al ${ }^{149}$ among those patients who experienced short-term (<90 days) pain relief from cervical medial branch RFA, the success rate of subsequent RFA was 33\%. Among the four patients with an initially successful procedure who underwent multiple repeat RFAs, the median duration of benefit was 218.5 days. Other studies have noted similarly poor results for repeat RFA after an initial failure. ${ }^{101} 392$ Although most studies attributed failure to technical difficulties and the potential to unmask other pain sources, including at adjacent levels, the repeat success rate for other neurolytic procedures after an initial failure has also been reported to be very low. ${ }^{394}$

\section{Rationale for repeating prognostic blocks before repeat RFA}

Whereas all studies specified that a positive response to prognostic MBB was a prerequisite for RFA, no studies were identified in which the prognostic $\mathrm{MBB}$ was repeated prior to subsequent RFA. Lord et $a l^{312}$ noted that, if an RFA was unsuccessful, repeat prognostic blocks could be used to test the technical success of the RFA if performed at the same levels. Likely, repeat MBBs at the levels of a previously successful RFA have not been studied 
in part due to the established high success rate of repeat RFA. However, if the patient's pain has changed in location or quality and/or the examination is no longer similar to the pre-RFA baseline, a repeat prognostic MBB can be considered. If an initial RFA is unsuccessful and is not attributable to technical failure, repeat $\mathrm{MBB}$ at a different location may be warranted.

\section{Initial and repeat procedure interval}

Cohen $e t a l^{20}$ identified no significant difference in the baseline duration of cervical pain between patients with a successful outcome and those who failed RFA treatment. However, in multicenter studies by the same group of authors, a shorter duration of pain correlated with better outcomes in studies examining predictors of response for lumbar medial branch RFA and sacroiliac joint lateral branch RF denervation. ${ }^{294}{ }^{395}$ No studies were identified which assessed the effect of pain duration on the success of repeat cervical medial branch RFA. Prolonged denervation of the paraspinal musculature after lumbar medial branch RFA has been shown to last over 12 months in some patients. ${ }^{327}$ The high success rate of repeat cervical medial branch RFA after a successful initial RFA treatment suggests that subsequent procedures may be performed shortly after recurrence of pain. However, RFA should never be performed pre-emptively since prolonged denervation of muscles may lead to irreversible interstitial fibrosis and the replacement of myocytes by adipocytes. ${ }^{396} 397$

\section{Recommendations}

The committee recommends that if an initial RFA is successful (clinically meaningful pain relief for $\geq 3$ months), it should be offered to patients who experience return of their cervical pain, assuming that the pain is similar in character and location to the initial pain; grade B, moderate level of certainty. Given the mean duration of benefit and drop-off in success rates noted in some studies with repeat RFA, we recommend repeating the procedure no more than two times a year; grade $\mathrm{B}$, moderate level of certainty. Although there are a paucity of studies examining cervical medial branch RFA success rates after repeating prognostic blocks, the high success rates reported after empirically repeating RFA indicate they are not necessary in most people; grade $\mathrm{C}$, low level of certainty.

\section{QUESTION 20: SHOULD THERE BE DIFFERENT STANDARDS IN SELECTING PATIENTS FOR RFA IN CLINICAL TRIALS AND CLINICAL PRACTICE?}

Clinical trials are the reference standard to determine the efficacy and effectiveness of novel therapeutics to treat pain, including invasive therapies such as cervical facet treatments. The current push for more evidence-based medicine has caused invasive therapies for pain to come under intense scrutiny due to a lack of evidence for efficacy. ${ }^{398}$ Invasive therapy trials face numerous challenges including difficulties with sham control groups, blinding, cost, and an inability to enroll subjects. ${ }^{388}$ This has resulted in invasive therapies bypassing the early phase clinical trial model for efficacy and jumping to 'real world' patient populations that reflect effectiveness. Whereas early phase clinical trials typically employ strict selection criteria to reduce variables that may affect outcomes, later phase selection criteria are loosened (as more is learned about the treatment) to evaluate outcomes in 'real world' patient populations. Differences between clinical research and clinical practice for invasive therapies such as cervical facet interventions may be more accentuated compared with those between medication prescribing and industry-sponsored drug trials. Understanding these differences is necessary to determine both the efficacy and clinical effectiveness of cervical facet therapies.

Compared with lumbar procedures, cervical procedures are associated with greater technical difficulties and risks. Balancing the risk/benefits of cervical facet blocks and RFA in clinical trials may result in more stringent selection criteria compared with clinical practice, which takes into consideration physician preference and individual factors (personalized medicine). This guideline critically evaluates the literature which was used to develop guidelines to inform clinical practice, which was subsequently modified to come up with recommendations for clinical trials. Whereas most recommendations show no differences between the two, for others there are distinctions. Table 22 summarizes the differences in recommendations between clinical trials and clinical practice. Details for the basis of these recommendations can be found in the previous sections which provide a thorough review of the literature for each question.

\section{Patient selection for diagnostic blocks}

Similar to all chronic pain treatments, patient selection for diagnostic cervical MBB plays a critical role in determining the likelihood of a positive outcome. There is consensus that failure of at least 3 months of conservative therapy is a reasonable threshold that should be implemented in both clinical trials and practice, although practice guidelines could allow for flexibility in extenuating circumstances. There is agreement that the natural course of acute pain (including neck) is favorable, allowing conservative therapies in the first 3 months to facilitate recovery. ${ }^{399}$ However, prospective studies on the clinical course of neck pain indicate that up to $40 \%$ of patients who do not respond to conservative treatment still suffer neck pain at 12 months. ${ }^{400}$

There are no physical examination signs that reliably predict response to facet joint blocks, though paraspinal tenderness and pain with certain movements (which are limited by the facet joints) may be weakly associated with cervical facetogenic pain. ${ }^{20}$ However, some studies have delineated referred pain patterns of individual facet joints and may improve the identification of putatively painful joints. ${ }^{49} 5177$ Therefore using pain referral maps and/or standardized tests such as algometry for paraspinal tenderness should be considered for clinical trials. Bilateral neck pain is often more multifactorial than unilateral pain and should be excluded from clinical trials unless the study is specifically designed to address this clinical problem or is properly powered for subgroup analysis. ${ }^{241}$ As with all clinical trials, mental health exclusion criteria to identify people with existing anxiety, depression, or post-traumatic stress should be more stringent in efficacy trials than in clinical practice due to the negative influence that these comorbid conditions have on pain outcomes. ${ }^{401}$

\section{MBB cut-offs and patient-reported outcomes}

Percent pain reduction after a diagnostic MBB is an important indicator of facet pain. Although there is no clear evidence on what threshold should be used, consensus supports $\geq 50 \%$ pain reduction, and this applies to both clinical trials and practice, possibly with a higher cut-off considered for whiplash injuries and younger age groups enrolled in studies. For clinical trials, since the magnitude of pain relief is likely to be greater for MBB than RFA, using higher cut-offs may theoretically lead to improved outcomes, but the clinical evidence does not support this consideration. Despite interest in using non-pain measures (such as function) as selection criteria, there is no evidence to support any modality as a sole criterion and using them is not 
Table 22 Guidelines for clinical trials versus clinical practice

\begin{tabular}{|c|c|c|}
\hline Factor & Clinical trial & Clinical practice \\
\hline \multicolumn{3}{|l|}{ Patient selection } \\
\hline $\begin{array}{l}\text { History and physical examination of cervical facet } \\
\text { joints }\end{array}$ & $\begin{array}{l}\text { Inclusion criteria: } \\
\text { Paraspinous muscle tenderness, ideally under fluoroscopy } \\
\text { Pain with movement (eg, extension, rotation, lateral flexion) } \\
\text { Pain consistent with referral maps } \\
\text { Radion criteria: } \\
\text { Radicular symptoms } \\
\text { Bilateral neck pain unless study adequately powered } \\
\text { Active psychological comorbidities }\end{array}$ & $\begin{array}{l}\text { Inclusion criteria: } \\
\text { Paraspinous muscle tenderness } \\
\text { Pain with movement } \\
\text { Pain consistent with referral maps } \\
\text { Exclusion criteria: } \\
\text { Radicular symptoms }\end{array}$ \\
\hline History and physical examination AA/AO joints & No recommendation & No recommendation \\
\hline Failure of conservative treatment & At least 3 months & $\begin{array}{l}\text { Preferably } 3 \text { months, but may be less in certain circumstances (eg, } \\
\text { incapacitating pain with strong suspicion of facetogenic origin, } \\
\text { competitive athlete, deployment) }\end{array}$ \\
\hline Radiological findings for facet joint pain & No recommendation & No recommendation \\
\hline Patient reported outcomes & $\begin{array}{l}\text { Follow IMMPACT and other relevant guidelines, more detailed than } \\
\text { clinical practice }\end{array}$ & Dependent on patient's goals \\
\hline Pain relief cut-off for positive MBB & $\geq 50 \%$ (consider higher cut-off for efficacy trials or subgroup analysis) & $\geq 50 \%$ \\
\hline Functional measures & $\begin{array}{l}\text { Sole criterion not recommended for assessing MBB results (composite } \\
\text { with pain relief should be considered for RFA effectiveness) }\end{array}$ & $\begin{array}{l}\text { Sole criterion not recommended for assessing MBB results } \\
\text { (composite with pain relief may be considered for RFA effectiveness) }\end{array}$ \\
\hline Repeat RFA & $\begin{array}{l}\geq 30 \% \text { for at least } 3 \text { months per IMMPACT and lumbar facet } \\
\text { guidelines } \\
29281\end{array}$ & $\begin{array}{l}\geq 30 \% \text { for at least } 3 \text { months per IMMPACT and lumbar facet } \\
\text { guidelines }{ }^{29281}\end{array}$ \\
\hline Repeat diagnostic MBB for repeat RFA & $\begin{array}{l}\text { No - previous RFA should be an exclusion criterion for studies not } \\
\text { evaluating repeat RFA }\end{array}$ & No \\
\hline \multicolumn{3}{|l|}{ Injection technique } \\
\hline $\mathrm{AO}$ and $\mathrm{AA}$ imaging & $\begin{array}{l}\text { Pre-injection CT or MRI, fluoroscopy and real-time contrast injection } \\
\text { with strong consideration of DSA or CT }\end{array}$ & $\begin{array}{l}\text { Pre-injection CT or MRI, fluoroscopy and real-time contrast injection } \\
\text { or DSA }\end{array}$ \\
\hline Approach & Posterior/posterior oblique & Posterior/posterior oblique \\
\hline \multicolumn{3}{|l|}{ Volume and prognostic test } \\
\hline Medial branch block & $\leq 0.3 \mathrm{~mL}$ & $\leq 0.3 \mathrm{~mL}$ \\
\hline Diagnostic block (IA vs MBB) & MBB & MBB \\
\hline Diagnostic block (single vs dual) & Single block (consider dual blocks only for efficacy studies) & $\begin{array}{l}\text { Single block (consider dual blocks in individuals with low index of } \\
\text { suspicion) }\end{array}$ \\
\hline Imaging & Fluoroscopy or US & Fluoroscopy or US \\
\hline \multirow[t]{2}{*}{ Approach } & Lateral (TON, C3-C7) & Lateral (TON, C3-C7) \\
\hline & Posterior oblique (C8) & Posterior oblique (C8) \\
\hline Volume and steroid use for $\mathrm{AA} / \mathrm{AO}$ injections & Non-particulate $\leq 1 \mathrm{~mL}$ & Non-particulate $\leq 1 \mathrm{~mL}$ \\
\hline Sedation & Avoid & Avoid \\
\hline \multicolumn{3}{|l|}{ RFA technique } \\
\hline \multirow[t]{2}{*}{ Stimulation } & Motor for all levels & Motor for all levels \\
\hline & Sensory for single lesions and $\mathrm{C} 2-3$ & Sensory for single lesions and $\mathrm{C} 2-3$ \\
\hline \multirow[t]{2}{*}{ Needle orientation } & Parallel (preferable) or near-parallel & Parallel or near-parallel \\
\hline & Posterior two-thirds of the articular pillar for $\mathrm{C2}-3$ & Posterior two-thirds of the articular pillar for $\mathrm{C2}-3$ \\
\hline Lesion size & No recommendation due to unknown risk/benefit & No recommendation due to unknown risk/benefit \\
\hline Cannulae confirmation & PA/lateral and possibly contralateral oblique & PA/lateral and contralateral oblique if necessary \\
\hline \multirow[t]{3}{*}{ Implanted devices } & \multirow[t]{3}{*}{ Exclude patients } & Neurostimulators - deactivate \\
\hline & & Pacemakers - asynchronous mode if possible \\
\hline & & Defibrillators - deactivate if possible \\
\hline Grounding pad placement & Dry, hairless skin devoid of tattoos & Dry, hairless skin devoid of tattoos \\
\hline Spinal hardware & $\begin{array}{l}\text { Exclude patients unless specifically addressing outcomes in this } \\
\text { population }\end{array}$ & $\begin{array}{l}\text { Avoid contact with hardware, adjust approach (eg, posterior oblique) } \\
\text { as necessary }\end{array}$ \\
\hline Repeat RFA & No more than twice/year & No more than twice/year \\
\hline Post-lesion steroids & No steroids for efficacy study unless administered to all patients & Per physician judgment based on risk:benefit analysis \\
\hline Anticoagulation & Exclude subjects who cannot stop anticoagulants & Discontinue only after careful risk:benefit assessment \\
\hline
\end{tabular}

AA, atlanto-axial; $A O$, atlanto-occipital; $C T$, computed tomography; DSA, digital subtraction angiography; IA, intra-articular; $M B B$, medial branch block; $M R I$, magnetic resonance imaging; PA, posteroanterior; RFA, radiofrequency ablation; TON, third occipital nerve; US, ultrasound.

feasible in clinical practice to evaluate short-term MBB results. However, in clinical trials, these measures may be useful to evaluate in exploratory analyses using a composite score that includes pain relief. When selecting outcome measures for clinical trials evaluating RFA and in accordance with IMMPACT guidelines, ${ }^{402}$ non-pain outcome domains should be measured. Since these outcomes were chosen because they are important to patients and for physicians to evaluate success, simple non-pain outcome measures such as function, satisfaction, and healthcare utilization (including analgesic consumption) may be assessed in clinical practice.

\section{Injection technique}

Injection technique is important to increase the chances of precision delivery to the targeted structure(s). There are only 
two recommended differences concerning technique. First, $\mathrm{AO} /$ AA injections require fluoroscopic guidance with an injection of contrast. DSA has been shown to detect vascular uptake that would otherwise be missed with fluoroscopy alone. ${ }^{134}$ However, DSA is not widely available and increases radiation exposure. The consequences of inadvertent vascular injection for upper joint injections include false-negative results and seizures. ${ }^{403}$

\section{Number of MBBs}

The use of dual blocks may increase the RFA success rate. However, this will invariably result in false-negative blocks and deny some patients the benefit of an RFA. There are also patient inconveniences and increased costs and risk exposure to consider. Nonetheless, for clinical trials that aim to show efficacy, the benefits of a higher percentage of true positives (enriched population) may outweigh the cons and should be considered in trial design.

\section{RFA technique and considerations}

RFA cannula placement is critical to a successful outcome. There is widespread agreement that both anteroposterior and lateral views are necessary to verify needle location. A contralateral oblique approach provides a third view that may increase precision and confirm that the cannula tip is not in the neural foramen. Its use may be particularly valuable when performing lower cervical procedures in obese patients. However, additional views increase procedure time and radiation exposure and may not be feasible for all cases in clinical practice.

Implanted devices and spinal hardware can complicate RFA procedures as the electrical current can affect the devices and contact with the spinal hardware can lead to thermal injury. Yet, precautions can be taken to reduce the likelihood of affecting the implanted device. Having prior surgery may also increase the rate of false-positive MBB and treatment failure. ${ }^{29} 404$ Due to these considerations, it is recommended that patients with implanted devices and spinal hardware be excluded in clinical trials. The exception is for clinical trials specifically evaluating RFA in patients with spinal hardware.

The use of steroids to prevent neuritis has not been studied in the cervical spine, although the risk is at least as high as in the lumbar spine at higher levels. Given the risks of repeated steroids which may include immune suppression and bone demineralization, in clinical practice their pre-emptive use should be made after a careful risk:benefit analysis. ${ }^{405}$ Since a small percentage of patients may experience prolonged benefit from MBB performed with LA and steroids, ${ }^{27} 217$ we recommend standardization in clinical trials (ie, either avoiding steroids in all research subjects or using them in everyone).

\section{Anticoagulation}

The vasculature of the neck is more extensive than in the lumbar region with a higher risk of penetrating vascular structures and bleeding. Therefore, unlike in the lumbar region where continuation is routinely recommended, the decision to continue or discontinue anticoagulants should be made only after a careful risk:benefit assessment for joint blocks and RFA. Whereas a risk to benefit analysis is justified in clinical practice, it is recommended that these patients be excluded in clinical trials (table 22).

\section{Recommendations}

This committee acknowledges that employing different standards for clinical practice and clinical trials for some elements of selection and performance, particularly those that purport to show efficacy, is reasonable. These differences reflect the different goals for investigators, patients, and physicians. Specific areas in which criteria may differ include: (1) patient selection for cervical MBB and RFA (with clinical practice erring on the side of enhanced access to care); (2) more non-pain secondary outcome measures for clinical trials than in clinical practice; (3) consideration of the requirement for DSA when evaluating AO/AA injections in clinical trials; (4) requiring the contralateral oblique approach to improve precision in clinical trials; (5) excluding patients with implanted devices and spinal hardware for clinical trials evaluating cervical medial branch RFA; and (6) excluding patients on anticoagulation in clinical trials to reduce risks and dropouts. Grade B recommendation, moderate level of certainty for differences in patient selection and non-pain secondary outcome measures. Grade C, low level of certainty for requiring a contralateral oblique view and excluding patients with implanted hardware, on anticoagulants, and requiring consideration of DSA for clinical trials (table 23).

\section{DISCUSSION}

\section{Effect of perspective}

These guidelines were developed to serve as a roadmap for pain physicians who treat cervical joint pain. There are wide variations in the conclusions of experts from different specialties on the effectiveness of pain management procedures, with trials and reviews performed by those who perform procedures much more likely to yield positive results than those performed by non-interventional pain and spine physicians. ${ }^{29} 406$ For neck pain and cervical facet interventions, there are much fewer studies and reviews conducted by non-specialists compared with the literature on LBP. However, among reviews that have been published, similar discrepancies exist in that those performed by pain specialists are more likely to recommend treatments as effective. ${ }^{27}{ }^{407}$ Reasons for incongruities include conscious and unconscious bias, differences in study interpretation which reflect variances in background and understanding, and perhaps a better ability for pain management physicians to select appropriate candidates and perform complex procedures. ${ }^{37}$

\section{Approval of participating organizations}

All participating organizations except for one (North American Spine Society) approved or supported the document, with their representative (BJS) being the only committee member to dissent on any question $(n=3)$. The North American Spine Society did not vote on individual questions. The American Academy of Physical Medicine and Rehabilitation approved 18 questions, abstained on two questions (laterality and differences between clinical trials and practice), and affirmed the value of the document. The American Academy of Neurology approved all questions and also affirmed the value of the document. The American Society of Anesthesiologists supported the document and approved of all questions, but since the document was not voted on by the Board of Directors or House of Delegates, the organization could not officially endorse the document. The Spine Intervention Society dissented on two questions (pain relief cut-off and number of diagnostic facet blocks) and abstained on three (utility of stimulation, differences between clinical trials and practice, and risk mitigation) but approved the document. As noted previously, the Departments of Defense and Veterans Affairs did not vote on the document, but each organisation received approval from their pain medicine leadership (table 24). 
Table 23 Summary of recommendations

\begin{tabular}{ll}
\hline Question & Recommendation \\
\hline $\begin{array}{l}\text { Use of history and physical examination to identify } \\
\text { painful AO or AA joints or to select patients for }\end{array}$ & $\begin{array}{l}\text { History and physical examination cannot reliably identify painful AO or AA joints, but can guide injection decisions which could confirm } \\
\text { the AO and AA joints as pain generators; Grade C, low level of certainty. }\end{array}$
\end{tabular}
injections

Use of history and physical examination to identify painful cervical facet joints and select patients for blocks

Correlation between radiological findings and prognostic block or RFA outcomes

Conservative treatment requirement before cervical facet blocks

Image guidance for cervical facet blocks and RFA

Optimal technique for $\mathrm{AO}$ and $\mathrm{AA}$ joint injections and risk mitigation

Approach for cervical MBB

Volumes for cervical MBB and IA injections

Therapeutic value of cervical MBB and IA injections

Performing bilateral cervical MBB and RFA, and limit on the number of levels treated

Diagnostic and prognostic utility of cervical injections

Use of sedation

Cut-off for designating a MBB as positive and use of non-pain measures

Number of blocks before RFA

Orientation of electrodes for RFA

Sensory and motor stimulation before RFA

Evidence for larger lesions

Risk mitigation

Repeating RFA

Differences between clinical trials and practice

No pathognomonic historical or examination signs can reliably predict response to facet joint blocks in individuals with chronic neck pain; Grade C, low level of certainty

The evidence is insufficient to assess the utility of radiological imaging for diagnosing cervical facet joint pain and as a prognostic indicator for the success of cervical facet blocks or RFA; Grade I. For procedural planning, radiological imaging should be considered when indicated; Grade C, low level of certainty

Conservative therapy should be used before prognostic blocks in those with chronic neck pain; Grade B, moderate level of certainty. The trial should be for 6 weeks, although this may vary based on a personalized approach; Grade C, low level of certainty. Grade I for concomitant use of conservative measures to accompany prognostic blocks

Fluoroscopy or US should be used for cervical MBB; Grade A recommendation, moderate level of certainty. Fluoroscopy (vs. CT) should be used for IA injections; Grade C, low level of certainty. Fluoroscopy should be used before RFA; Grade A, high level of certainty for imaging, Grade B, moderate level of certainty for use of fluoroscopy

Advanced imaging should be obtained before injections; Grade C, low level of certainty. Posterior approach with real-time fluoroscopy or DSA in multiple views; Grade B, moderate level of certainty. Grade C, low level of certainty for steroid use; if steroids are injected, $<1 \mathrm{~mL}$ non-particulate steroids should be used

A fluoroscopically-guided lateral approach should be considered for TON and C3-C7 MBB, but a posterior or posterior oblique approach should be used for C8 MBB. The smallest needles possible should be used; Grade I.

Volumes $\leq 0.3 \mathrm{~mL}$ should be used for cervical MBB and $\leq 1 \mathrm{~mL}$ for IA injections; Grade C, low level of certainty for MBB, grade C, low level of certainty for IA injections

Therapeutic IA injections should not be routinely used; Grade C, low-to-moderate level of certainty. Grade D recommendation, moderate level of certainty against use of steroids during MBB

Bilateral MBB may be performed at one session, but bilateral RFA should be avoided. Treating $>2$ spinal levels ( $>3$ nerves) during one session should not be done routinely; Grade C recommendation, low level of certainty.

Cervical MBB meet most criteria for a diagnostic intervention, while IA injections meet full criteria but carry a high technical failure rate; Grade C, low-to-moderate level of certainty. MBB may be more predictive of RFA outcomes than IA injections; Grade C, low level of certainty. AO and AA local anesthetic injections may be diagnostic and predictive for steroid injections; grade $\mathrm{C}$, low level of certainty Sedation should not routinely be given for diagnostic procedures; Grade B, moderate level of certainty

$\geq 50 \%$ pain relief should be used as the cut-off to maximize access to care; Grade C, low-to-moderate level of certainty. Non-pain measures can be used in conjunction with pain relief, but not as the sole criterion for designating a block as positive; grade $B$ recommendation, moderate level of certainty

A single block should be used to select patients for RFA in the absence of extenuating circumstances; Grade B, low-to-moderate level of certainty

A near-parallel approach should be used; Grade B, low-to-moderate level of certainty. For surgeries involving the articular pillars, a modified (posterior oblique or lateral) with advanced imaging and multiple lesions may be necessary; Grade C, low level of certainty Sensory stimulation should be considered when single lesions are planned and with C2-3 denervation; Grade C, low level of certainty. Motor stimulation may be beneficial for safety and efficacy; Grade B, low-to-moderate level of certainty

There is indirect evidence that larger lesions may improve RFA results; Grade C, low-to-moderate level of certainty. Grade C, low level of certainty for larger lesions to increase duration of pain relief

Aspirate and use real-time fluoroscopy or DSA to prevent vascular uptake; Grade B, moderate level of certainty. Position electrode in the posterior two-thirds of C2-3 facet joint to avoid vascular damage; Grade C, low level of certainty. Discontinue anticoagulants only after a careful risk: benefit assessment; Grade I. Non-particulate steroids can be injected post-RFA when there is a high risk for post-procedure neuritis, and a short course of NSAIDs may reduce post-RFA pain; Grade C, low level of certainty. There is inconsistent evidence supporting the peri-procedural use of gabapentin; Grade I. Discussion with relevant healthcare teams and device manufacturers should be undertaken before performing RFA in a person with an implanted device and their guidance considered; Grade C, low level of certainty. RFA can be performed in individuals with hardware, but may require a modified technique; Grade C, low level of certainty.

RFA can be repeated in patients who obtain meaningful relief lasting $\geq 3$ months when their baseline pain returns; Grade B, moderate level of certainty. For pain that returns in a similar quality and location as the baseline pain, repeat MBBs are not necessary; Grade C, low level of certainty

Because of different objectives, differences in patient selection (more rigorous for trials) and minor differences in performance (eg. for quality assurance in studies, to increase study power) may be indicated

AA, atlanto-axial; AO, atlanto-occipital; DSA, digital subtraction angiography; IA, intra-arterial; MBB, medial branch block; NSAID, non-steroidal anti-inflammatory drug; RFA, radiofrequency ablation; TON, third occipital nerve.

Differences between the lumbar and cervical facet guidelines

Aside from the inclusion of interventions targeting the $\mathrm{AO}$ and AA joints, there were several differences between recommendations for lumbar facet procedures ${ }^{29}$ and those in the cervical spine that warrant mentioning. Because of shorter distances (ie, less depth from the skin to the anatomic target), different trajectories, and a higher incidence of critical vessels overlying the cervical facets, US may be more useful for cervical MBB than for lumbar facet blocks, although fluoroscopy is recommended for RFA in both regions. Routine advanced radiological imaging (eg, MRI or CT) was not deemed essential before lumbar facet blocks, and given that there is a higher prevalence of facetogenic pain in the neck than the back, one might have expected the same in the cervical region. ${ }^{275}$ However, advanced radiological imaging was conditionally recommended before upper cervical facet procedures to avoid vascular injuries in cases of anatomic variations.

Two of the most controversial questions in both the lumbar facet joint guidelines and this guideline revolved around the number of prognostic blocks and cut-offs for designating a block as positive. Recommending two blocks in the neck but one in the lumbar spine would have been inconsistent considering that 
Table 24 Summary of agreement of committee members and partner societies

\begin{tabular}{|c|c|c|}
\hline Question & Committee members & Societies* $t$ \\
\hline Guidelines en bloc & 22 approved & 14 approved or supported, 1 disapproved \\
\hline History and physical examination to identify painful atlanto-occipital and atlanto-axial joints & 22 approved & 15 approved, 0 disapproved \\
\hline History and physical examination to identify painful cervical facet joints & 22 approved & 15 approved, 0 disapproved \\
\hline Correlation of radiological studies with painful cervical facet joints & 22 approved & 15 approved, 0 disapproved \\
\hline Requirement for conservative therapy before cervical facet blocks & 22 approved & 15 approved, 0 disapproved \\
\hline Necessity of image guidance for cervical facet interventions & 22 approved & 15 approved, 0 disapproved \\
\hline Technique, use of steroids and risk mitigation for atlanto-occipital and atlanto-axial joint injections & 22 approved & 15 approved, 0 disapproved \\
\hline Technique for cervical facet blocks & 22 approved & 15 approved, 0 disapproved \\
\hline Ideal volume for cervical facet blocks & 22 approved & 15 approved, 0 disapproved \\
\hline Therapeutic value of cervical facet blocks & 22 approved & 15 approved, 0 disapproved \\
\hline Limitations on laterality (bilateral vs unilateral) and number of levels for cervical facet interventions & 22 approved & 14 approved, 1 abstained \\
\hline Diagnostic and prognostic value of cervical facet blocks & 22 approved & 15 approved, 0 disapproved \\
\hline Effect of sedation on the validity of cervical facet blocks & 22 approved & 15 approved, 0 disapproved \\
\hline Pain relief cut-off for designating a cervical facet block as positive & 21 approved, 1 disapproved & 14 approved, 1 disapproved \\
\hline Number of facet blocks that should be performed before radiofrequency ablation & 21 approved, 1 disapproved & 14 approved, 1 disapproved \\
\hline Orientation of electrodes for cervical medial branch radiofrequency ablation & 22 approved & 15 approved, 0 disapproved \\
\hline Utility of sensory and motor stimulation during radiofrequency ablation & 22 approved & 14 approved, 1 disapproved \\
\hline Utility of and means to create larger radiofrequency lesions & 22 approved & 15 approved, 0 disapproved \\
\hline Risk mitigation for cervical facet interventions & 22 approved & 14 approved, 1 disapproved \\
\hline Repeating radiofrequency ablation & 22 approved & 15 approved, 0 disapproved \\
\hline Differences between clinical practice and clinical trials & 21 approved, 1 disapproved & 13 approved, 2 abstained \\
\hline
\end{tabular}

*North American Spine Society did not vote on any question.

tSince this document has neither been presented to nor approved by either the American Society of Anesthesiologists (ASA) Board of Directors or House of Delegates, it does not represent an official or approved statement or policy of the Society. Although the document is supported by the ASA, variances from the recommendations contained in the document may be acceptable based on the judgment of the responsible anesthesiologist. The Canadian Pain Society acknowledges that variances from the recommendations may be acceptable based on the judgment of the treating physician and that these guidelines do not represent an official policy from the Society.

the higher published prevalence rate of facetogenic pain in the neck compared with the low back should decrease the risk of a false-positive block. In contrast, the more prominent role of the facet joints in neck pain than LBP theoretically could have led to recommending a cut-off for a positive block above $50 \%$ pain relief, but neither the studies that stratified RFA outcome by prognostic block pain relief nor the IMMPACT guidelines supported a higher threshold recommendation. ${ }^{19} 2023281285$

The risks of AO, AA, and facet procedures including bleeding complications and injury to aberrant vasculature and surrounding nerves (eg, cervical nerve roots) are greater in the cervical spine than in the lumbar spine. Minimizing these risks resulted in recommendations to consider reviewing radiological or US imaging before embarking on cervical joint procedures, perform RFA procedures one side at a time to reduce the risk of cervical muscle weakness, use smaller gauge needles when feasible, and to consider discontinuing anticoagulants before RFA procedures if it is deemed that the benefits outweigh the risks.

\section{Maximizing access to care}

Similar to the lumbar facet guidelines, we sought to prioritize access while reducing the total number of required procedures. Although medial branch RFA may carry slightly greater risks in the neck than the low back, the risks of properly performed cervical medial branch RFA are still much lower than the risks of alternative therapies such as chronic opioid therapy and surgery. ${ }^{26408}$ Although low, prognostic MBB carries risks that are additive when performed multiple times. The correlative of a single positive prognostic $\mathrm{MBB}$ in the cervical spine being more likely to be a true positive block than in the lumbar spine is that the false-negative rate is also higher in the cervical spine, putting a greater proportion of patients at risk of not receiving a potentially therapeutic procedure if multiple blocks are required. ${ }^{29} 275$ Although the committee still advocates a personalized, shared-decision approach to treating suspected cervical facetogenic pain, we felt that performing two blocks in the cervical spine is even more difficult to justify than it is in the low back.

\section{Guideline limitations}

Unlike standards for which there is little room for deviation, guidelines tend to be more flexible and allow for variations based on physician judgment and unique patient characteristics, providing recommendations in areas of uncertainty. Thus, what may be an ideal treatment course for one patient may be inappropriate for another. For areas of medicine in which there is a lack of high-quality clinical trials to guide treatment and a consensus regarding best practices, the development of inclusive guidelines becomes even more important. Along similar lines, it is important to recognize that patients, payers, regulatory agencies, and even providers may have different needs and goals.

Second, we did not grade the included studies as all grading scales used to rate evidence quality consider only methodological factors while failing to consider the more important aspects of patient selection and procedural technique. ${ }^{3536409}$ This is relevant because not only technical performance but also patient selection (ie, not including patients with secondary gain, comorbid psychological conditions, other sources of pain, or a diffuse pain phenotype) play pivotal roles in clinical trial outcomes. This can be gleaned from the wide variability in enrollment percentages and outcome measures. Whereas technical quality scales have been developed for procedures such as ESIs, existing ones for facet blocks and RFA are dated, methodologically flawed and have not been validated. ${ }^{410} 411$ 
Third, by their very nature, guidelines are a byproduct of the opinions and clinical experience of the group, which in our case contained pain physicians. The clinical basis for this was that the questions we considered were mostly technical ones. Administratively, for transparency and equipoise purposes we sought out committee members only from medical societies with stakeholder interests in interventional pain management, who in turn selected representatives with a track record of peer-reviewed publications or grant funding in the area of cervicogenic headache or facet joint pain.

\section{CONCLUSIONS}

Clinical trials evaluating cervical facet blocks and RFA are characterized by widely disparate outcomes, and there is enormous variation in selecting patients and performing procedures. These multi-society guidelines have been developed to serve as a roadmap to improve outcomes, enhance safety, and minimize unnecessary tests and procedures. Unlike standards, which often come from an unimpeachable authority and define standards of care, our recommendations are not meant to usurp clinician judgment or personalized medicine. As has been eloquently summarized previously, the practice of evidence-based pain medicine should consider not only the best available research but also take into account clinical experience and expertise, patient values and preferences, and practical concerns. ${ }^{412}$ The authors of these guidelines hope researchers, clinicians, and patients will continue to conduct and participate in high-quality research to answer some of the questions addressed in these guidelines in which evidence was not available.

\section{Author affiliations}

'Anesthesiology, Wake Forest School of Medicine, Winston-Salem, North Carolina, USA

${ }^{2}$ Anesthesiology, Wake Forest Baptist Health, Winston-Salem, North Carolina, USA ${ }^{3}$ Anesthesiology, Perioperative and Pain Medicine, Stanford Hospital and Clinics, Redwood City, California, USA

${ }^{4}$ Anesthesiology, Imperial College Healthcare NHS Trust Haemodialysis Clinic, Hayes Satellite Unit, Hayes, UK

${ }^{5}$ Anesthesia and Pain Management, University of Toronto and University Health Network - Toronto Western Hospital, Toronto, Ontario, Canada

${ }^{6}$ Anesthesiology, University of Kansas Medical Center, Kansas City, Kansas, USA

${ }^{7}$ Spine and Nerve Center of the Virginias, West Virginia University - Health Sciences Campus, Morgantown, West Virginia, USA

${ }^{8}$ Stanford University School of Medicine, Palo Alto, California, USA

${ }^{9}$ Anesthesiology, Mayo Clinic, Rochester, Minnesota, USA

${ }^{10}$ Neurology, Mayo Clinic, Rochester, New York, USA

${ }^{11}$ Fullerton Orthopaedic Surgery Medical Group, Fullerton, California, USA

${ }^{12}$ Physical Medicine and Rehabilitation, University of Utah School of Medicine, Salt Lake City, Utah, USA

${ }^{13}$ Anesthesiology and Pain Medicine, Seoul National University College of Medicine, Seoul, South Korea

${ }^{14}$ Anesthesiology and Pain Medicine, Seoul National University Hospital, Jongno-gu, South Korea

${ }^{15}$ Center for Pain Medicine, Summa Western Reserve Hospital, Cuyahoga Falls, Ohio, USA

${ }^{16}$ Pain Diagnostics and Interventional Care, Sewickley, Pennsylvania, USA

${ }^{17}$ Pain Diagnostics and Interventional Care, Edgeworth, Pennsylvania, USA

${ }^{18}$ Physical Medicine and Rehabilitation, Vanderbilt University, Nashville, Tennessee, USA

${ }^{19}$ Anesthesiology, Maastricht University Medical Centre, Maastricht, Limburg, The Netherlands

${ }^{20}$ Anesthesiology, UCSD Medical Center - Thornton Hospital, San Diego, California, USA

${ }^{21}$ Anesthesia, WRNMMC, Bethesda, Maryland, USA

${ }^{22}$ Neurology, VA Healthcare Center District of Columbia, Washington, District of Columbia, USA

${ }^{23}$ Anesthesiology, Neurology, Physical Medicine and Rehabilitation and Psychiatry, Pain Medicine Division, Johns Hopkins School of Medicine, Baltimore, Maryland, USA
Twitter Meredith C B Adams @meredithadamsmd, Timothy R Deer @doctdeer, Jennifer Hah @JenniferHahMD, David Wonhee Lee @dwleemd and Samer Narouze @NarouzeMD

Acknowledgements The authors would like to acknowledge Angie Stengel (ASRA-PM) for her administrative assistance in coordinating conference calls and outreach to participating organisations. The authors would like to acknowledge Emma Adhiambo Arigi for help with medical editing. The authors would like to acknowledge Mohesh Mohan for drawing figures 1-4.

Contributors SPC and RWH: Concept design, committee chairs, developed initial list of questions and outline, participated in writing and editing manuscript. Other authors: Assisted with refinement of questions, participated in writing and editing manuscript.

Funding The American Society of Regional Anesthesiology and Pain Medicine and American Academy of Pain Medicine contracted with Emma Adhiambo Arigi of Nascent Medical, LLC, for assistance with manuscript preparation. SPC received funding for this project from the Department of Defense, Musculoskeletal Injury Rehabilitation Research for Operational Readiness (MIRROR), grant \#HU00011920011.

Competing interests SPC has served as a consultant for Avanos, SPR, Releviate, Persica and Scilex in the past 3 years. ZLM receives research funding from Avanos. Anuj Bhatia receives research funding from Medtronic and consults for Bioventus. DAP has consulted for Avanos, Boston Scientific, Heron, Medtronic, Wise and Nevro. He has received research support from Avanos, Medtronic, Nevro, Stimgenics, and Abbott. DWL has served as a member of the Abbott speaker's bureau. WMH receives funding from US WorldMeds. BJS is a consultant for State Farm and AIM Specialty Health. NK served on an advisory board for Bright Minds Biosciences, received research funding from Nevro Corporation, and received royalties from UpToDate. TD is a consultant for Abbott, Vertos, Axonics, Flowonix, SpineThera, Saluda Medical, Nalu, Medtronic, Nevro, SI Bone, Stimgenics, SPR Therapeutics, Cornerloc, Boston Scientific, PainTeq, Ethos, and Vertiflex; is a member of the advisory board for Abbott, Vertos, Flowonix, Nalu, SPR Therapeutics and Vertiflex; has stock options in Bioness, Vertiflex, Axonic, Vertos, SpineThera, Nalu, Cornerloc, PainTeq and SPR Therapeutics, and has common stock in Saluda Medical. He is a research consultant for Abbott, Vertos, Mainstay Medical, Saluda Medical, SPR Therapeutics, Boston Scientific and Vertiflex, and has a patent pending for the dorsal root ganglion paddle lead with Abbott.

\section{Patient consent for publication Not required.}

Provenance and peer review Commissioned; externally peer reviewed.

Open access This is an open access article distributed in accordance with the Creative Commons Attribution 4.0 Unported (CC BY 4.0) license, which permits others to copy, redistribute, remix, transform and build upon this work for any purpose, provided the original work is properly cited, a link to the licence is given, and indication of whether changes were made. See: https://creativecommons.org/ licenses/by/4.0/.

\section{ORCID iDs}

Meredith C B Adams http://orcid.org/0000-0002-3969-4279

Anuj Bhatia http://orcid.org/0000-0001-6292-8654

Andrea Chadwick http://orcid.org/0000-0002-0570-9997

Timothy R Deer http://orcid.org/0000-0001-8907-7730

W Michael Hooten http://orcid.org/0000-0001-5645-6355

Jee Youn Moon http://orcid.org/0000-0001-5551-7750

Samer Narouze http://orcid.org/0000-0003-1849-1402

Steven P Cohen http://orcid.org/0000-0001-5928-2127

\section{REFERENCES}

1 Safiri S, Kolahi A-A, Hoy D, et al. Global, regional, and national burden of neck pain in the general population, 1990-2017: systematic analysis of the global burden of disease study 2017. BMJ 2020;368:m791.

2 Fejer R, Kyvik KO, Hartvigsen J. The prevalence of neck pain in the world population: a systematic critical review of the literature. Eur Spine J 2006;15:834-48.

3 GBD 2015 Disease and Injury Incidence and Prevalence Collaborators. Global, regional, and national incidence, prevalence, and years lived with disability for 310 diseases and injuries, 1990-2015: a systematic analysis for the global burden of disease study 2015. Lancet 2016;388:1545-602.

4 Hogg-Johnson S, van der Velde G, Carroll LJ, et al. The burden and determinants of neck pain in the general population: results of the Bone and Joint Decade 20002010 Task Force on Neck Pain and its Associated Disorders. Spine 2008:33:S39-51.

5 Aprill C, Axinn MJ, Bogduk N. Occipital headaches stemming from the lateral atlanto-axial (C1-2) joint. Cephalalgia 2002;22:15-22.

6 Manchikanti L, Singh V, Rivera J, et al. Prevalence of cervical facet joint pain in chronic neck pain. Pain Physician 2002;5:243-9.

7 Aprill C, Bogduk N. The prevalence of cervical zygapophyseal joint pain. A first approximation. Spine 1992;17:744-7. 
8 Bogduk N, Marsland A. The cervical zygapophysial joints as a source of neck pain. Spine 1988;13:610-7.

9 Speldewinde GC, Bashford GM, Davidson IR. Diagnostic cervical zygapophyseal joint blocks for chronic cervical pain. Med J Aust 2001:174:174-6.

10 Barnsley L, Lord SM, Wallis BJ, et al. The prevalence of chronic cervical zygapophysial joint pain after whiplash. Spine 1995:20:20-5.

11 Barnsley L, Lord S, Bogduk N. Whiplash injury. Pain 1994;58:283-307.

12 Lord SM, Barnsley L, Wallis BJ, et al. Chronic cervical zygapophysial joint pain after whiplash. A placebo-controlled prevalence study. Spine 1996;21:1737-44.

13 Aprill C, Dwyer A, Bogduk N. Cervical zygapophyseal joint pain patterns. II: A clinical evaluation. Spine 1990;15:458-61.

14 Manchikanti L, Manchikanti KN, Pampati V, et al. The prevalence of facetjoint-related chronic neck pain in postsurgical and nonpostsurgical patients: a comparative evaluation. Pain Pract 2008;8:5-10.

15 Nevalainen MT, Foran PJ, Roedl JB, et al. Cervical facet oedema: prevalence, correlation to symptoms, and follow-up imaging. Clin Radiol 2016;71:570-5.

16 Lee MJ, Riew KD. The prevalence cervical facet arthrosis: an osseous study in a cadveric population. Spine J 2009;9:711-4.

17 van der Donk J, Schouten JS, Passchier J, et al. The associations of neck pain with radiological abnormalities of the cervical spine and personality traits in a general population. J Rheumatol 1991;18:1884-9.

18 International Spine Intervention Society. Cervical medial branch thermal radiofrequency neurotomy. In: Bogduk N, ed. Practice guidelines for spinal diagnostic and treatment procedures. 2nd edn. San Francisco, 2013: 133-69.

19 Burnham T, Conger A, Salazar F, et al. The effectiveness of cervical medial branch radiofrequency ablation for chronic facet joint syndrome in patients selected by a practical medial branch block paradigm. Pain Med 2020;21:2071-6.

20 Cohen SP, Bajwa ZH, Kraemer JJ, et al. Factors predicting success and failure for cervical facet radiofrequency denervation: a multi-center analysis. Reg Anesth Pain Med 2007:32:495-503.

21 Engel A, King W, Schneider BJ, et al. The effectiveness of cervical medial branch thermal radiofrequency neurotomy stratified by selection criteria: a systematic review of the literature. Pain Med 2020;21:2726-37.

22 Falco FJE, Datta S, Manchikanti L, et al. An updated review of the diagnostic utility of cervical facet joint injections. Pain Physician 2012;15:E807-38.

23 Holz SC, Sehgal N. What is the correlation between facet joint radiofrequency outcome and response to comparative medial branch blocks? Pain Physician 2016;19:163-72.

24 Manchikanti L, Sanapati MR, Pampati V, et al. Update of utilization patterns of facet joint interventions in managing spinal pain from 2000 to 2018 in the US fee-forservice Medicare population. Pain Physician 2020;23:E133-49.

25 Manchikanti L, Pampati V, Soin A, et al. Trends of expenditures and utilization of facet joint interventions in fee-for-service (FFS) Medicare population from 20092018. Pain Physician 2020;23:S129-47.

26 Cohen SP, Hooten WM. Advances in the diagnosis and management of neck pain BMJ 2017:358:33221

27 Manchikanti L, Kaye AD, Soin A, et al. Comprehensive evidence-based guidelines for facet joint interventions in the management of chronic spinal pain: American Society of Interventional Pain Physicians (ASIPP) guidelines facet joint interventions 2020 guidelines. Pain Physician 2020;23:51-127.

28 van Eerd M, de Meij N, Kessels A, et al. Efficacy and long-term effect of radiofrequency denervation in patients with clinically diagnosed cervical facet joint pain: a double-blind randomized controlled trial. Spine 2021;46:285-93.

29 Cohen SP, Bhaskar A, Bhatia A, et al. Consensus practice guidelines on interventions for lumbar facet joint pain from a multispecialty, international working group. Reg Anesth Pain Med 2020;45:424-67.

30 U.S. Preventive Services Task Force. Grade definitions. Available: https://www.uspr eventiveservicestaskforce.org/Page/Name/grade-definitions [Accessed 29 Nov 2020].

31 Cohen SP, Bhatia A, Buvanendran A, et al. Consensus guidelines on the use of intravenous ketamine infusions for chronic pain from the American Society of Regional Anesthesia and Pain Medicine, the American Academy of Pain Medicine, and the American Society of Anesthesiologists. Reg Anesth Pain Med 2018:43:521-46

32 Deer TR, Narouze S, Provenzano DA. The Neurostimulation Appropriateness Consensus Committee (NACC): recommendations on bleeding and coagulation management in neurostimulation devices. Neuromodulation 2017:20:51-62.

33 Deer TR, Pope JE, Hayek SM, et al. The Polyanalgesic Consensus Conference (PacC): recommendations for intrathecal drug delivery: guidance for improving safety and mitigating risks. Neuromodulation 2017;20:155-76.

34 Helm li S, Simopoulos TT, Stojanovic M, et al. Effectiveness of thermal annular procedures in treating discogenic low back pain. Pain Physician 2017;20:447-70.

35 Oxford Centre for Evidence-Based Medicine. Levels of evidence, March 2009 Available: http://www.cebm.net/blog/2009/06/11/oxford-centre-evidence-basedmedicine-levels-evidence-march-2009 [Accessed 1 Aug 2021].

36 The GRADE Working Group. GRADE. Available: www.gradeworkinggroup.org [Accessed 21 Feb 2021].

37 Cohen SP, Wallace M, Rauck RL. Unique aspects of clinical trials of invasive therapies for chronic pain. Pain Rep 2019;4:e687.
38 Narouze S. Cervicogenic headache. In: Benzon HT, Raja SN, Liu SS, eds. Essentials of pain medicine. 3rd edn. Philadelphia, PA: Elsevier Saunders, 2011: 278-82.

39 Bogduk N, Corrigan B, Kelly P, et al. Cervical headache. Med J Aust 1985;143:202-7.

40 Alix ME, Bates DK. A proposed etiology of cervicogenic headache: the neurophysiologic basis and anatomic relationship between the dura mater and the rectus posterior capitis minor muscle. J Manipulative Physiol Ther 1999;22:534-9.

41 Bogduk N. The anatomy of occipital neuralgia. Clin Exp Neurol 1981;17:167-84.

42 Yin W, Willard F, Dixon T, et al. Ventral innervation of the lateral C1-C2 joint: an anatomical study. Pain Med 2008;9:1022-9.

43 Walker MT, Spitzer EM, Anatomy VM. Imaging, and common pain-generating degenerative pathologies of the spine. In: Benzon HT, Raja SN, Liu SS, eds. Essentials of pain medicine. 3rd edn. Philadelphia, PA: Elsevier Saunders, 2011: 53-79.

44 Kobayashi T, Miyakoshi N, Konno N, et al. Acute neck pain caused by arthritis of the lateral atlantoaxial joint. Spine J 2014;14:1909-13.

45 Wasserman BR, Moskovich R, Razi AE. Rheumatoid arthritis of the cervical spineclinical considerations. Bull NYU Hosp Jt Dis 2011;69:136-48.

46 Klimo P, Rao G, Brockmeyer D. Congenital anomalies of the cervical spine. Neurosurg Clin N Am 2007:18:463-78.

47 Tulsi RS. Some specific anatomical features of the atlas and axis: dens, epitransverse process and articular facets. Aust N Z J Surg 1978;48:570-4.

48 Yang SY, Boniello AJ, Poorman CE, et al. A review of the diagnosis and treatment of atlantoaxial dislocations. Global Spine J 2014;4:197-210.

49 Cooper G, Bailey B, Bogduk N. Cervical zygapophysial joint pain maps. Pain Med 2007:8:344-53

50 Dreyfuss P, Michaelsen M, Fletcher D. Atlanto-occipital and lateral atlanto-axial joint pain patterns. Spine 1994;19:1125-31.

51 Fukui S, Ohseto K, Shiotani M, et al. Referred pain distribution of the cervical zygapophyseal joints and cervical dorsal rami. Pain 1996;68:79-83.

52 Bogduk N. The neck and headaches. Neurol Clin 2004;22:151-71.

53 Bogduk N. Cervicogenic headache: anatomic basis and pathophysiologic mechanisms. Curr Pain Headache Rep 2001:5:382-6.

54 Bartsch T, Goadsby PJ. Stimulation of the greater occipital nerve induces increased central excitability of dural afferent input. Brain 2002;125:1496-509.

55 Antonaci F, Fredriksen TA, Sjaastad O. Cervicogenic headache: clinical presentation, diagnostic criteria, and differential diagnosis. Curr Pain Headache Rep 2001:5:387-92

56 Ehni G, Benner B. Occipital neuralgia and C1-C2 arthrosis. N Engl J Med 1984:310:127.

57 Star MJ, Curd JG, Thorne RP. Atlantoaxial lateral mass osteoarthritis. A frequently overlooked cause of severe occipitocervical pain. Spine 1992;17:S71-6.

58 Riesenburger RI, Klimo P, Yao KC. A fourth atlantoaxial joint: an initial description. Spine J 2011:11:e6-9.

59 Salunke P, Futane S, Vaiphei K. Posterior bilateral supernumerary atlantoaxial facets: true or false joint? Spine 2013;38:E1633-5

60 Boucher AB, Kashlan ON, Gary MF, et al. Atlantoaxial pseudoarticulation as a cause of neck pain: case illustration. J Neurosurg Spine 2018;30:182-3.

61 Eaton RG, Viljoen SV. Unilateral atlantoaxial pseudoarticulation: a case report, literature review, and proposed mechanism. Surg Neurol Int 2020;11:20.

62 Narouze SN, Casanova J, Mekhail N. The longitudinal effectiveness of lateral atlantoaxial intra-articular steroid injection in the treatment of cervicogenic headache. Pain Med 2007:8:184-8.

63 Bogduk N. The neck and headaches. Neurol Clin 2014;32:471-87.

64 Roche CJ, King SJ, Dangerfield PH, et al. The atlanto-axial joint: physiological range of rotation on MRI and CT. Clin Radiol 2002:57:103-8.

65 Elliott RE, Tanweer O, Smith ML, et al. Outcomes of fusion for lateral atlantoaxia osteoarthritis: meta-analysis and review of literature. World Neurosurg 2013;80:e337-46

66 Park S, Woo J-E, Kim S, et al. Torticollis caused by nontraumatic craniovertebral junction abnormalities. J Craniofac Surg 2018;29:1266-70.

67 Vesela M, Stetkarova I, Lisy J. Prevalence of C1/C2 involvement in Czech rheumatoid arthritis patients, correlation of pain intensity, and distance of ventral subluxation. Rheumatol Int 2005:26:12-15.

68 Lord SM, Barnsley L, Wallis BJ, et al. Percutaneous radio-frequency neurotomy for chronic cervical zygapophyseal-joint pain. N Engl J Med 1996;335:1721-6.

69 MacVicar J, Borowczyk JM, MacVicar AM, et al. Cervical medial branch radiofrequency neurotomy in New Zealand. Pain Med 2012;13:647-54.

70 Chang U-K, Kim DH, Lee MC, et al. Changes in adjacent-level disc pressure and facet joint force after cervical arthroplasty compared with cervical discectomy and fusion. J Neurosurg Spine 2007:7:33-9.

71 Bogduk N. On cervical zygapophysial joint pain after whiplash. Spine 2011:36:S194-9.

72 Spitzer WO, Skovron ML, Salmi LR, et al. Scientific monograph of the Quebec Task Force on whiplash-associated disorders: redefining "whiplash" and its management. Spine 1995:20:1s-73.

73 Smith AD, Jull G, Schneider G, et al. A comparison of physical and psychological features of responders and non-responders to cervical facet blocks in chronic whiplash. BMC Musculoskelet Disord 2013;14:313. 
74 IHS classification ICHD-3: cervicogenic headache. Available: https://ichd-3.org/ 11-headache-or-facial-pain-attributed-to-disorder-of-the-cranium-neck-eyes-earsnose-sinuses-teeth-mouth-or-other-facial-or-cervical-structure/11-2-headacheattributed-to-disorder-of-the-neck/11-2-1-cervicogenic-headache/ [Accessed 7 Dec 2020]

75 Lord SM, Barnsley L, Wallis BJ, et al. Third occipital nerve headache: a prevalence study. J Neurol Neurosurg Psychiatry 1994;57:1187-90.

76 Barnsley L, Bogduk N. Medial branch blocks are specific for the diagnosis of cervical zygapophyseal joint pain. Reg Anesth 1993;18:343-50.

77 Dwyer A, Aprill C, Bogduk N. Cervical zygapophyseal joint pain patterns. I: A study in normal volunteers. Spine 1990;15:453-7.

78 Cohen SP, Strassels SA, Kurihara C, et al. Randomized study assessing the accuracy of cervical facet joint nerve (medial branch) blocks using different injectate volumes. Anesthesiology 2010;112:144-52.

79 King W, Lau P, Lees R, et al. The validity of manual examination in assessing patients with neck pain. Spine J 2007;7:22-6.

80 Schneider GM, Jull G, Thomas K, et al. Derivation of a clinical decision guide in the diagnosis of cervical facet joint pain. Arch Phys Med Rehabil 2014;95:1695-701.

81 Schneider GM, Jull G, Thomas K, et al. Intrarater and interrater reliability of select clinical tests in patients referred for diagnostic facet joint blocks in the cervical spine. Arch Phys Med Rehabil 2013;94:1628-34.

82 Heller CA, Stanley $P$, Lewis-Jones $B$, et al. Value of $X$ ray examinations of the cervical spine. BMJ 1983;287:1276-8.

83 Gore DR, Sepic SB, Gardner GM, et al. Neck pain: a long-term follow-up of 205 patients. Spine 1987;12:1-5

84 Rudy IS, Poulos A, Owen L, et al. The correlation of radiographic findings and patient symptomatology in cervical degenerative joint disease: a cross-sectional study. Chiropr Man Therap 2015;23:9.

$85 \mathrm{Kim} \mathrm{JH}$, Sharan A, Cho W, et al. The prevalence of asymptomatic cervical and lumbar facet arthropathy: a computed tomography study. Asian Spine J 2019;13:417-22.

86 Morishita K, Kasai Y, Uchida A. Hypertrophic change of facet joint in the cervical spine. Med Sci Monit 2008;14:CR62-4.

87 Tiwari $\mathrm{P}$, Kaur $\mathrm{H}$, Kaur $\mathrm{H}$, et al. Prevalence of facet joint arthritis and its association with spinal pain in mountain population - a cross-sectional study. J Craniovertebr Junction Spine 2020;11:36-45.

88 Park MS, Lee YB, Moon S-H, et al. Facet joint degeneration of the cervical spine: a computed tomographic analysis of 320 patients. Spine 2014:39:E713-8.

89 Matar HE, Navalkissoor S, Berovic M, et al. Is hybrid imaging (SPECT/CT) a useful adjunct in the management of suspected facet joints arthropathy? Int Orthop 2013;37:865-70

90 Lehman VT, Murphy RC, Kaufmann TJ, et al. Frequency of discordance between facet joint activity on technetium Tc99m methylene diphosphonate SPECT/CT and selection for percutaneous treatment at a large multispecialty institution. AJNR Am J Neuroradiol 2014;35:609-14.

91 Houseni M, Chamroonrat W, Zhuang $\mathrm{H}$, et al. Facet joint arthropathy demonstrated on FDG-PET. Clin Nucl Med 2006;31:418-9.

92 Sawicki LM, Schaarschmidt BM, Heusch P, et al. Value of ${ }^{18}$ F-FDG PET/MRI for the outcome of CT-guided facet block therapy in cervical facet syndrome: initial results. J Med Imaging Radiat Oncol 2017;61:327-33.

93 Rydman E, Kasina P, Ponzer S, et al. Association between cervical degeneration and self-perceived nonrecovery after whiplash injury. Spine J 2019;19:1986-94.

94 Daimon K, Fujiwara H, Nishiwaki Y, et al. A 20-year prospective longitudinal MRI study on cervical spine after whiplash injury: follow-up of a cross-sectional study. J Orthop Sci 2019;24:579-83.

95 Uhrenholt L, Grunnet-Nilsson N, Hartvigsen J. Cervical spine lesions after road traffic accidents: a systematic review. Spine 2002;27:1934-41

96 Hechelhammer L, Pfirrmann CWA, Zanetti M, et al. Imaging findings predicting the outcome of cervical facet joint blocks. Eur Radiol 2007;17:959-64.

97 Le Clec'h Y, Peterson CK, Brunner F, et al. Cervical facet joint imaging-guided injections: a comparison of outcomes in patients referred based on imaging findings vs palpation for pain. J Manipulative Physiol Ther 2016;39:480-6.

98 Kirpalani D, Mitra R. Cervical facet joint dysfunction: a review. Arch Phys Med Rehabil 2008:89:770-4

99 Sapir DA, Gorup JM. Radiofrequency medial branch neurotomy in litigant and nonlitigant patients with cervical whiplash: a prospective study. Spine 2001;26:E268-73.

100 Slipman CW, Lipetz JS, Plastaras CT, et al. Therapeutic zygapophyseal joint injections for headaches emanating from the C2-3 joint. Am J Phys Med Rehabil 2001;80:182-8.

101 Barnsley L. Percutaneous radiofrequency neurotomy for chronic neck pain: outcomes in a series of consecutive patients. Pain Med 2005;6:282-6.

102 Barnsley L, Lord SM, Wallis BJ, et al. Lack of effect of intraarticular corticosteroids for chronic pain in the cervical zygapophyseal joints. N Engl J Med 1994;330:1047-50.

103 Stovner LJ, Kolstad F, Helde G. Radiofrequency denervation of facet joints C2-C6 in cervicogenic headache: a randomized, double-blind, sham-controlled study. Cephalalgia 2004:24:821-30.

104 Vasseljen 0, Woodhouse A, Bjørngaard JH, et al. Natural course of acute neck and low back pain in the general population: the HUNT study. Pain 2013;154:1237-44.
105 Vos C, Verhagen A, Passchier J, et al. Management of acute neck pain in general practice: a prospective study. Br J Gen Pract 2007;57:23-8.

106 Gustavsson C, Denison E, von Koch L. Self-management of persistent neck pain: two-year follow-up of a randomized controlled trial of a multicomponent group intervention in primary health care. Spine 2011;36:2105-15.

107 Walker MJ, Boyles RE, Young BA, et al. The effectiveness of manual physical therapy and exercise for mechanical neck pain: a randomized clinical trial. Spine 2008:33:2371-8

108 Gross A, Kay TM, Paquin J-P, et al. Exercises for mechanical neck disorders. Cochrane Database Syst Rev 2015;1:CD004250.

109 Bertozzi L, Gardenghi I, Turoni F, et al. Effect of therapeutic exercise on pain and disability in the management of chronic nonspecific neck pain: systematic review and meta-analysis of randomized trials. Phys Ther 2013:93:1026-36.

110 Sihawong R, Janwantanakul P, Sitthipornvorakul E, et al. Exercise therapy for office workers with nonspecific neck pain: a systematic review. J Manipulative Physio/ Ther 2011;34:62-71

111 Cohen SP. Epidemiology, diagnosis, and treatment of neck pain. Mayo Clin Proc 2015;90:284-99.

112 Berry H, Liyanage SP, Durance RA, et al. A double-blind study of benorylate and chlormezanone in musculoskeletal disease. Rheumatol Rehabil 1981;20:46-9.

113 Borenstein DG, Korn S. Efficacy of a low-dose regimen of cyclobenzaprine hydrochloride in acute skeletal muscle spasm: results of two placebo-controlled trials. Clin Ther 2003;25:1056-73.

114 Bronfort G, Evans R, Anderson AV, et al. Spinal manipulation, medication, or home exercise with advice for acute and subacute neck pain: a randomized trial. Ann Intern Med 2012;156:1-10.

115 Hsieh L-F, Hong C-Z, Chern S-H, et al. Efficacy and side effects of diclofenac patch in treatment of patients with myofascial pain syndrome of the upper trapezius. J Pain Symptom Manage 2010;39:116-25.

116 Headache Classification Committee of the International Headache Society (IHS). The International classification of headache disorders, 3rd edition (beta version) Cephalalgia 2013;33:629-808

117 Bogduk N, Govind J. Cervicogenic headache: an assessment of the evidence on clinical diagnosis, invasive tests, and treatment. Lancet Neurol 2009;8:959-68.

118 Borusiak P, Biedermann $\mathrm{H}$, Bosserhoff $\mathrm{S}$, et al. Lack of efficacy of manual therapy in children and adolescents with suspected cervicogenic headache: results of a prospective, randomized, placebo-controlled, and blinded trial. Headache 2010;50:224-30

119 Haas M, Spegman A, Peterson D, et al. Dose response and efficacy of spinal manipulation for chronic cervicogenic headache: a pilot randomized controlled trial. Spine J 2010;10:117-28

120 Hall T, Chan HT, Christensen L, et al. Efficacy of a C1-C2 self-sustained natural apophyseal glide (SNAG) in the management of cervicogenic headache. J Orthop Sports Phys Ther 2007;37:100-7.

121 Jull G, Trott $P$, Potter $H$, et al. A randomized controlled trial of exercise and manipulative therapy for cervicogenic headache. Spine 2002;27:1835-43.

122 Nilsson N. A randomized controlled trial of the effect of spinal manipulation in the treatment of cervicogenic headache. J Manipulative Physiol Ther 1995;18:435-40.

123 Nilsson N, Christensen HW, Hartvigsen J. The effect of spinal manipulation in the treatment of cervicogenic headache. J Manipulative Physiol Ther 1997;20:326-30.

124 Rathmell JP, Manion SC. The role of image guidance in improving the safety of pain treatment. Curr Pain Headache Rep 2012;16:9-18.

125 Abrecht CR, Saba R, Greenberg P, et al. A contemporary medicolegal analysis of outpatient interventional pain procedures: 2009-2016. Anesth Analg 2019:129:255-62.

126 Manchikanti L, Malla Y, Wargo BW, et al. Complications of fluoroscopically directed facet joint nerve blocks: a prospective evaluation of 7,500 episodes with 43,000 nerve blocks. Pain Physician 2012;15:E143-50.

127 Heckmann JG, Maihöfner C, Lanz S, et al. Transient tetraplegia after cervical facet joint injection for chronic neck pain administered without imaging guidance. Clin Neurol Neurosurg 2006;108:709-11.

128 Fitzgibbon DR, Posner KL, Domino KB, et al. Chronic pain management: American Society of Anesthesiologists closed claims project. Anesthesiology 2004;100:98-105.

129 Rathmell JP, Michna E, Fitzgibbon DR, et al. Injury and liability associated with cervical procedures for chronic pain. Anesthesiology 2011;114:918-26.

130 Purcell-Jones G, Pither CE, Justins DM. Paravertebral somatic nerve block: a clinical, radiographic, and computed tomographic study in chronic pain patients. Anesth Analg 1989;68:32-9.

131 American Society of Anesthesiologists Task Force on Chronic Pain Management, American Society of Regional Anesthesia and Pain Medicine. Practice guidelines for chronic pain management: an updated report by the American Society of Anesthesiologists Task Force on Chronic Pain Management and the American Society of Regional Anesthesia and Pain Medicine. Anesthesiology 2010;112:810-33.

132 Spine Intervention Society. Safety practices for interventional pain procedures. Intra-articular (zygapophysial) joint injections. Available: https://cdn.ymaws.com/ www.spineintervention.org/resource/resmgr/patient safety/safety_practices/ safetypractices_module2.2_fa.pdf [Accessed 1 Aug 2021]. 
133 Kennedy DJ, Mattie R, Scott Hamilton A, et al. Detection of intravascular injection during lumbar medial branch blocks: a comparison of aspiration, live fluoroscopy, and digital subtraction technology. Pain Med 2016;17:1031-6.

134 Jeon YH, Kim SY. Detection rate of intravascular injections during cervical medial branch blocks: a comparison of digital subtraction angiography and static images from conventional fluoroscopy. Korean J Pain 2015;28:105-8.

135 Levinson DR. Medicare payments for facet joint injection services, 2008. Department of Health and Human Services Office of Inspector General. Available: http://oig.hhs. gov/oei/reports/oei-05-07-00200.pdf [Accessed 12 Nov 2020].

136 Finlayson RJ, Etheridge J-PB, Vieira L, et al. A randomized comparison between ultrasound- and fluoroscopy-guided third occipital nerve block. Reg Anesth Pain Med 2013:38:212-7.

137 Siegenthaler A, Mlekusch S, Trelle S, et al. Accuracy of ultrasound-guided nerve blocks of the cervical zygapophysial joints. Anesthesiology 2012;117:347-52.

138 Siegenthaler A, Schliessbach J, Curatolo M, et al. Ultrasound anatomy of the nerves supplying the cervical zygapophyseal joints: an exploratory study. Reg Anesth Pain Med 2011;36:606-10.

139 U.S. Centers for Medicare and Medicaid Services, Medicare Coverage Database, Local Coverage Determination (LCD). Facet joint interventions for pain management (L38801). Available: https://www.cms.gov/medicare-coveragedatabase/details/lcd-details.aspx? LCDId $=38801 \& v e r=6 \&$ DocType $=4 \& b c=$ AICAAAAAAAAA\&

140 BlueCross/BlueShield. Diagnosis and treatment of facet joint pain. Corporate Medical Policy. Available: https://www.bcbst.com/mpmanual/Lumbar_Facet_ Steroid_Injections_for_Treatment_of_Low_Back_Pain.htm [Accessed 1 Aug 2021].

141 Cigna Medical Coverage Policies. Musculoskeletal facet joint injections/medial branch blocks. CMM 201.4: non-indications. Available: https://www.evicore.com/-/ media/files/evicore/provider/network-standard/cmm-201-facet-joint-injections.pdf [Accessed 1 Aug 2021].

142 UnitedHealthcare Commercial Medical Policy. Epidural steroid and facet joint injections for spinal pain. policy number: 2019T0004FF. Available: https://www. uhcprovider.com/content/dam/provider/docs/public/policies/comm-medical-drug/ epidural-steroid-facet-injections-spinal-pain.pdf [Accessed 1 Aug 2021].

143 Obernauer J, Galiano K, Gruber H, et al. Ultrasound-guided versus computed tomography-controlled facet joint injections in the middle and lower cervical spine: a prospective randomized clinical trial. Med Ultrason 2013;15:10-15.

144 Eichenberger U, Greher M, Kapral S, et al. Sonographic visualization and ultrasoundguided block of the third occipital nerve: prospective for a new method to diagnose C2-C3 zygapophysial joint pain. Anesthesiology 2006;104:303-8.

145 Park KD, Lim D-J, Lee WY, et al. Ultrasound versus fluoroscopy-guided cervical medial branch block for the treatment of chronic cervical facet joint pain: a retrospective comparative study. Skeletal Radiol 2017;46:81-91.

146 Paredes S, Finlayson RJ, Narouze S. Ultrasound-guided cervical medial branch blocks: a systematic review and meta-analysis. Ann Head Med 2020;03.

147 Finlayson RJ, Etheridge J-PB, Tiyaprasertkul W, et al. A randomized comparison between ultrasound- and fluoroscopy-guided C7 medial branch block. Reg Anesth Pain Med 2015;40:52-7.

148 Park D, Seong MY, Kim HY, et al. Spinal cord injury during ultrasound-guided C7 cervical medial branch block. Am J Phys Med Rehabil 2017;96:e111-4.

149 McDonald GJ, Lord SM, Bogduk N. Long-term follow-up of patients treated with cervical radiofrequency neurotomy for chronic neck pain. Neurosurgery 1999:45:61-7.

150 Narouze SN, Provenzano DA. Sonographically guided cervical facet nerve and joint injections: why sonography? J Ultrasound Med 2013;32:1885-96.

151 Siegenthaler $A$, Eichenberger U, Curatolo M. A shortened radiofrequency denervation method for cervical zygapophysial joint pain based on ultrasound localization of the nerves. Pain Med 2011;12:1703-9.

152 Khan M, Meleka S. CT guided cervical medial branch block and radiofrequency ablation. J Clin Neurosci 2020;78:393-6.

153 Finlayson RJ, Gupta G, Alhujairi M, et al. Cervical medial branch block: a novel technique using ultrasound guidance. Reg Anesth Pain Med 2012;37:219-23.

154 Narouze SN. Ultrasound-guided cervical spine injections: ultrasound "prevents" whereas contrast fluoroscopy "detects" intravascular injections. Reg Anesth Pain Med 2012:37:127-30.

155 Won SJ, Lee U-Y, Cho SU, et al. Feasibility of ultrasound guided atlanto-occipital joint injection. Ann Rehabil Med 2012;36:627-32

156 Narouze SN. Atlanto-axial and atlanto-occipital joints injection in the treatment of headaches and neck pain. In: Deer TR, Leong MS, Buvanendran A, eds. Comprehensive treatment of chronic pain by medical, interventional, and integrative approaches: the American Academy of Pain Medicine textbook on patient management. 1st edn. New York, NY: Springer, 2013: 297-302.

157 Narouze SN. Interventional management of head and face pain: nerve blocks and beyond. New York: Springer, 2014.

158 Centeno C, Williams CJ, Markle J, et al. A new atlanto-occipital (C0-C1) joint injection technique. Pain Med 2018;19:1499-500.

159 Dreyfuss P, Rogers J, Dreyer $S$, et al. Atlanto-occipital joint pain. A report of three cases and description of an intraarticular joint block technique. Reg Anesth 1994; 19:344-51
160 Chevrot A, Cermakova E, Vallée C, et al. C1-2 arthrography. Skeletal Radiol 1995:24:425-9.

161 Mellström A, Grepe A, Levander B. Atlantoaxial arthrography. A postmortem study. Neuroradiology 1980;20:135-44.

162 Elgueta MF, Ortiz Jimenez J, Wang NN, et al. Anatomical variations of the vertebral artery in the upper cervical spine: clinical relevance for procedures targeting the C1/ C2 and C2/C3 joints. Reg Anesth Pain Med 2018;43:367-71.

163 Aiudi CM, Hooten WM, Sanders RA, et al. Outcomes of C1-2 joint injections. J Pain Res 2017;10:2263-9.

164 International Spine Intervention Society. Cervical medial branch thermal radiofrequency neurotomy. In: Bogduk N, ed. Practice guidelines for spinal diagnostic and treatment procedures. 2nd edn. San Francisco, 2013: 133-76.

165 Lee D-G, Cho Y-W, Jang S-H, et al. Effectiveness of intra-articular steroid injection for atlanto-occipital joint pain. Pain Med 2015;16:1077-82

$166 \mathrm{El} \mathrm{Abd} \mathrm{OH,} \mathrm{Rosenberg} \mathrm{D,} \mathrm{Gomba} \mathrm{L,} \mathrm{et} \mathrm{al.} \mathrm{The} \mathrm{lateral} \mathrm{atlanto-axial} \mathrm{joint} \mathrm{as} \mathrm{a}$ source of headache in congenital atlanto-occipital fusion. Am J Phys Med Rehabil 2008:87:232-7.

167 Zhou L, Hud-Shakoor Z, Hennessey C, et al. Upper cervical facet joint and spinal ram blocks for the treatment of cervicogenic headache. Headache 2010;50:657-63.

168 Busch E, Wilson PR. Atlanto-occipital and atlanto-axial injections in the treatment of headache and neck pain. Reg Anesth 1989;14:45.

169 Kuklo TR, Riew KD, Orchowski JR, et al. Management of recalcitrant osteoarthritis of the atlanto-axial joint. Orthopedics 2006;29:633-8.

170 Lamer TJ. Ear pain due to cervical spine arthritis: treatment with cervical facet injection. Headache 1991;31:682-3.

171 Shin SM, Kwak SG, Lee DG, et al. Clinical effectiveness of intra-articular pulsed radiofrequency compared to intra-articular corticosteroid injection for management of atlanto-occipital joint pain: a prospective randomized controlled pilot study. Spine 2018:43:741-6.

172 Glémarec J, Guillot P, Laborie Y, et al. Intraarticular glucocorticosteroid injection into the lateral atlantoaxial joint under fluoroscopic control. A retrospective comparative study in patients with mechanical and inflammatory disorders. Joint Bone Spine 2000:67:54-61.

173 Hetta DF, Elawamy AM, Hassanein MM, et al. Efficacy of atlantoaxial joint glucocorticoid injection in patients with rheumatoid arthritis: a randomized trial. Pain Physician 2019;22:E295-302

174 Shanthanna H, Busse J, Wang L, et al. Addition of corticosteroids to local anaesthetics for chronic non-cancer pain injections: a systematic review and metaanalysis of randomised controlled trials. Br J Anaesth 2020;125:779-801.

175 Narouze S. Complications of head and neck procedures. Techniques Reg Anesth Pain Manage 2007;11:171-7.

176 McNabney C, Chavda A, Alabsi H, et al. Anatomic considerations for injection of the lateral atlanto-axial joint. Pain Med 2019:20:2115-9.

177 Okubadejo GO, Talcott MR, Schmidt RE, et al. Perils of intravascula methylprednisolone injection into the vertebral artery: an animal study. J Bone Joint Surg Am 2008;90:1932-8.

178 Edlow BL, Wainger BJ, Frosch MP, et al. Posterior circulation stroke after C1-C2 intraarticular facet steroid injection: evidence for diffuse microvascular injury. Anesthesiology 2010;112:1532-5

179 Tang E. Complications of C1-C2 facet injection. Anesthesiology 2011;114:222-4.

180 Datta S, Manchikanti L. It is time to abandon atlanto-axial joint injections: do no harm! Anesthesiology 2011;114:222-4.

181 Jasper JF. Role of digital subtraction fluoroscopic imaging in detecting intravascular injections. Pain Physician 2003:6:369-72.

182 Van Boxem K, Rijsdijk M, Hans G, et al. Safe use of epidural corticosteroid injections: recommendations of the WIP Benelux Work Group. Pain Pract 2019;19:61-92.

183 Reid PJ, Holman PJ. latrogenic pyogenic osteomyelitis of C-1 and C-2 treated with transoral decompression and delayed posterior occipitocervical arthrodesis. Case report. J Neurosurg Spine 2007:7:664-8.

184 Spine Intervention Society. Safety practices for interventional pain procedures. Facet interventions: medical branch blocks. Available: https://cdn.ymaws.com/ www.spineintervention.org/resource/resmgr/patient_safety/safety_practices/ safetypractices_module2.1_fa.pdf [Accessed 27 Nov 2020].

185 Lee YI, Soh HJ, Kim ED. Postdural puncture headache after cervical medial branch block. Soonchunhyang Med Sci 2018;24:196-8

186 Schneider B, Popescu A, Smith C. Ultrasound imaging for cervical injections. Pain Med 2020;21:196-7.

187 Wahezi SE, Molina JJ, Alexeev E, et al. Cervical medial branch block volume dependent dispersion patterns as a predictor for ablation success: a cadaveric study. PM R 2019:11:631-9.

188 Barnsley L, Lord S, Wallis B, et al. False-positive rates of cervical zygapophysial joint blocks. Clin J Pain 1993:9:124-30.

189 Lord SM, Barnsley L, Bogduk N. The utility of comparative local anesthetic blocks versus placebo-controlled blocks for the diagnosis of cervical zygapophysial joint pain. Clin J Pain 1995:11:208-13.

190 Stojanovic MP, Dey D, Hord ED, et al. A prospective crossover comparison study of the single-needle and multiple-needle techniques for facet-joint medial branch block. Reg Anesth Pain Med 2005;30:484-90. 
191 Tubbs RS, Mortazavi MM, Loukas M, et al. Anatomical study of the third occipital nerve and its potential role in occipital headache/neck pain following midline dissections of the craniocervical junction. J Neurosurg Spine 2011;15:71-5.

192 Carr CM, Plastaras CT, Pingree MJ, et al. Immediate adverse events in interventional pain procedures: a multi-institutional study. Pain Med 2016;17:2155-61.

193 Lee H-I, Park Y-S, Cho T-G, et al. Transient adverse neurologic effects of spinal pain blocks. J Korean Neurosurg Soc 2012;52:228-33.

194 Verrills P, Mitchell B, Vivian D, et al. The incidence of intravascular penetration in medial branch blocks: cervical, thoracic, and lumbar spines. Spine 2008;33:E174-7.

195 Dreyfuss P, Schwarzer AC, Lau P, et al. Specificity of lumbar medial branch and L5 dorsal ramus blocks. A computed tomography study. Spine 1997;22:895-902.

196 Triffterer L, Machata A-M, Latzke D, et al. Ultrasound assessment of cranial spread during caudal blockade in children: effect of the speed of injection of local anaesthetics. Br J Anaesth 2012;108:670-4.

197 Rosenberg PH, Saramies L, Alila A. Lumbar epidural anaesthesia with bupivacaine in old patients: effect of speed and direction of injection. Acta Anaesthesio/ Scand 1981;25:270-4.

198 Gomes S, Drakidis A, Silva P, et al. Spread of fluid: role of tip configurations in needles. Skin Res Technol 2018;24:235-41.

199 Choi J, Kim N, Smuck M, et al. Effect of injectate viscosity on epidural distribution in lumbar transforaminal epidural steroid injection. Pain Res Manag 2019;2019:2651504.

200 Bogduk N. The clinical anatomy of the cervical dorsal rami. Spine 1982;7:319-30.

201 Sim WS, Park HJ, Kwon JH, et al. Fluoroscopic evaluation of the influence of needle gauge on epidural spread in caudal block. Medicine 2019;98:e15896.

202 Lord SM, McDonald GJ, Bogduk N. Percutaneous radiofrequency neurotomy of the cervical medial branches: a validated treatment for cervical zygapophysial joint pain. Neurosurg Quart 1998;8:288-308.

203 Kweon TD, Kim JY, Lee HY, et al. Anatomical analysis of medial branches of dorsal rami of cervical nerves for radiofrequency thermocoagulation. Reg Anesth Pain Med 2014;39:465-71

204 Dory MA. Arthrography of the cervical facet joints. Radiology 1983;148:379-82.

205 Dory MA. Arthrography of the lumbar facet joints. Radiology 1981;140:23-7.

206 Jung MW, Schellhas K, Johnson B. Use of diagnostic injections to evaluate sacroiliac joint pain. Int J Spine Surg 2020;14:30-4.

207 Cohen SP, Hurley RW. The ability of diagnostic spinal injections to predict surgical outcomes. Anesth Analg 2007;105:1756-75.

208 Cosman ER, Dolensky JR, Hoffman RA. Factors that affect radiofrequency heat lesion size. Pain Med 2014;15:2020-36.

209 Kellgren J. On the distribution of pain arising from deep somatic structures with charts of segmental pain areas. Clin Sci 1939:4:35.

210 Wahezi SE, Alexeev E, Georgy JS, et al. Lumbar medial branch block volumedependent dispersion patterns as a predictor for ablation success: a cadaveric study. PM R 2018;10:616-22.

211 Nath S, Nath CA, Pettersson K. Percutaneous lumbar zygapophysial (facet) joint neurotomy using radiofrequency current, in the management of chronic low back pain: a randomized double-blind trial. Spine 2008:33:1291-7.

212 Tekin I, Mirzai H, Ok G, et al. A comparison of conventional and pulsed radiofrequency denervation in the treatment of chronic facet joint pain. Clin J Pain 2007;23:524-9.

213 van Kleef M, Barendse GA, Kessels A, et al. Randomized trial of radiofrequency lumbar facet denervation for chronic low back pain. Spine 1999;24:1937-42.

214 Cohen SP, Doshi TL, Constantinescu OC, et al. Effectiveness of lumbar facet joint blocks and predictive value before radiofrequency denervation: the facet treatment study (FACTS), a randomized, controlled clinical trial. Anesthesiology 2018;129:517-35.

215 Hussain A, Usmani H, Huda MF. Comparison of cervical medial branch nerve block versus trigger point injection in patients with chronic neck pain. Indian J Pain 2020;34:27-33.

216 Manchikanti L, Singh V, Falco FJE, et al. Evaluation of lumbar facet joint nerve blocks in managing chronic low back pain: a randomized, double-blind, controlled trial with a 2-year follow-up. Int J Med Sci 2010;7:124-35.

217 Manchikanti L, Singh V, Falco FJE, et al. Cervical medial branch blocks for chronic cervical facet joint pain: a randomized, double-blind, controlled trial with one-year follow-up. Spine 2008;33:1813-20

218 Rocha IDda, Cristante AF, Marcon RM, et al. Controlled medial branch anesthetic block in the diagnosis of chronic lumbar facet joint pain: the value of a three-month follow-up. Clinics 2014;69:529-34.

219 Sutton T. Hoarseness following cervical facet denervation: a case report. J Pain 2011;12:P17.

220 Wahezi SE, Silva K, Shaparin N, et al. Currently recommended TON injectate volumes concomitantly block the GON: clinical implications for managing cervicogenic headache. Pain Physician 2016;19:E1079-86.

221 Finlayson RJ, Etheridge J-PB, Tiyaprasertkul W, et al. A prospective validation of biplanar ultrasound imaging for C5-C6 cervical medial branch blocks. Reg Anesth Pain Med 2014;39:160-3.
222 Finlayson RJ, Thonnagith A, Elgueta MF, et al. Ultrasound-guided cervical medial branch radiofrequency neurotomy: can multitined deployment cannulae be the solution? Reg Anesth Pain Med 2017;42:45-51.

223 Park S-C, Kim K-H. Effect of adding cervical facet joint injections in a multimoda treatment program for long-standing cervical myofascial pain syndrome with referral pain patterns of cervical facet joint syndrome. J Anesth 2012:26:738-45.

224 Bureau NJ, Moser TP, Gouvion A, et al. CT fluoroscopy-guided transforaminal and intra-articular facet steroid injections for the treatment of cervical radiculopathy: injectate distribution patterns and association with clinical outcome. Eur Radiol 2020;30:5933-41.

225 Won H-S, Jang H-Y, Moon H-S, et al. Fluoroscopic findings of extra-cervical facet joint flow and its incidence on cervical facet joint arthrograms. J Clin Med 2020;9:3919. doi:10.3390/jcm9123919

226 Cousins MJ, Mather LE. Clinical pharmacology of local anaesthetics. Anaesth Intensive Care 1980:8:257-77.

227 Barnsley L, Lord S, Bogduk N. Comparative local anaesthetic blocks in the diagnosis of cervical zygapophysial joint pain. Pain 1993;55:99-106.

228 Arnér S, Lindblom U, Meyerson BA, et al. Prolonged relief of neuralgia after regional anesthetic blocks. A call for further experimental and systematic clinical studies. Pain 1990;43:287-97.

229 Bisby MA. Inhibition of axonal transport in nerves chronically treated with local anesthetics. Exp Neurol 1975;47:481-9.

230 Cassuto J, Sinclair R, Bonderovic M. Anti-inflammatory properties of local anesthetics and their present and potential clinical implications. Acta Anaesthesio/ Scand 2006;50:265-82.

231 Manchikanti L, Singh V, Falco FJE, et al. Comparative outcomes of a 2-year follow-up of cervical medial branch blocks in management of chronic neck pain: a randomized, double-blind controlled trial. Pain Physician 2010;13:437-50.

232 Hove B, Gyldensted C. Cervical analgesic facet joint arthrography. Neuroradiology 1990;32:456-9.

233 Roy DF, Fleury J, Fontaine SB, et al. Clinical evaluation of cervical facet joint infiltration. Can Assoc Radiol J 1988;39:118-20.

234 Lee DW, Huston C. Fluoroscopically-guided cervical zygapophyseal therapeutic joint injections may reduce the need for radiofrequency. Pain Physician 2018;21:E661-5.

235 Zhang J, Tsuzuki N, Hirabayashi S, et al. Surgical anatomy of the nerves and muscles in the posterior cervical spine: a guide for avoiding inadvertent nerve injuries during the posterior approach. Spine 2003;28:1379-84.

236 Nolan JP, Sherk HH. Biomechanical evaluation of the extensor musculature of the cervical spine. Spine 1988:13:9-11. doi:10.1097/00007632-198801000-00003

237 Amonoo-Kuofi HS. The density of muscle spindles in the medial, intermediate and lateral columns of human intrinsic postvertebral muscles. J Anat 1983;136:509-19.

238 Kulkarni V, Chandy MJ, Babu KS. Quantitative study of muscle spindles in suboccipital muscles of human foetuses. Neurol India 2001:49:355

239 McLain RF. Mechanoreceptor endings in human cervical facet joints. Spine 1994;19:495-501.

240 Armstrong B, McNair P, Taylor D. Head and neck position sense. Sports Med 2008;38:101-17.

241 van Eerd M, Patijn J, Lataster A, et al. Cervical facet pain. Pain Pract 2010;10:113-23. doi:10.1111/j.1533-2500.2009.00346.x

242 Kettler A, Werner K, Wilke H-J. Morphological changes of cervical facet joints in elderly individuals. Eur Spine J 2007;16:987-92.

243 Ahmed MM, Lake WB, Resnick DK. Progressive severe kyphosis as a complication of multilevel cervical percutaneous facet neurotomy: a case report. Spine J 2012:12:e5-8.

244 Stoker GE, Buchowski JM, Kelly MP. Dropped head syndrome after multilevel cervical radiofrequency ablation: a case report. J Spinal Disord Tech 2013;26:444-8.

245 Curatolo M, Bogduk N. Diagnostic blocks for chronic pain. Scand J Pain 2010;1:186-92.

246 National Cancer Institute. NCI dictionary of cancer terms. Available: https://www. cancer.gov/publications/dictionaries/cancer-terms/def/diagnosis [Accessed $1 \mathrm{Apr}$ 2019]

247 Hogan QH, Abram SE, Hogan Quinn H. Neural blockade for diagnosis and prognosis. A review. Anesthesiology 1997;86:216-41.

248 de Craen AJ, Tijssen JG, de Gans J, et al. Placebo effect in the acute treatment of migraine: subcutaneous placebos are better than oral placebos. J Neurol 2000;247:183-8

249 Thomas M, Eriksson SV, Lundeberg T. A comparative study of diazepam and acupuncture in patients with osteoarthritis pain: a placebo controlled study. Am J Chin Med 1991:19:95-100.

250 Freire V, Grabs D, Lepage-Saucier M, et al. Ultrasound-guided cervical facet joint injections: a viable substitution for fluoroscopy-guided injections? J Ultrasound Med 2016;35:1253-8.

251 Bogduk N. A commentary on appropriate use criteria for sacroiliac pain. Pain Med 2017:18:2055-7.

252 Kaplan M, Dreyfuss P, Halbrook B, et al. The ability of lumbar medial branch blocks to anesthetize the zygapophysial joint. A physiologic challenge. Spine 1998;23:1847-52. 
253 Terry MJ, Moeschler SM, Hoelzer BC, et al. Pain catastrophizing and anxiety are associated with heat pain perception in a community sample of adults with chronic pain. Clin J Pain 2016;32:875-81.

254 Cohen SP, Mullings R, Abdi S. The pharmacologic treatment of muscle pain. Anesthesiology 2004;101:495-526

255 Cerezo-Téllez E, Torres-Lacomba M, Mayoral-Del Moral O, et al. Prevalence of myofascial pain syndrome in chronic non-specific neck pain: a population-based cross-sectional descriptive study. Pain Med 2016;17:2369-77.

256 Walega DR, Kendall MC, Nagpal G, et al. Evaluation of anxiety in procedure-naive patients during cervical and lumbar epidural steroid injection procedures. Reg Anesth Pain Med 2015:40:255-61.

257 Trentman TL, Rosenfeld DM, Seamans DP, et al. Vasovagal reactions and other complications of cervical vs. lumbar translaminar epidural steroid injections. Pain Pract 2009;9:59-64.

258 Kennedy DJ, Schneider B, Smuck M, et al. The use of moderate sedation for the secondary prevention of adverse vasovagal reactions. Pain Med 2015;16:673-9.

259 Liu F, Fang T, Zhou F, et al. Association of depression/anxiety symptoms with neck pain: a systematic review and meta-analysis of literature in China. Pain Res Manag 2018:2018:3259431:1-9.

260 Rees CS, Smith AJ, O'Sullivan PB, et al. Back and neck pain are related to mental health problems in adolescence. BMC Public Health 2011;11:382.

261 Manchikanti L, Pampati V, Damron KS, et al. A randomized, prospective, doubleblind, placebo-controlled evaluation of the effect of sedation on diagnostic validity of cervical facet joint pain. Pain Physician 2004;7:301-9.

262 Manchikanti L, Pampati V, Damron KS, et al. The effect of sedation on diagnostic validity of facet joint nerve blocks: an evaluation to assess similarities in population with involvement in cervical and lumbar regions (ISRCTNo: 76376497). Pain Physician 2006:9:47-51.

263 Cohen SP, Hameed H, Kurihara C, et al. The effect of sedation on the accuracy and treatment outcomes for diagnostic injections: a randomized, controlled, crossover study. Pain Med 2014;15:588-602.

264 Dreyfuss $P$, Cohen $S$, Chen AS, et al. Is immediate pain relief after a spinal injection procedure enhanced by intravenous sedation? PM R 2009;1:60-3.

265 Erdek MA, Halpert DE, González Fernández M, et al. Assessment of celiac plexus block and neurolysis outcomes and technique in the management of refractory visceral cancer pain. Pain Med 2010;11:92-100.

266 Chen Y, Vu T-NH, Chinchilli VM, et al. Clinical and technical factors associated with knee radiofrequency ablation outcomes: a multicenter analysis. Reg Anesth Pain Med 2021:46:298-304.

267 Cucuzzella TR, Delport EG, Kim N, et al. A survey: conscious sedation with epidural and zygapophyseal injections: is it necessary? Spine J 2006;6:364-9.

268 Kim N, Delport E, Cucuzzella T, et al. Is sedation indicated before spinal injections? Spine 2007;32:E748-52

269 American Society of Anesthesiologists (ASA). Statement on anesthetic care during interventional pain procedures for adults, 2019. Available: https://www.asahq.org/ standards-and-guidelines/statement-on-anesthetic-care-during-interventional-painprocedures-for-adults [Accessed 1 Aug 2021]

270 Neal JM, Barrington MJ, Brull R, et al. The second ASRA Practice Advisory on neurologic complications associated with regional anesthesia and pain medicine: Executive summary 2015. Reg Anesth Pain Med 2015:40:401-30.

271 Spine Intervention Society. Conscious sedation. Available: https://www. spineintervention.org/news/386491/New-FactFinder-on-Conscious-Sedation.htm [Accessed 1 Aug 2021].

272 Cohen SP, Strassels SA, Kurihara C, et al. Establishing an optimal "cutoff" threshold for diagnostic lumbar facet blocks: a prospective correlational study. Clin J Pain 2013;29:382-91.

273 Manchikanti L, Pampati S, Cash KA. Making sense of the accuracy of diagnostic lumbar facet joint nerve blocks: an assessment of the implications of $50 \%$ relief, $80 \%$ relief, single block, or controlled diagnostic blocks. Pain Physician 2010;13:133-43

274 Derby R, Melnik I, Lee J-E, et al. Correlation of lumbar medial branch neurotomy results with diagnostic medial branch block cutoff values to optimize therapeutic outcome. Pain Med 2012;13:1533-46.

275 Cohen SP, Huang JHY, Brummett C. Facet joint pain-advances in patient selection and treatment. Nat Rev Rheumatol 2013;9:101-16

276 Gellhorn AC, Katz JN, Suri P. Osteoarthritis of the spine: the facet joints. Nat Rev Rheumatol 2013;9:216-24.

277 McLain RF, Pickar JG. Mechanoreceptor endings in human thoracic and lumbar facet joints. Spine 1998;23:168-73.

278 Bogduk N, Aprill C. On the nature of neck pain, discography and cervical zygapophysial joint blocks. Pain 1993;54:213-7.

279 Kumar S, Narayan Y, Prasad N, et al. Cervical electromyogram profile differences between patients of neck pain and control. Spine 2007;32:E246-53.

280 Ribeiro DC, Belgrave A, Naden A, et al. The prevalence of myofascial trigger points in neck and shoulder-related disorders: a systematic review of the literature. $B M C$ Musculoskelet Disord 2018;19:252
281 Dworkin RH, Turk DC, Wyrwich KW, et al. Interpreting the clinical importance of treatment outcomes in chronic pain clinical trials: IMMPACT recommendations. J Pain 2008;9:105-21.

282 Cohen SP, Hayek S, Semenov Y, et al. Epidural steroid injections, conservative treatment, or combination treatment for cervical radicular pain: a multicenter, randomized, comparative-effectiveness study. Anesthesiology 2014;121:1045-55.

283 Juch JNS, Maas ET, Ostelo RWJG, et al. Effect of radiofrequency denervation on pain intensity among patients with chronic low back pain: the mint randomized clinical trials. JAMA 2017;318:68-81.

284 Predel H-G, Ebel-Bitoun C, Peil B, et al. Efficacy and safety of diclofenac + capsaicin gel in patients with acute back/neck pain: a multicenter randomized controlled study. Pain Ther 2020;9:279-96.

285 Shin W-R, Kim H-I, Shin D-G, et al. Radiofrequency neurotomy of cervical medial branches for chronic cervicobrachialgia. J Korean Med Sci 2006;21:119-225.

286 Colloca L. The placebo effect in pain therapies. Annu Rev Pharmacol Toxicol 2019;59:191-211

287 Carette S, Leclaire R, Marcoux S, et al. Epidural corticosteroid injections for sciatica due to herniated nucleus pulposus. N Engl J Med 1997;336:1634-40.

288 Friedly JL, Comstock BA, Turner JA, et al. A randomized trial of epidural glucocorticoid injections for spinal stenosis. N Engl J Med 2014;371:11-21.

289 Gilron I, Carr DB, Desjardins PJ, et al. Current methods and challenges for acute pain clinical trials. Pain Rep 2019;4:e647.

290 Reckziegel D, Vachon-Presseau E, Petre B, et al. Deconstructing biomarkers for chronic pain: context- and hypothesis-dependent biomarker types in relation to chronic pain. Pain 2019;160 Suppl 1:S37-48.

291 Cohen SP, Atanelov L, Rammasubu C, et al. Can changes in vital signs be used to predict the response to lumbar facet blocks and radiofrequency denervation? A prospective, correlational study. Reg Anesth Pain Med 2014:39:333-40.

292 Gellhorn AC. Cervical facet-mediated pain. Phys Med Rehabil Clin N Am 2011;22:447-58

293 Gazelka HM, Knievel S, Mauck WD, et al. Incidence of neuropathic pain after radiofrequency denervation of the third occipital nerve. J Pain Res 2014;7:195-8.

294 Cohen SP, Hurley RW, Christo PJ, et al. Clinical predictors of success and failure for lumbar facet radiofrequency denervation. Clin J Pain 2007;23:45-52.

295 Royal MA, Bhakta B, Gunyea I, et al. Radiofrequency neurolysis for facet arthropathy: a retrospective case series and review of the literature. Pain Pract 2002;2:47-52.

296 Smuck M, Crisostomo RA, Trivedi K, et al. Success of initial and repeated medial branch neurotomy for zygapophysial joint pain: a systematic review. $P M R$ 2012:4:686-92.

297 Tzaan WC, Tasker RR. Percutaeous radiofrequency facet rhizotomy-experience with 118 procdedures and reappraisal of its value. Can J Neuro/ Sci 2000;27:125-30.

298 van Eerd M, de Meij N, Dortangs E, et al. Long-term follow-up of cervical facet medial branch radiofrequency treatment with the single posterior-lateral approach: an exploratory study. Pain Pract 2014;14:8-15.

299 Derby R, Melnik I, Choi J, et al. Indications for repeat diagnostic medial branch nerve blocks following a failed first medial branch nerve block. Pain Physician 2013;16:479-88.

300 Cohen SP, Moon JY, Brummett CM, et al. Medial branch blocks or intra-articular injections as a prognostic tool before lumbar facet radiofrequency denervation: a multicenter, case-control study. Reg Anesth Pain Med 2015:40:376-83.

301 Stojanovic MP, Sethee J, Mohiuddin M, et al. MRI analysis of the lumbar spine: can it predict response to diagnostic and therapeutic facet procedures? Clin J Pain 2010;26:110-5.

302 Cohen SP, Williams KA, Kurihara C, et al. Multicenter, randomized, comparative cost-effectiveness study comparing 0,1 , and 2 diagnostic medial branch (facet joint nerve) block treatment paradigms before lumbar facet radiofrequency denervation. Anesthesiology 2010;113:395-405.

303 MacVicar J, Borowczyk JM, MacVicar AM, et al. Lumbar medial branch radiofrequency neurotomy in New Zealand. Pain Med 2013:14:639-45.

304 McCormick ZL, Reddy R, Korn M, et al. A prospective randomized trial of prognostic genicular nerve blocks to determine the predictive value for the outcome of cooled radiofrequency ablation for chronic knee pain due to osteoarthritis. Pain Med 2018;19:1628-38.

305 van Suijlekom HA, van Kleef M, Barendse GA, et al. Radiofrequency cervical zygapophyseal joint neurotomy for cervicogenic headache: a prospective study of 15 patients. Funct Neurol 1998;13:297-303.

306 Hamer JF, Purath TA. Response of cervicogenic headaches and occipital neuralgia to radiofrequency ablation of the C2 dorsal root ganglion and/or third occipital nerve. Headache 2014;54:500-10.

307 Govind J, King W, Bailey B et al. Radiofrequency neurotomy for the treatment of third occipital headache. J Neurol Neurosurg Psychiatry 2003;74:88-93.

308 National Institutes of Health. Federal pain research strategy. Available: https://iprcc. nih.gov/sites/default/files/iprcc/FPRS_Research_Recommendations_Final_508C.pdf [Accessed 1 Aug 2021].

309 Cheng J, Gutenberg LV, Dalton JE. Comparative long-term outcomes of lateral versus posterior approach to cervical facet medial branch radiofrequency ablation. (American Academy of Pain Medicine 2013 Meeting abstract \#179). Pain Med $2013 ; 14: 586$ 
310 Bogduk N, Macintosh J, Marsland A. Technical limitations to the efficacy of radiofrequency neurotomy for spinal pain. Neurosurgery 1987;20:529-35.

311 van Eerd M, Lataster A, Sommer M, et al. A modified posterolateral approach for radiofrequency denervation of the medial branch of the cervical segmental nerve in cervical facet joint pain based on anatomical considerations. Pain Pract 2017;17:596-603.

312 Lord SM, Barnsley L, Bogduk N. Percutaneous radiofrequency neurotomy in the treatment of cervical zygapophysial joint pain: a caution. Neurosurgery 1995;36:732-9.

313 Klessinger S. Radiofrequency neurotomy for the treatment of therapy-resistant neck pain after ventral cervical operations. Pain Med 2010;11:1504-10.

314 Little JS, Ianuzzi A, Chiu JB, et al. Human lumbar facet joint capsule strains: II. Alteration of strains subsequent to anterior interbody fixation. Spine $J$ 2004:4:153-62.

315 Lang JK, Buchfelder M. Radiofrequency neurotomy for headache stemming from the zygapophysial joints C2/3 and C3/4. Cent Eur Neurosurg 2010;71:75-9.

316 Ellwood S, Shupper P, Kaufman A. A retrospective review of spinal radiofrequency neurotomy procedures in patients with metallic posterior spinal instrumentation - is it safe? Pain Physician 2018;21:E477-82.

317 Seichi A, Kimura A, Higashi T, et al. Localization of the medial branches of the cervical dorsal rami during cervical laminoplasty. Spine 2012;37:E1603-6.

318 Ebraheim NA, Haman ST, Xu R, et al. The anatomic location of the dorsal ramus of the cervical nerve and its relation to the superior articular process of the lateral mass. Spine 1998;23:1968-71.

319 Marks R. Distribution of pain provoked from lumbar facet joints and related structures during diagnostic spinal infiltration. Pain 1989;39:37-40.

320 Li J, Kong X, Gozani SN, et al. Current-distance relationships for peripheral nerve stimulation localization. Anesth Analg 2011;112:236-41.

321 Johnson CR, Barr RC, Klein SM. A computer model of electrical stimulation of peripheral nerves in regional anesthesia. Anesthesiology 2007;106:323-30.

322 Klein SM, Melton MS, Grill WM, et al. Peripheral nerve stimulation in regional anesthesia. Reg Anesth Pain Med 2012;37:383-92.

323 Cohen SP, Strassels SA, Kurihara C, et al. Does sensory stimulation threshold affect lumbar facet radiofrequency denervation outcomes? A prospective clinical correlational study. Anesth Analg 2011;113:1233-41.

324 Brendler SJ. The human cervical myotomes: functional anatomy studied at operation. J Neurosurg 1968;28:105-11.

325 Dreyfuss P, Halbrook B, Pauza K, et al. Efficacy and validity of radiofrequency neurotomy for chronic lumbar zygapophysial joint pain. Spine 2000;25:1270-7.

326 Koh JC, Kim DH, Lee YW, et al. Relationship between paravertebral muscle twitching and long-term effects of radiofrequency medial branch neurotomy. Korean J Pain 2017;30:296-303.

327 Dreyfuss $P$, Stout A, Aprill C, et al. The significance of multifidus atrophy after successful radiofrequency neurotomy for low back pain. PM R 2009;1:719-22.

328 Paterno J, Rathmell JP, Gilligan C. Cryoanalgesia and radiofrequency ablation. In: Bajwa Z, Wootton RJ, Warfield CA, eds. Principles and practice of pain medicine. 3rd edn. New York: McGraw-Hill Education, 2016.

329 Bogduk N, Long DM. The anatomy of the so-called "articular nerves" and their relationship to facet denervation in the treatment of low-back pain. J Neurosurg 1979:51:172-7.

330 Abbott Z, Smuck M, Haig A, et al. Irreversible spinal nerve injury from dorsal ramus radiofrequency neurotomy: a case report. Arch Phys Med Rehabil 2007;88:1350-2

331 Pait TG, McAllister PV, Kaufman HH. Quadrant anatomy of the articular pillars (lateral cervical mass) of the cervical spine. J Neurosurg 1995;82:1011-4.

332 Sangari SK, Heinneman TE, Conti MS, et al. Quantitative gross and CT measurements of cadaveric cervical vertebrae (C3-C6) as guidelines for the lateral mass screw fixation. Int J Spine Surg 2016;10:43.

333 Xu R, Ebraheim NA, Nadaud MC, et al. The location of the cervical nerve roots on the posterior aspect of the cervical spine. Spine 1995;20:2267-71.

334 Organ LW. Electrophysiologic principles of radiofrequency lesion making. App/ Neurophysiol 1976;39:69-76.

335 Ball RD. The science of conventional and water-cooled monopolar lumbar radiofrequency rhizotomy: an electrical engineering point of view. Pain Physician 2014;17:E175-211

336 Provenzano DA. Think before you inject: understanding electrophysiological radiofrequency principles and the importance of the local tissue environment. Reg Anesth Pain Med 2014;39:269-71.

337 Provenzano DA, Cosman ER, Wilsey JT. Hypertonic sodium chloride preinjectate increases in vivo radiofrequency ablation size: histological and magnetic resonance imaging findings. Reg Anesth Pain Med 2018;43:776-88.

338 Provenzano DA, Liebert MA, Somers DL. Increasing the $\mathrm{NaCl}$ concentration of the preinjected solution enhances monopolar radiofrequency lesion size. Reg Anesth Pain Med 2013;38:112-23.

339 Provenzano DA, Watson TW, Somers DL. The interaction between the composition of preinjected fluids and duration of radiofrequency on lesion size. Reg Anesth Pain Med 2015;40:112-24.
340 Provenzano DA, Cosman E, Wilsey J. Comparisons of monopolar lesion volumes with hypertonic saline solution in radiofrequency ablation: a randomized, double-blind, ex vivo study. Pain Physician 2020;23:E425-7.

341 Eckmann MS, Martinez MA, Lindauer S, et al. Radiofrequency ablation near the bone-muscle interface alters soft tissue lesion dimensions. Reg Anesth Pain Med 2015;40:270-5.

342 Kim YN, Rhim H, Choi D, et al. The effect of radiofrequency ablation on different organs: ex vivo and in vivo comparative studies. Eur J Radiol 2011:80:526-32.

343 Provenzano DA, Lutton EM, Somers DL. The effects of fluid injection on lesion size during bipolar radiofrequency treatment. Reg Anesth Pain Med 2012;37:267-76.

344 Provenzano DA, Lassila HC, Somers D. The effect of fluid injection on lesion size during radiofrequency treatment. Reg Anesth Pain Med 2010;35:338-42.

345 Zachariah C, Mayeux J, Alas G, et al. Physiological and functional responses of water-cooled versus traditional radiofrequency ablation of peripheral nerves in rats. Reg Anesth Pain Med 2020;45:792-8.

346 Smith HP, McWhorter JM, Challa VR. Radiofrequency neurolysis in a clinical model. J Neurosurg 1981;55:246-53.

347 Podhajsky RJ, Sekiguchi Y, Kikuchi S, et al. The histologic effects of pulsed and continuous radiofrequency lesions at 42 degrees $C$ to rat dorsal root ganglion and sciatic nerve. Spine 2005;30:1008-13.

348 Choi EJ, Choi YM, Jang EJ, et al. Neural ablation and regeneration in pain practice. Korean J Pain 2016;29:3-11.

349 Vallejo R, Benyamin R, Tilley DM, et al. An ex vivo comparison of cooledradiofrequency and bipolar-radiofrequency lesion size and the effect of injected fluids. Reg Anesth Pain Med 2014;39:312-21

350 Bogduk N, Dreyfuss P, Baker R, et al. Complications of spinal diagnostic and treatment procedures. Pain Medicine 2008;9:S11-34.

351 Cohen SP, Hurley RW, Buckenmaier CC, et al. Randomized placebo-controlled study evaluating lateral branch radiofrequency denervation for sacroiliac joint pain. Anesthesiology 2008;109:279-88.

352 Gazelka HM, Welch TL, Nassr A, et al. Safety of lumbar spine radiofrequency procedures in the presence of posterior pedicle screws: technical report of a cadaver study. Pain Med 2015;16:877-80.

353 Manchikanti L, Hirsch JA, Kaye AD, et al. Cervical zygapophysial (facet) joint pain: effectiveness of interventional management strategies. Postgrad Med 2016;128:54-68.

354 Bureau NJ, Moser T, Dagher JH, et al. Transforaminal versus intra-articular facet corticosteroid injections for the treatment of cervical radiculopathy: a randomized, double-blind, controlled study. AJNR Am J Neuroradiol 2014;35:1467-74.

355 Rathmell JP, Benzon HT, Dreyfuss P, et al. Safeguards to prevent neurologic complications after epidural steroid injections: consensus opinions from a multidisciplinary working group and national organizations. Anesthesiology 2015;122:974-84.

356 Pollak KA, Stephens LS, Posner KL, et al. Trends in pain medicine liability. Anesthesiology 2015;123:1133-41.

357 Dobrogowski J, Wrzosek A, Wordliczek J. Radiofrequency denervation with or without addition of pentoxifylline or methylprednisolone for chronic lumbar zygapophysial joint pain. Pharmacol Rep 2005;57:475-80.

358 Singh JR, Miccio VF, Modi DJ, et al. The impact of local steroid administration on the incidence of neuritis following lumbar facet radiofrequency neurotomy. Pain Physician 2019;22:69-74.

359 Ehsanian R, Rosati RM, Kennedy DJ, et al. Antiplatelet and anticoagulant risk fo select spine interventions: a retrospective cohort. Pain Med 2020;21:910-7.

360 Manchikanti L, Benyamin RM, Swicegood JR, et al. Assessment of practice patterns of perioperative management of antiplatelet and anticoagulant therapy in interventional pain management. Pain Physician 2012;15:E955-68.

361 Narouze S, Benzon HT, Provenzano D, et al. Interventional spine and pain procedures in patients on antiplatelet and anticoagulant medications (second edition): guidelines from the American Society of Regional Anesthesia and Pain Medicine, the European Society of Regional Anaesthesia and Pain Therapy, the American Academy of Pain Medicine, the International Neuromodulation Society, the North American Neuromodulation Society, and the World Institute of Pain. Reg Anesth Pain Med 2018:43:225-62

362 Lee CJ, Kim YC, Shin JH, et al. Intravascular injection in lumbar medial branch block: a prospective evaluation of 1433 injections. Anesth Analg 2008;106:1274-8.

363 Finlayson RJ, Etheridge J-PB, Chalermkitpanit P, et al. Real-tme detection of periforaminal vessels in the cervical spine: an ultrasound survey. Reg Anesth Pain Med 2016;41:130-4.

364 Endres S, Shufelt A, Bogduk N. The risks of continuing or discontinuing anticoagulants for patients undergoing common interventional pain procedures. Pain Med 2017:18:403-9.

365 Bernstein J, Furman MB, Gilhool L, et al. The risks of continuing or discontinuing anticoagulants in diverse interventional pain procedures. Pain Med 2018;19:1885-6.

366 Kuo H-C, Liu F-L, Chen J-T, et al. Thromboembolic and bleeding risk of periprocedural bridging anticoagulation: a systematic review and meta-analysis. Clin Cardiol 2020;43:441-9 
367 Saffarian M, Lee H, McCormick ZL, Spine Intervention's Society Patient Safety Committee. Anticoagulants and antiplatelet agents for cervical medial branch radiofrequency neurotomy, 2021. Available: https://cdn.ymaws.com/www. spineintervention.org/resource/resmgr/factfinder/21/07.ff.anticoags\&cmbrfn.pdf [Accessed 1 Aug 2021].

368 Heit JA. Epidemiology of venous thromboembolism. Nat Rev Cardiol 2015;12:464-74

369 Engel A, Rappard G, King W, et al. The effectiveness and risks of fluoroscopicallyguided cervical medial branch thermal radiofrequency neurotomy: a systematic review with comprehensive analysis of the published data. Pain Med 2016;17:658-69.

370 Bicket MC, Chakravarthy K, Chang D, et al. Epidural steroid injections: an updated review on recent trends in safety and complications. Pain Manag 2015;5:129-46.

371 Welsh S, Varner SM, Hernandez MT, et al. The role of gabapentin in the prevention of postoperative neuritis following radiofrequency ablation of cervical and lumbar medial branch nerves. Ind J Basic App Med Res 2014;3:501-6.

372 Ma K, Yiqun M, Wu T, et al. Efficacy of diclofenac sodium in pain relief after conventional radiofrequency denervation for chronic facet joint pain: a double-blind randomized controlled trial. Pain Med 2011:12:27-35.

373 Ramos JA. Spinal injection of local anesthetic during cervical facet joint injection. Braz J Anesthesiol 2016:66:654-6.

374 Smith M, Ferretti G, Mortazavi S. Radiographic changes induced after cervical facet radiofrequency denervation. Spine J 2005;5:668-71.

375 Roark C, Whicher S, Abosch A. Reversible neurological symptoms caused by diathermy in a patient with deep brain stimulators: case report. Neurosurgery 2008;62:E256.

376 Bautista A, Dadabayev A, Rosenquist E, et al. Bipolar radiofrequency neurotomy to treat neck and back pain in patients with automatic implantable cardioverte defibrillator. Pain Physician 2016;19:E505-9.

377 Osborne MD. Radiofrequency neurotomy for a patient with deep brain stimulators: proposed safety guidelines. Pain Med 2009;10:1046-9.

378 American Society of Anesthesiologists. Practice advisory for the perioperative management of patients with cardiac implantable electronic devices: pacemakers and implantable cardioverter-defibrillators: an updated report by the American Society of Anesthesiologists Task Force on Perioperative Management of Patients with Cardiac Implantable Electronic Devices. Anesthesiology 2011;114:247-61.

379 Pfeiffer D, Tebbenjohanns J, Schumacher B, et al. Pacemaker function during radiofrequency ablation. Pacing Clin Electrophysiol 1995;18:1037-44.

380 Moore S, Firstenberg MS, Trohman RG. Long-term effects of radiofrequency catheter ablation on previously implanted pacemakers. PACE 1993;16:947.

381 Smith C, DeFrancesch F, Patel J, et al. Radiofrequency neurotomy for facet joint pain in patients with permanent pacemakers and defibrillators, 2018. Available: https:// cdn.ymaws.com/www.spineintervention.org/resource/resmgr/factfinder/factfinder_ 2018_08_rfn_pacem.pdf [Accessed 26 Aug 2021].

382 Smith C, DeFrancesch F, Patel J, et al. Radiofrequency neurotomy for facet joint pain in patients with permanent pacemakers and defibrillators. Pain Med 2019:20:411-2.

383 Katz SS, Savitz MH. Percutaneous radiofrequency rhizotomy of the lumbar facets. Mt Sinai J Med 1986:53:523-5.

384 McCormick ZL, Walega DR. Third-degree skin burn from conventional radiofrequency ablation of the inferiomedial genicular nerve. Pain Med 2018;19:1095-7.

385 Ogsbury JS, Simon RH, Lehman RAW. Facet "denervation" in the treatment of low back syndrome. Pain 1977;3:257-63.

386 Burnham T, Hilgenhurst G, McCormick ZL. Second-degree skin burn from a radiofrequency grounding pad: a case report and review of risk-mitigation strategies. PM R 2019:11:1139-42.

387 Lamer TJ, Smith J, Hoelzer BC, et al. Safety of lumbar spine radiofrequency procedures in patients who have posterior spinal hardware. Pain Med 2016;17:1634-7

388 Cohen SP, Wallace M, Rauck RL, et al. Unique aspects of clinical trials of invasive therapies for chronic pain. Pain Rep 2019;4:e687.

389 Husted DS, Orton D, Schofferman J, et al. Effectiveness of repeated radiofrequency neurotomy for cervical facet joint pain. J Spinal Disord Tech 2008;21:406-8.

390 Bogduk N, Yoganandan N. Biomechanics of the cervical spine. Part 3: Minor injuries. Clin Biomech 2001:16:267-75.

391 Crawford JR, Nuffort LE. Defending claims involving future radiofrequency neurotomy treatments. For the defense 2018; October: 64-69. Available: https:// www.lommen.com/wp-content/uploads/2018/10/John-Crawford-Lauren-NuffortArticle-Defending-Claims-Involving-Future-Radiofrequency-Neurotomy-Treatments. pdf [Accessed 5 Apr 2021].
392 Speldewinde GC. Outcomes of percutaneous zygapophysial and sacroiliac joint neurotomy in a community setting. Pain Med 2011;12:209-18.

393 Rambaransingh B, Stanford G, Burnham R. The effect of repeated zygapophysial joint radiofrequency neurotomy on pain, disability, and improvement duration. Pain Med 2010;11:1343-7.

394 McGreevy K, Hurley RW, Erdek MA, et al. The effectiveness of repeat celiac plexus neurolysis for pancreatic cancer: a pilot study. Pain Pract 2013;13:89-95.

395 Cohen SP, Strassels SA, Kurihara C, et al. Outcome predictors for sacroiliac joint (lateral branch) radiofrequency denervation. Reg Anesth Pain Med 2009;34:206-14

396 Carraro U, Boncompagni S, Gobbo V, et al. Persistent muscle fiber regeneration in long term denervation. past, present, future. Eur J Trans/ Myol 2015;25:4832.

397 Carlson BM. The biology of long-term denervated skeletal muscle. Eur J Trans/ Myol 2014:24:3293.

398 Chou R, Hashimoto R, Friedly J, et al. Epidural corticosteroid injections for radiculopathy and spinal stenosis: a systematic review and meta-analysis. Ann Intern Med 2015;163:373-81.

399 Binder A. The diagnosis and treatment of nonspecific neck pain and whiplash. Eura Medicophys 2007:43:79-89.

400 Hill J, Lewis M, Papageorgiou AC, et al. Predicting persistent neck pain: a 1-year follow-up of a population cohort. Spine 2004;29:1648-54.

401 Blozik E, Laptinskaya D, Herrmann-Lingen C, et al. Depression and anxiety as major determinants of neck pain: a cross-sectional study in general practice. $B M C$ Musculoskelet Disord 2009;10:13.

402 Turk DC, Dworkin RH, Allen RR, et al. Core outcome domains for chronic pain clinical trials: IMMPACT recommendations. Pain 2003;106:337-45.

403 Chung SG. Convulsion caused by a lidocaine test in cervical transforaminal epidural steroid injection. PM R 2011;3:674-7.

404 Cohen SP, Larkin TM, Chang AS, et al. The causes of false-positive medial branch (facet joint) blocks in soldiers and retirees. Mil Med 2004;169:781-6.

405 Brinks A, Koes BW, Volkers ACW, et al. Adverse effects of extra-articular corticosteroid injections: a systematic review. BMC Musculoskelet Disord 2010;11:206

406 Cohen SP, Bicket MC, Jamison D, et al. Epidural steroids. Reg Anesth Pain Med 2013;38:175-200.

407 Carragee EJ, Hurwitz EL, Cheng I, et al. Treatment of neck pain. Spine 2008;33:S153-69.

408 Dowell D, Haegerich TM, Chou R. CDC guideline for prescribing opioids for chronic pain-United States, 2016. JAMA 2016;315:1624-45

409 Lundh A, Gøtzsche PC. Recommendations by Cochrane Review Groups for assessment of the risk of bias in studies. BMC Med Res Methodol 2008;8:22.

410 Bicket MC, Hurley RW, Moon JY, et al. The development and validation of a quality assessment and rating of technique for injections of the spine (AQUARIUS). Reg Anesth Pain Med 2016:41:80-5.

411 Geurts JW, van Wijk RM, Stolker RJ, et al. Efficacy of radiofrequency procedures for the treatment of spinal pain: a systematic review of randomized clinical trials. Reg Anesth Pain Med 2001:26:394-400.

412 Masic I, Miokovic M, Muhamedagic B. Evidence based medicine - new approaches and challenges. Acta Inform Med 2008:16:219-25.

413 Jull G, Bogduk N, Marsland A. The accuracy of manual diagnosis for cervical zygapophysial joint pain syndromes. Med J Aust 1988;148:233-6.

414 Perez-Roman RJ, Brusko GD, Burks SS, et al. Use of single-photon emission computed tomography imaging for hypermetabolic facet identification in diagnosis of cervical and axial back pain. World Neurosurg 2020;137:e487-92.

415 Manchikanti L, Damron K, Cash K, et al. Therapeutic cervical medial branch blocks in managing chronic neck pain: a preliminary report of a randomized, double-blind, controlled trial: clinical trial NCT0033272. Pain Physician 2006;9:333-46.

416 Manchukonda R, Manchikanti KN, Cash KA, et al. Facet joint pain in chronic spinal pain: an evaluation of prevalence and false-positive rate of diagnostic blocks. J Spinal Disord Tech 2007:20:539-45.

417 Hahn T, Halatsch M-E, Wirtz C, et al. Response to cervical medial branch blocks in patients with cervicogenic vertigo. Pain Physician 2018;21:285-94.

418 Manchikanti L, Singh V, Pampati V, et al. Is there correlation of facet joint pain in lumbar and cervical spine? An evaluation of prevalence in combined chronic low back and neck pain. Pain Physician 2002;5:365-71.

419 Manchikanti L, Boswell MV, Singh V, et al. Prevalence of facet joint pain in chronic spinal pain of cervical, thoracic, and lumbar regions. BMC Musculoskelet Disord 2004;5:15

420 Yin W, Bogduk N. The nature of neck pain in a private pain clinic in the United States. Pain Med 2008;9:196-203. 